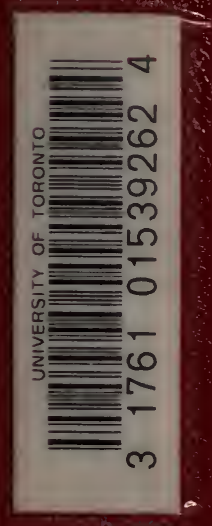
सut 



\section{,}


Digitized by the Internet Archive in 2007 with funding from Microsoft Corporation 


\title{
MANUAL OF FORESTRY
}

FOR THE

\section{NORTHEASTERN UNITED STATES}

\author{
BEING VOL. I OF
}

“FORESTRY IN NEW ENGLAND" REVISED

BY

RALPH CHIPMAN HAWLEY, M. F. PROFESSOR OF FORESTRY, YALE UNIVERSITY

AND

AUSTIN FOSTER HAWES, M. F.

FORMERLY STATE FORESTER OF CONNECTICUT AND OF VERMONT

SECOND EDITION

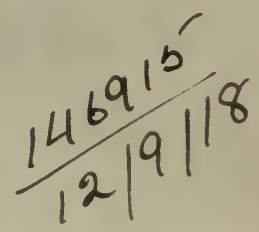

NEW YORK

JOHN WILEY \& SONS, INC.

LONDON: CHAPMAN \& HALL, LiMited

I9 8

\section{LIBRARY}

FACULTY OF FORESTRY

UNIVERSITY OF TORONTO 
COPYRIGHT, I9I8, BY

RALPH C. HAWLEY

AND

AUSTIN F. HAWS

SD
144

A 12438 1918

Stanhope Dress

F. H. GILSON COMPANY 
To

\section{HENRY. SOLON GRAVES}

FORESTER OF THE UNITED STATES.

WITH A DEEP SENSE OF OUR PERSONAL OBLIGATIONS TO HIM AS OUR PRECEPTOR IN THE YALE SCHOOL OF TORESTRY WHICH HE ORGANIZED AND BUILT UP TO RANK AS THE FOREMOST SCHOOL OF FORESTRY IN THIS COUNTRY, AND IN RECOGNITION OF HIS SERVICES

TO AMERICAN FORESTRY AS AN

EDUCATOR, WRITER AND

ADMINISTRATOR 



\section{PREFACE.}

Throughout America and especially in the eastern United States there has been a rapid awakening of interest in forestry during the past few years. The disappearance of old forests, together with increased prices of lumber, has made ready converts to the forestry propaganda of the federal and state governments; but up to the present time nearly the only available literature on the subject is in the form of government bulletins. There are, to be sure, a number of good books on the trees written from a botanical standpoint, and several books dealing with forestry in a general way, besides a very few advanced textbooks. There is now such widespread interest in the subject, that a book dealing with the specific forestry problems of New England will not only be of interest to the nature lover but of real assistance to the land owner who wishes to adopt approved methods of forest culture, or to the student of forestry. Books are legion dealing with specific agricultural problems, and it is intended that this work shall be for the woodland owner what these are for the agriculturist. Every year more people are moving from the cities and acquiring country places. Many owners of this class cannot afford their personal time for farm supervision, and, without this supervision of the owner, farming is apt to be too expensive. Forestry particularly appeals to this class of owners because it requires less frequent attention than any other land culture.

It is gratifying to find that the farmers are taking up forestry in the same practical way in which they are accustomed to handle other problems, and the authors frequently have been asked by farmers to recommend some good book on forestry. Practical problems, such as the planting of an old hill pasture to pine, or the advisability of pruning pine and spruce; the 
proper treatment of a sugar orchard, - these and many similar questions are constantly being asked by the up-to-date farmer.

Lumbermen also are becoming interested in forestry, and, while they have not yet to any extent adopted modern methods of cutting, this is largely due to unfavorable conditions and ignorance of such methods.

In preparing this book the authors have been governed by a twofold purpose: first, by the desire to present a book which might be of practical assistance to all classes of land owners in the East; and second, to produce a textbook treating of forestry in New England. The latter is greatly needed, especially in the various agricultural colleges where courses in forestry are given, and where it is essential that thorough instruction in the forest problems of the north-eastern United States be furnished. There is even a wider field for a book dealing with a definite section of the country, so arranged as to serve as a handbook for owners of woodland in the section treated. It has been the aim of the authors throughout to present the material in the simplest and least technical form possible, with the view of making everything clear to persons not familiar with forestry.

Forestry in New England as revised is arranged in two volumes: Vol. I. "A Manual of Forestry for the North-Eastern United States," Vol. II, "New England Forests and their Management." While written with special reference to New England, the book has a much wider field of direct application. Forest conditions similar to those in portions of New England prevail over a large part of New York and New Jersey, in Pennsylvania, and also in south-eastern Canada.

Vol. I is intended to furnish the woodland owner with a brief survey of the whole field of forestry, and to give him suffcient knowledge to rightly understand and be able to carry out the treatment recommended in Vol. II for his forest land. The subjects in Vol. I are too comprehensive to be fully covered in one volume. In many cases the presentation here will be sufficient, but if a complete discussion is needed various more technical works restricted to a single subject should be consulted. 
For example, two books by Graves, "Forest Mensuration" and "Principles of Handling Woodlands," cover mainly the three subjects "Silvicultural Methods of Reproduction," "Timber Estimating" and "The Growth of Trees and Forests," which are here included in three chapters.

As a textbook, then, for the post-graduate forest schools giving the highest grade of instruction, this book will have a greater value for its detailed discussion of New England forests in Vol. II, than for the portion dealing with general forestry. But it is hoped that, for the undergraduate forest schools giving a slightly lower grade of instruction, all portions of the book will prove useful.

The publications of the United States Forest Service as well as those issued by the Forestry Departments of the various eastern states, have been freely consulted, and much of the information which they contain has been incorporated in these pages.

Free use has also been made of various books dealing with the subjects treated in these chapters. Among them are the following: "History of the Lumber Industry in America" by Defebaugh; "Studies in Forestry" by Nisbet; "Principles of Handling Woodlands" and "Forest Mensuration" by Graves; "A Textbook of Botany" by Strasburger, Schenck, Noll and Schimper; "Handbook of Trees of the Northern States and Canada" by Hough; and various articles in Forestry Quarterly too numerous to mention.

All the tables in the appendix, with the exception of certain log rules and several tables taken from a "Manual for Northern Woodsmen" by Prof. Austin Cary, have been secured from state or federal forest service publications. In connection with each table acknowledgment is made of the source from which it was obtained.

The sketches and a majority of the pictures are original although a large number were secured from other sources. Wherever a picture was not taken by the authors its origin is stated beneath the picture. 
In conclusion, the authors wish to render acknowledgment to the many friends who have assisted with helpful suggestions in the preparation of this book.

In this revision an attempt has been made to conform as closely as possible with the Terminology compiled by the Society of American Foresters. ${ }^{1}$

1 Forest Terminology, Journal of Forestry, Vol. XV, No. I, p. 68. Published by the Society of American Foresters. 


\section{CONTENTS.}

Chapter I. Silvics $\ldots \ldots \ldots \ldots \ldots \ldots \ldots \ldots \ldots \ldots \ldots \ldots \ldots \ldots \ldots \ldots \ldots \ldots$

Forest Types.............................. 8

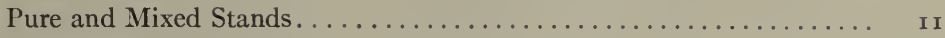

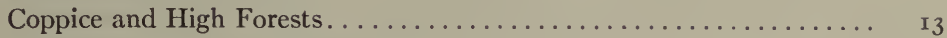

Even and Uneven-aged Forests................... I4

Chapter II. Silvicultural Characteristics of the Important New

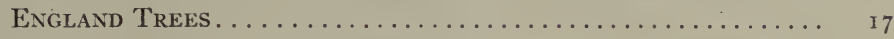

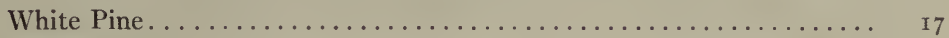

-Norway Pine.................................. 2I

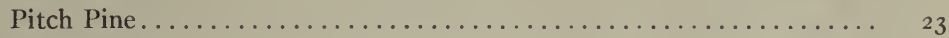

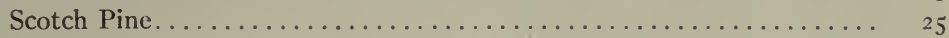

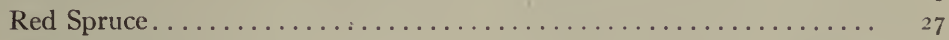

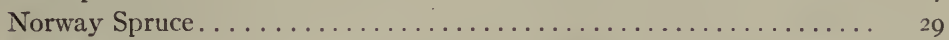

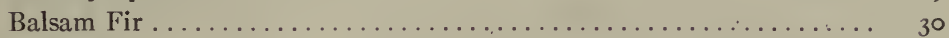

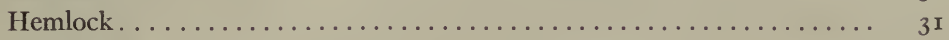

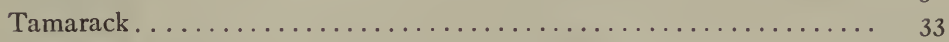

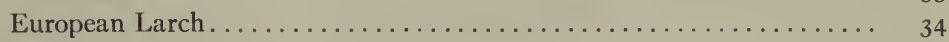

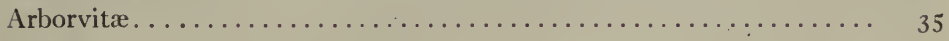

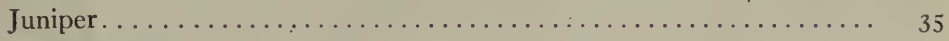

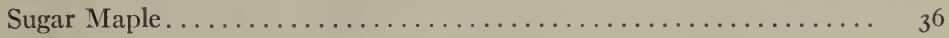

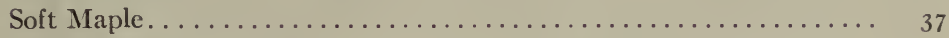

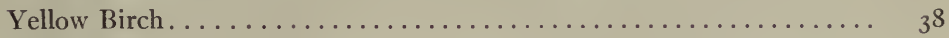

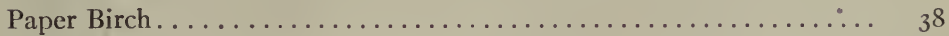

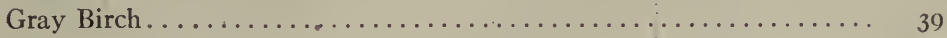

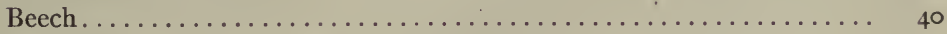

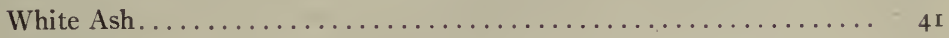

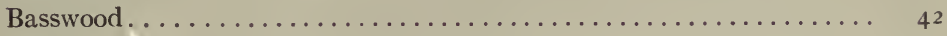

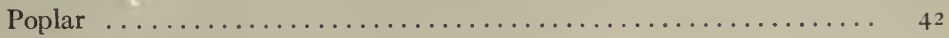

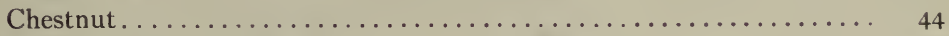

White and Red Oaks.............................. $4^{6}$

Tulip Tree..................................... 47

Chapter III. Silvicultural Methods of Reproduction.......... 49

I. Methods depending on Reproduction by Seed ............ 49

Selection Method ............................ 49

Clear Cutting Methods....................... $5^{\mathrm{r}}$

Clear Cutting with Artificial Reproduction............ 53 
PAGE

Clear Cutting with Natural Reproduction. . . . . . . . . . . 54

Clear Cutting the Whole Stand.................. 54

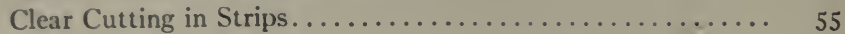

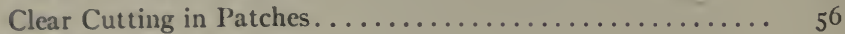

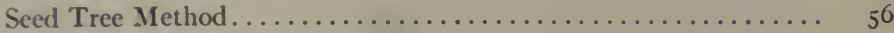

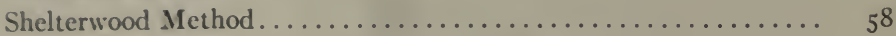

II. Methods depending on Reproduction Wholly or Partly from Sprouts 62

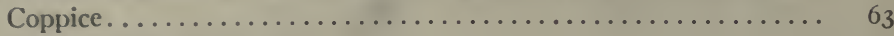

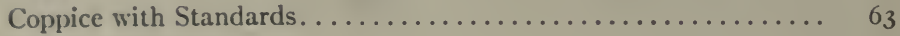

Pole-wood Coppice............................. 64

Chapter IV. Forest Planting and Seeding ............... 68

Chapter V. Intermediate Cuttings................. 77

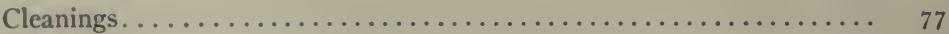

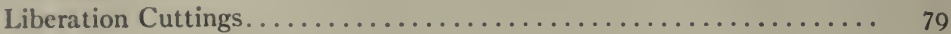

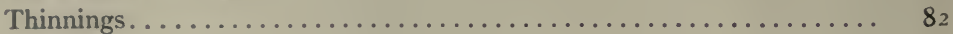

Salvage Cuttings. . . . . . . . . . . . . . . . 94

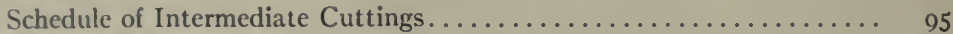

Methods of Controlling Cuttings.................... 96

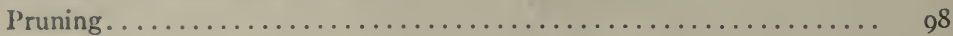

Chapter Vi. Injuries from Animals................... Ioo

Chapter VII. Forest Ixsects and Fungr................ IO 4

Insects. .............................. 104

White-pine Weevil............................. ro4

Pine-bark Aphid . ............................. Io6

European Pine-shoot Moth. ...................... 108

Spruce-destroying Beetle ....................... r. ro9

- Spruce Budworm. .......................... I I I

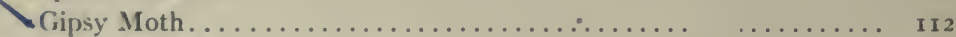

Brown-tail Moth. .......................... II5

Larch Sawfly ........................... I 6

Pine Sawfly . ............................... I 8

Elm-leaf Beetle ................................ I 8

Forest Tent Caterpillar .......................... I 20

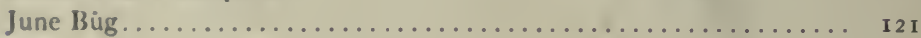

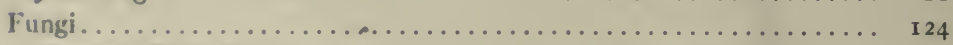

Chestnut Bark Disease....................... I 24

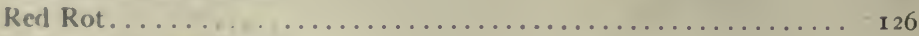

Polyporus schweinitzii ....................... I 28

White-pine Blister Rust........................ I 29

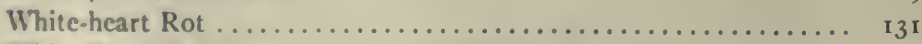

White Pine Blight.............................. 134 
Chapter ViII. Forest Fires.................... I 36

Kinds of Fires and Damage Done ................... I36

Causes of Fires. ............................. I

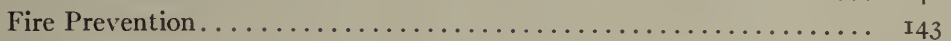

Fire Lines. . . . . . . . . . . . . . . . . . . . . 47

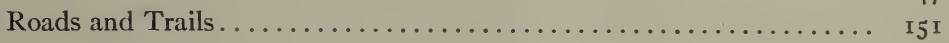

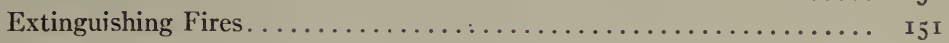

Estimating the Damage done by Forest Fires.............. I $_{57}$

Chapter IX. Timber Estimating and Marketing............. i6 i

Estimating Timber on Small Wood Lots ................. I62

Estimating Timber on Large Wood Lots ................ I66

Estimating Timber on Large Forest Tracts................. 166

The Money Value of Standing Timber................. I

Chapter X. Utilization of Forest Products.............. I 75

Lumber Grades. ............................. I 75

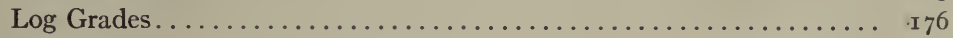

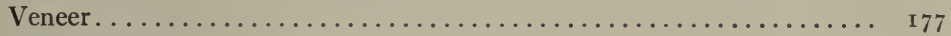

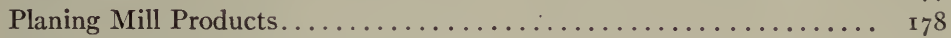

Sounding Boards and Clapboards.................... I 78

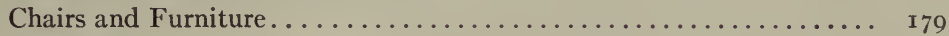

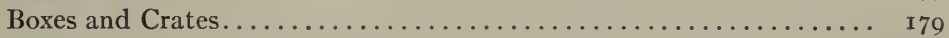

Shuttles, Spools and Bobbins....................... I 79

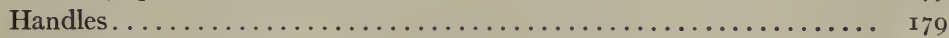

Vehicles and Vehicle Parts. ....................... I 80

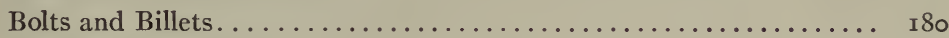

Cooperage Stock. ............................ I 8 I

Railroad Ties............................ I 8 I

Poles and Posts.........................

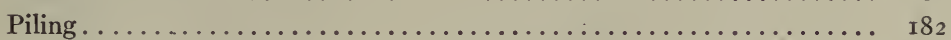

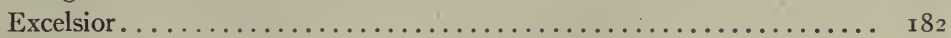

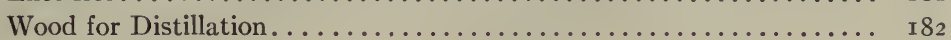

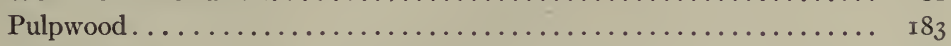

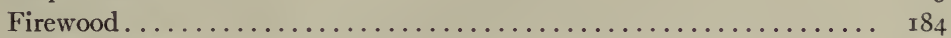

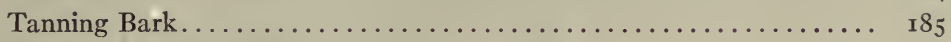

Maple Sugar and Syrup. ......................... I 86

Prices............................... 86

Chapter XI. Growth of Trees and Forests............... I 88

Growth of Trees............................... 188

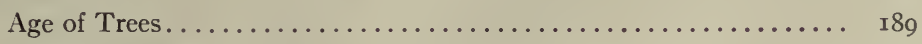

Diameter Growth.............................. I

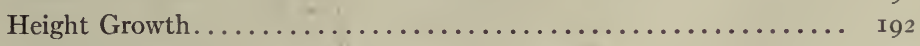

Volume Growth................................ I93

Growth of Stands............................. I95 
Age of Stands................................ 196

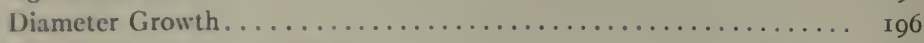

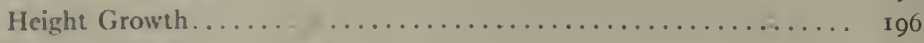

Volume Growth . . . . . . . . . . . .

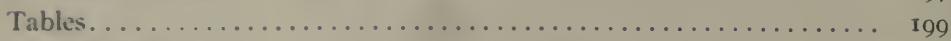

Log Rules.................................. ${ }_{205}$

Volume Tables..................................... 217

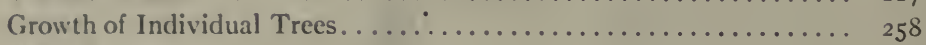

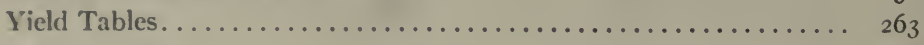

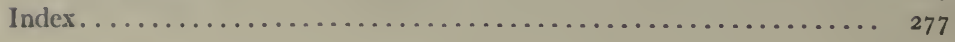




\section{A MANUAL OF FORESTRY \\ FOR THE}

\section{NORTH-EASTERN UNITED STATES}

\section{CHAPTER I.}

SILVICS.

IN order to approach the subject of Silvics intelligently it will be well for the reader to have in mind the following definitions adopted by the Society of American Foresters.

Forestry is the science and art of managing forests in continuity for forest purposes, i.e., for wood supplies and forest influences. The main branches of forestry are forest policy, silviculture, forest economy or forest management, forest protection and forest utilization.

Silvics. A branch of ecology that treats of the life of trees in the forest; forest ecology.

Silviculture is the art of producing and tending a forest; the application of the knowledge of silvics in the treatment of a forest.

In any study of forests over a wide range of country, as a whole continent, it must be apparent that climate determines the character of the forest just as it affects the growth of agricultural crops in certain regions or belts. In a small region, such as New England, the climatic factors are less noticeable, but cannot be overlooked.

The average temperature of a region is of less importance in determining the range of different trees than the lowest and highest extremes of temperature. In these extremes we have 
an explanation of the inability of the eucalyptus of southern California to live in New England, and of the fact that the canoe birch, although growing from the Atlantic to the Pacific, does not extend as far south as Long Island Sound. In a less noticeable way it is probably the extreme cold of winter which limits the chestnut to southern New England and the region farther south. Aside from this matter of extremes it is not so much the winter's cold that is injurious to species, as the late frosts in spring when the young leaves and shoots are still tender, and the early frosts of the autumn before the summer's growth has sufficiently hardened to withstand the cold. The late frosts of the spring of igro killed back the new growth of pine and fir in northern Vermont. Ash seedlings are frequently killed by late frosts.

Besides temperature there are other climatic factors influencing tree growth. It has been found, for example, that the southern limits of forest trees are mainly determined by the quantity and the regularity of the rainfall during summer. Taken as a whole, broadleaf trees consume on the average about ten times as much water as conifers, and, owing to the light foliage of pine, this species requires much less soil moisture than spruce or fir. The lack of rain for even two or three days may be fatal to young seedlings. White pine plantations established two years previously were badly injured by the prolonged drought and hot weather of rigr. With age and development of the root system the ability of the tree to resist drought increases. A mature tree with the assistance of its reserve supplies of water can withstand a drought of several months' duration. Precipitation outside of the growing season is also valuable, in thoroughly wetting the soil, because during the growing season when the trees are in foliage the soil is seldom thoroughly wet.

Aside from these climatic factors, heat and rainfall, which influence the general distribution of forests, the factors most important to individual tree growth are light and soil moisture, and to a lesser extent the physical and chemical character of the soil. Each genus, and in some respects each species, reaches its 
best development under a certain set of conditions of soil, climate, etc., called its optimum, and varies whenever found under different conditions. Since topography, exposure, and altitude affect these factors, they must also be taken into account. Near their northern limits of distribution all trees ascend the mountains to a greater height on the southern than on the northern sides, because of warmth requirements.

Trees derive most of their nourishment from the carbonic acid of the atmosphere, but they depend upon the soil for water and mineral supplies; these can only be taken up when held in solution by the soil. Water is a chief essential of tree growth, part of it being retained in the wood. Greenwood often contains as much as 50 per cent by weight of water. Water in the plant serves as a carrier for the minerals (the salts, oxides, etc.), which, being non-volatile, remain in the plant after the water is given off. The process of taking up minerals in solution through the roots, of depositing these minerals, and of giving off water from the leaves is called transpiration; this is one of the leading features of plant life. Trees of normal size lose by this process from to to 25 gallons of water daily, and it has been estimated that a large oak with 700,000 leaves gives off 244,000 pounds of water in the five months from June to November, or an average of 25 tons a month - nearly one ton a day. Transpiration is greater in the daytime than in the night, and leaves exposed to the sun transpire from three to ten times as much water as those that are shaded. There has not yet been developed any very satisfactory theory explaining the movement of water to the top of a high tree. It is known that the minute root hairs at the ends of the roots fasten themselves to the soil particles and withdraw water from them even when they appear dry; and it is probable that the transpiration current, which flows through the wood to the leaves, is forced up by a combination of atmospheric and root pressure aided by osmotic force ${ }^{1}$ and capillarity. As has been said, the conifers are more moderate in their demands.

${ }^{1}$ See "A Text Book of Botany," Part I, Sect. II, by Strasburger, Schenck, Noll, and Schimper. 
on water than the broad-leaved genera. This is the reason why sand plains, such as those of Cape Cod, can support the pine. The water table is always found to be farther removed from the surface of the ground under forest than outside it or under a cutover forest; under old forests it is lower than under young stands. Seedlings spring up in a forest when the roots of the adjoining trees are cut through, thus allowing the water table to come nearer the surface. From the illustration of the oak mentioned above it will be readily realized, in dry seasons especially, that the amount of water available per tree might well be the controlling factor influencing growth or life itself. Forests transpire more moisture than other vegetation under the same conditions. Any deficit caused by excess of transpiration over precipitation is necessarily made up by water from the open. Other things being equal and leaving the surface out of account, the soil under a mature forest is drier than in the open. Thus seedlings grown in the open get more moisture in a dry season than under large trees, but, on the other hand, the intense heat in the open may more than counterbalance the greater supply of water.

The chief element of dry wood is carbon, which forms about one-half the dry weight of plants. This element is entirely absorbed from the carbon dioxid of the atmosphere through the process called assimilation. As there are only two grams of carbon in 10,000 liters of air, one tree with a dry weight of 5000 kilograms requires about i 2 million cubic yards of air to furnish the carbon. But for the fact that the air is being constantly resupplied with carbon exhaled by animals and poured forth from factories and chimneys these figures would seem startling. The process of assimilation, or the taking of carbon from the carbon dioxid, can only be carried on by the chlorophyll or green bodies in the leaves, by the action of sunlight, and a definite amount of heat. The first products of assimilation are carbohydrates, either in solution or as starch grains. The process ceases at night and the starch grains are dissolved and pass out of the cell. The surplus products that are not needed at once 
are stored. This surplus is greatest at the end of the growing season, and upon its amount depends all growth of the next year either of mother-plant or offspring in germinating seed. This material is stored in the form of starch or sugars in the embryo of the seed, in tubers, bulbs, roots, and medullary rays of the wood.

All trees require a certain amount of light in order to carry out this work of assimilation. With regard to their ability to bear shade, marked differences occur among the various species of trees, so that they may be classed as: light-demanding or intolerant trees, such as larch, red cedar, and gray birch; and shade-enduring or tolerant species, such as beech, spruce, hemlock. Between these is a class of intermediate trees, including white pine and chestnut. The demands of various species for light may be gauged by the general density of the foliage of the crown and the capacity of overshadowed twigs to retain life.

Authorities ${ }^{1}$ agree that we are far from a thorough understanding of the effect of light upon tree growth, but it has been demonstrated that filtered light in the forest has little value as a means of decomposition of carbon dioxid. The important light in the forest is weakened white light. ${ }^{2}$

Until very recently it was thought by foresters that the amount of light to which a tree has access determines its growth more than any other factor. Recent investigations of soil moisture indicate that this is an even more important factor, so that while it was customary formerly to attribute increased growth, after thinning a forest, to more light, it now appears that it is due as much to the increased supply of water available for the roots.

The physical qualities of soil, especially as related to ability to retain moisture, are more important than the chemical constituents, for almost all soils are chemically able to bear trees. The root systems of various species vary greatly with regard

${ }^{1}$ Light in Relation to Tree Growth, by R. Zon and H. S. Graves, U.S. Dept. Agr. For. Ser. Bul. 92 (I9II).

${ }^{2}$ G. P. Burns, Bul. 193, Vt. Agr. Exp. Sta. (Igi6). 
to shape and the depth to which they reach; but even shallowrooting kinds derive advantage when the soil over which they grow is deep, owing to the greater fertility within easy reach of their roots. Some species, like the oak, have a strong tap root; others, such as beech and birch, develop strong side roots, but no tap root; and still others, like spruce, have a pronounced shallow root system. Spruce and birch require least depth of soil, oak most. Whether the soil is loose or binding is a matter of great importance for tree growth. As a rule, the broadleaf trees do better than the conifers on the stiffer classes of land, although soils of average tenacity are on the whole most suitable for all kinds of trees. The chief constituents of soil are clay, lime, and sand; and as clay yields the most valuable materials for plants, the qualities of soil are often determinable to some extent by the quantity of clay in them. Clay soils are hard and interfere with the movement of moisture; sands are too porous; limes too easily heated; loamy soil, therefore, is usually best.

The chief chemical constituents of wood are carbon, hydrogen, oxygen, and nitrogen, but the ashes of wood also contain sulphur, phosphorus, chlorine, silicon, potassium, sodium, calcium, magnesium, and iron. The carbon is obtained solely from the carbonic acid of the air; the hydrogen and oxygen are derived chiefly from the water in the soil; and the nitrogen from the ammonia of the soil formed by nitrifying bacteria from organic decaying matter. These other chemicals taken from the soil in salts and oxides are contained in very small quantities. Thus iron, though very important for the formation of chlorophyll in the leaves, is present only in very small quantities, so the old remedy of driving nails into a dying tree was of no value.

The percentage of pure ash in the dry leaves of trees varies from 2.3 per cent in white pine to 7.6 per cent in the ash tree, and dry leaves have a higher percentage of minerals than wood. This indicates the well-known fact that conifers are less demanding as regards chemicals than broadleafs. For this reason the soil improves under coniferous crops if a good canopy is main- 
tained, as the minerals accumulate. It also illustrates the way in which a forest soil is annually renewed by the return of the leaves rich in minerals.

Of all the elements taken from the soil nitrogen is the most important. The chief source of nitrogen is the raw humus composed of decayed leaves and wood. It has been found that dead leaves mixed with soil absorb nitrogen from the atmosphere in large quantities, probably through the assistance of bacteria, mosses, and lichens. This capacity of the bacteria is reduced by frost, so the supply of nitrogen is less in the open in places exposed to frost. Some plants take in nitrogen from the air through their leaves. About ro pounds of nitrogen are carried to the ground per acre annually by rain, and the litter of leaves and twigs carries to the ground in a beech forest 40 pounds, in spruce 28 pounds, and in pine 26 pounds of nitrogen per acre. On the other hand, the annual consumption of nitrogen for wood production is 9 pounds for beech per acre; 12 pounds for spruce and fir; and $6 \frac{1}{2}$ pounds for birch. An investigation in a plantation of maritime pine on a sand dune 56 years after planting produced, from a layer of soil 6 inches deep, 7 tons of organic matter per acre with nitrogen 1.5 per cent, or 248 pounds of nitrogen per acre. This is an annual accumulation of 4.5 pounds per acre. In another plantation the average accumulation was 7.2 pounds per year. ${ }^{1}$

As regards the chemical composition of soil, sour, marshy soils are unsuited to most species except Scotch and white pine and spruce. These are about the only species that will thrive on pure peat. Ash, maple, beech, and elm require a moderate amount of lime in the soil, and oak, locust, European larch, and Austrian pine thrive best on soils which contain some lime, while chestnut seems to do better in a soil containing very little lime. Some recent investigations in soil seem to show the commanding importance of lime as a controlling factor in tree growth. Most trees are lime-loving to a certain extent, but an overabundance of lime in all cases is unfavorable. The hardwoods -

1 See Forestry Quarterly, Vol. VI, p. 290, and Vol. VII, p. 192. 
oak, ash, maple, chestnut, beech - seem to demand the presence of a considerable quantity of potash; spruce, fir, pine, and birch thrive on soils rich neither in lime nor potash. For the production of wood only, the demands vary as follows in high forests: from 4 to 20 pounds of lime; from 2 to ro pounds of potash, and from $\frac{4}{5}$ to $4 \frac{1}{3}$ pounds of phosphoric acid per acre per year. The combined influence of all these factors dependent on soil and situation is shown in the amount of timber produced per acre and in the quality of the timber.

When the trees of a wood are tall and straight, free from branches, and tapering but little, it is the best possible indication that the soil and situation are eminently suited to the woodland crops growing on them.

These factors of climate, soil, etc., have influenced the distribution of trees in such a way as to form forest "types." In crossing a mountain ridge we find one type of forest in the swamp at its base, which is quite distinct in its composition and appearance from that on the drier, rolling land just beyond. On the steeper slopes another forest type is substituted, just as the human type raised in the wild mountains differs from that of the fertile valleys below. Scientific forestry largely deals with the causes for these varied types, while applied forestry, based on this knowledge, tries to develop in every locality the type which is best fitted to exist there.

The term stand is a general descriptive term referring to an aggregation of trees standing on a limited area, of more or less uniformity of composition and condition, or of age. Thus in a certain type we may have a stand of young growth; a stand of diseased and damaged trees; a stand of exceptionally tall specimens, etc. These stands are usually confined to a comparatively small area.

\section{Forest Types.}

In every forest the ceaseless struggle going on gradually brings about many changes unseen by the casual observer. In the small openings of the forest, caused by windfall, snow 
breakage, or other causes, seeds of trees germinate and begin to grow. The kind of trees that come up here depends, as has already been shown, on many factors - the kinds of seed trees near, the covering of the soil and moisture content, the light available, etc. On the burned-over and freshly-exposed mineral soils, poplar, bird cherry, and birch spring up freely; on the abandoned fields, pine and spruce are especially apt to appear; and on the moss-covered decaying logs of the northern woods, little hemlocks, fir, and spruce seedlings start. In a few.

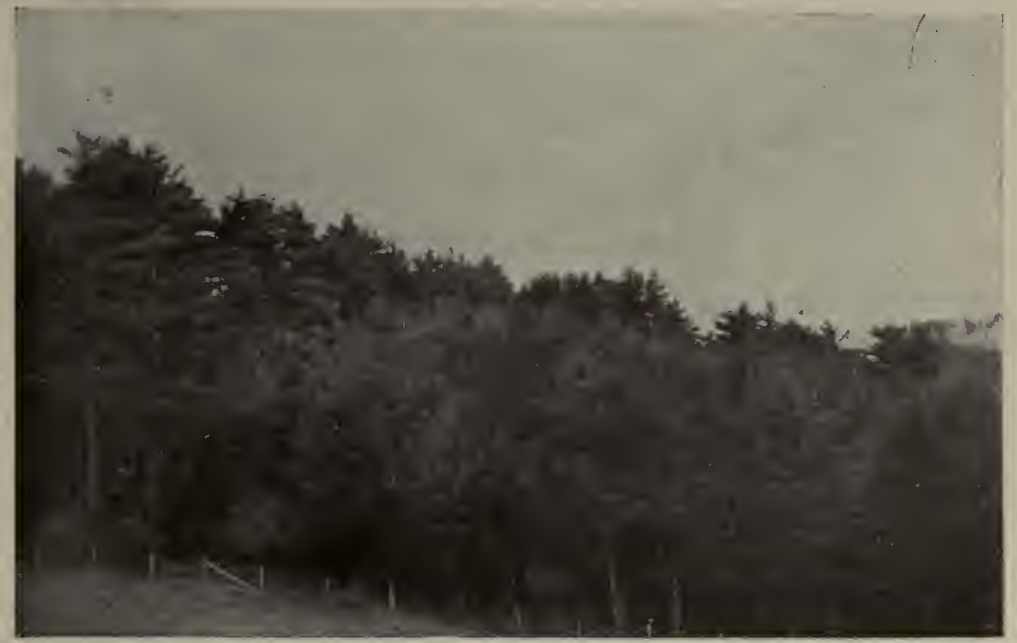

Fig. I. - Two stands of white pine of different age classes. The one at the right is 40 years, that on the left 70 years of age.

years the growth and very existence of these seedlings are influenced and other changes take place. The tops of the old trees may spread out and shade the openings, so that only the tolerant seedlings can endure; or the remaining old stand may be felled and an unlimited amount of light admitted. Under this impetus certain rapid-growing species may push up to the entire exclusion of the others, or these others if they are tolerant of shade may be relegated to an understory of secondary importance. On an acre of forest soil thousands of such seedlings 
may start, but in the course of their various struggles and under innumerable external influences their ranks are so thinned that only a few hundred grow into fair-sized trees. A stand of 1000 trees per acre 20 feet high by the time it is 80 feet high and correspondingly large will seldom contain over 400 trees to the acre. The trees that are killed in this constant strife fall to the ground after a few years, decay, and add to the humus of the soil. As the forest grows old gaps are caused by these deaths and reproduction again takes place. Whether the same kind of trees will come in depends upon the conditions at that time.

In every region certain combinations of forest trees and underbrush are characteristic of different sites. As already explained, this community of tree life is called a "type," and is influenced by soil, exposure, elevation, moisture, and other factors. As examples of types, we may mention the "spruce slope type," characteristic of the steep mountain slopes of northern New England, and "chestnut oak type," of the trap ridges of Connecticut. Under natural conditions such a forest type maintains itself century after century on the site to which it has become adapted. Accordingly it is known as the permanent type of that particular site. Circumstances not in the regular course of nature may entirely change the conditions and cause the appearance of a different forest type. Such influences are windfall, extensive damage by heavy snows, by insects or fungi, by fires, and by lumbering or clearing for farming. The type following any change of this sort is a temporary type, as, for example, the "poplar type" on burns, or the "old-field type" on abandoned cleared lands. Gradually this temporary type, if left to itself, will change into the permanent type and after perhaps fifty or one hundred years the forest will have the form and composition that it had before the change. Such is nature's way of asserting her rights.

Every forest type will be found under a considerable variety of condition of soil, moisture, etc., and, of course, will make its best development where the sum total of conditions is most 
favorable. Foresters recognize this situation as Quality I for the type, and usually speak of Qualities II and III as designating respectively poorer sites.

\section{Pure AND Mixed Stands.}

One of the first things to notice in the study of a forest is the kind of trees that are present and the proportion of the more important ones. In the virgin forests of northern New England, for example, we find spruce, hemlock, birch, maple, beech, probably basswood, and several other species. The hardwood forests of Connecticut and Rhode Island, on the other hand, consist of chestnut, oak, hickory, maple, birch, elm, hornbeam, etc. Both of these are termed "mixed forests." But in the former region, especially in Maine, there are extensive areas that have been burned over which are now covered with canoe birch. There are old pastures in northern Vermont now overgrown with impenetrable thickets of arborvitæ; and further south, with white pine. These are "pure forests," being composed of but one species. As used in this country a stand is called "pure" if 80 per cent of the main crop is composed of one species.

A study of the causes of these differences reveals the fact that pure forests are usually composed of trees whose seeds are light and are, therefore, borne long distances and in great numbers by the winds. Anyone accustomed to tramp in winter must have seen the snow-covered fields, though far from trees, well sprinkled with birch seed. Although these light-seeded species often occur in mixed forests, the heavier-seeded varieties are characteristic of them and never form pure forests except under particularly unfavorable circumstances. Such exceptions are the summits of the trap ridges of Connecticut where the soil is too scant to support any tree life except a very open, pure forest of chestnut oak.

There are, of course, artificially pure forests, as those which are planted, or those from which all but one species have been removed. This brings us to the question which has been pro- 
lific of discussion among foresters, as to whether pure or mixed forests are more profitable.

Naturally there are advantages in a mixture of deep and shallow-rooted trees, since a greater store of soil moisture and fertility is thus made available. So also different trees having somewhat different requirements as to chemical or physical properties of soil can abstract more from a given area than could one species, and a mixture of trees having different degrees of shade endurance can dwell more closely and form a heavier stand per acre. But the chief advantage of a mixture is in case of some catastrophe which devastates one species but spares the others. The tamarack may suffer from insect ravages, as was the case twenty years or more ago. If other species are in mixture they remain to take up the area, to reproduce, and also, to some extent, to present a barrier to the invasion of insects. In case of a severe windstorm, the more shallow-rooted trees may be overturned in exposed situations, unless protected by a mixture of windfirm varieties. So against all forest enemies a mixture forms a safeguard. There is also a financial advantage in raising mixed forests. The length of time required to grow timber is so great that it is impossible to predict what species will be more valuable by the time of maturity. In Europe the first forestry measures were induced by a scarcity of fuel wood in the vicinity of the large cities. Hardwoods were, therefore, cultivated in these early operations, but to-day when railroad transportation has brought coal to the cities from long distances and manufacture is given an impetus, the demand is for softwood lumber and the systems of management have been changed to produce it. A mixed forest provides against such changes of the market by furnishing different classes of timber. On the other hand, pure forests have now well-recognized advantages, the primary one being the simplicity of management. While the chances for injury are greater than with mixed forests, the profits are also greater if such injury is avoided, for a pure forest of trees adapted to a situation will produce more valuable timber than a mixed one. 
Much can be said theoretically in favor of each kind. For practical purposes in New England, it may be said that good management of our existing mixed forests will gradually restrict the mixture to two or three of the most valuable species; while plantations will be made pure, at least over small areas. As certain soil-fertilizing qualities are furnished by the heavy shade and decaying foliage of less valuable species, such as beech and hemlock, they may be sometimes planted, but this planting should usually be in the form of under-planting.

Mixed forests undoubtedly have a greater esthetic value than large pure forests, and for this reason will always be characteristic of estate forests.

\section{Coppice and High Forests.}

Nearly all the deciduous trees of New England have the ability to resprout when cut, a power common to only one or two conifers. In some cases these sprouts spring from the top of the stump, but with most trees from its base. In the New England forest, chestnut is the most prolific sprouter as regards the number of sprouts, their thriftiness, and the advanced age to which it is able to produce them. While the white oak sprouts but little after the age of sixty years, there are numerous cases of chestnuts which have grown from stumps one hundred and ten years or more old. Besides the chestnut and various species of oak, the red maple and white ash and basswood are prolific sprouters. Next to these in this regard are some species of birch and hickory; but the species characteristic of the northern forest, such as sugar maple, yellow birch, and beech, sprout comparatively little, and the trees resulting from them rarely amount to anything.

A forest produced by sprouts is a coppice or low forest, so called because the trees seldom attain the height of those raised from seed, and are grown mostly for the production of smalldimension materials, especially fuel.

As distinct from this is the high forest composed of trees that have grown from seed. Practically all our virgin forests were 
of this character, and wherever a second growth of conifers has come up on an old pasture it is a high forest, even if not over ten feet in height, the distinction being that trees sprung from seed will in time produce tall timber.

A combination of the coppice and high-forest forms is known as the "composite form," in which seedling trees and sprouts are grown together.

The effect of these different methods of reproduction are nowhere better exemplified than in the forests of northern and southern New England. The slopes of the White and the Green Mountains when once denuded of their spruce become reclothed with conifers only after a series of years. In the lower and warmer regions of Massachusetts and Connecticut, on the other hand, the hills are immediately reclothed with forest of the same species that were cut. Such are the advantages of the unkept woods of this region over those of the north. But as a practical system the simple coppice can be advised only in regions where there is a profitable market for fuel wood, as small-dimension material is its chief product. In America the sale of such products is slight compared with the demand for lumber, ties, poles, etc., so the land owner should gradually transform the coppice forest to a high forest, either of the same or more valuable species.

\section{Even and Uneven-Aged Forests.}

If several specimens of the paper or canoe birch in a stand grown on an old burn are cut, it will be found that the ages vary but little, as, for example, from twenty to twenty-five years. In Connecticut it has been the practice of farmers for over a century to cut their wood lot "clean" whenever the trees were of a sufficient size to furnish the material desired. This was formerly cordwood, but during the past generation the use of coal has become so general that other products are now taken from the wood lot. In either case it has been the custom to cut all the trees on a certain area. These are of species that sprout naturally from the stump, and the result is that 
another forest all of whose trees are of the same age comes up to take the place of its predecessor. These are called "evenaged forests."

Of a very different character is the virgin forest of the Adirondacks or the White Mountains. Here one will find stunted spruces that have not attained a height of three feet in fifty

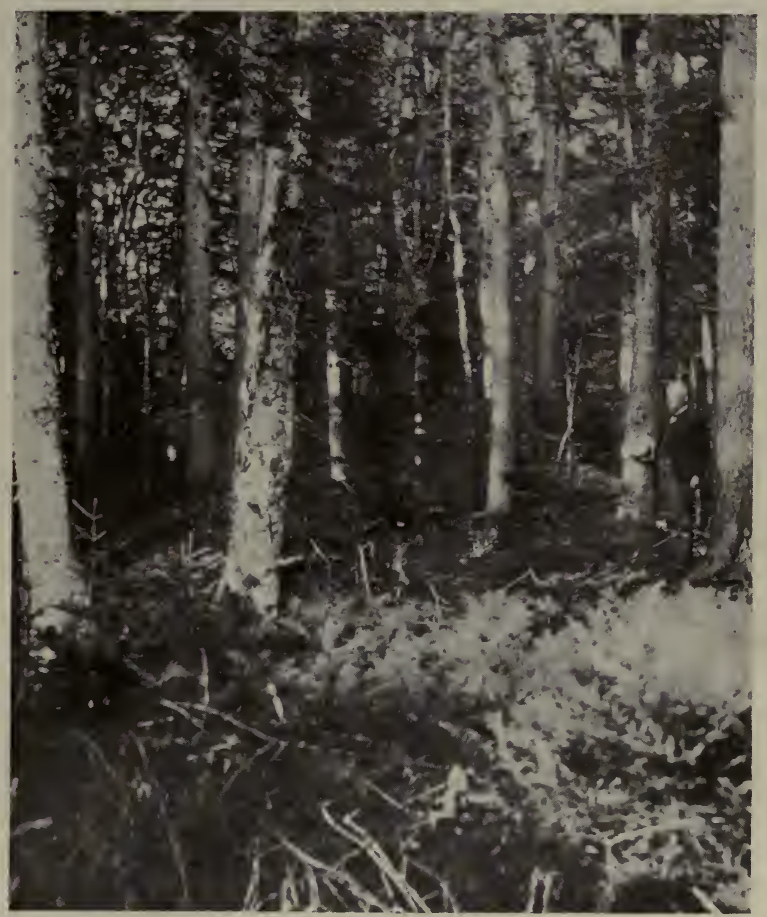

Fig. 2. - A virgin forest of a mixed uneven-aged character. Spruce, yellow birch, paper birch, maple and beech are the chief species.

years along with one-year-old seedlings overshadowed by larger spruce and immense yellow birch that have been growing for over three centuries. This is an uneven-aged, or as it is often termed, a selection forest. Patches of seedlings spring up here and there in small openings where a few grow into saplings and finally into large trees. With such a variety of sizes and species 
these forests are often most beautiful, but on account of their unevenness are usually least profitable to manage.

A stand in which two height or age classes of considerable difference, usually, are developed or are intended to be maintained, as upper story or overwood and lower story or underwood is called a two-storied forest. We sometimes have twostoried forests of white birch and spruce, in which both stories are of the same age, but in which the birch is considerably higher owing to its more rapid growth. 


\section{CHAPTER II.}

\section{SILVICULTURAL CHARACTERISTICS OF THE IMPORTANT NEW ENGLAND TREES.}

IN the first chapter the relation of climatic influences, such as soil, light, etc., to tree growth has been traced and the kinds of forests to be dealt with have been described. The differences existing between forests are due to the trees composing them, and the presence of these in turn is due to the natural conditions previously mentioned. Through the centuries of its evolution each tree species, as each animal species, has acquired certain definite characteristics which the forester calls silvicultural to distinguish them from the botanical characteristics by which a species is identified. Scientific forest management must be based on an accurate knowledge of these characteristics of the different tree species.

The most important silvicultural characteristics of trees, which it is the purpose of this chapter to describe, are the following:

(a) Range and distribution.

(b) Requirements as to soil, light, and moisture.

(c) Rate of growth and longevity.

(d) Seed production and ability to reproduce by seed and sprouts.

(e) Liability to damage by fire, insects, fungi, etc.

(f) Purposes for which used.

\section{White Pine (Pinus strobus).}

The white pine extends from Newfoundland and southern Labrador to western Minnesota and Manitoba. It reaches its southern limit in central Illinois, Indiana, and the southern Appalachians, where it is found as far south as northern Georgia 
and Alabama. It originally grew in all sections of New England except on the higher mountains and in the region comprising southeastern Rhode Island and Cape Cod.

Few forest trees bear seed every year and the white pine is rather more irregular in this respect than are most trees. There is a common saying that the pine bears a seed crop only once in seven years. This notion, however, is incorrect. There was a good seed crop in Vermont in 1907, in parts of the State in r9ro, and in other parts in I9I. It takes two years for the pine cones to mature. At the end of the first season the cones are about one inch long and of a purplish color. The mature cones begin to open early in September when the seed blows out and is carried by the wind for considerable distances. As there are two seeds on each scale, there may be eighty or more seeds in a cone. Usually about one pound of seed is secured from a bushel of cones. Some large-topped pines will yield from two to three bushels of cones, which carry anywhere from 50,000 to 100,000 - seeds. A few such trees scattered over a tract are important factors toward its restocking. Much of the seed is carried twice the length of the tree and some of it considerably farther. It germinates best where there is plenty of light, as in a pasture at the edge of the woods, or in an opening caused by windfall. The little seedlings require a great deal of light and will soon die if deprived of it.

These facts are important reasons for making cuttings in a pine forest the season following a seeding. On account of the length of time required to mature the cones, it is always possible to know a year ahead when there is to be a good crop, and the harvest should be planned accordingly. If the cutting is made in the fall or winter following seeding, when the ground is covered with seed, germination goes on well in the soil which is stirred up by lumbering, and the seedlings grow well under the increased light. If made the year before, the seed from these trees will be lost; if made the year after, the seed would largely have germinated and died for lack of light and moisture. This explains why it is that occasionally one finds a splendid second 
growth of pine following the cutting of pine, and at other times there is no growth at all.

Cones are often formed on very young pine trees, but until the trees become thirty years old there is either no seed in these cones, or the seed is liable to be sterile.

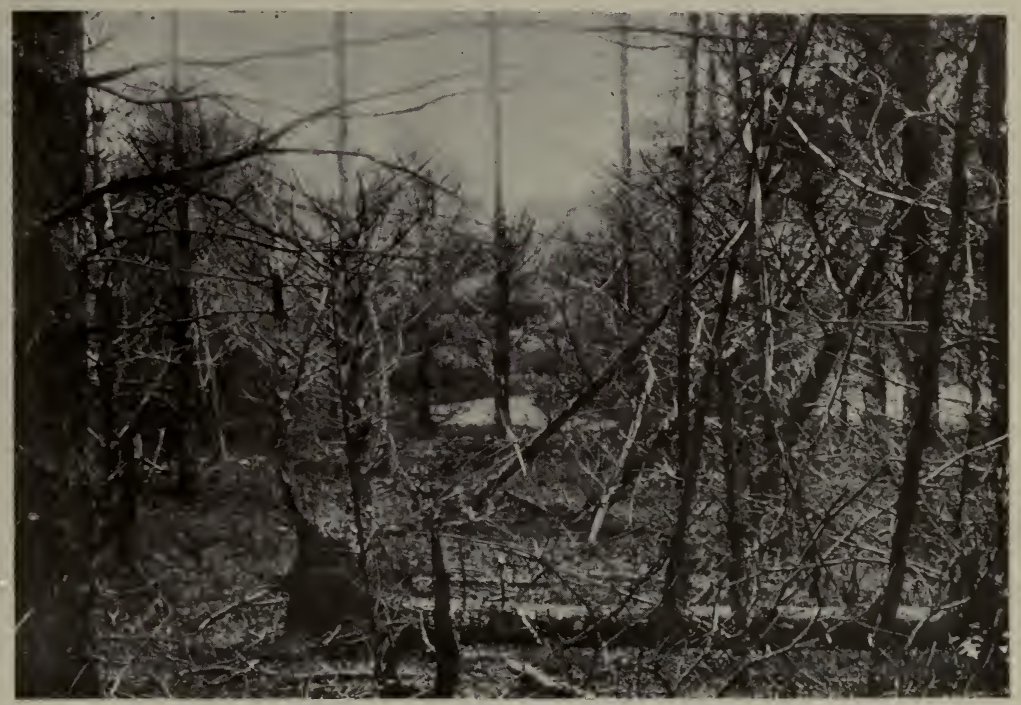

By permission of the U. S. Forest Service.

Fig. 3. - Windfalls as the result of planting white pine on low, wet ground where the drainage is insufficient.

The white pine is very indifferent in its demands upon soil and moisture and thrives on all but the driest of New England's sandy plains; it will grow also on hummocks, in swamps, even with clay substratum. However, it makes its best development on a fairly moist loam soil. In regard to light, it is more exacting. Under a light shade the seedlings will exist for several years, but they will make little growth and in a heavy wood are sure to succumb. The rate of growth, as with all species, depends upon conditions. On the whole, it is the most rapid growing native tree of New England, and usually averages over a foot a year in height. The annual height growth is sometimes over three feet, and the diameter growth is proportionately large. 
It has been known to attain a diameter of thirty-two inches in seventy-seven years. Unlike some rapid growers the white pine lives to an advanced age, occasionally three hundred years or more, though trees of that age are now rare. In youth it is very susceptible to damage by fire, but as it gradually substitutes

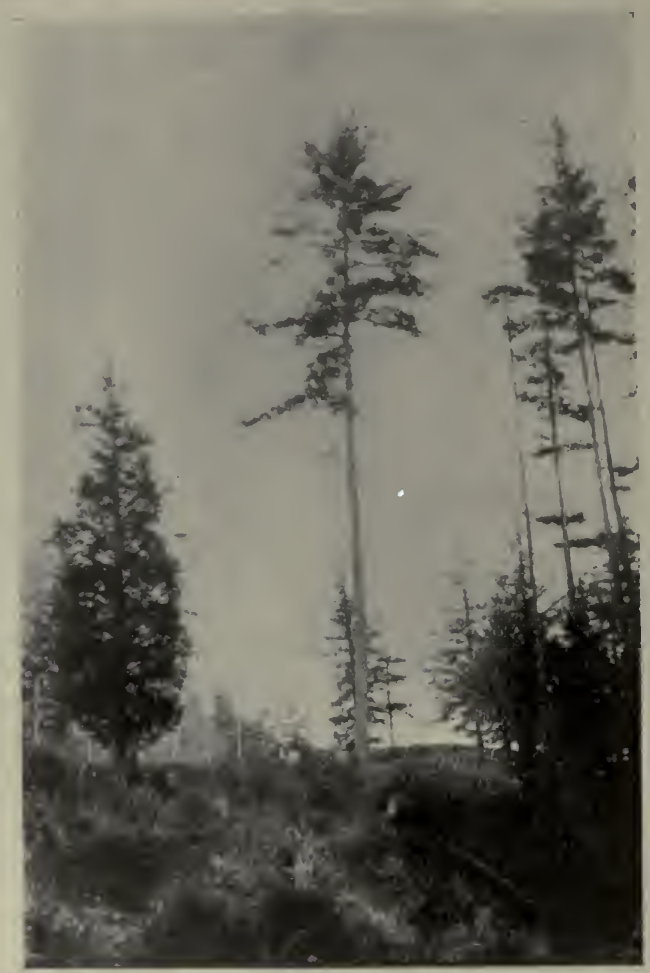

Fig. 4. - A white pine of the best type for lumber; with straight trunk, without dead branches.

a thick bark for the thin, green, smooth bark of youth, it becomes more resistant.

Its chief native enemy is the white pine weevil, ${ }^{1}$ but recently the blister rust disease, ${ }^{1}$ has been found so widespread throughout New England and eastern New York on its other host, the currant, that the white pine has fallen somewhat into disrepute.

1 For a description of the insect and fungus enemies of pine, see Chapter VII. 
Until more is known about the seriousness of this disease the planting of white pine will be confined to regions which are fairly free from currants. Even in such localities it will be safer to mix it with some other tree such as the red or Scotch pines. In this way the planter will avoid the result of having all his eggs in one basket if the white pines are killed.

On account of its smooth grain and the softness of its wood the white pine is a most valuable wood for many purposes. Until it became scarce it was the chief building lumber. Now the better grades are used largely for interior finishing and other special purposes. The cheaper grades are used for match stock and the very poorest grades for box boards. Its high value and rapid growth, combined with its ability to thrive on the sandiest and poorest sites, make the white pine the most important tree to raise in New England; it should be encouraged wherever it occurs.

\section{Norway or Red Pine (Pinus resinosa).}

The red pine has about the same range east and west as the white pine, but does not extend so far south. In New England it is a comparatively rare tree, and is scattered inexplicably in small clumps from the Canadian line to northern Connecticut. In the Adirondacks it is a common tree of the lake shores. It derives its name from the fact that it was first noticed near Norway, Maine.

Measurements made in several New England plantations show an average height of thirty-five feet and a diameter of six inches in thirty years. In mixture with white pine its diameter and height growth averages fully equal to that of the latter. It does not attain as large a size as does white pine, specimens one hundred feet high and three feet in diameter being rare.

The main advantages of the red over the white pine lie not only in the fact that it makes a better growth, especially on poor soils, but that it prunes itself of branches earlier, is more hardy, and is less subject to injury by insects and fungi. It withstands 
a range of temperature of from -50 degrees $\mathrm{F}$. to +105 degrees $\mathrm{F} .{ }^{1}$ and thrives in sections where there are frosts every month of the year. It is usually found on soils where there is considerable sand and gravel, and for such soils, entirely lacking in clay or loam, is undoubtedly preferable to white pine for planting.

The Norway pine has a well-developed tap-root when young, and develops strong laterals, so that it is usually very wind-firm. For this reason it may be planted not only where the soil is thin but on exposed sites. It is somewhat more exacting as regards direct sunlight than white pine. Seedlings require direct sun- light and should not be planted in small openings of a forest or under any trees. It has been found, however, that Norway pine seedlings will stand sun exposure and weeds much better than will those of white pine.

Norway pine produces seed only once in 3 to 5 years. The cones are small and usually not plentiful, so that the seed is comparatively expensive. The young seedlings are particularly susceptible to damage by damping-off, and for these reasons nursery stock is usually more expensive than that of white or Scotch pine. Trees begin to produce seed at the age of about 25 years. Where the soil has been cleared of leaf litter good reproduction of this species is often secured 300 yards distant from seed trees, but the seed seldom germinates on a leaf litter.

After the seedling stage the Norway pine is remarkably free from enemies. On account of its thicker bark, it resists fire better than white pine, although young trees are, of course, killed by a hot fire. It is seldom attacked by the pine weevil and misshapen trees are very rare. It is also safe from the white pine blister-rust disease, and for this reason is recommended for planting in proximity to white pine suspected of being thus diseased.

While the wood of the Norway is somewhat redder in color, heavier and more resinous, it is sufficiently light, soft and straight grained to secure practically the same prices as white pine

${ }^{1}$ Woolsey and Chapman, Norway Pine in the Lake States, U. S. Dept. Agr. Bulletin 139 (1914). 
lumber. The wood is somewhat the stronger of the two. It is chiefly used for dimension stuff and house construction, also for boxes and shingles.

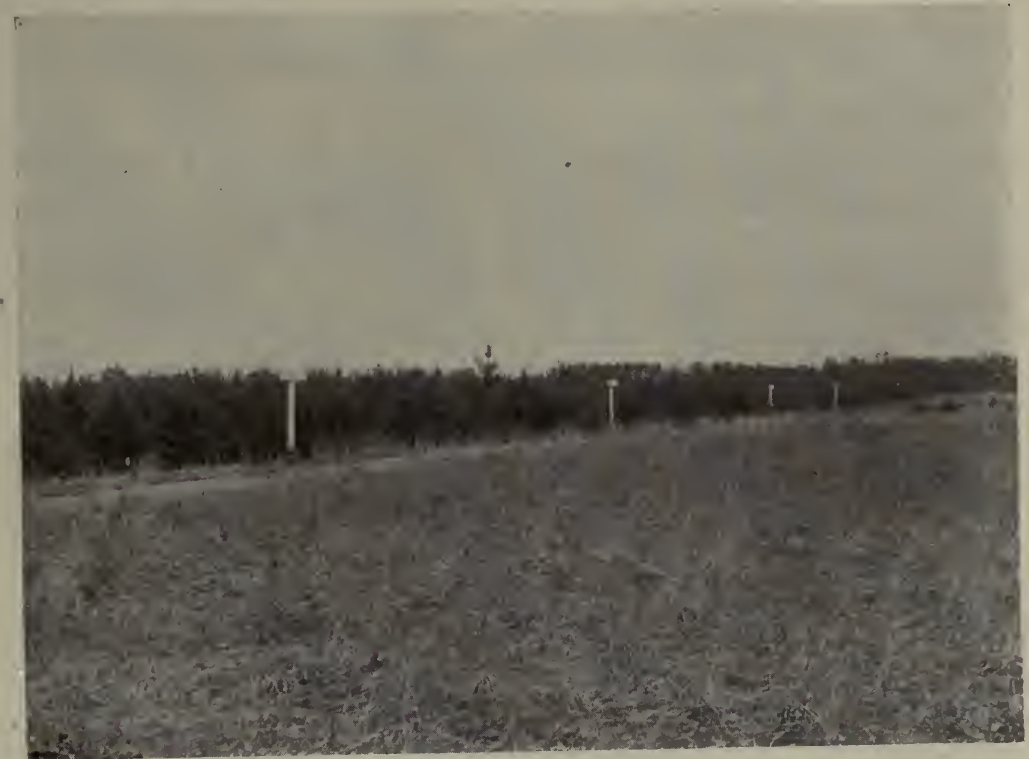

By permission of the Connecticut State Forester.

Fig. 5. - Experimental plantations of the Connecticut Agricultural Station. Reading from left to right the species are:- red pine, Scotch pine, Austrian pine, white pinc. The pines are ro years of age.

Norway pine stumpage of old growth has sold as high as \$I2 per thousand feet on a national forest in Michigan. In the northeast it is seldom separated from white pine.

On account of its rapidity of growth and freedom from insects and serious diseases, ${ }^{1}$ the red pine is a species that should be planted extensively.

\section{Pitch Pine (Pinus rigida).}

This is emphatically an eastern pine, being confined to a belt along the Atlantic from southern Maine to Georgia, and extend-

1 The leaves of the red pine are sometimes attacked by a rust which has as its alternate host the goldenrod. 
ing westward only to the edge of the Mississippi valley. It occurs throughout New England except in the extreme northern part, and in the mountains.

It is the outcast of the pines and occurs pure only on the sandiest plains where other trees thrive with difficulty. On better soils it is sometimes mixed with other pines and with hardwoods. It is characteristic of sand plains in the Champlain valley, on Cape Cod, and in the lower Connecticut valley. In early colonial times in the last-named region it was important as the source of tar and turpentine which were produced in large quantities to supply our early ship-building industry. To-day there are few stands of any size or age, as it has suffered from fire more than any other species, owing to the hot, dry localities which it inhabits.

Its habits are those of the red pine accentuated, in its ability to withstand drought, heat, poor soil, and in its greater demands for light. Its tendency is to grow rather short and crooked but, on the better soils it attains a height of sixty or seventy feet. Pitch pine seedlings grow more rapidly at first than those of our other native pines, but their growth is slower after three or four years. The pitch pine is a prolific annual seeder and reproduction on land not burned over is usually good, since the seed germinates well on the driest of mineral or needle-covered soils. This species also has the ability (uncommon in conifers) to sprout from the stump. After fires, especially, it is common to find numerous sprouts growing from the stump. As a rule, however, these do not mature.

This tree has no serious enemies, and as the bark is often an inch thick it is very fire-resistant. It is this ability to withstand fire that accounts for its frequent occurrence pure where other trees once in mixture, such as the white pine, have been killed by fire.

The shade cast by the pitch pine is not very dense, and the conditions for reproduction of white pine and other species are often best under its mild protection, so that it is a valuable agent in the natural reproduction of worn-out, sandy plains. 
On account of the poor quality of the timber and its smaller yield per acre, the pitch pine is not an especially desirable species.

\section{Scotch Pine (Pinus sylvestris).}

This is a foreign tree and resembles the Norway pine in appearance, but its foliage is somewhat bluer and its bark redder. It is native throughout Europe where several varieties are distinguished and is common in Sweden and Russia. In the Vosges Mountains of Eastern France it reaches an elevation of 2700 feet, ${ }^{1}$ and in the Maritime Alps and the Pyrenees an elevation of 6000 feet. In its native haunts it attains a height of 120 feet

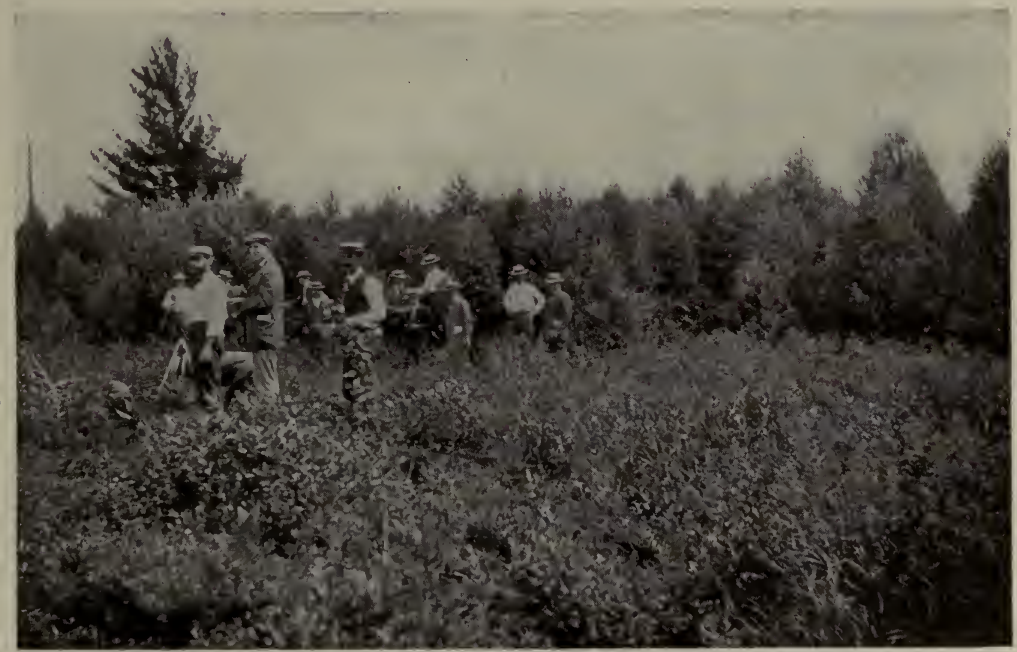

Fig. 6. - A 7-year-old plantation of Scotch pine on sandy soil.

and a diameter of from three to five feet. In America it has been extensively planted, generally with success. The largest plantations in the East are those on the New York state lands near Saranac Lake.

Although it will grow on the driest and most acid soils, as well

1 D. Cannon, "Semer et Planter." Paris, I894. 
as on those rich in lime, it thrives best, like all other trees, on more favorable sites. There are probably few soils in the northeast too poor for this species up to an elevation of 2000 feet. The Scotch pine has a strong root system, forms a dense crown cover, and is able to compete with practically all kinds of brush growth which it soon outgrows and smothers.

It has been established in Europe that the three trees which do the most to enrich the soil are beech, hornbeam, and Scotch pine; hence this is a splendid species for reforesting worn-out and badly managed soils.

Its strong root system which enables it to monopolize the soil makes it disadvantageous to plant it in mixture with other species.

The growth of the Scotch pine is very rapid after it becomes established, surpassing the white pine on very sandy sites. On the better loam sites the white pine grows about as well. The leaders of the Scotch pine sometimes make a growth of forty inches, and often between two and three feet.

The quality of the wood is said to be best in the north of Europe, while in New England it can be compared fairly well with the native red or Norway pine. The wood as a fuel is in great demand by European bakers; it is also used for paper pulp. mine props, telegraph poles, railroad ties and for general building purposes. In France the lumber is considered superior to that of the American white pine.

The seed crop is abundant every two or three years, but as yet all seed used in America is imported. Experience has shown that the seed which comes from northern Europe produces better timber trees than that from the southern part of its range.

In this country the Scotch pine has escaped all enemies except a blister-rust which occasionally attacks young trees of this species as well as pitch pine. The alternate host of this fungus is the sweet fern. 


\section{Red Spruce (Picea rubens).}

This is a distinctly eastern species of the cooler regions, extending west from New Brunswick and Nova Scotia, nearly through New York, and in the Appalachians as far south as northern Georgia. In New England it occurs throughout Maine, New Hampshire, and Vermont, and on the higher hills of central and western Massachusetts.

All spruces are tolerant of shade, and it is one of the wellknown traits of this species that it can exist for half a century or more under heavy shade without making appreciable growth, and then shoot up with the vitality of youth if the shade is removed.

As might be expected from its preference for a cool climate it naturally selects moist situations. Together with balsam and tamarack it is one of the first trees to grow on the gradually forming lands of our northern swamps. However, a lack of water does not prevent its growth, for it inhabits high elevations in the Green and White Mountains where it often forms pure stands of excellent timber. Its root system is very shallow and where grown on hardpan or on ledges, trees are liable to be blown over if exposed to the wind by the removal of surrounding trees.

Under favorable circumstances, though the spruce can hardly be considered a rapid-growing species, it often grows from ten inches to a foot a year in height. More often in virgin forest it grows very slowly, and very old specimens are common. A growth of a tenth of an inch per year in diameter is a fair average for virgin spruce. Four hundred and seventeen annual rings have been counted on a tree less than a foot in diameter, which grew on the upper slope of a Maine mountain.

The seed years are more frequent than those of pine and it begins to seed at an early age.

Trees bear prolific crops of cones which open some two or three weeks later than those of white pine, owing to the cooler situations in which the spruce occurs. For a germinating bed 
it prefers decaying logs or moss, but does well on bare mineral soil or one covered with needles. In any small opening in a spruce forest numerous seedlings can generally be found, and on

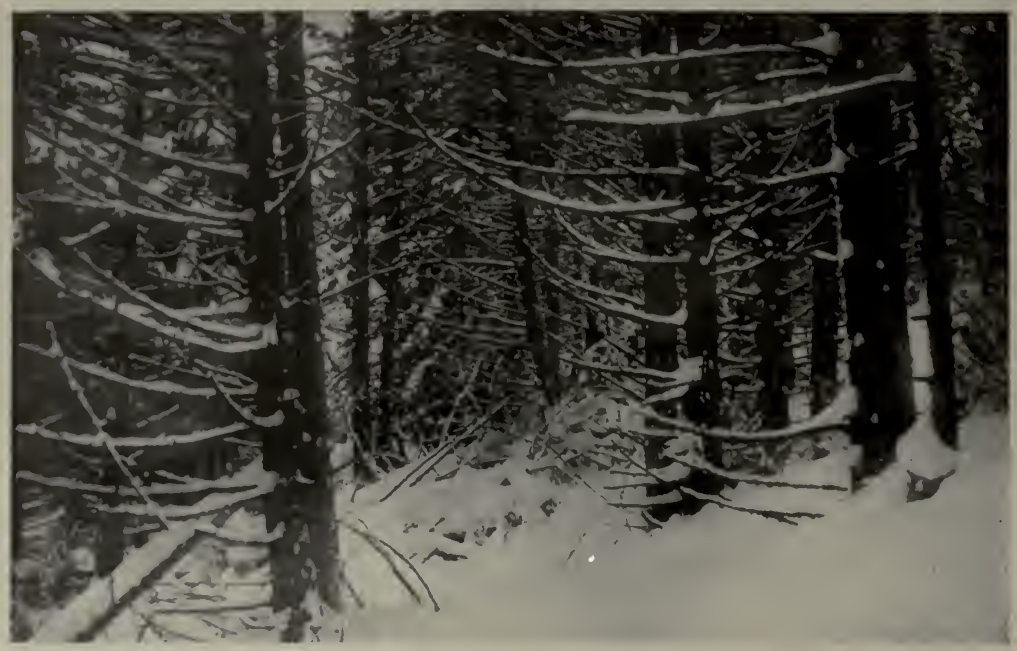

Fig. 7. - A stand of spruce 60-70 years of age on an old field. Note the number and size of dead branches still on the trees.

abandoned fields in the spruce region reproduction invariably follows. The young roots cannot penetrate the leaf litter of a hardwood forest, and spruce reproduction in such places is, therefore, scarce.

Like most conifers it is severely damaged by fire, and, as mentioned above, is very susceptible to windfall. There are also several bark-boring insects which cause periodic damage. Though spruce is neither as rapid growing nor as valuable as white pine, its natural adaptability to the higher and northern portions of New England, its value for many uses as lumber and pulp, its fair growth and easy reproduction, all combine to make it the most important tree to encourage in the higher elevations. 


\section{Norway Spruce (Picea excelsa).}

The Norway spruce, like the Scotch pine, is native throughout northern Europe, but is not peculiar to Norway any more than the pine is to Scotland. It is distinctly a mountain tree, occurring in the French Alps as high as 6000 feet. However, it thrives not only on thin mountain soils but also on the plains, provided the soil is not too dry. It grows more rapidly than our own red spruce and the lumber is apparently as good. It is much in demand in Europe, not only for general construction purposes but for such special uses as the manufacture of musical instruments. Wood fit for this work is only found in the mountains. Trees I30 feet high are not uncommon in France. One of the best plantations of this species in this country is that of the Billings' Estate at Woodstock, Vermont, now 36 years old. Tests of the wood of these trees, made by the International Paper Company, showed that it made a whiter and stronger pulp than our native spruce.

This species is well adapted for planting in the Northeast on any sites which are not too dry, up to an elevation of 2500 feet. It can be especially recommended for planting openings in the forest, because a certain amount of shade does not interfere with its growth. On worn-out farm lands it is easily killed out by strong grass growth in dry seasons.

There are two objections to the Norway spruce. One is that in New England it does not seem to live much more than fifty years. This is not a serious objection from the standpoint of raising pulp, since an excellent crop may be secured in thirty to forty years. The other objection is that it does not reproduce itself well. Although it seeds plentifully, seedlings in the neighborhood of old trees are rare. The tree has the same reputation in Germany where it is largely propagated by planting.

The young plants are very susceptible to the scorching influence of sunlight and for that reason planting on southern exposures should be done in the early fall, so that the trees may 
become established before encountering hot weather. On wet or cold sites, on the other hand, spring planting should be adopted.

\section{Balsam Fir (Abies balsamea).}

This tree is a northern species extending from Labrador to the Rockies, and southward in the Appalachians to West Virginia. It is not native in southern New England, though in the west it extends through the Berkshires into northern Connecticut. It is chiefly confined to regions where the average summer temperature does not exceed 70 degrees F., ${ }^{1}$ and reaches its best development in Maine where there is an average rainfall of 43 inches. Conditions of moisture and temperature are often similar in swamps and on the upper mountain slopes, and the ground in both cases is apt to be covered with sphagnum moss. On the mountains, however, the fir, like other trees, does not attain as large size as at lower elevations.

The balsam fir is short lived and consequently never reaches the proportions often attained by spruce. Trees two feet in diameter and ninety feet high are rare. The foliage persists from eight to thirteen years, considerably longer than that of white pine. The root system is shallow, being similar to that of spruce. The lateral roots extend out in all directions a distance of five feet or more.

Fir cones ripen in one year, while those of pine require two growing seasons. Ordinarily the tree begins to seed when twenty years old and the size of a good Christmas tree. Good seed years occur at intervals of two, three or four years, according to the locality. The seed requires more moisture for germination than spruce, and where moisture conditions are suitable they germinate freely on rotten logs, mineral soil, moss, or even on hardwood leaf litter. In pure stands of balsam there are often from 200,000 to 300,000 seedlings to the acre.

The balsam requires less light than tamarack, white pine and arborvitæ, but more light than either spruce or hemlock. Small

${ }^{1}$ Zon, Balsam Fir, U. S. Dept. Agr. Bul. 55 (1914). 
dead firs under heavy shade are much more common than dead spruce. It will live under shade the first few years, but requires more light as it develops. For good development the balsam requires a richer and moister soil than spruce. It reaches its largest size on flats where the soil is a moderately moist, deep loam. In wet swamps with acid soils and on pure sand it grows very slowly.

The balsam is particularly apt to be attacked by fungi which cause its decay and death at an early age. Because of rot this tree is much more apt to be broken off by wind than to be uprooted, as is the spruce. It is also especially susceptible to injury by fire, since the cambium is but slightly protected by thin bark.

The balsam is a fairly rapid growing tree, though not as much so as the white pine. During the first five years its height. growth is much slower than that of pine or Norway spruce, but from that point onwards until sixty years old, it averages, under favorable conditions, nearly a foot a year. Crowded in a forest its growth is somewhat less. The most rapid diameter growth is between the ages of twenty and seventy years, during which time it requires an average of nine years for one inch of growth on the radius.

Balsam fir is used both for pulp and lumber. Because of its pitch content it is inferior for pulp purposes to spruce. Most pulp mills in the northeast now use balsam up to 40 per cent mixed with spruce. For lumber purposes it is customary to sell balsam with spruce and there is usually no difference in price, except for first grade.

\section{HEMLOcK (Tsuga canadensis).}

The range of hemlock is from Newfoundland west to Minnesota and south to Georgia. It is common throughout New England and New York.

The hemlock is only a little more particular than the pine in regard to soil as it will grow in dry situations, though like many 
other species it prefers a deep, fertile, well-drained soil. It is rather a tree of the hillside than of the plain, and especially prefers cool glens or ravines, probably on account of the atmospheric moisture.

It stands a great deal of shade, even surpassing the spruce in this ability, and because of this is able to establish itself under a dense cover. For this reason, hemlock trees of all ages are common in a stand.

Under the shade of a mature forest the growth of the average hemlock is very slow. There is often a period of suppression of from thirty to seventy and sometimes to two hundred years. Even at this advanced age ${ }^{1}$ if light is admitted a hemlock will respond and show an increased growth. Trees of the same diameter, and in the same stand often differ in age by more than a century. A dominant tree with plenty of light may grow fairly rapidly.

Trees having a moderate amount of light begin to bear seed when from thirty to fifty years old. As a rule seed is produced abundantly every two or three years. The cones mature in a single season and the seed falls during late autumn. It is often carried considerable distances by the wind. The seed germinates well on moss-covered logs and decayed stumps; in fresh mineral soil; and in a moist, well-decomposed leaf litter. Seedlings may be killed by too little shade and this explains why reproduction in the open is not common as with pine and spruce.

Although the hemlock is a shallow rooted species it is seldom thrown by the wind. In the case of ground fires, however, the tree suffers where other deeper rooted varieties escape injury. The most common and worst injury to hemlock by wind is the so-called "wind shake," which is a separation of the rings of the wood caused by the tree being rocked back and forth. "Wind shake" and "butt rot" often make it necessary to discard the butt $\log$ or cut high stumps. As a whole the hemlock is fairly free from serious insects or fungi.

${ }^{1}$ E. H. Frothingham, The Eastern Hemlock, No. 152, U. S. Dept. of Agri. (1915.) 
Hemlock wood is soft, light, stiff, but brittle, not strong, splintery and commonly cross grained. The lumber is accordingly of inferior quality, but with the growing scarcity of spruce an increasing amount of hemlock is being used for pulp. The bark has an additional value for tanning purposes.

Altogether when its rather slow growth and low value are taken into account, hemlock cannot be highly recommended in forestry operations, and in future will be chiefly raised for esthetic purposes.

\section{TAMARACK (Larix laricina).}

Tamarack is one of our most northerly trees, ranging from Labrador and Newfoundland northwest to Alaska, and south to Illinois and Pennsylvania. In New England it is not at all common but is found in many restricted localities, usually on the border of a swamp or the edge of a pond. It does not extend into southern New England, the northern part of Connecticut being its southern limit.

It requires more light than most trees, but will live in water and on sour soils. Tamarack is occasionally found on hillsides but very rarely. It is but seldom found on sand, preferring a loam soil. It has a tendency to form pure stands but is often mixed with balsam, birch, spruce, and cedar. "The root system is shallow but very compact.

Tamarack grows rapidly on well-drained soils, but very slowly on the average swampy site. It seeds abundantly and is a good reproducer especially on abandoned fields. The seed germinates well in pasture grass or on the moss-covered soils of swamps.

The tamarack is our only deciduous conifer.

Many years ago the tamarack was practically destroyed by the worm of the larch sawfly which eats the foliage. For this reason it is seldom that one finds a large, live tamarack although dead specimens two feet in diameter are common. Of late years, however, the sawfly has not been abundant and the tamarack 
is again prospering; in many places it is encroaching on old pastures.

Its wood is durable and strong and is used for posts, poles, railroad ties, and in ship building. In early times it was transported in large quantities from Maine to England for the last purpose. Wherever it occurs it should be encouraged.

\section{European LaRch (Larix Europcea).}

This is a European tree very similar to its American relative, the tamarack. In the Alps of France and Italy, it reaches an elevation of 3000 to 6000 feet, and may, therefore, be classed as essentially a mountain tree. Unlike the tamarack, it thrives only on well-drained soils and requires a deep and moderately fertile soil. It has been planted somewhat widely throughout New England and prospers in all sections.

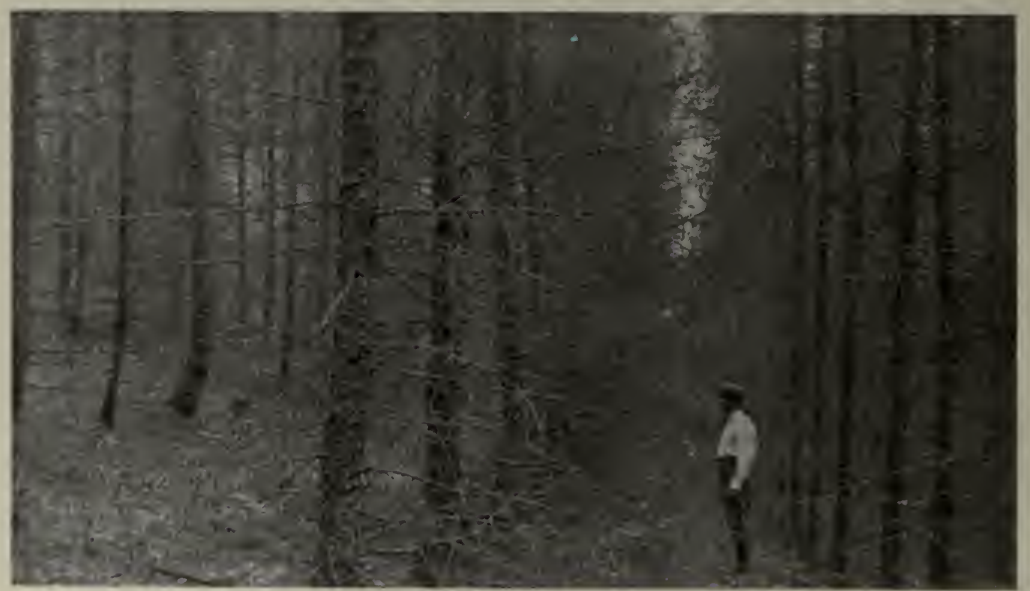

Fig. 8. - A pure plantation of European larch, planted in rows I 2 by I $_{2}$ feet.

It is fully as intolerant of shade as the tamarack and requires a sheltered, warm situation, so that it is well adapted for planting on south slopes. Here and there in the vicinity of cemeteries and other places where the larch has been planted a few seedlings can be found, but the examples of European larch reproduction in 
this country are few. Aside from the damage by the larch sawfly, to which it is subject with the tamarack, the larch appears to be very free from enemies.

Larch is a rapid grower, exceeding white pine in height growth but not in diameter growth. This quality combined with the durability of the wood in the soil makes it an excellent tree to plant for the raising of posts, ties, poles, etc.

\section{Arborvite or Northern White Cedar (Thuja occidentalis).}

This is a northern species common throughout eastern Canada and as far west as Minnesota and extending south in the Appalachians to northern Georgia. It is confined to the northern portions and seldom is found in Connecticut. It usually grows in wet areas forming dense thickets known as cedar swamps, but also frequents hillside pastures in Vermont. It is intolerant of shade as is shown by the characteristic death of the lower limbs when grown close together.

Cedar produces an abundant crop of seed almost every year. It prefers for a germinating bed bare mineral soil or old pasture. As the tree advances in age it is apt to be affected by a fungus which causes the red rot of the heartwood, and renders it useless.

The cedar is very slow growing, although in swamps it grows as well or better than other conifers. As the wood is very durable in the soil it may be encouraged in wet situations for the production of posts and poles.

\section{JUNIPER OR RED CEDAR (Junipirus virginiana).}

This is one of the mostly widely distributed conifers, being well scattered over the United States from New England to North Dakota and Texas. In New England its range is restricted to the southern portion. It is characteristic of abandoned pastures in Connecticut and parts of Massachusetts where it is easily recognized by its picturesque conical form similar to the cypress of the Mediterranean. It is very intolerant and slow growing, of ten being killed out by faster growing and more tolerant trees. 
Red cedar is not fastidious as to soil for it is often found on ledges and sand plains. Although slow growing it is a long-lived tree, but seldom in New England does it attain a height of over sixty feet or a diameter of over twelve inches.

Its seed, which is in the form of a berry, is largely distributed by birds. It is supposed that some chemical action which takes place in the bird's stomach aids germination. In old pastures reproduction is plentiful under old hardwood trees and along fence lines.

The wood is very durable and in great demand for posts and lumber for chests, but on account of its slow growth it is not a tree to be particularly favored.

\section{Sugar Maple (Acer saccharum).}

The sugar maple extends throughout the eastern part of the country from the Atlantic to the great plains of Dakota and Oklahoma and south to the Gulf of Mexico. It occurs everywhere in New England, but is more abundant in the northern portion and is especially associated with spruce. However, the sugar maple is never mixed with the spruce in the swamps or the higher mountain slopes, but on the lower slopes and gently rolling land where the soil is neither very wet nor dry. It seldom occurs on sand, and is an unmistakably lime-loving species. The maple prefers a well-drained, deep loam soil. It is one of the most tolerant trees as regards shade, and young seedlings do well even where they receive no direct sunlight. Although large-topped and ornamental trees on well-fertilized lands often make a conspicuously good growth, it is on the whole a slow-growing species. In the sugar bushes of Vermont and the virgin forests of Maine it is not infrequent to find trees from three to four centuries old. Although like most deciduous trees it is able to reproduce by sprouts from the stump, as a matter of fact it seldom does so in New England except in the southern portion. It more than makes up for this however, by being a very prolific seeder. The seed matures in the 
fall and is often thickly scattered over the ground near old trees. It germinates well in pasture grass or on bare mineral soil. The result is that our northern forests often have dense thickets of maple saplings. On account of the thickness of the bark it suffers comparatively little from fire. It sometimes suffers severely from defoliation by the forest tent caterpillar. An injury to the sap is caused and often ends in the death of the tree. Another common insect enemy is the maple borer which makes great sores on the trunk.

\section{Soft Maple or Red Maple (Acer rubrum).}

The range of this species is slightly more restricted than that of hard maple, as it extends westward only as far as eastern Minnesota and Nebraska, but it reaches a little farther south in Florida. It is found throughout New England but is more common in the southern section. In the northern portion another species, $A$. spicatum or mountain maple, commonly takes its place and is similar in character.

The red maple is not in the least fastidious as to soils for it is the most common deciduous tree of swamp lands and is found as well on very dry sites, although seldom on sand plains. In the swamps its growth is only medium, but on the old fields of southern New England where it is a characteristic feature it grows rapidly. It does not, however, attain great age and specimens over fifteen inches in diameter and eighty feet high are rare.

It produces an abundant crop of seed every spring and reproduction both by seed and by sprouts is good. The seed germinates best on old fields and also on soil made bare by fire.

The bark of red maple is soft and the tree is easily damaged by fire. It has no serious insect or fungus enemies.

As the wood is of inferior quality it is used chiefly for fuel. Except in swamps and as a pioneer in the reëstablishment of forests on old fields, it is of little importance silviculturally, and it is bound to play a less and less important part as such worthless species gradually are eliminated. 


\section{Yellow Birch (Betula lutea).}

The yellow birch extends westward from Newfoundland and Nova Scotia into Minnesota and south in the Appalachians to northern Georgia. It occurs throughout New England from northern Maine to Long Island Sound.

It is less particular in regard to the character of the soil or moisture than the sugar maple, but is less tolerant of shade than that tree. In second growth stands it is a fairly rapid grower, but under virgin conditions the growth is similar to that of maple and it lives to equally advanced age. Like all birches this species is a very prolific seeder, and as the seed is very light it is blown long distances. Birch seed germinates particularly well on burned-over land where the mineral soil is exposed. Openings in spruce forests caused by windfall or fire or camp clearings frequently grow up to a dense stand of seedlings either of pure yellow birch or of this mixed with other species. This tree has no serious natural enemies and is little damaged by fire.

\section{PAPER Birch (Betula papyrifera).}

The range of the paper birch extends across the continent to the Rocky Mountains but not very far south. It occurs throughout New England but only occasional specimens are found in Connecticut and Rhode Island.

This tree thrives best on a fresh, well-drained soil, being fond of moisture but not of swampy land. Although frequently found on dry slopes it does not prosper there as well as the yellow birch. Paper birch is one of the most intolerant trees and is often killed out, for lack of light, by slow-growing but more tolerant species, which started under its protection but finally caught up with it in old age. Although rapid growing in youth, it is comparatively short lived, trees over one hundred years old being uncommon. Specimens over eighteen inches in diameter and seventy-five feet high are scarce.

It produces an abundant supply of seed, but on account of 
its intolerance of shade reproduction is only successful under favorable light conditions such as those obtained on burned areas. These also furnish the bed on which the seed germinates best because the bare mineral soil is exposed. When cut at an age of less than sixty years the stumps sprout prolifically and these sprouts grow even more rapidly for forty or fifty years than trees grown from seed.

The wood of the paper birch is used principally in the manufacture of spools, bobbins, dowels, shuttles, toys, pegs, etc.

Paper birch is very susceptible to injury by fires.

Grown in pure stands as it usually is, this birch is one of the most beautiful trees. In fact, it is difficult to imagine anything more beautiful than such a grove with the sunlight filtering through the foliage upon the pure white bark. In too many places this beauty is destroyed by the ruthless peeling of the bark for souvenir purposes. It should be realized that the white bark never grows again, and that once peeled the beauty of the tree is gone forever.

On account of its rapid growth, its value for special purposes, and its prolific reproduction on burns, this tree always will be one of considerable importance in northern New England.

\section{Gray Birch (Betula populifolia).}

The tree is found from New Brunswick south through Delaware and Maryland and west through New York. It occurs in all parts of New England, but chiefly in the three southern states.

The gray birch is a poor imitation of the paper birch but is sometimes confused with it on account of the whitish color of its bark. This, however, does not peel so readily and is a dirty white compared with the clean white bark of its superior. Furthermore, this tree seldom attains a diameter over eight inches or a height over fifty feet, and is short lived.

The gray birch is as characteristic of the old fields of southern New England as is the red cedar. It grows rapidly in such 
situations where there is plenty of light, but under shade is soon killed out. It thrives on the driest of sand plains differing in that respect from the paper birch, but is also occasionally found in rather swampy places. The quality or texture of the soil seems to be of less importance than the amount of light available. It produces a large crop of seed every fall which is blown long distances. This germinates best on bare mineral soil, though often starting well on a thin sod. For the first twenty years or so it grows very rapidly and when cut sprouts vigorously, so that in many cases it is an undesirable weed on account of the difficulty of keeping it out of the fields.

The gray birch is easily killed by ground fires, but has no serious enemies.

It seldom attains lumber size, and is an indifferent fuel, but is beginning to be used for spool and bobbin manufacture and other purposes for which its wood, which is similar to that of the paper birch, is fitted. However, it is not a tree that will ever be favored by the forester.

\section{ВЕECH (Fagus atropunicea).}

The range of the beech extends throughout the eastern United States from the Atlantic to Wisconsin and Texas and south to the Gulf of Mexico. In New England it is found principally in the forests of the three northern states. As found in New England, it occurs always in mixture with other trees, and prefers a loam soil. However, it frequently grows on very poor sandy soils or other dry situations. It is one of the most shade enduring trees, and on this account it is able to grow under a dense cover of other species. Like the yellow birch and maple it is slow growing and lives to an advanced age. Although it suckers from the roots, its chief means of reproduction is by seed, which being a heavy nut cannot be transported by the wind. Heavy seed crops occur only at long intervals, although some seed is borne every three or four years. The seed germinates best on a mineral soil well mixed with humus. In Connecticut, Rhode Island, and southeastern Massachusetts the beech repro- 
duces very poorly from seed and is forced to depend on root suckers.

Its smooth, heavy bark is a good fire resister, and it has no serious enemies. The lumber is used for heavy planking, for tool handles, etc., but is of relatively low value, and the tree will never hold an important position in forestry operations.

\section{White AsH (Fraximus Americana).}

The white ash occurs throughout the eastern half of the country, west into Nebraska and Texas, and south into Georgia and Mississippi. In New England scattered specimens are found in all sections, but it is most common in the northern hardwood forests.

The white ash usually occurs as individuals mixed with other trees, seldom forming a large proportion of the stand. It prefers a moist loam soil and is almost never found on dry, sandy sites. It also requires considerable light, and, when favored with good light and soil, makes a fairly rapid growth.

The ash seeds nearly every fall, but some years more heavily than others. The seed has a long wing and is carried considerable distances by the wind. It germinates best on a mineral soil rich in humus, and where such conditions prevail near seed trees reproduction is usually good, although never so plentiful as with some species, as birch and maple.

The ash is frequently covered with the oyster-shell bark louse, but has no serious enemies and investigation indicates that it is not attacked by the gipsy moth. The bark is not very thick and consequently the trunk is seriously injured by ground fires.

Ash lumber has a high value for carriage manufacture, scythe snathes, tennis racquets, and other special uses requiring bending qualities.

On account of its high value and its rapid growth, the white ash is the best deciduous tree of New England to cultivate and should be especially favored by the forester. 


\section{Basswood (Tilia Americana).}

The natural range of the basswood is practically the same as that of the white ash. In New England it is found chiefly in the northern hardwoods region. It is also similar to ash in its requirements as to a good moist loam soil and plenty of light, but will survive in comparatively dry situations. It grows rapidly but seldom reaches advanced age without becoming decayed in the center.

The seed has a wing which helps to carry it some distance. It germinates best on moist mineral soil rich in humus and seedling reproduction in the north woods is usually fair. The tree has the further advantage of being a prolific sprouter, by which it reproduces almost entirely in Connecticut and Massachusetts. Clumps of basswoods are common wherever the tree occurs.

It is little troubled by insects, but is easily damaged by fire. Its wood being light, straight-grained, and easily worked, gives it a demand for many purposes, as for lumber, clapboards, excelsior, etc.

The high value of the lumber, its rapid growth, and ability to reproduce by seed and sprouts, make the basswood second only to ash in the forester's estimation, especially in northern New England.

\section{Poplar (Populus tremuloides, $P$. grandidentata, P. balsamea).}

Since the characteristics of these three species are very similar, they will be considered together. The trembling aspen is the most widely distributed tree in America, ${ }^{1}$ being found from Hudson Bay to Mexico. In New England, P. tremuloides is more common in the northern, and P. grandidentata in the southern portion. These true poplars should not be confused with the tulip tree which is called in some sections yellow poplar and is common in the southern hardwood forest, but has a different character from the real poplars.

1 Weigle and Frothingham, The Aspens, Forest Service Bul. 93 (I9I I). 
The aspens are cold-enduring trees. For their best development they require deep, fresh or moist, but porous and welldrained soils. Sandy loams mixed with decayed vegetable matter are the best. However, they are often found on thin, dry, sandy soils as well as in poorly drained situations.

The intolerance of shade shown by aspens, and its effect upon the life history of aspen stands is the most important feature bearing upon the relation of these species with other trees. Throughout their life history the poplars endure less shade than any of their companions. Unless the poplar has full light from the beginning it is soon killed out by its more tolerant neighbors. In this way aspen stands which may be nearly pure during youth gradually give way to longer-lived and more shade-enduring species, and only rarely succeed themselves.

Poplar is commonly known as a rapid growing tree and it is true that as a rule it grows faster than spruce, or fir or even paper birch during the first twenty or thirty years. It is short-lived, however, and usually infested by a fungus, Fomes igniarius, by the time it is forty, and begins to die at the top. The bark is thin and the tree is damaged easily by fire. The average maximum size attained by poplar in the northeast is from sixty to ninety feet in height and from eighteen to twenty inches in diameter. Sound trees over one hundred years old are seldom found.

As among all poplars and willows the staminate and pistillate flowers of the aspens are borne on separate trees, except in rare instances. The trees blossom and the seed falls in early summer. Thrifty trees begin to bear seed when only twenty years old. Although a great quantity of seed is produced a large proportion of it is abortive, and unless it falls on mineral soil, on recently burned over or cleared land or on other open spots not covered with vegetation or leaves, it has little chance of developing. This is why the aspen is so typical of burned areas. Besides the reproduction from seed this tree is prolific of sprouts or root suckers. Following fires in a poplar stand, and especially after lumbering, a large proportion of the next generation of poplar is from root suckers. 
Aspen wood is light, soft, weak, compact, and very perishable in contact with the soil. The lumber is easily worked, seasons rapidly, but warps and checks badly. Its chief uses are for paper pulp, excelsior and fuel, box boards and veneer. As a fuel it makes a quick, hot fire suitable for baking. The fiber is short and therefore produces a weak paper unless mixed with longer fibers as those of spruce. Mixed with about 40 per cent sulphite spruce pulp the poplar produces a paper which is tough, white and is in common use in the manufacture of books and magazines.

On account of its rapid growth, its power to cover burns, and yield a profitable crop in a short term of years the poplar bids fair to become one of the more important trees in forestry.

\section{Chestnut (Castanea dentata).}

The chestnut is a southern tree and extends north only to the southern portions of Vermont, New Hampshire, and Maine. It extends west into the Mississippi valley and south into Alabama and Georgia.

Chestnut prefers a rather moist loam soil, although it sometimes grows on sand plains and on the dry, trap ridges of Connecticut where, however, it is unable to compete with the chestnut oak. Perhaps of all deciduous trees it is the most conspicuously independent of lime. As regards light, however, it is more exacting. The young seedlings cannot thrive long under shade any more than can the sprouts which spring in great numbers from the stumps. This sprouting capacity of the species is its strongest characteristic, and the one by which, with each successive cutting, it gains in the struggle for existence with the rival inmates of the wood lot. Trees sprout to a more advanced age than any other species, and vigorous sprouts are common on specimens i 10 to 120 years old. Seed years are not infrequent, but the nuts are eaten so extensively by men and rodents, and are so injured by insects, that reproduction depends largely upon sprouts. The chestnut is one of the most rapid growing New England trees. The young sprouts are especially fast growing, often making a height of five or eight feet the first year. In 
the course of forty or fifty years, however, the seedlings overtake the sprouts and live to a greater age. Most of the chestnuts

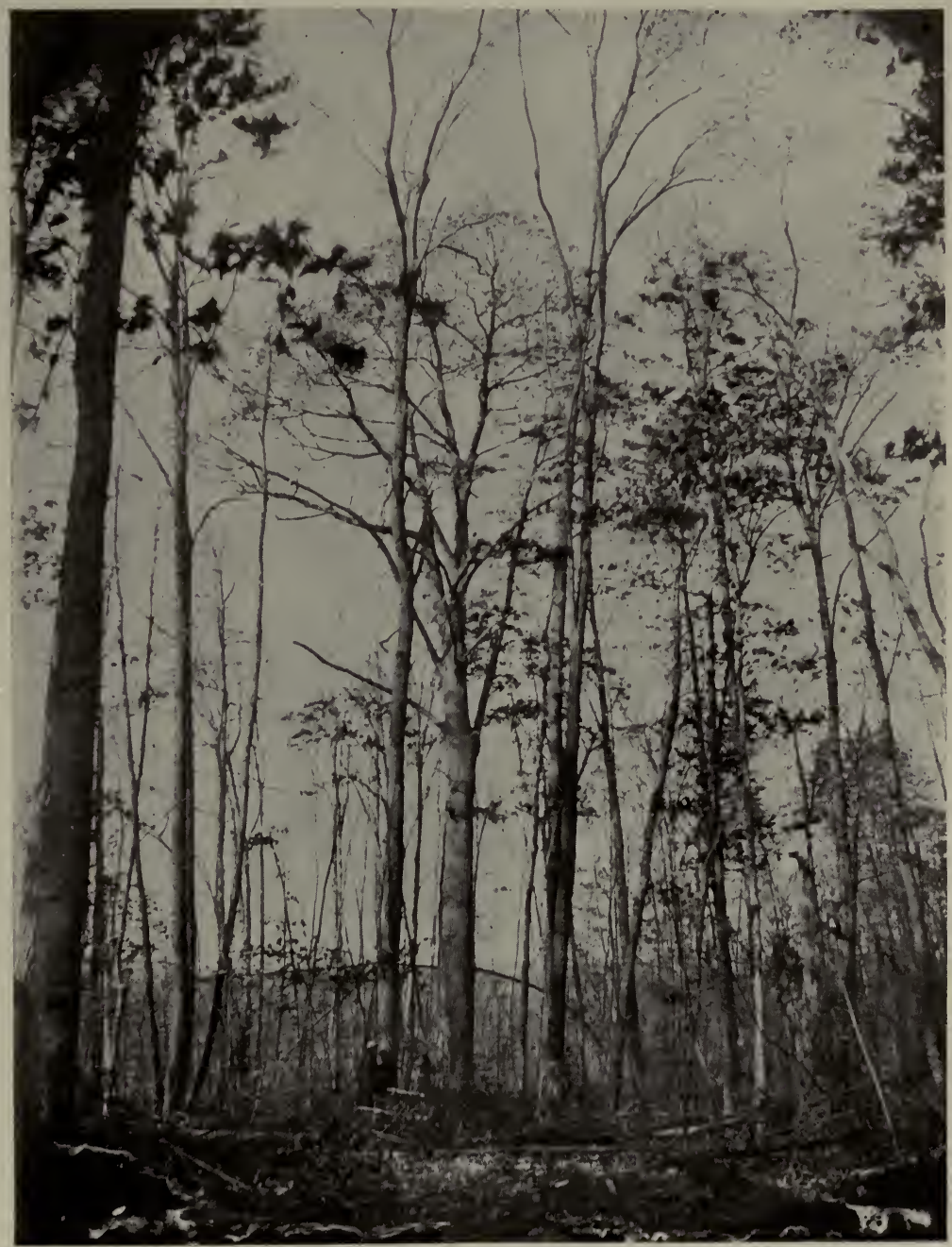

By permission of the Connecticut State Forester.

Fig. 9. - A plantation of chestnut and black locust 68 years of age.

of southern New England are of second or third growth, and it is seldom that a tree over $15 \circ$ years is found, though in the 
virgin forests of the south they attain an advanced age. The smooth bark of the young chestnut renders it particularly liable to damage by fire, and even the older trees are so severely scorched that they become liable to fungous diseases. Chestnut killed back by fire often sprouts again, and it is common to see groups of fairly thrifty sprouts surrounding the old dead stubs. There is a special bark fungus, Diaporthe parasitica, discussed in the chapter on Fungi, which is now so serious an enemy of the chestnut as to threaten its extermination commercially.

Chestnut wood is particularly durable in the soil and has a wide range for poles, piles, ties, etc., as well as for lumber. On account of its wide use and consequent value, its ability to sprout and its rapid growth, the chestnut was the most valuable tree of southern New England, until the bark disease appeared.

\section{White AND RED OAKS (Quercus alba AND Quercus rubra).}

These two trees, which are the most important of the New England oaks, although somewhat different in character, may well be considered together. The oaks are essentially southern trees, extending up into New England from southern regions. The white oak has a range similar to that of chestnut; scattering specimens of the red oak extend to the Canadian line, and are found on Mount Kineo in Maine, and on an island in Lake Memphremagog, Vermont, although it is doubtful if it is native there. Neither species is especially fastidious as regards soil, for although they prefer a well-drained loam they frequently grow on dry sand or heavy clay. They do not thrive in swamps and are seldom found there. Both oaks can stand a fair amount of shade, more than the chestnut but less than maple. They differ widely as regards rapidity of growth. The red oak on good soil often grows nearly as fast as chestnut; with the other species the growth is slower. Both attain a very advanced age and the oaks are proverbially the longest lived trees. Both reproduce fairly well from seed. White oak seeds abundantly once in several years, but a seed crop of red oak is produced every other year. The nuts, of course, cannot be transported any 
considerable distance except by squirrels and similar means. The acorns germinate best on a mineral soil lightly covered with leaves. In southern New England the chief reproduction of oak is by sprouts. The sprouting capacity of the white oak decreases rapidly after sixty years. The red oak is a better sprouter, and here again is a close second to the chestnut.

Oak bark is so thick that it is little damaged by surface fires. The white oaks, however, are scorched severely by hot surface fires, after which they become infested with fungi.

In eastern Massachusetts and the adjacent territory the oaks are damaged and frequently killed by the gipsy and brown-tail moths.

Oak lumber is strong and the white oak particularly is durable in the soil. It has accordingly many uses and sells at a good price. The numerous uses make the oaks important trees to produce, but their rather slow growth is a factor against them from the forester's standpoint. Red oak will be planted much more than the white.

\section{Tulip Tree, Whitewood, Yellow Poplar (Liriodendron tulipifera).}

This tree, known in different parts of its range by these various names, is a southern species extending from Massachusetts west into Illinois and Arkansas and south to the Gulf of Mexico. In New England it is most common in Connecticut.

In the region treated in this book, the whitewood, as it commonly is called here, is usually a tree of the rich, moist bottom lands, and rarely grows on dry upland sites. In its requirement as to light it is exacting, though the seedlings sometimes start under a light shade.

The tulip is a fairly rapid grower, although in this section its growth is probably less rapid than farther south. It is also a long-lived tree. It has a characteristically straight form, free from defects, and veterans two feet through and eighty or ninety feet high are sometimes found even in this northern extension of its range. In the south it grows much larger. 
Seed is borne prolifically, and being light and equipped with a wing, like ash seed, it is carried considerable distances. The seed germinates easily on light leaf litter or bare mineral soil, but as only a small percentage of the seed is fertile, reproduction in this region is somewhat scanty. It sprouts occasionally from the stump but cannot be considered a vigorous sprouter.

The tulip has a tender bark and is easily damaged by fire. Although the leaves are sometimes badly infested with a scale insect it has no serious insect or fungous diseases.

The lumber is smooth, clear-grained, soft, and usually free from defects, hence, easily workable. Known in the market as whitewood, although usually of a greenish-yellow color, the lumber has many uses, as in the manufacture of carriages and furniture, for cheap interior finish, etc. Near the seacoast it is used for piling.

On account of its rapid growth and its value the tulip is a tree to be encouraged in sites suited to its production. 
CHAPTER III.

\section{SILVICULTURAL METHODS OF REPRODUCTION.}

IN order to harvest different kinds of forests and to insure an equally good growth after cutting, various systems of cutting have been developed. Often they differ very little from ordinary methods of lumbering, but in other cases may demand a considerable money investment and a high degree of forestry knowledge. The forester, or the layman who handles his own forests, should have these systems definitely in mind, as only in this way can he secure satisfactory results in the reproduction of the desired species. Thus far these systems have been little used in America, but as our market conditions approach those of Europe they will be adapted to our conditions. And even under our present rough conditions it is as well to have some ideal to work for, some definite method to follow, as in other agricultural lines.

\section{Methods Depending on Reproduction by Seed.}

\section{$A$. THE SELECTION METHOD.}

This method, as its name implies, is adapted to selection stands.

Since the virgin forest of all countries is an uneven-aged or irregular high forest, the first and crudest system deals with this and is called "selection," because the trees to be harvested are selected here and there as they become mature. As the old trees are removed seedlings gradually take their place. By this method no area is ever cut clean, and for that reason it appeals to those interested in the woods mainly for æsthetic reasons. It is so well known that with many it stands, unfortunately, for the whole of forestry, with ill-advised legislation in some localities imposing a minimum diameter limit for cuttings. As forestry 
develops in this country the selection forest will gradually be supplanted by even-aged stands managed under one of the other methods. In the application of this system the whole stand may be cut through every year, or the stand is divided into blocks each of which is cut over periodically. In this case the interval between cuts is called the cutting cycle. Under ideal conditions this would be about ten years. Care must be taken always that trees of all ages be maintained, otherwise a time will come when

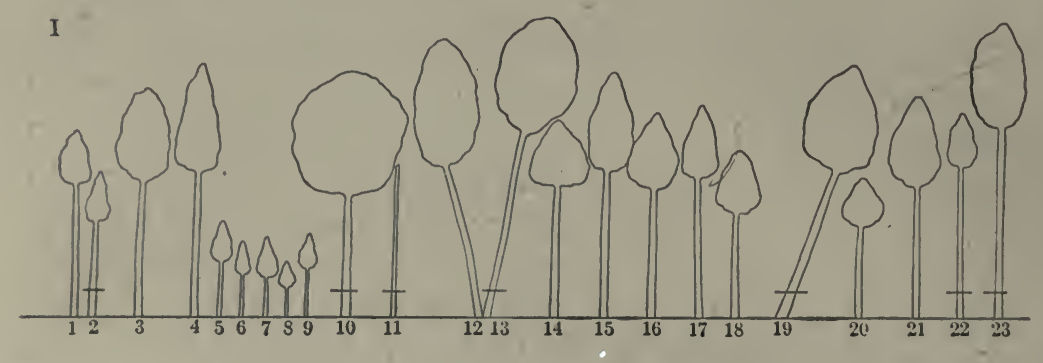

II

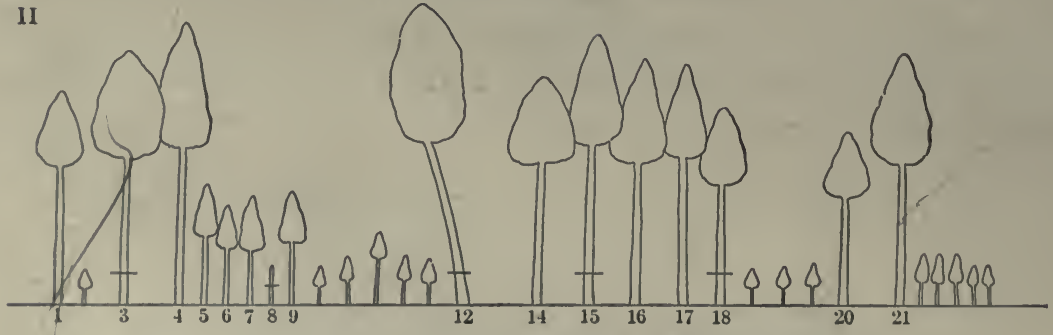

Fig. 10. - The selection system in a stand of spruce and hardwoods.

I. First cutting.1

II. Ten years later. Reproduction has started in the openings, and the stand is marked for a second cutting.

the cut must be reduced and the revenue correspondingly diminished. If the whole stand is cut over annually the amount removed should correspond with the annual growth of the whole stand. If it requires ten years to get through the forest the equivalent of the growth of ten years would be removed at each cutting. Thus, in one of our white pine forests having an area

${ }^{1}$ In this and succeeding diagrams, trees to be cut are indicated by dashes. 
of 100 acres and with an annual growth of 500 board feet per acre and a cutting cycle of ten years 5000 board feet per acre, or 500,000 board feet on the whole area, can be removed each decade. If the rotation in this forest, or the length of time required to mature the crop, is one hundred years, the area cut over annually, with a cutting cycle of ten years, would be ro acres, and the annual cut from this area would amount to 50,000 board feet. In our virgin forests where there is a great range of age classes, all

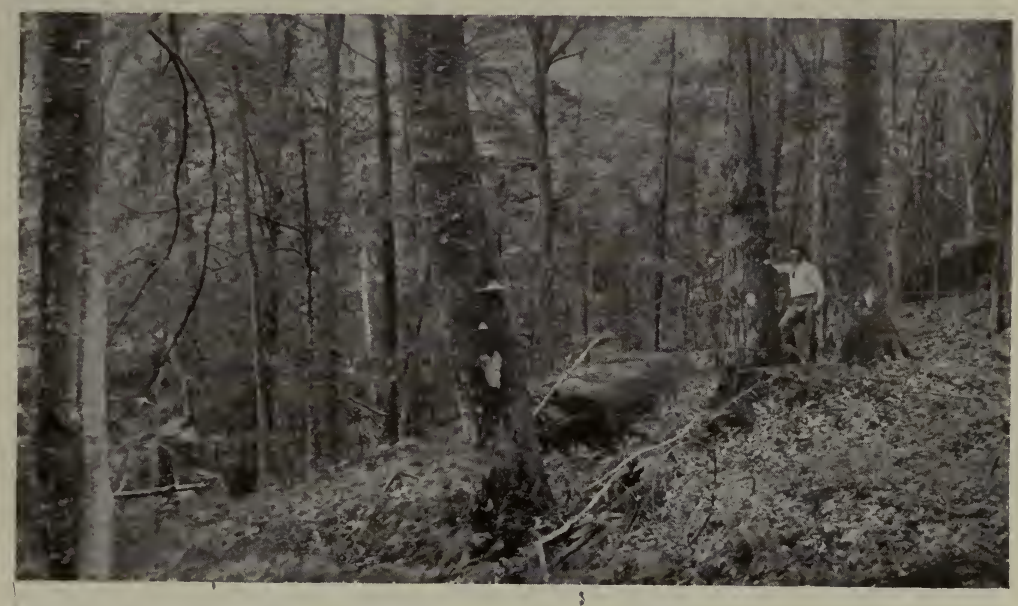

Fig. Ir. - The hardwood type. A stand containing mature timber marked for selection cutting. (The marked trees are blazed.) Note overmature and unhealthy condition of many trees.

mature trees are grouped in the oldest-age class and the first cuttings will tend to eliminate them, so that in the forests of twenty years hence we shall have comparatively few trees over one hundred years old.

\section{B. THE CLEAR-CUTTING METHODS.}

Where such a large proportion of the trees is cut that the remainder does not influence the growth of reproduction, it is called a "clear cutting." The clearing may be done in one or a series of operations but is usually accomplished in twenty years at most. While selection is best adapted for many virgin forests 
under present conditions, there are certain exigencies which make clear cutting, especially of even-aged forests, more profitable as well as preferable from a silvicultural standpoint. For example, in the pure spruce forests of the steep slopes of the White Mountains there is such great danger of windfall if scattered trees are left that some form of clear cutting is a necessity. This is also the case where logging is so difficult and expensive that only infrequent operations can be profitable; and. where trees are so large that later removal would injure valuable reproduction. In many culled forests so little of value is left that it is practically necessary to cut clean the inferior growth and replant. Of course there are certain disadvantages in the use of these methods, among the most important being the exposure of the soil, especially on steep slopes, to erosion. Berry bushes and other weeds are apt to spring up on such areas and seriously interfere with reproduction. Young trees are more apt to be injured by sun, wind, frost, and insects than when started under shade. Good forestry principles demand that the areas cut clean shall not be very large.

Young growth may be secured after clear cutting either by natural seedling or artificially by sowing or planting. The detailed methods of accomplishing artificial reproduction will be discussed later under the chapter on Planting, so only its theory need be considered here. It will be readily seen that natural reproduction is a rather slow process, while restocking by planting can be accomplished at once, and is more certain to be successful. Then, again, the varieties obtainable by natural means are limited to those already present; but in planting, the species best adapted to the soil or most remunerative may be substituted. On the other hand, natural reproduction is apparently, though not always actually, cheaper. Natural reproduction follows nature's methods closely and for that reason will be the method largely used for the present in this country, and, in fact, has preference in certain kinds of forests in Europe. 
I. Clear Cutting with Artificial Reproduction.

By this method the area in question is cut clean and the planting or seeding is done afterwards. It is desirable that the slash or limbs be disposed of in some way before planting. This method was the chief one used by the Cornell Forest School some

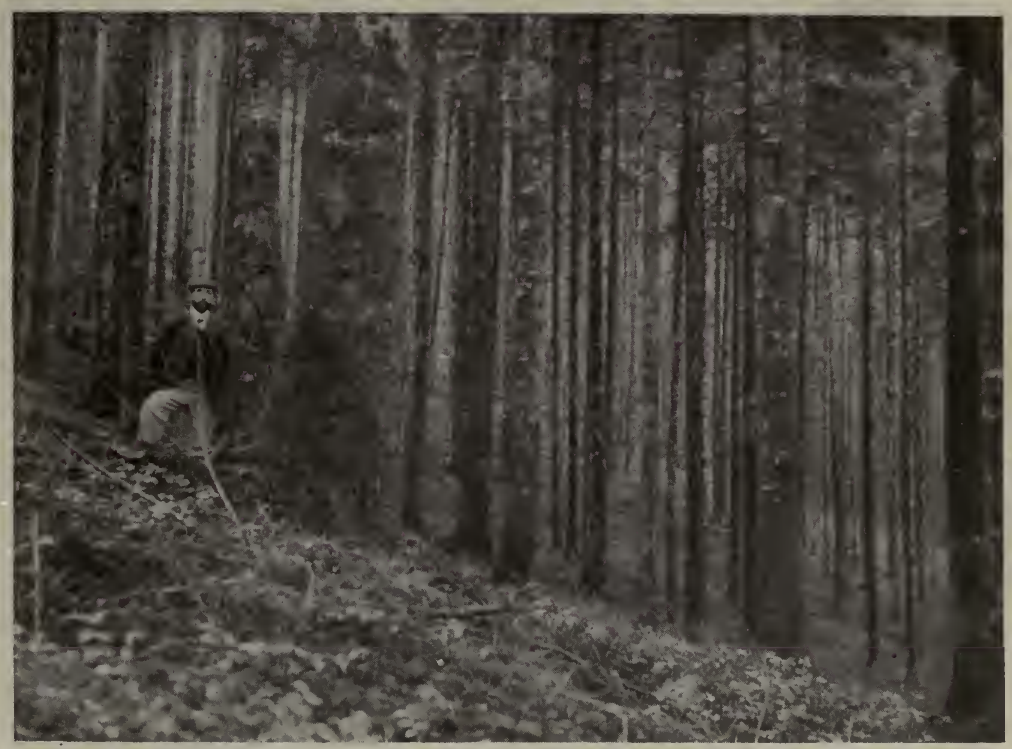

Fig. I2. - A stand of European silver fir in the Vosges Mountains, France, roo to I50 years, managed on the selection system.

ten years ago in the management of its extensive tracts in the Adirondacks and for which the school became so unpopular that it was given up. It was not realized at that time that any form of clear cutting could be good forestry. It is a method admirably adapted for small tracts well protected from fire, in stands which are either overmature or have been so damaged that desirable natural reproduction is impossible, and wherever intensive management is possible. 


\section{Clear Cutting with Natural Reproduction.}

The success of this method depends on the thoroughness with which the area is seeded from trees standing on the border of, or scattered over, the cut area. Naturally, it can be used with light-seeded trees only. The completeness of the seeding is proportional to the area cut and the ability of the seed to be carried long distances and to germinate on bare areas. For example, the method on a large cut-over area would be much more successful with poplar than with spruce.

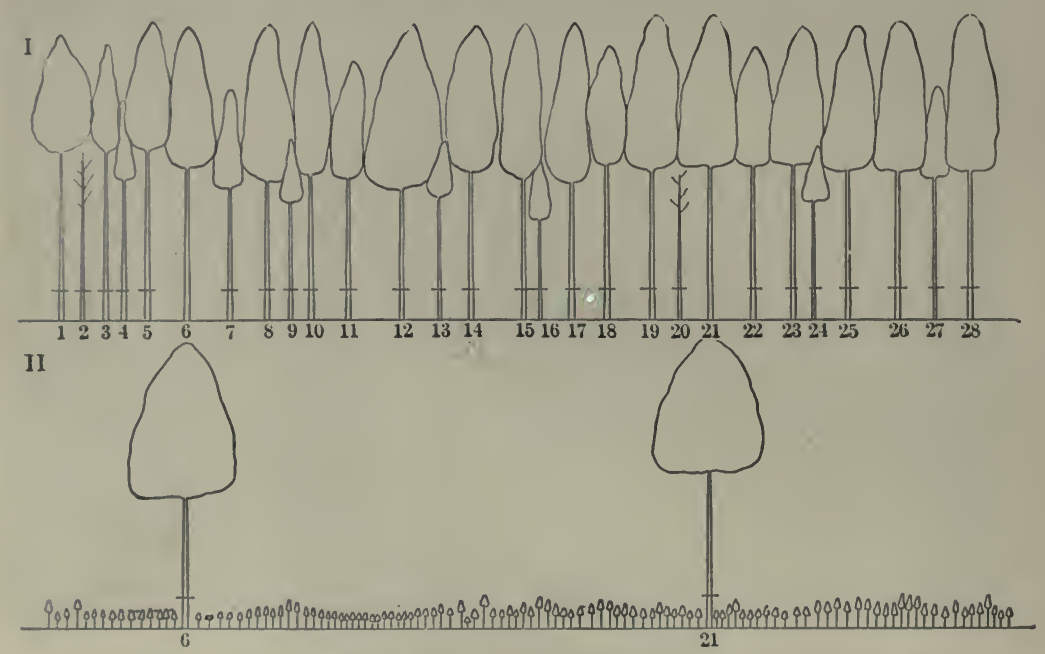

Fig. 13. - The seed tree method.

I. A mature stand marked for a reproduction cutting. The entire stand is to be cut except for occasional seed trees.

II. Ten years later, showing the reproduction fully established and the old seed trees marked for removal.

\section{a. Clear Cutting the Whole Stand.}

If the cutting is made just after a seed year, there may be enough seed on the ground to warrant cutting off the whole stand. Occasionally one finds a place where a pine or a spruce stand happened to be cut at such a time, and a dense growth of seedlings has resulted. 
Very often a mature stand of timber may be surrounded by younger stands which would naturally be left for a number of years. If such a mature stand is cut clean the area will be seeded in for a considerable distance on all sides from the surrounding younger stands; and if this cut-over area is not too large it will be completely reseeded in this way.

\section{b. Clear Cutting in Strips.}

As market conditions improve it will become feasible to cut a stand clean in two or more operations instead of taking out
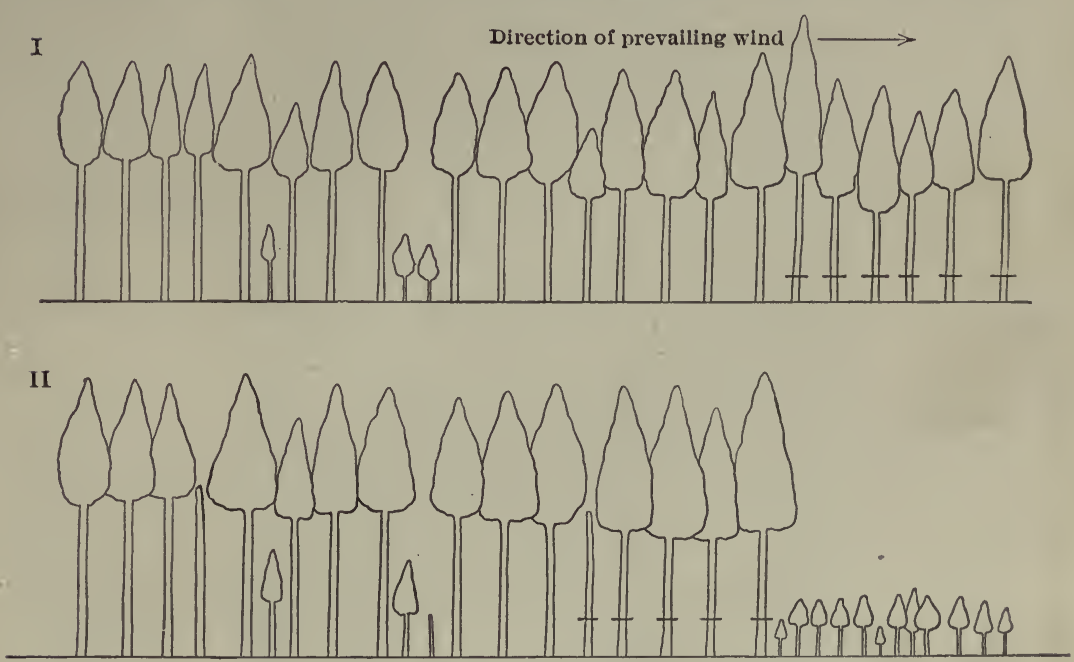

Fig. 14. - The progressive strip method.

I. A mature stand marked for reproduction cutting.

II. Ten years later. The first strip is reproduced and a second is ready to be cut.

the bulk of the timber at once. When this is practicable one of the forms of the strip system will be of value in New England. The strip system may be applied in either of two ways: I, with alternate strips; 2, with progressive strips.

I. The strips are here cut at fairly regular distances removing about half the timber and leaving alternate strips uncut to seed up the cleared areas. The best results are obtained where the 
cut strips are not much wider than the height of the bordering trees, although they may be three times as wide with some lightseeded species. It is customary to allow several seed years to pass between cuttings so that the area may be well reproduced. The remaining stand can, of course, be cut clean and replanted; or the seed tree method may be applied on these alternate strips. If the period between cuttings were long enough to allow the new generation to produce seed this would be unnecessary, but it is not the practice to wait so long.

2. Under this method the stand is removed by a series of strips, beginning on one side and progressing in the direction of the prevailing wind across the area. The last strips must be reproduced by some other method. An interval of several seed years is allowed to elapse between the cuttings. It would, therefore, take a very long time to cut over a whole forest in this way. To overcome this delay the stand is divided into several nearly equal areas and a series of strips is established in each.

\section{c. Clear Cutting in Patches (Group Method).}

Irregular patches of unequal size are cut usually where a group of reproduction is already started. These first openings are not over 200 feet across and do not aggregate over one-third the entire area. When these patches are entirely reproduced from the surrounding stand, the cuttings are enlarged gradually until all is cleared. The last strips will, of course, have to be reproduced by some other method.

\section{THE SEED TREe METHOD.}

In some localities where there is little danger of windfall and with well-rooted species, clean cutting with reserves of scattered trees is advisable. This method is adapted only to trees with light seeds which are able to reproduce on open areas. The best number of seed trees to be left varies considerably, but they should not be farther apart than their heights, three to eight per acre. Often very limby or partially decayed trees, so long as 
they are windfirm, may be left for this purpose. They should have large crowns occupying at least half the tree's height, since these bear the largest crops of seed, whilesuppressed and spindling trees have very little seed. The investment consequent on this method is relatively low. Wherever many or valuable trees

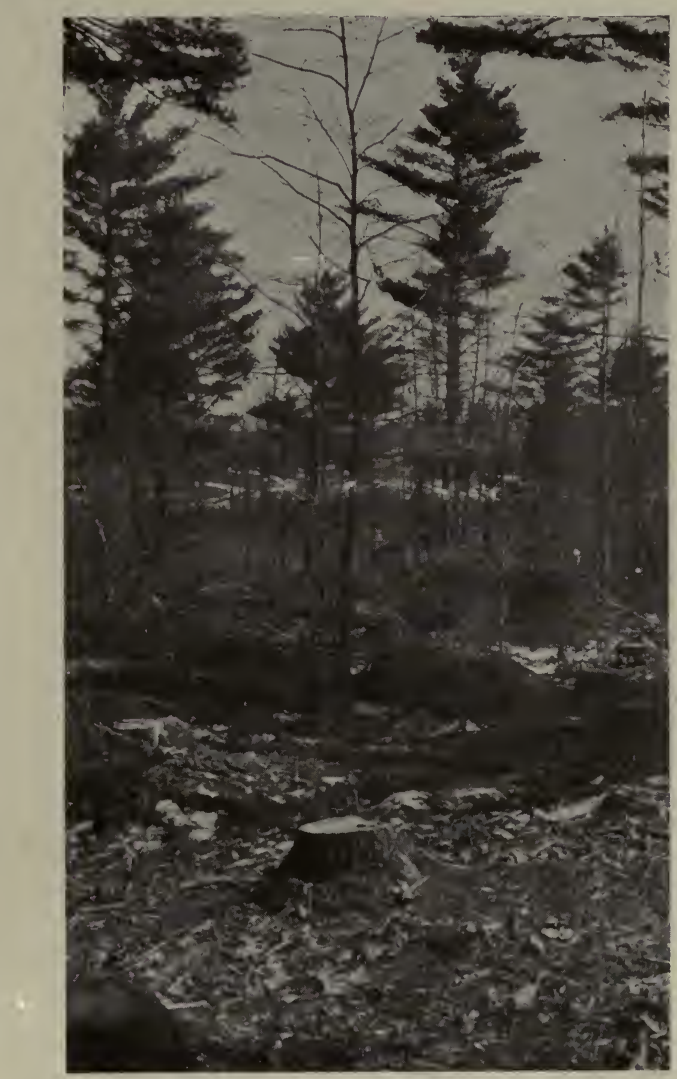

By permission of the Massachusetts State Forester.

Fig. 15. - The seed tree method. Pine seed trees are seen together with some hardwoods. These latter will be cut clear for cordwood, only pine remaining.

are required as seed trees some other method should be substituted.

After reproduction has been established the seed trees usually are removed. 
Where there is danger of windfall in leaving single trees small groups of three to ten or more seed trees are left standing together. This is done to better prevent windfall.

Where trees are left for seed alone, inferior individuals may be retained. If trees are left for greater growth as well as for seed, only straight, thrifty specimens are reserved. This modification is well adapted to stands of moderate age where there are many trees capable of continuing a thrifty growth for years, probably for another rotation. If, for example, the rotation used in white pine were seventy-five years, these reserves or standards might be left over one rotation, until they were one hundred and fifty years old, when they would be very valuable for special purposes, as for derrick sticks, besides having served as seed trees. While under the previous method less than a dozen trees per acre are required for seeding, under this system from $\mathrm{I}_{5}$ to 25 reserves per acre may be left. Naturally the-reproduction is better on this account.

\section{THE SHELTERWOOD METHOD.}

There are certain disadvantages connected with all of the clear-cutting methods which are overcome by shelterwood. Under the former methods the soil is exposed and reproduction is retarded by drought and frost. It is also impossible to use them with heavy-seeded trees, such as oak, chestnut, and beech.

The principle of shelterwood is to open and remove the stand gradually by a series of thinnings. This results in reproduction under the shelter of the mother trees which are not all cut until complete reproduction has been accomplished. A more even distribution of seed results because there are large numbers of seed trees well distributed over the area, and the young seedlings are protected by the shade of the remaining trees. The mother trees also benefit from the thinnings and make a more rapid growth during the remainder of their lives.

The method can be applied only with windfirm species or where there is no danger from windfall, as the system of cutting leaves many trees isolated. On account of the gradual removal of the 
stand, by means of several cuttings, shelterwood is best suited for well-settled regions where intensive management can be practiced.

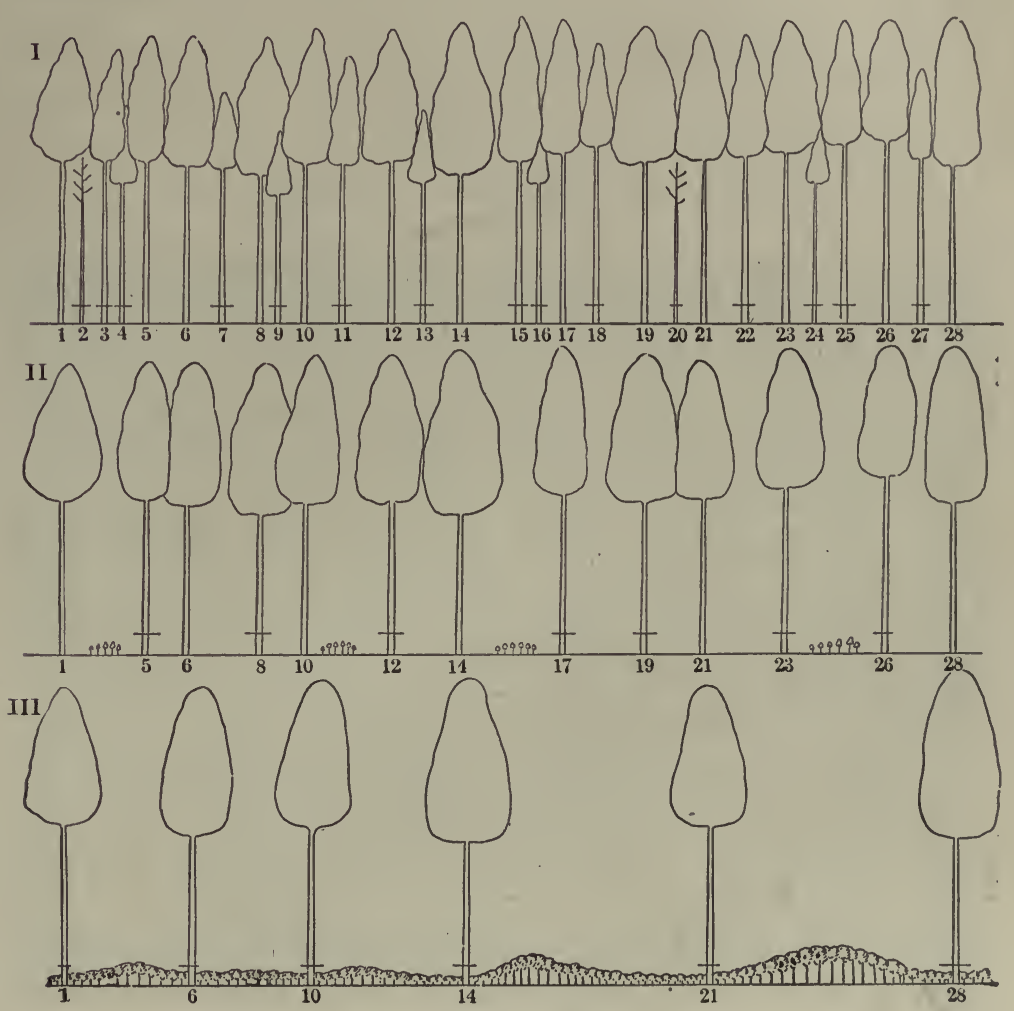

Fig. 16. - The shelterwood method.

I. An even-aged stand sixty years old marked for the preparatory cutting.

II. Five years after the preparatory cutting has been made. The seedbed has been made more favorable for germination and a little reproduction may be seen in the more open places. The stand is marked for the seed cutting.

III. Ten years after the seed cutting. Complete reproduction has been secured and the stand is marked for the final cutting.

The simplest form of this method, and the only one that can be applied with crude market conditions, is to remove the stand in two cuttings about twenty years apart. The first, intended to give opportunity for reproduction to start, is called 
the "seed or reproduction cutting," and removes about 75 per cent of the merchantable timber. Ten to twenty years later the second or "final cutting" removes the remainder of the old stand.

The maturest and least thrifty timber is selected for the first cutting, while thrifty trees and good seed producers are the kind retained for the final cutting. These trees should be left distributed over the areas as uniformly as possible.

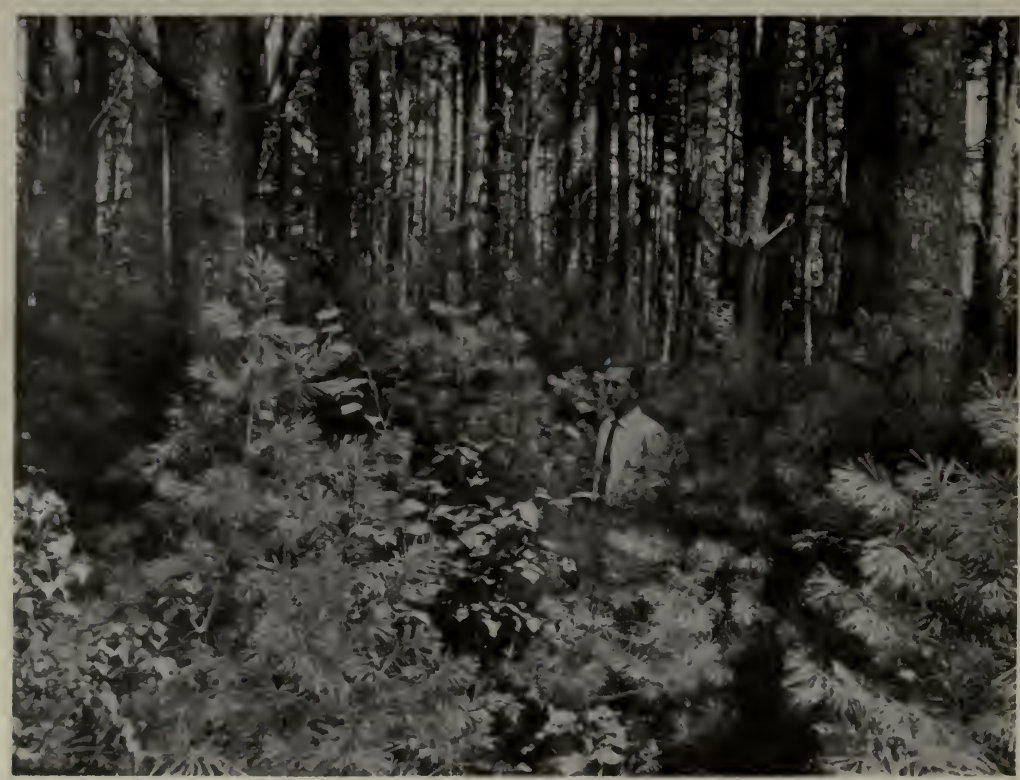

By permission of the U.S. Forest Service.

Fig. 17. - Reproduction of white pine under the shelter of a mature stand.

With the better market conditions which prevail in portions of New England, one of the more intensive forms, such as have been developed in Europe, can be used. The cuttings fall into three classes:

I. Preparatory cuttings.

2. Seed cuttings.

3. Removal cuttings including the final cutting. 
The purpose of the preparatory cutting is to prepare the soil for the reception and germination of the seed. Often in a dense stand, such as many of our spruce stands, there is a heavy layer of "duff" or decaying needles, and the seed cannot come in contact with the mineral soil, and hence may either fail to germinate or die soon after it germinates.

The increased circulation of air following a thinning disintegrates the humus and makes a favorable seedbed, and the remaining trees cast enough shade to prevent the rank growth of injurious weeds. The preparatory cutting also gradually accustoms the mother trees to isolation, and tends to make them more windfirm. This cutting removes the inferior trees - those which are diseased, suppressed, defective, or particularly liable to windfall, and weed species not desired in the next crop. From 20 to 30 per cent of the volume of the stand is removed in the preparatory cuttings, leaving a space of not over three to five feet between the crowns of the remainder. After an interval of from five to ten years the humus should be sufficiently decomposed to leave the mineral soil exposed in spots, when it is time for the seed cutting. This is a heavy thinning made during a seed year by taking out from one-quarter to one-half of the original stand, and with the purpose of establishing proper conditions for the start of reproduction. The best results are obtained with heavy-seeded trees, if this cutting can be made after the seed has fallen. The largest and most spreading-topped trees are removed at this time, as felling them later might damage the reproduction. If unfavorable conditions exist, the reproduction after the seed cutting may be assisted artificially by planting or simply by stirring up the soil with mattocks, or by pasturing hogs with the purpose of rooting up the litter and exposing the mineral soil.

The shelter trees which are left to shade the ground and the little seedlings (thus distinguishing the method particularly from the clear-cutting methods) are taken out in the removal cuttings as soon as the reproduction is well established. The first of these cuttings is made within three or four years of the seed 
cutting. Under the most intensive system, as developed in Europe, there are three or four of these removal cuttings, including the final cutting, occurring at intervals of about three years. The inevitable breakage in the reproduction caused by these cuttings, if severe enough to leave gaps, is repaired by planting.

The following table shows the occurrence of the various cuttings used in this method, covering a period of twenty-five years. The number of preparatory and removal cuttings will undoubtedly be decreased and the total length of the period from the first to the last cutting will be shortened in the use of the system in New England.

TABLE SHOWING DISTRIBUTION OF CUTTINGS UNDER SHELTERWOOD SYSTEM AS MOST INTENSIVELY APPLIED.

\begin{tabular}{|c|c|c|c|}
\hline Kind of cutting. & $\begin{array}{c}\text { Date of } \\
\text { beginning. }\end{array}$ & $\begin{array}{l}\text { Approximate } \\
\text { number of } \\
\text { cuttings. }\end{array}$ & $\begin{array}{l}\text { Percentage of } \\
\text { original stand } \\
\text { removed. }\end{array}$ \\
\hline 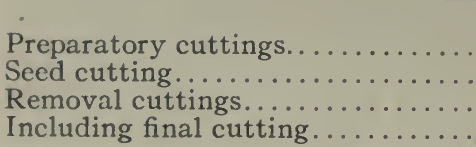 & $\left.\begin{array}{l}1900 \\
1910 \\
1915 \\
1925\end{array}\right\}$ & $\begin{array}{l}3 \\
\text { I } \\
4\end{array}$ & $\begin{array}{l}\text { Per cent. } \\
25 \text { to } 40 \\
25 \text { to } 50 \\
\text { 1o to } 50\end{array}$ \\
\hline
\end{tabular}

\section{Methods Depending on Reproduction Wholly or Partly from Sprouts (Coppice).}

The methods already described depend for their success upon the production and growth of young trees from seed. The following methods depend largely on the ability of trees to sprout when cut back. Naturally they can only be applied in forests composed of trees which sprout readily. In this country the most prolific sprouters are chestnut, oak, basswood, birch, maple, especially soft maple, ash, hickory, and other hardwoods.

There are three systems depending wholly or partly on sprout reproduction:

A. Coppice.

B. Coppice with Standards.

C. Pole-wood Coppice. 


\section{A. COPPICE.}

Under this method, which is so simple that it has long been practiced in southern New England, the stand is cut clear and allowed to sprout up again from the stumps. Usually several sprouts start from a single stump although only a few live to attain tree size. In the western part of Connecticut where the forests have been repeatedly cut at intervals of about twenty years for the production of charcoal for the iron mines, it is possible to distinguish three or four generations of stumps in many wood lots, each younger generation of stumps surrounding the older ones. The method is so easy of application that neglect is common and a forest is very apt to deteriorate. Some species continue to sprout freely much longer than others, but nearly all after a certain age fail to sprout vigorously. Chestnut, for example, generally sprouts well if cut at Ioo years or even at I 20 years, while white oak sprouts poorly after sixty years. To maintain thrifty, fully-stocked coppice stands short rotations are necessary. Ordinarily the rotation must be less than forty years except for a species like chestnut, which sprouts well to a considerable age. Therefore coppice is chiefly applicable for the production of fuel, and for this purpose is generally applied in Europe on a rotation of about twenty years. In this country where fuel wood is as yet such a drug on the market, the method has little to recommend it. To secure the best results in sprouting the trees should be cut between September 15 and April I. The stumps should be left with a clean slanting surface so that water will not settle in them and cause decay.

\section{B. COPPICE WITH STANDARDS.}

There already exists a form of forest which may be considered as a transition stage between coppice and high forest and which when fashioned by the science of the forester is called a coppice with standards forest. This is a forest composed largely of sprouts, but with an admixture of larger trees grown from seed. In the Rhine Valley of Baden this method has, perhaps, reached 
its highest perfection. Here the forest is laid off in regular subdivisions, one of which is cut each year of the rotation of the coppice, which is usually twenty years. In most cases an area is cut every twenty years and allowed to resprout. But instead of cutting quite clear a few selected trees or standards are left to grow on for several more rotations. The standards are trees from the seed and not sprouts. These standards are obtained either by planting or by natural seeding, a little of which is apt to take place even in simple coppice stands. At the end of the next twenty-year period the poorer trees are cut along with the stand of coppice, but the best, perhaps thirty to the acre, are left to grow for another coppice rotation. Again, part are removed and a few allowed to grow on to sixty, eighty, or one hundred years, thus producing timber of various dimensions at each cutting. When the system is once under way a stand of coppice together with standards of several different ages and sizes will be found on the same acre. .

The reason that trees grown from seed are selected for standards is that such trees live to a greater age and attain larger proportions than those grown from sprouts. When a cutting among the standards is made the spaces formerly occupied by the old standards are filled with seedlings by planting. Trees are selected as standards which are of valuable species and will have a high value when mature. Since these standards are crowded only during the first part of their lives, they form short, thickset bodies and usually produce one or two large logs of fast growth.

\section{POLE-WOOD COPPICE.}

This method combines reproduction by sprouts and reproduction by seed in varying proportions. The seedling reproduction is secured under shelter, as in the shelterwood system; and the pole-wood coppice system stands in a position midway between the coppice system and the shelterwood system. Its advantages are that sprout reproduction, which requires so little skill to secure, is utilized, and yet long enough rotations can be used to 

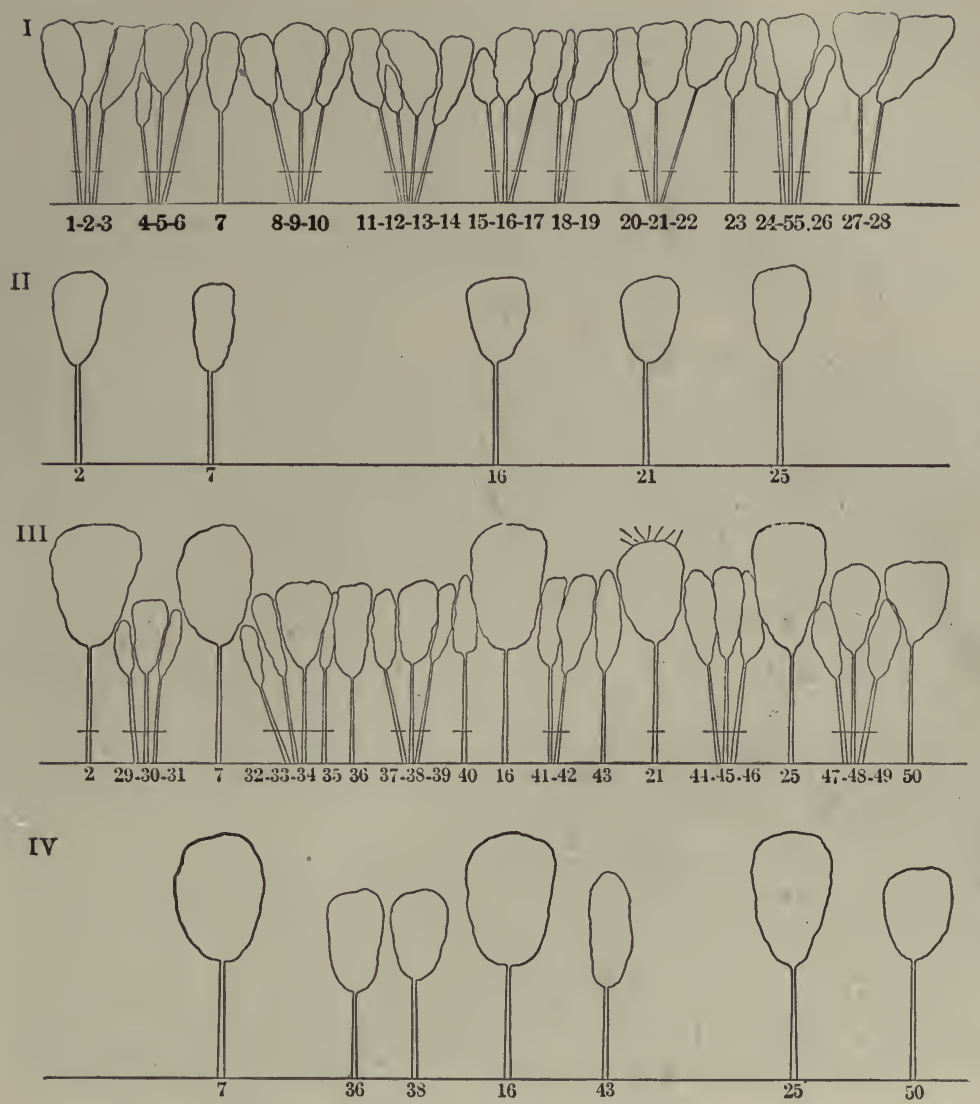

Fig. 18. - Coppice with standards.

I. A sprout stand 25 years of age, which it is desired to manage on the coppice with standards' method; the rotation for coppice to be 25 years and that for standards any multiple of 25 years. The stand is marked for the reproduction cutting, everything being taken except a few selected standards (trees nos. 2, 7, I6, $2 \mathrm{I}$ and 25), which are either of seedling origin or are thrifty sprouts.

II. Same stand immediately after the cutting, showing standards left.

III. Same stand 25 years later. A second crop of coppice is ready to cut and the standards are 50 years old. The cutting will take all the coppice except selected standards. All the standards of the older age class which are unhealthy, like no. 2I, or where standing too thickly, are removed.

IV. Same stand immediately after the cutting. Two age classes of standards are left: trees nos. 7,16 and 25 of the 50-year class and nos. $36,38,43$ and 50 of the younger class. 
5

grow saw timber, owing to the fact that seedling reproduction can be relied on to fill the gaps where sprouting has failed. The rotation instead of being limited to forty years or less, as in coppice, may be as high as eighty years.

In New England its field of usefulness is in the southern and central portions where the hardwoods reproduce extensively by sprouts. The method is applied by making two cuttings. The

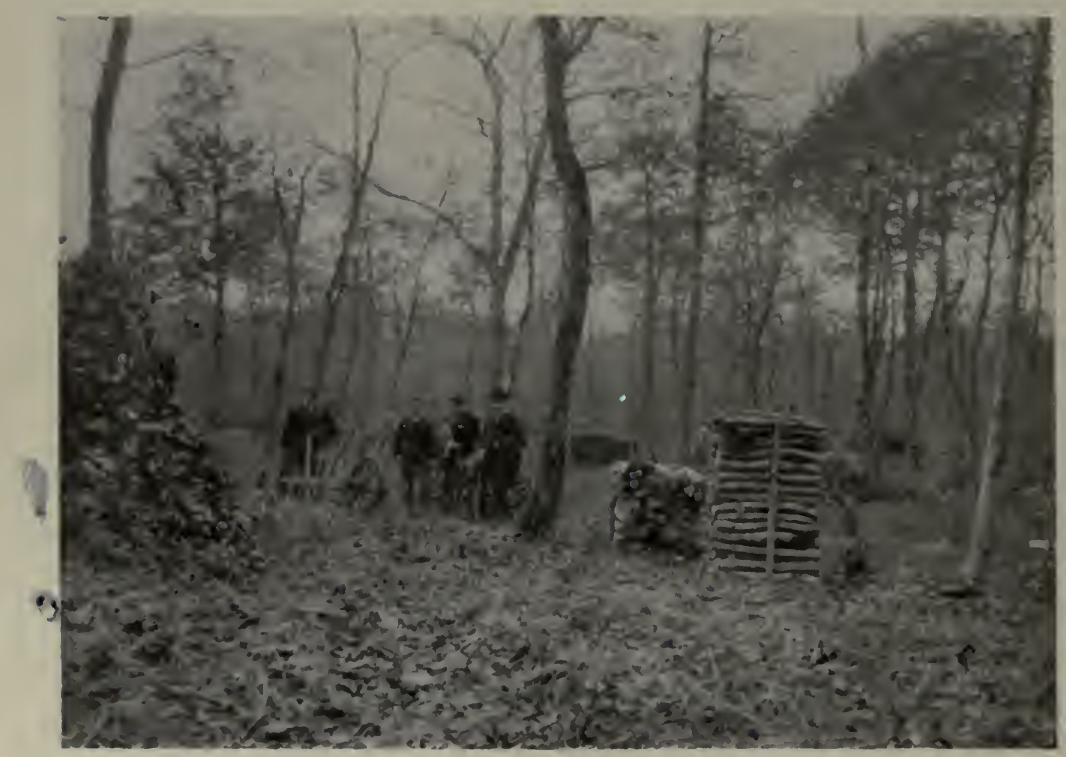

Fig. 19. - Coppice with standards as used in Europe. The coppice has just been cut leaving the standards.

first resembles the seed cutting in shelterwood and is intended to get seedling reproduction started. About 30 to 40 per cent of the volume is taken out, the poorest specimens being cut. Where the stand is composed of species like chestnut, which will sprout well even on an eighty-year rotation, there is less need to secure seedling reproduction and the seed cutting can be very light. ${ }^{1}$

1 Even in stands where at eighty years every stump will sprout, the stumps are relatively so far apart that the young sprouts do not form a close stand, and a mixture of seedlings is needed to grow clear-bodied trees. 
Where trees like white oak, which sprouts poorly at sixty to eighty years, occur, the seed cutting must be made heavy enough to encourage complete seedling reproduction. Five to ten years after the seed cutting, or as soon as good seedling reproduction is established and has secured a few years' start, the remainder of the stand is removed in the final cutting. Sprouts at once start and with the seedlings on the ground develop a mixed stand of seedlings and sprouts. 


\section{CHAPTER IV.}

\section{FOREST PLANTING AND SEEDING.}

The essential difference between forestry and lumbering lies in the measures taken when harvesting timber to make provision for a second growth. We have described the various silvicultural methods by which this may be brought about. It often

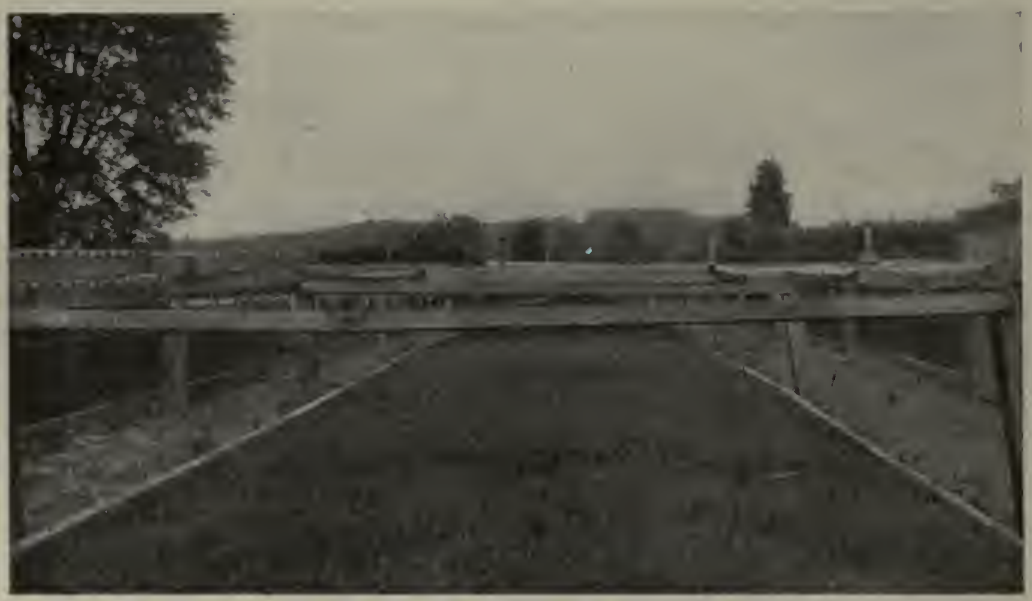

Fig. 20. - One-year-old white pine seedlings grown for forest planting.

happens that these attempts are not wholly successful and large gaps occur in the young stand. These are as much to be deplored in good forest management as they would be in raising corn or tobacco, and in addition to the natural methods it is necessary to resort to artificial means of stocking. Among these methods clear cutting with artificial reproduction was described. Under this system planting or sowing is depended upon entirely for the new stand.

1 For a complete treatise on this subject see "Seeding and Planting in the Practice of Forestry," by James W. Toumey. 
In all parts of the country there is land once used for agriculture, which was either unsuited for that purpose or has become exhausted by a system of farming which did not maintain the fertility of the soil. Such lands are often better suited for the raising of forests than any agricultural crop, and must be stocked artificially. Much land forested to-day is not covered with fast growing trees or with timber that possesses high value. Such lands are not producing so much or so valuable wood as they might. Another opportunity for artificial reproduction is found in introducing better species into such woodlands. This can often be satisfactorily accomplished by setting out one to two hundred plants per acre. Although only partially stocking the land at the time of planting, if cared for they will finally develop and dominate the stand. The desired change in the forest is thus accomplished for a fraction of the expense necessary to plant the whole area. It will be apparent that there are numerous opportunities for the use of artificial reproduction, and it is necessary that the best methods of accomplishing this be thoroughly understood.

Artificial establishment of a forest may be effected by planting or by seeding. By "seeding" is meant the use of seed on the land to be restocked; "planting" implies that small trees raised in a nursery or taken from the woods are used, and it has been found that planting is almost always preferable, because for the same amount of money a more complete stand can be secured by planting and because two or three years of the rotation are saved thereby.

Several methods of seeding are practiced. Broadcast sowing of seed, the most common, is also least often productive of the best results. This may be modified by brushing in, or raking the seed. Sometimes the ground is prepared in advance for the reception of the seed by stirring the soil with a harrow. Where the land is sufficiently free from rocks and brush very satisfactory results can often be secured by plowing and harrowing the land and then sowing the forest seed with some farm crop, such as buckwheat. This, however, is an expensive 
method and land which can be so treated is usually fitted for agriculture.

Partial seeding instead of broadcasting is sometimes tried. Where plowing is possible furrows may be run across a tract at intervals of from six to ten feet and seed sown broadcast in these furrows. Another modification is the so-called "seed-spot method." In the application of this system, spots favorable for germination are prepared, every six or eight feet, by scraping away the sod for a foot square and loosening the soil. Seeds are then sown in each spot and are pressed in by the foot or buried at different depths according to the nature of the seed. Depressions made in this way or from plowing a furrow give the seedlings the benefit of more moisture than is available on level ground, and free them for a brief period from the encroachments of grass and weeds.

Several good methods of planting are recognized. In New England the tool most used is the mattock or old-fashioned grub hoe, as it is often called. With this the sod must first be scraped away for a space about a foot square, that the seedling may not be harmed by grass or weeds. With a strong stroke of the mattock the blade is driven well into the soil. Then by raising the handle and turning it slightly to the right the soil is broken on one side, while under the blade a cleft is made into which the rootlets of the plant may be placed before the blade is removed. The mattock is then taken out and the earth made firm with the foot. This is called the slit system of planting. Sometimes with a light sod the preliminary scraping away may be omitted, thus shortening the operation but decreasing the efficiency.

A more thorough way of planting and one surer of results is to scrape away the sod, and then to remove the earth from the center of the square. In this hole the tree is set by hand or with the aid of a trowel. Fine dirt should be packed tightly around the plant. This and the slit method are recommended for ordinary work. In either case the emphasis must be placed on the removal of the sod before the hole is made. 
In wet places where planting is desirable it is customary to make mounds of earth and set the plants in the center of these. This is, of course, a more expensive method.

One precaution above all others must be taken in forest planting, especially with conifers, and that is, not to expose the fine rootlets to drying influences of sun or wind, even for a few minutes, because they are very tender and will be killed by such

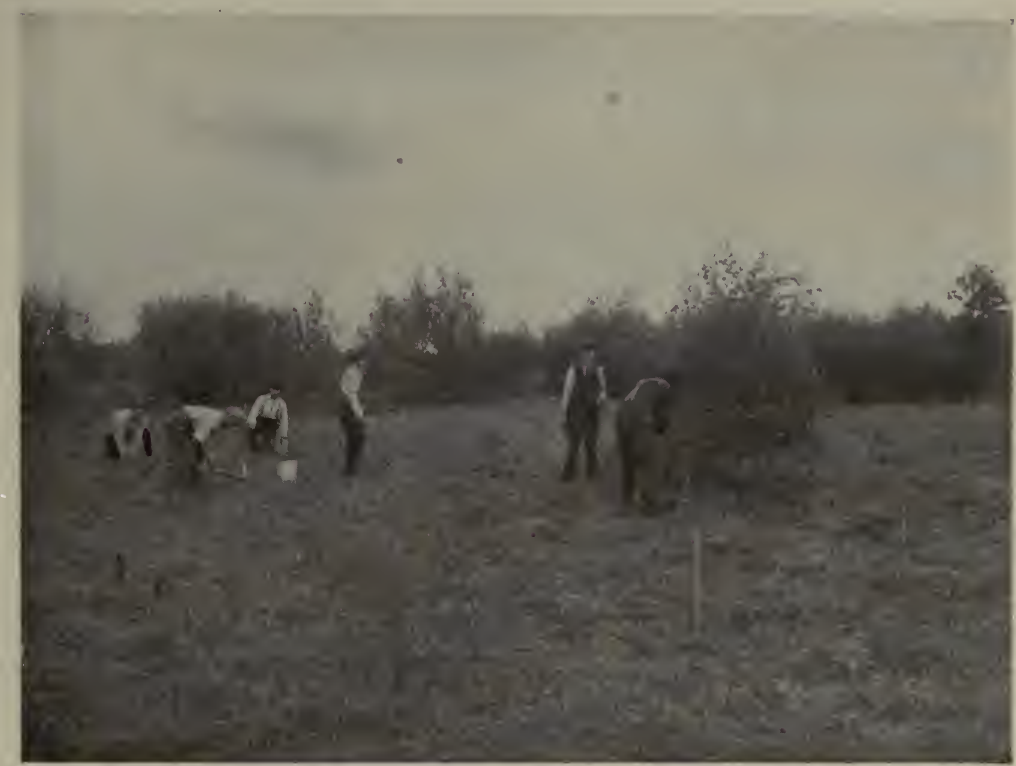

By permission of the Connecticut State Forester.

Fig. 21. - A small planting crew organized in units of two men.

exposure. When the nursery stock arrives at the plantation it should be heeled in immediately near the place of final planting. To do this a slanting ditch is dug slightly deeper than the length of the roots. The bundles of trees are untied and loosened, and the roots carefully spread out and covered with soil. This is called "heeling in" the plants. It is well to wet the roots by pouring on water after the plants have been heeled in. The soil should be firmly pressed against the tree roots and if several days are to elapse before planting, some boughs should be spread 
over them for a shade. It is better yet to dig the ditch where there is shade.

Just before planting, the roots should be thoroughly puddled, that is, dipped in a thick mud. For this a mixture of clay and loam is preferable, of such consistency that it will stick to the roots but will not harden on them, in case of a prolonged drought. The plants should be carried to their destination either in pails half filled with a mixture of mud and water or in baskets with plenty of wet sphagnum moss to cover their roots.

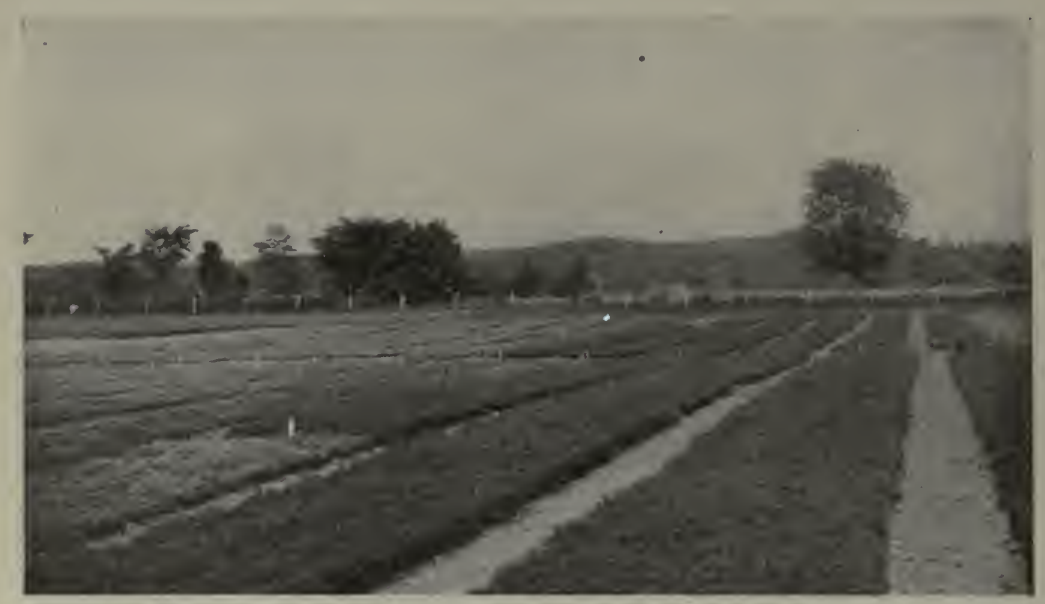

Fig. 22. - Nursery beds of 2-year-old pine-seedlings.

Forest planting usually is done in the spring, preferably as soon as the ground is free from frost. The planting season lasts for a period of four to six weeks until the spring rains are over and vigorous growth on the young plants has begun. Fall planting is sometimes practiced. The fall droughts experienced in parts of the east are a serious drawback to planting at this time of year. Where open winters with a scanty cover of snow are the rule, excessive loss from heaving by the frosts results from fall . planting.

An important consideration is the size of the plants with which the plantation is established. A small, inexpensive plant is 
wanted, yet one hardy enough to withstand the severe conditions to which it is often exposed. What are known as two-year-old seedlings and three-year-old transplants are the two grades ordinarily employed in establishing commercial plantations. The former has been grown for two years in a seedbed; the latter was transplanted after one or two years in a seedbed and has

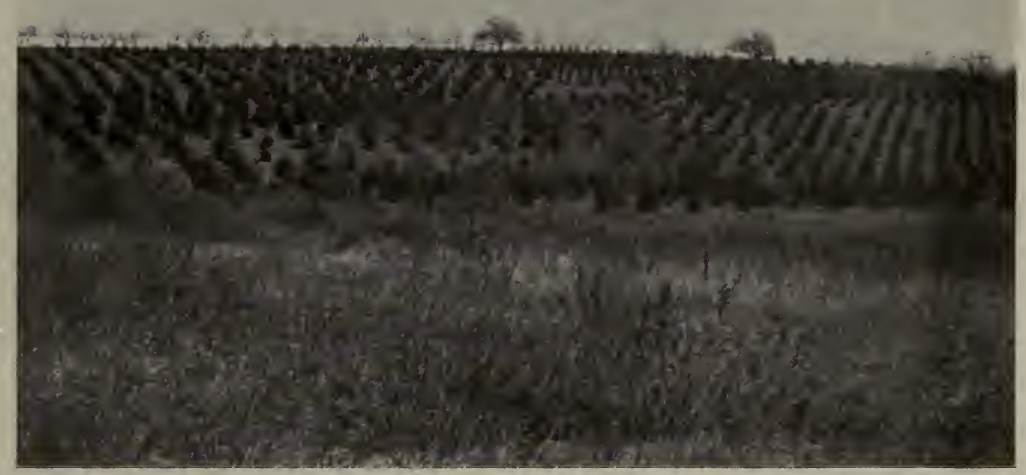

By permission of the Connecticut State Forester.

Fig. 23. - A-plantation of white pine about 8 years old spaced 6 by 12 feet. This is too wide.

grown one or two years since transplanting. Three-year-old transplants cost approximately three times as much as twoyear-old seedlings and are much stronger plants. The present tendency is to use seedlings only on the most favorable sites, and this is the wiser course.

The relative merits of pure and mixed forests have already been discussed. It is safe to say that most of the planting in this country will be pure, that is, that there will be little mixture of species on the same area. This is because it is simpler and, on the whole, a pure plantation of a tree well adapted to the soil is more satisfactory than a mixture. It is well, however, for the 
reasons mentioned in discussing pure and mixed forests, to plant small areas with different species. In future planting of white pine it will be advisable to mix it with some other species, as Norway pine, because of the danger from the Blister Rust disease. The white pine is the more valuable, and if it escapes the disease can be favored by a thinning at the proper time. On the other hand, if the plantation becomes diseased the white pine can be removed and a good stand of Norway pine left.

Commercial planting, whether pure or mixed, should, however, be restricted to a few species of known value and adapted to the site. White and Norway pines, Norway and white spruces, European larch, white ash, and red oak are the standard trees for commercial plantations in New England. On the whole, conifers or softwood trees in contrast to the hardwoods recommend themselves especially for forest planting for the following reasons:

I. Softwood lumber is in greater demand for general purposes, and, therefore, commands the best prices.

2. The conifers, such as pine and spruce, are more rapid growing than the hardwoods.

3. The conifers yield more lumber to the acre in a given length of time than deciduous species, because the trees stand closer together and grow faster.

4. Much of the land to be planted is of very light soil and is, therefore, better adapted to such trees as the pine than to any other species.

The question of the proper spacing of trees is one which has led to endless discussion on the part of European foresters, and it must be decided in every case according to the owner's particular aims. In many of the early German plantations the trees were spaced not farther than one meter (three feet) apart. The general tendency to-day, even in Europe where nursery stock and labor are still comparatively cheap, is toward more open spacing, and the practice thus far in New England is to plant about five or six feet apart.

For most purposes a spacing of six by six feet is recommended. 
The following table gives the number of trees required to stock one acre when set at different distances apart.

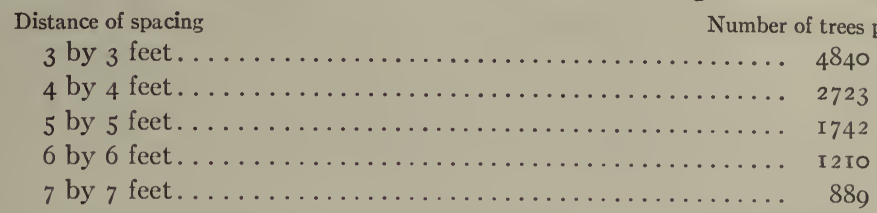

The general principles underlying spacing may be stated here and the planter may judge for himself what distance best meets his own requirements. Close planting forces the trees up in order to secure light, and thus produces a rapid height growth. At the same time it kills the lower limbs for lack of light, thus

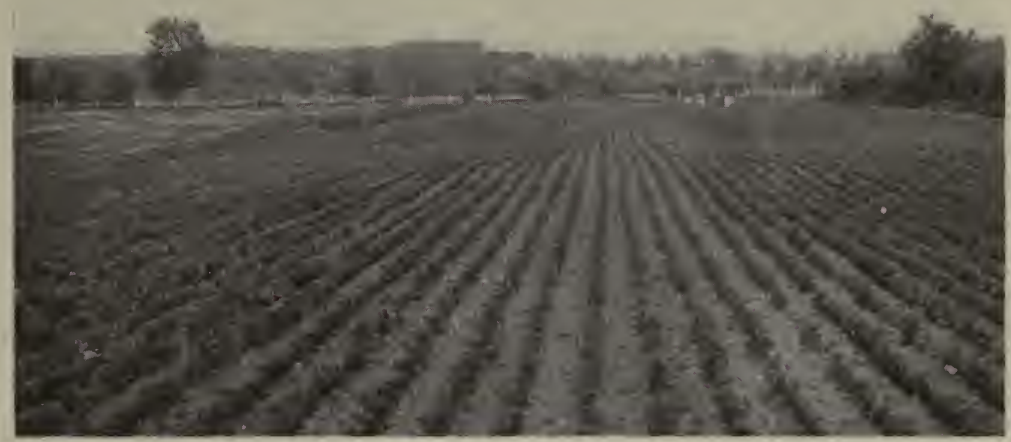

Fig. 24. - A block of 3-year-old white pine transplants; the best stock with which to start a commercial plantation.

causing natural pruning. The result is a long, slender log fairly free from knots. Open planting, on the other hand, produces a large-branch system, a rapid diameter growth, especially near the base, and a rather slow height growth. The result is a short, thick log tapering rapidly from base to top and rather knotty. For the production of high-grade lumber the former is evidently to be advised; for a heavy production of fuel wood, pulpwood, railroad ties, or other inferior materials, the open spacing may 
be more profitable. One should also remember that tolerant trees must be planted closer than intolerant trees in order to secure equally good pruning.

Cost of planting varies enormously and depends primarily on the stock used, price of labor, spacing of the plants, and condition of the planting site. Often adverse weather conditions or other factors cause heary losses, and extra expense is required to secure a complete reproduction. Good stands have been secured for less than $\$_{5}$ per acre and sometimes more than $\$_{30}$ per acre have been spent. On the average New England planting site, using three-year-old transplants at $\$ 5.50$ to $\$ 6$ per thousand, set six by six feet apart, and with labor at $\$$ I.75 per day, the cost per acre should not exceed $\$_{15}$; it can rarely

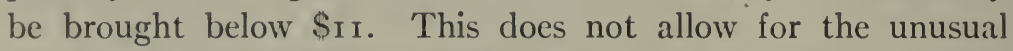
losses which sometimes occur, due to prolonged droughts. Where areas as large as several thousand acres are to be planted and the stock is grown by the planter, the cost may be a few dollars an acre less than this estimate, which is based on stock that is purchased.

The success of seeding is governed so largely by chance and weather conditions that the cost of a successful sowing is more uncertain than that of a plantation, and cannot be figured accurately in advance. The few successful sowings which have come under the observation of the writers have cost more than the amount given for an average plantation. It is believed when sufficient care is taken in preparing the site, and securing the same success as would be obtained by planting, that the cost in every case would be higher than that of the plantation.

With plantations carefully made there is seldom a loss of over I5 per cent, but where careless methods are used, or where planting is followed by extremely dry weather the loss may easily be as high as 50 per cent.

It is unnecessary to fertilize a forest plantation, and little care is necessary beyond protection from fire, grazing, insects, and fungi, described in later chapters. 


\section{CHAPTER V. \\ INTERMEDIATE CUTTINGS.}

IN Chapter III the different methods of cutting with the purpose of securing a new stand (reproduction cuttings) were discussed. Such cuttings are needed in mature timber in order that a young stand may replace the old one, ${ }^{1}$ and occur only during the latter part of the life of the stand. There is then a long period extending from the time that the old stand is removed and the new one established until the new stand has itself developed to maturity and become ready for a reproduction cutting.

During this period, i.e., between reproduction cuttings, there may be, and in a stand under management ordinarily are, several cuttings, which are termed intermediate cuttings. Their purpose is to improve the existing stand in composition, rate of growth, and value of the final product, without any attempt to secure reproduction.

Intermediate cuttings are made in immature stands, ranging from those only a year or two in age to stands nearly ready for reproduction cuttings.

Intermediate cuttings may advantageously be divided into four kinds, as follows, each of which will be separately discussed:

I. Cleanings.

2. Liberation cuttings.

3. Thinnings.

4. Salvage cuttings.

I. Cleanings. - As a stand begins to grow there are almost sure to be certain trees present which, because they threaten to injure better trees, are not wanted. These trees may be of an inferior species or they may simply be poor individuals of some

1 Artificial reproduction, i.e., planting or seeding is sometimes employed. 
valuable species, or often worthless shrubs. In any case, they need to be removed in order that the stand may eventually be of the highest possible character. This type of cutting is called a cleaning, and always takes place in young stands, usually when

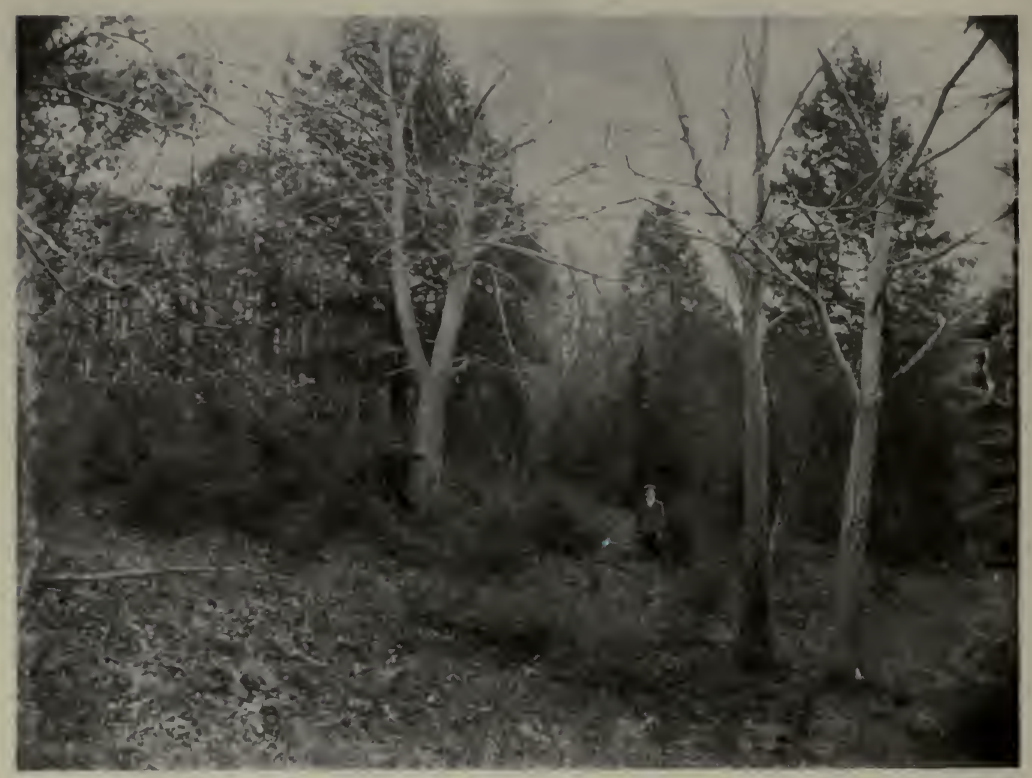

By permission of the Connecticut State Forester.

Fig. 25. - The spreading hardwoods should be taken out to liberate the seedling growth.

they are from three to ten years of age. Frequently one cleaning is not sufficient and another must be made three to five years after the first.

The trees removed differ but little in age from those left and oftentimes are the same age but of more rapid growth. When a few years older they are usually of the type termed "advance growth," by which is meant trees that seeded in first and obtained a few years start of the rest of the stand. Because of their comparative freedom from side crowding they have rather branchy crowns and will not develop into high-grade trees.

The expense of the cleaning can often be reduced and the purpose as well accomplished by lopping off the tops of the trees 
instead of cutting them at the base. They should be lopped back far enough so that the tops of the trees to be freed are above them.

One is tempted in making a cleaning to remove all trees of inferior species, all shrubs, and all poor individuals from the stand. But from both the financial and silvicultural standpoints only the'material should be cut which is actually hindering the development of better trees. If all inferior species were to be cut, great gaps might be left in the stand, since there may be no valuable trees in mixture with the poor ones. In such a place a cleaning need not be made.

A small hatchet or a brush hook is an excellent tool with which to make cleanings where the material is small or the tops are to be lopped, but often in stands five to ten years of age an axe is needed.

Inasmuch as a cleaning is in such young stands that no merchantable material is secured from the cutting, it results in a present financial loss. Cleanings should only be made where a small expenditure will be justified by the improved development of the stand. A stand of white pine overtopped by gray birch is an example of where they are justifiable. The forest of nearly pure pine which can be secured by removing the over-topping birch will be so valuable as to more than pay the expense of the cleaning.

The cost depends so largely upon the amount and size of the material to be removed that it may range from a few cents to several dollars per acre. An expenditure of more than $\$ 3$ per acre for a cleaning is usually unnecessary and the work can often be done for 25 to 50 cents per acre.

As a general rule cleanings should be made as needed in all plantations to protect the planted species, and wherever there is a wide difference in value between the species being injured and the one injuring it. A cleaning is an intensive forestry operation and hence in many places is impracticable.

2. Liberation Cuttings. - Liberation cuttings are used in young stands from a year or two old to those of middle age. 
The operation consists in removing older trees which, by their widespreading crowns are interfering with a younger growth that it is desired to favor. Unlike cleanings where the trees removed differ in age from those left by only a few years, liberation

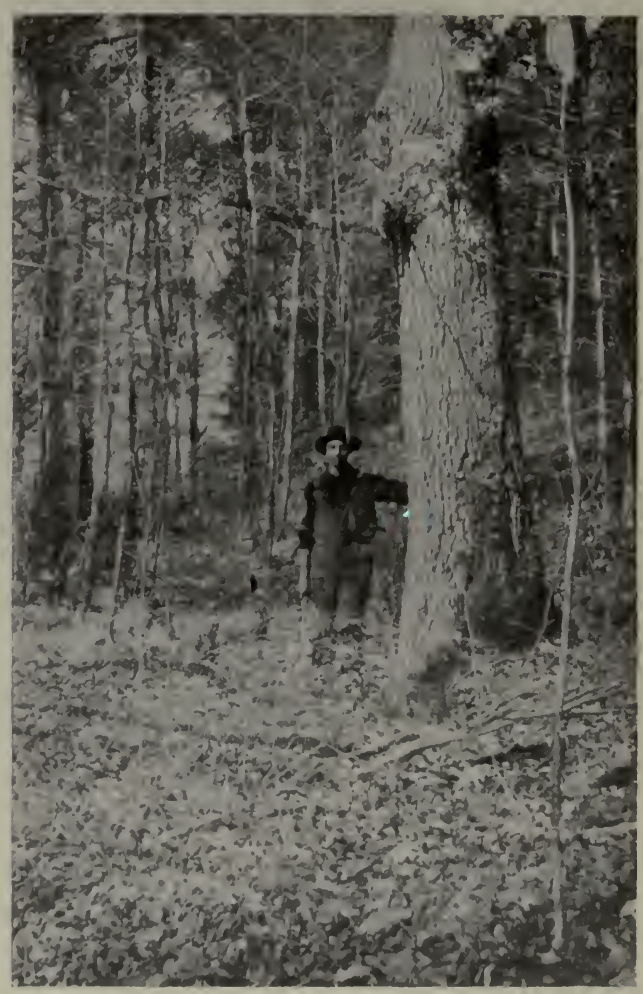

Fig. 26. - A liberation cutting is needed to remove the large oak to free the young growth which is already feeling the effects of the crowding.

cuttings remove trees of a much older age class than the remainder of the stand.

A study of the diagrams of cleanings and liberation cuttings on page $8 \mathrm{I}$ will make this point clear. Two diagrams of liberation cuttings are given. The first is in a very young stand of seedlings with large trees high above them. This form is very 


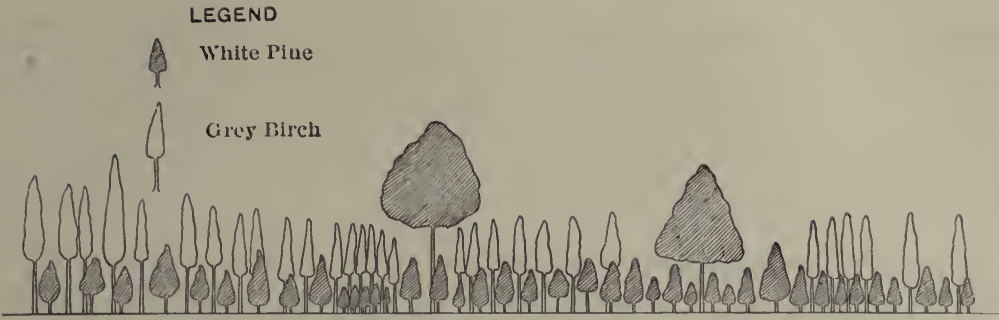

Fig. 27. - A cleaning. The stand contains white pine 5-8 years old, overtopped by gray birch 6-ro years old. The gray birch should be cut out or lopped back. Two older white pines ( 8 years of age) forming "advance growth" should also be cut, as they will produce knotty lumber and suppress several most promising trees.

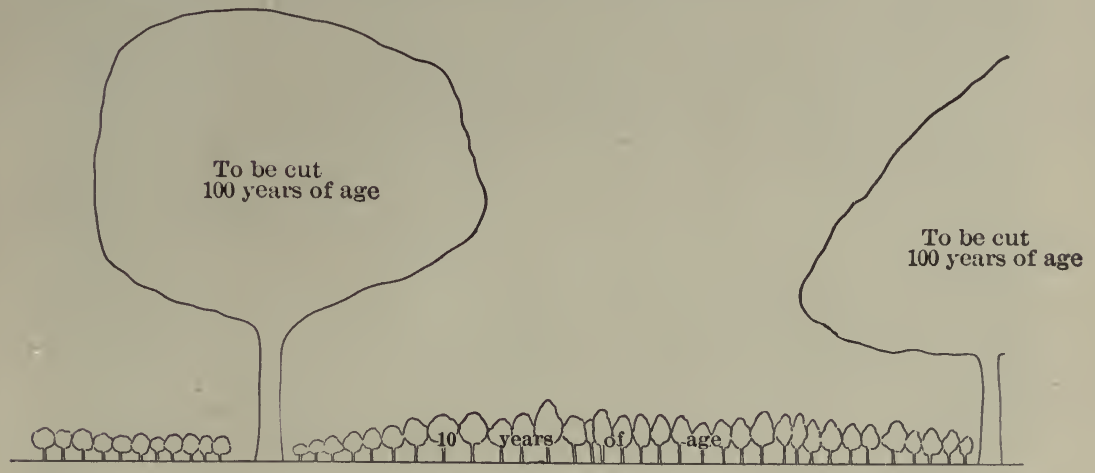

Fig. 28. - A liberation cutting in which the young stand has not yet been seriously affected by the overtopping trees.

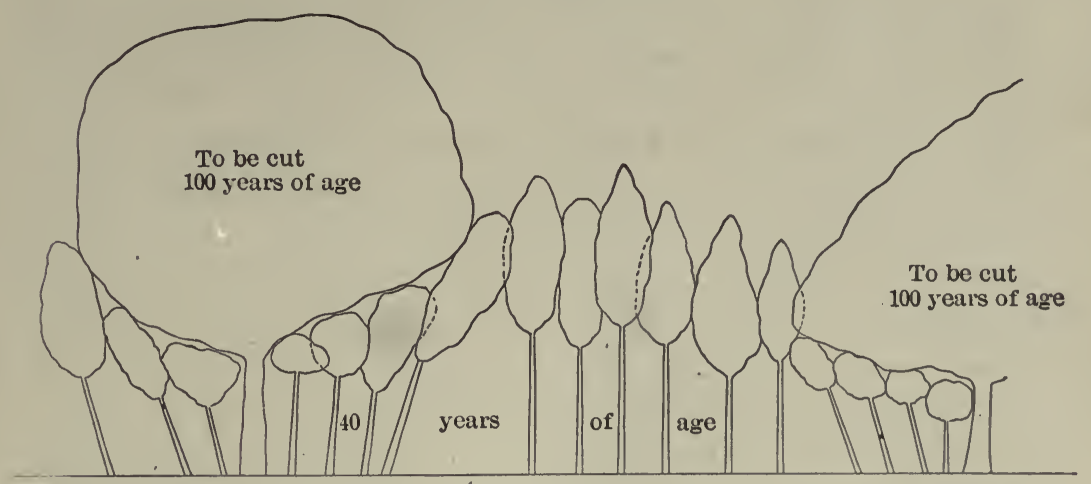

Fig. 29. - A liberation cutting in a middle-aged stand, where the crowns are already deformed by the large trees which should be at once cut to prevent further injury. 
similar to the final cutting under the shelterwood method of reproduction. In Fig. 29 a middle-aged stand is shown with older trees interfering. Here the crowns of the main stand have reached the crowns of the interfering trees and are already somewhat deformed. If the cutting were delayed much longer the stand would be seriously injured.

The material removed in liberation cuttings is of merchantable size either for timber or cordwood, but is usually of poor quality, being knotty and frequently extremely limby. From the size of the trees to be cut it often appears that a handsome profit can be made, but owing to the scattered location of the trees singly among younger trees, the logging is usually expensive and the trees, on account of their widespreading crowns and large limbs, are hard to cut up. In most cases the trees can be disposed of for enough to at least pay the costs of the operation; so that no financial loss is ordinarily required in making liberation cuttings.

Liberation cuttings are needed especially in abandoned fields which have gradually reverted to forest, or on cut-over lands where in previous cuttings poor individuals had been allowed to stand.

As liberation cuttings pay for themselves they have a wider range of application in practical work than do cleanings, but at the same time, since the material removed is of a low grade, it cannot readily be sold where the markets are poor. A good rule is to make liberation cuttings wherever the material will at least cover the cost of removal.

3. Thinnings. - As a young stand of trees grows older, individuals which at first had ample space for development become crowded. There commences a struggle between them, which becomes more intense year by year, for light, growing space, moisture and nourishment. As the struggle goes on certain trees obtain a slight advantage over their neighbors and may finally succeed in completely overtopping and killing them. In accomplishing this, however, the leading trees, as well as those overtopped, are inevitably restricted in crown development, and therefore are retarded in rate of growth and prevented from 
attaining the size possible if they had not been so seriously hindered by the competition with neighboring trees.

In order to prevent part of this competition and to keep the leading trees in the stand growing at a rapid rate thinnings are

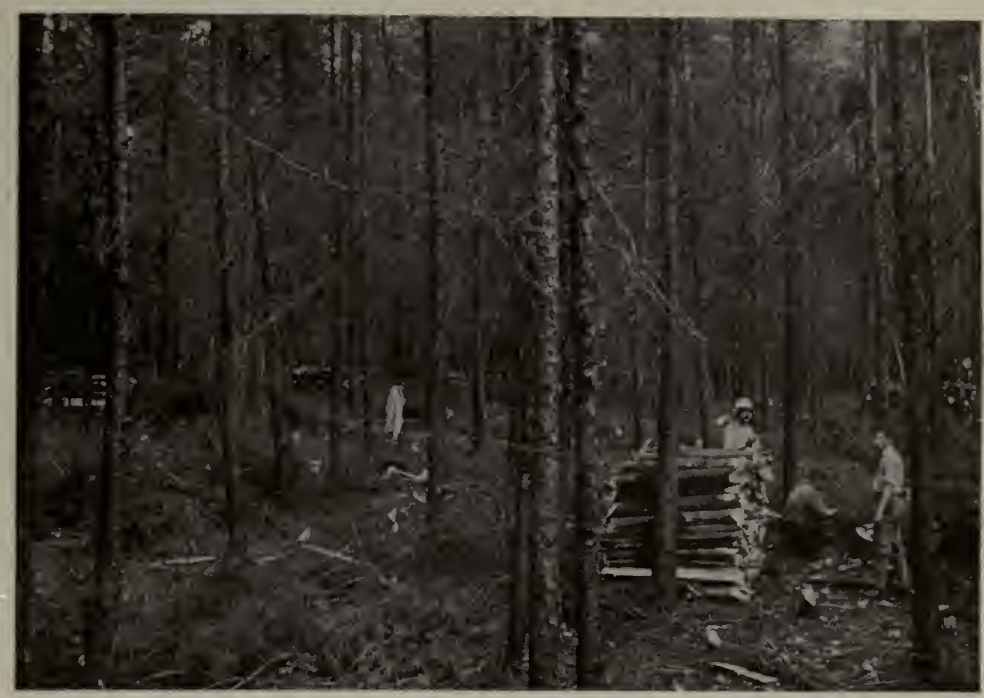

Fig. 30. - Plantation of white pine and European larch on first quality soil. The stand has just received a $\mathrm{C}$ grade thinning. Total yield 40 cords per acre. Amount cut 16 cords per acre. Age 27 years. In the foreground most of the pine was removed, leaving the larch.

made. ${ }^{1}$ Thinnings remove the trees which have fallen behind the best trees of the stand but which still crowd them and hamper their development.

It is convenient in discussing thinnings to divide the trees in a stand into five classes, called crown classes, depending on the relative position of each class with respect to the other trees in the stand.

1 The struggle for existence is best noticed in even-aged stands where trees of the same age are competing. It is in such stands (even-aged) that thinnings are particularly needed, although in forests of other forms there will be found small even-aged groups here and there in which thinnings are useful. 
These crown classes are as follows:

Dominant; which contains the leading trees having comparatively symmetrical crowns and receiving full light.

Codominant; which includes trees a little shorter than the dominant ones and with smaller crowns crowded on the side.

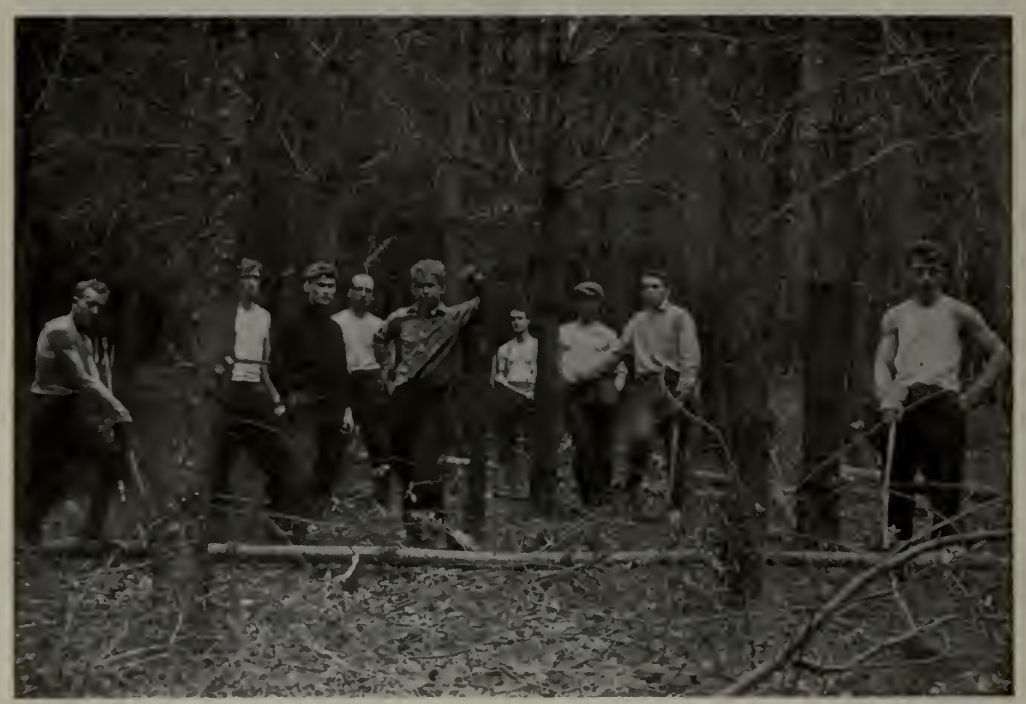

Fig. 31. - The same plantation before thinning. Note the dense dark appearance of the stand in contrast to its appearance after thinning. Although the stand is 27 years old the dead branches still persist on the trees down to the ground. On the trees in the foreground the lower dead limbs have been knocked off.

Intermediate; comprising trees shorter than those in the preceding class and with crowns open to light only from above and seriously crowded on all sides.

Overtopped; including all living trees with crowns entirely overtopped. They can obtain only filtered light.

Dead; containing all standing' dead trees.

There may be in a stand a wide range from dominant to dead trees and it may often be difficult to distinguish in which of two adjacent classes a tree belongs. This is especially true between dominant and codominant trees and between codominant and 
intermediate. As a general rule dominant and the better codominant trees are favored in thinnings, while the other three classes are cut out. Just what is taken out depends mainly on the heaviness of the thinning, which may range from an extremely light cutting to one as heavy as a reproduction cutting. The

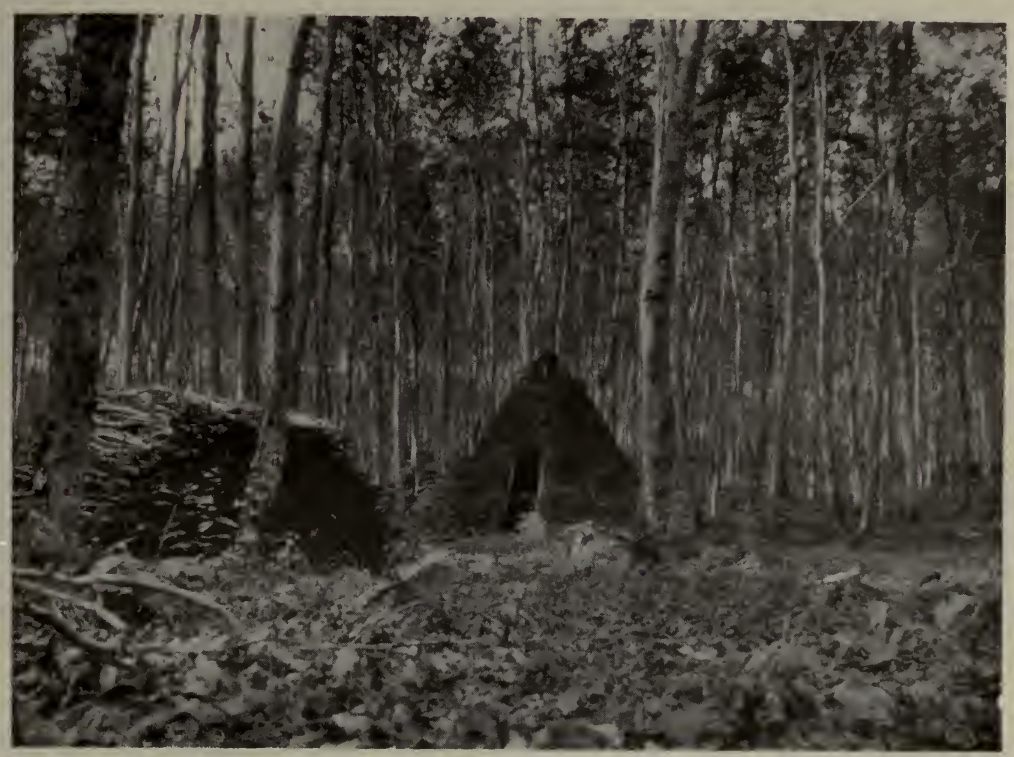

Fig. 32. - A stand of beech and oak in Europe, 40 to 50 years of age. A light thinning has just been finished.

following four classes of thinnings are recognized, depending on the heaviness of the cutting:

Grade A. - Light thinning; removing dead and dying trees.

Grade B. - Moderate thinning; removing dead, overtopped, and the poorer intermediate trees.

Grade C. - Heavy thinning, removing dead, overtopped, intermediate, and a few codominant trees.

Grade D. - Very heavy thinning, removing dead, overtopped, intermediate, and codominant trees.

Which grade to use depends mainly on the purpose for which 
the stand is managed. Light and moderate thinnings favor the production of high-grade timber free from knots. This is the principal advantage of the competition between trees in a dense stand, and thinnings of Grades A and B do not greatly lessen the competition in a stand, since this is largely between trees of the intermediate, codominant, and dominant classes.

Heavy thinnings, by giving the trees ample growing space, result in the production of shorter-boled and more knotty trees;

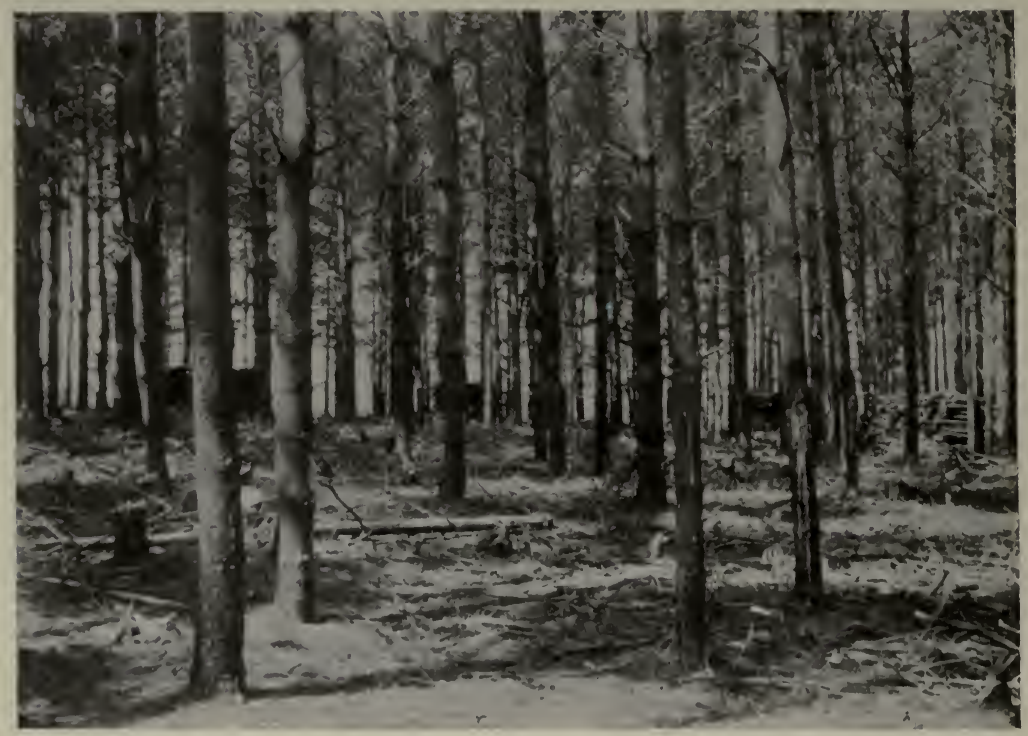

By permission of the Connecticut Slate Forester.

Fig. 33. - A white pine stand 34 years old secured by artificial seeding. A $\mathrm{C}$ grade thinning has just been made.

and, on account of the greater growing space, in more rapid growth and higher yield in a given time. Where quantity without regard to the highest quality is wanted heavier thinnings are needed than where timber of high technical quality is the primary consideration.

In general, as the thinnings increase in severity, the diameter and hence volume growth of the trees rises, but there always is a 
point beyond which heavier thinnings, while possibly still increasing the rate of growth on the individual trees, lower the growth of the stand as a whole. This is because the gaps between trees become so large that the total growth per acre from the few fast-growing trees is less than would be secured from those left after a lighter thinning.

Cuttings heavier than Grade D are too severe to secure the highest growth per acre, although phenomenal growth on individual trees may result.

Thinnings of Grades A and B interfere so little with the natural competition that their effect in increasing the rate of growth of a stand is negligible. A Grade $\mathrm{C}$ thinning is needed to appreciably increase the growth rate, and at the same time this grade does not so open the stand as to prevent the production of clear timber. For most owners in New England, Grade C or occasionally Grade D thinnings will be the most valuable.

In making thinnings of whatever grade it should always be remembered that the trees to be cut are chosen on the basis of their crown development. Too often a beginner examines the spacing of the trees on the ground and endeavors to cut wherever the number of trees is great, with the object of securing a uniform spacing of the trunks. This is altogether wrong and can be easily avoided if the crowns of the trees are used as the guide in selection.

Another method of thinning, somewhat different from the one already described, is known as the French method because of its origin and use in France. By this method certain trees are selected, when the stand is about thirty years of age, which will be favored and are to form the final crop at the end of the rotation. The number of trees per acre to be selected varies with the species, the product to be produced, and various other factors, but for the purpose of this discussion may be said to range from one to two hundred.

When these trees have been picked out a thinning is made with the object of giving them every opportunity for rapid growth. They are set free by cutting the surrounding trees 
which are at the time seriously crowding them. The cutting is made regardless of the crown class of those cut. Codominant and dominant trees as well as those of the lower crown classes are removed if hindering the chosen trees.

A second principle of the method is that practically nothing is removed unless it actually is interfering with the chosen in-

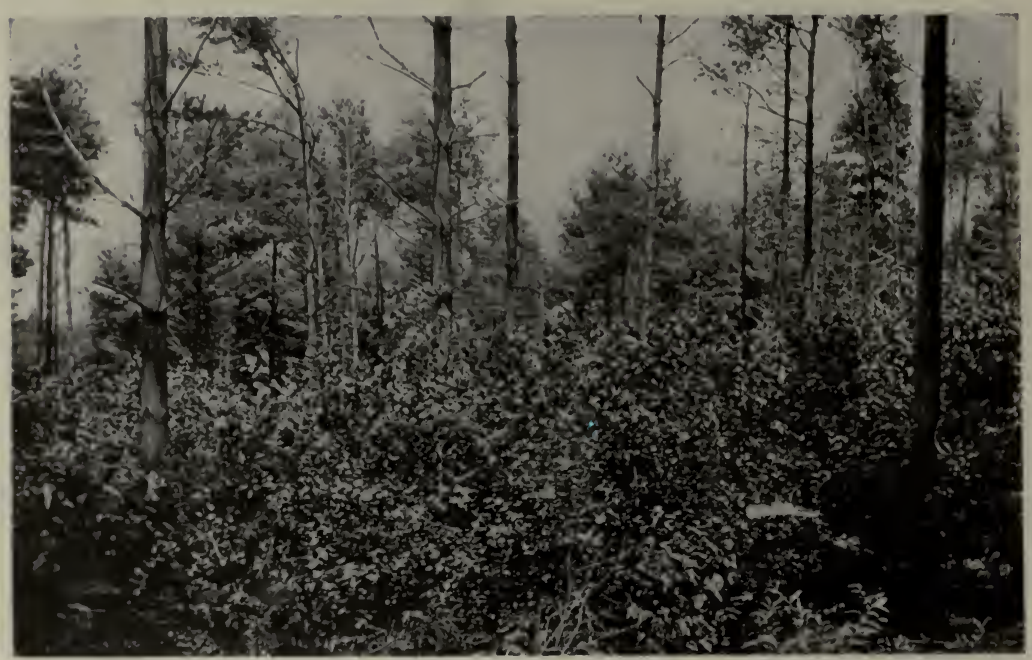

By permission of the Connecticut Stale Forester.

Fig. 34. - Same stand as in Fig. 35, but 2 years after the thinning. Poplar and gray birch have reproduced abundantly, largely owing to the abundant light which was admitted to the forest floor. A lighter thinning would have encouraged white pine reproduction.

dividual. The only exception is in the case of dead trees or those that will die in a very few years. These are cut but the overtopped and intermediate classes are allowed to remain if not hindering the chosen trees. The French method really amounts to a Grade D thinning in the upper crown classes, and a Grade A thinning in the lower classes, taking out the poorest material.

- The chief advantage of the method is that the trees to form the final crop being selected so early can be kept free and growing rapidly. It is thought that equally good timber can be pro- 
duced faster under the French method of thinning than under that ordinarily used. Up to the present time there is no adequate data to conclusively prove this. With poor markets the method may sometimes be employed when another could not, since some larger-sized material is secured from the heavy cutting in the dominant and codominant classes, while the lower classes, furnishing cordwood principally, are left uncut.

Silviculturally the lower classes of trees assist in forcing the height growth of the chosen trees, and furnish a good cover to the soil which is in this way better protected than in Grades C and $\mathrm{D}$ thinnings as ordinarily made.

A practical disadvantage of the French method is that the numerous overtopped and intermediate trees left standing make the execution of the thinning difficult. The felling of the trees is often badly hampered, and considerable breakage of standing trees occurs. Moreover, the piling and removal of the wood is made more expensive by the many standing small trees.

In actually carrying out a thinning in the field it is often advantageous, and, in fact necessary, to secure the best results, not to hold rigidly to a thinning of any given grade. For instance, a Grade C thinning may be the kind desired, but where dominant trees of a worthless species or diseased trees occur, it is best to cut them, making in such places a heavier cutting. The theory of thinnings as given here is exceedingly simple but in application many problems will come up which cannot be covered in the space of this discussion, and are best solved through field experience.

The lessening of the competition between the individual trees which effects an increase in the rate of growth has already been mentioned as the chief purpose of thinnings, but the results which come through the aid of thinnings have not yet been fully stated.

The increase in rate of growth of the individual trees results in obtaining trees of merchantable size several years sooner than is possible in an unthinned stand. In other words, thinnings enable the forester to shorten the rotation in which a given 
product is produced. This shortening may be as great as twentyfive per cent. For example, if an unthinned stand of pure chestnut is merchantable for ties in forty years, a similar stand which has been properly thinned should have trees of the same size in thirty years.

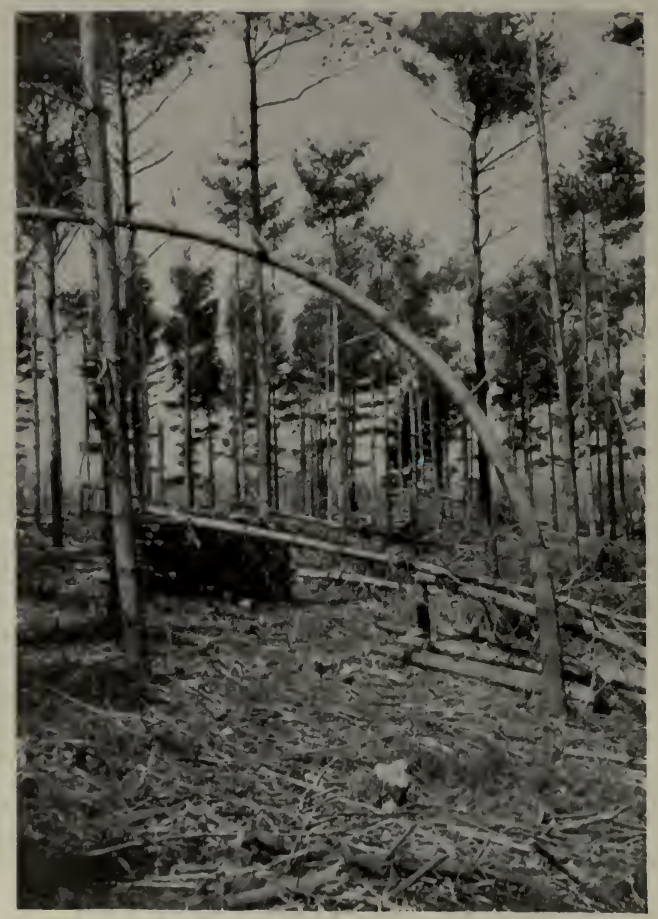

By permission of the Connecticut State Forester.

Fig. 35. - Portion of the same stand as shown in Fig. 33. Here a heavy D grade thinning was made and a large number of the trees were broken off by the wind. The trees were too slender for such a heavy thinning.

Besides increasing the growth of the individual trees the total yield of the stand is raised, by which is meant that in a single rotation (or given number of years) more material is produced by a thinned stand than by a similar one unthinned. There may be as much as thirty per cent added volume produced by the 
thinned stand. This increased production is made possible because the yield from the thinnings largely utilizes material which in an unthinned stand dies and decays before the final cutting. The struggle between the trees is slowly killing the weaker individuals. As the stand grows older, they pass from the codominant to the intermediate class, then to the overtopped, and finally are numbered among the dead. The great difference in number of trees per acre between young and mature stands (both fully stocked), which is apparent on the most casual investigation, gives an idea of the large number of trees and quantity of material lost through decay in an unthinned stand. Besides utilizing material otherwise wasted, the one thinned when ready for harvesting will have as great or sometimes even greater volume than the unthinned stand.

A higher grade product, taking the average for the whole stand, is furnished by the thinned than by the unthinned stand. In the latter there may be a few exceptionally fine trees, but with them are many inferior specimens, merchantable only for cordwood. In the former a smaller number of trees per acre will be found on which the growth has been concentrated. Individually none of them may contain such high-grade timber as the exceptional tree in the unthinned stand, but, on the other hand, every tree can be used for better products ${ }^{1}$ than cordwood and the average value per tree is much higher.

Thinnings raise the grade of the final product in another way: by enabling the forester to eliminate worthless species from the stand when it is young. Oftentimes in unthinned stands a species of low lumber value will be found occupying a prominent place in mature stands, but in properly thinned stands this need never happen.

Theoretically thinnings should be begun as soon as the competition between the trees becomes strong. This occurs usually when a stand is ten to twenty years of age. Thinnings in such young stands ordinarily do not yield material salable even as cordwood under present market conditions in New England.

1 With light thinnings timber of high technical value can be produced. 
The first thinning should be deferred until the material taken out is large enough for cordwood and the returns will at least cover the cost of the operation. This will rarely occur before the stand is twenty years old, and not later than the thirtieth year.

Thinnings should be repeated whenever needed. Unless the thinning was very heavy this should be in five to ten years. The time for making the next one can be judged by observing the crowns. If the openings left by the previous cutting have

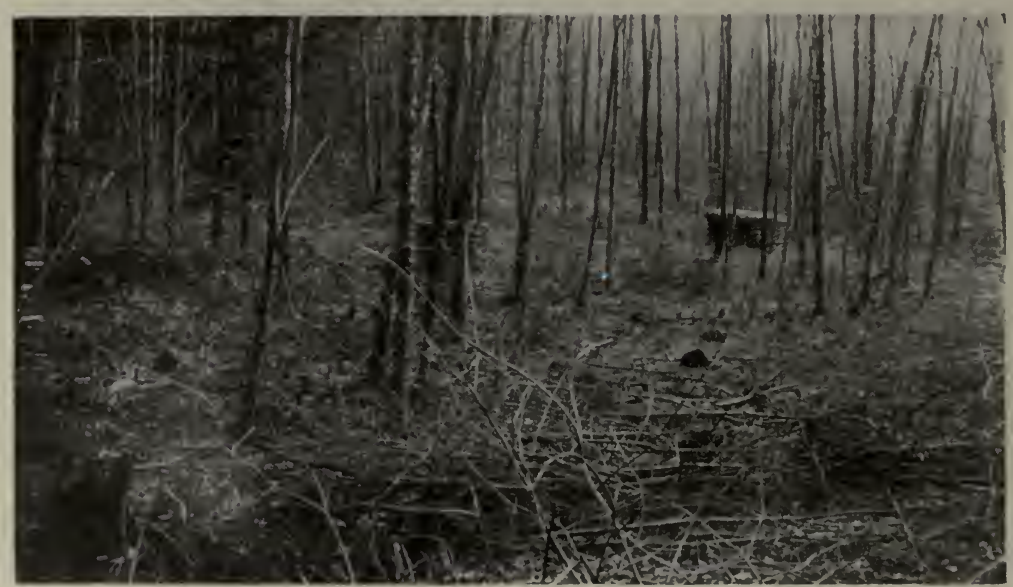

Fig. 36. - A C grade thinning in a 38 -year-old stand of mixed hardwoods containing oak, chestnut, maple, black and yellow birches. Yield per acre 27 cords; actually cut $6 \frac{1}{4}$ cords per acre.

been filled and the crowns of the trees are once more in close contact, competition has again assumed serious proportions and it is time for another thinning.

The best method is to make small openings in the crown cover which will close together within a few years, necessitating an early repetition of the operation. When only small gaps in the cover are made there is no danger of the trees producing knotty timber nor of the stand becoming insufficiently stocked with trees. The soil is best protected by light thinnings, frequently 
repeated. They should be carried on until the time comes to start reproduction cuttings.

At the present time in many quarters there is a prejudice against making thinnings through ignorance of their value and especially through belief that they are impracticable. One objection raised is that the uncut trees will be thrown by wind. There is sometimes danger of this on wet ground, with shallow-rooted species, on exposed sites and in stands past middle age when

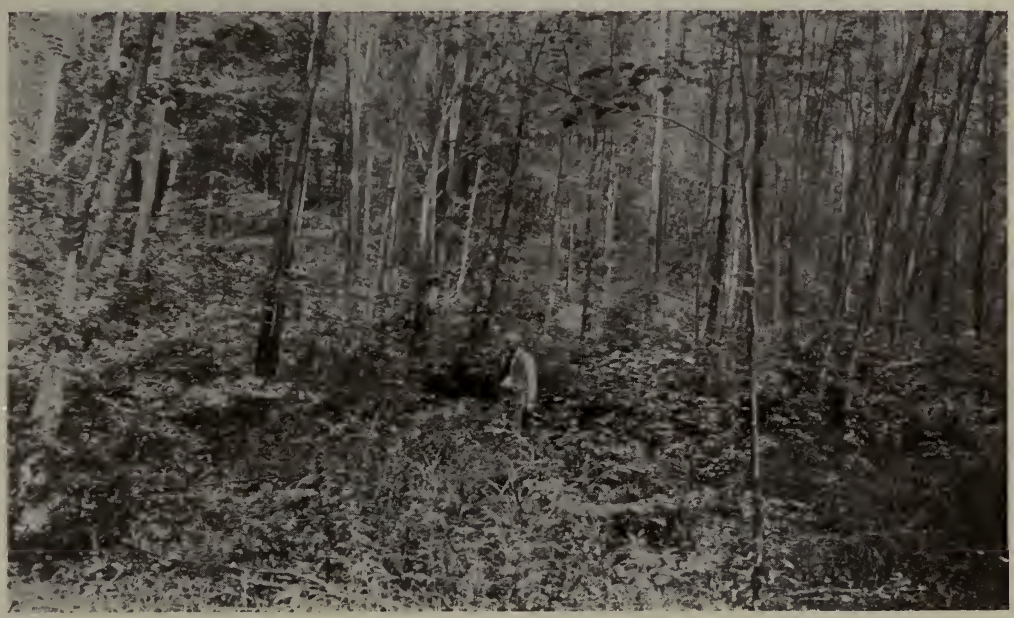

Fig. 37. - The same stand as in the previous picture but 3 years after the thinning. The crowns have already closed together and another thinning could safely be made.

thinned for the first time. In such stands the trees often have very small crowns and root systems and depend on each other for support. If thinnings are begun when the stand is twenty to thirty years of age and made light there will not be any large loss due to windfall.

Another objection is made that the trees, in being cut and removed, will injure the standing trees. This arises through the mistaken idea that the smaller trees are left and the larger are cut, while the reverse is true. Thinnings are often confused in the lay mind with the selection cutting described in Chapter II. 
As a matter of fact, the removal of the lower crown classes rarely inflicts a serious injury on a standing tree.

The cost of cutting and removing the material is somewhat greater than in cases where the stand is cut clear, but there is not the great difference sometimes assumed. The added cost will, of course, vary with the conditions, but ten to twenty-five per cent will represent the usual range. Frequently unfamiliarity with the style of cutting and unwillingness to learn on the part of the woodsmen are the chief factors in increasing the cost.

Thinnings in young stands yield only cordwood and in stands of all ages a large per cent of the material cut is cordwood. Where this cannot be sold at a profit, as is the case in portions of New England, thinnings are not practicable. Usually in coniferous stands they can be made under poorer market conditions than in hardwood forests, as in the former smaller-sized logs are cut into lumber or put into other products of greater value than cordwood.

4. Salvage Cuttings. - Frequently a cutting is advisable in a stand with the purpose of removing and utilizing material which has been damaged by wind, insects, fungi, fire, or other causes. It is altogether too common a happening to have a large per cent of the trees in a stand killed by fire. Such a cutting, intended to take out injured material, is called a salvage cutting. It is made without regard to the crown classes or species of the trees cut, simply taking out all injured individuals. As the extent of injury varies greatly so does the severity of salvage cuttings. They may range from the removal of occasional trees to clear cuttings. In cases where the injured stand is mature or nearly mature it is often possible to begin the reproduction cuttings early, and arrange them so as to utilize the damaged trees. But in immature stands special salvage cuttings are made in case of injury. Salvage cuttings, so heavy as to remove a large percentage of the trees, call for a sacrifice in immature stands, as the trees are cut before reaching the most profitable size. However, as long as fire, wind, insects, etc., cause extensive 
injury in the forests, salvage cuttings are demanded as a regular part of management, to make the best of a bad situation.

When promptly made, before decay has progressed far, salvage cuttings usually yield material of merchantable size. Where the returns from material taken out will not pay the expenses of removal, salvage cuttings are not ordinarily recommended.

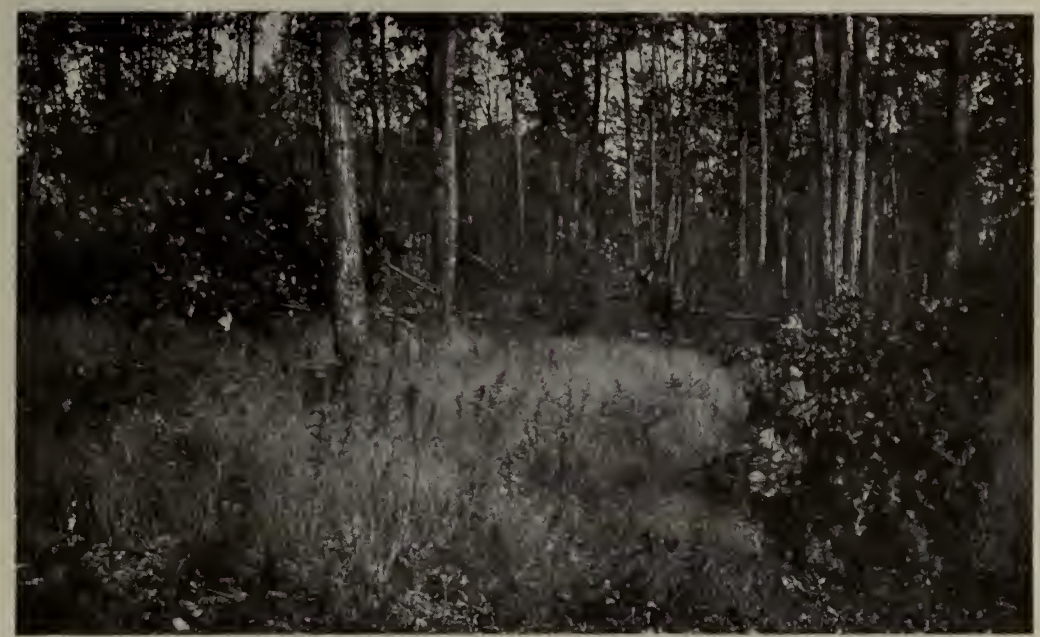

Fig. 38. - A salvage cutting. Note the undergrowth of grass and weeds which has started as a result of the heavy cutting. To avoid such undergrowth intermediate cuttings should be made as light as possible. The fallen tree, weakened at the base by fire and fungi, has been broken off by the wind.

Schedule of Intermediate Cuttings. - In order to illustrate the relative time at which the different kinds of intermediate cuttings are made, the following table has been drawn up for a planted stand of white pine, this particular type of forest serving as a good example for even-aged stands of other species. The rotation has been set at sixty years. If it was intended to reproduce the stand naturally, a reproduction cutting would be substituted for the last thinning. 
SCHEDULE OF INTERMEDIATE CUTTINGS FOR A WHITE PINE PLANTATION.

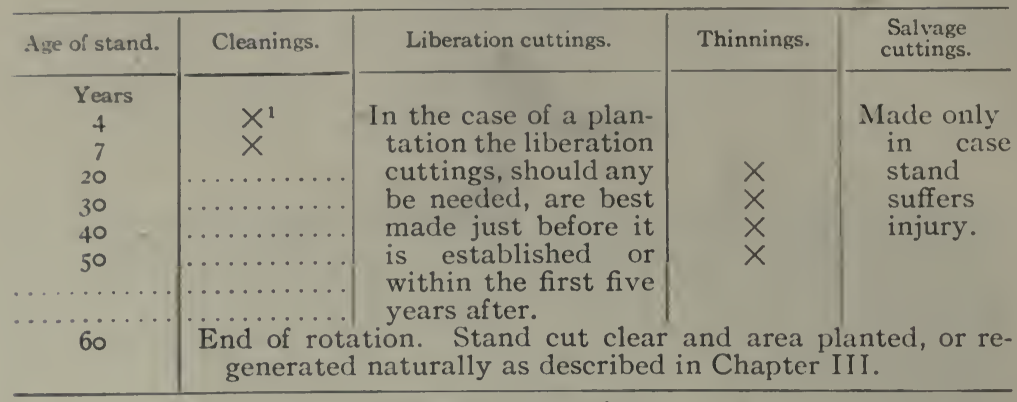

${ }^{1}$ Crosses indicate cuttings.

Methods of Controlling Cuttings. - In order to be sure that the style of cutting desired is actually carried out on any particular tract, it is necessary to oversee the work with great care. This is so whether an intermediate or reproduction cutting is made. It is especially true where the cutting is done by a contractor, or is in charge of old lumber jacks, trained to wasteful methods and unwilling to accept new ideas.

Control of the cutting can be assured best by marking all trees to be cut (or those to be left) and frequently inspecting the cuttings to see that the marking is being followed, or by outlining the general plan of cutting to a foreman and then frequently inspecting his work to be sure that he carries out the plan correctly.

The choice of the method of control will be mainly determined by the style of cutting.

In thinnings it is best to mark carefully either the trees to be cut or those to be left. Cleanings, liberation cuttings, and salvage cuttings (because in making them it is usually a simpler proposition to recognize what should be removed) can often be satisfactorily controlled by furnishing the foremen in charge with general instructions and then looking over the work at frequent intervals. Many times, however, the trees to be cut in liberation and salvage cuttings should be marked. 
In reproduction cuttings, where clear cutting is to take place, laying out the areas to be cut suffices. Where seed trees are to be left, or the selection method or one calling for only a partial clearance is to be used, marking of the trees is advisable.

It may seem as though in a selection cutting the use of a diameter limit would take the place of marking, but there are so many cases in every operation where trees above the limit should be left and those below cut, that the trees should be marked, even when a diameter limit roughly controls the cutting.

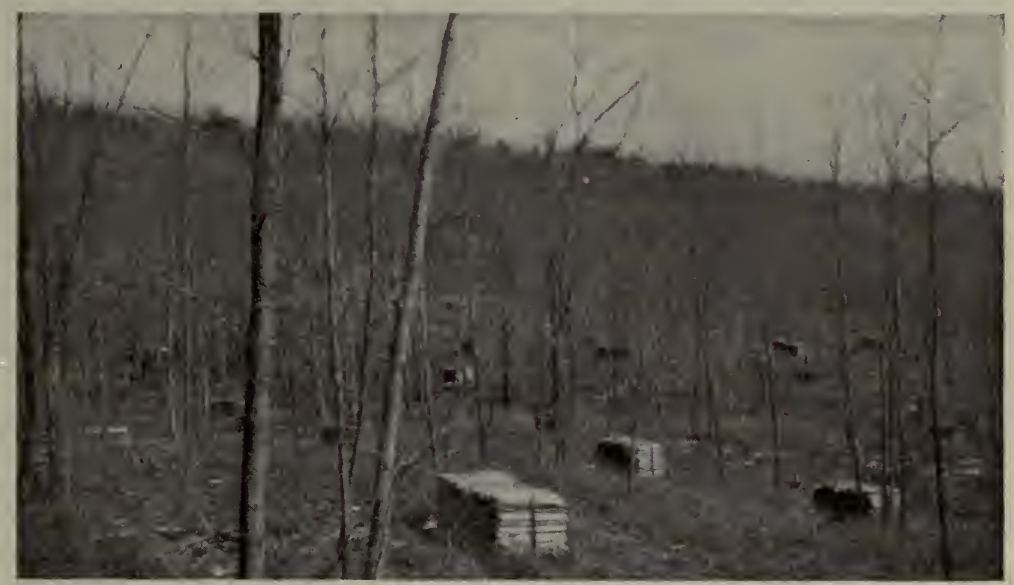

Fig. 39. - A salvage cutting in a stand of chestnut and oak. Fire has injured many trees and the chestnut bark disease was present. After the cutting, an open stand of the fire-resistant oak remained. The material cut was too small for anything but cordwood.

In marking the trees, either those to be cut or those to be left may be marked. Usually it is best to adopt the easiest method. Thus, on areas to be cut clear, with patches of seed trees to be left, the few seed trees should be marked; but in a selection cutting, where comparatively few trees are to be removed, these should be marked.

The trees can be marked by axe blazes or by dabs of paint. To insure full control of a cutting it is best to mark the base of the trees below the point of cutting, as well as a point easily seen 
three to five feet above ground. Then, after the trees are felled, inspection of the stumps shows whether they were marked for removal.

If axe blazes are used for marks it is well to have a distinctive stamp on the head of the axe and stamp each blaze, thus preventing marking by unauthorized parties.

Pruning. - Pruning as used in forestry really should be classed as a type of intermediate cutting, for its purpose is to improve the quality of the crop. It is an operation which as yet has been little used, and will be used only in occasional cases, where forest management can be on a highly intensive scale, and with certain species, like white pine, in which natural pruning is poor, even when grown in a crowded stand.

Pruning should only be practiced where clear lumber is wanted, and where such lumber is sufficiently valuable to pay the cost of the operation. The way in which pruning raises the value of the forest crop is through the early removal of lower limbs, allowing the production of clear lumber free from knots. (See Fig. 40.)

Forest pruning usually is restricted to the removal of dead limbs. There are two reasons why the removal of live limbs is bad; first, because the wounds left by the pruning of live limbs offer good opportunities for the entrance of fungi or insects, and second, because the removal of live limbs disturbs the balance between the crown and root systems of the tree, and may often result in retarding its growth. It is claimed, also, that in the case of some species pruning of live limbs causes loose knots in the timber. A few of the lower live limbs often can be removed without appreciable injury to the tree.

It is impracticable to prune higher than the first log length, or as high as a man can reach with his pruning tools. Pruning should be done at the earliest possible moment, as soon as the branches have died for the distance up the trunk that the trimming is to be done. In this way there will be a smaller knotty center inside the log. The pruning can ordinarily be done before the trees become twenty years of age. 
Only the trees intended for the final crop should be pruned, as to prune those of the subordinate crown classes, which will die or be removed in thinnings, would be a useless expense.

Various tools can be successfully used in forest pruning. If only dead limbs are removed, a blow from the back side of an axe

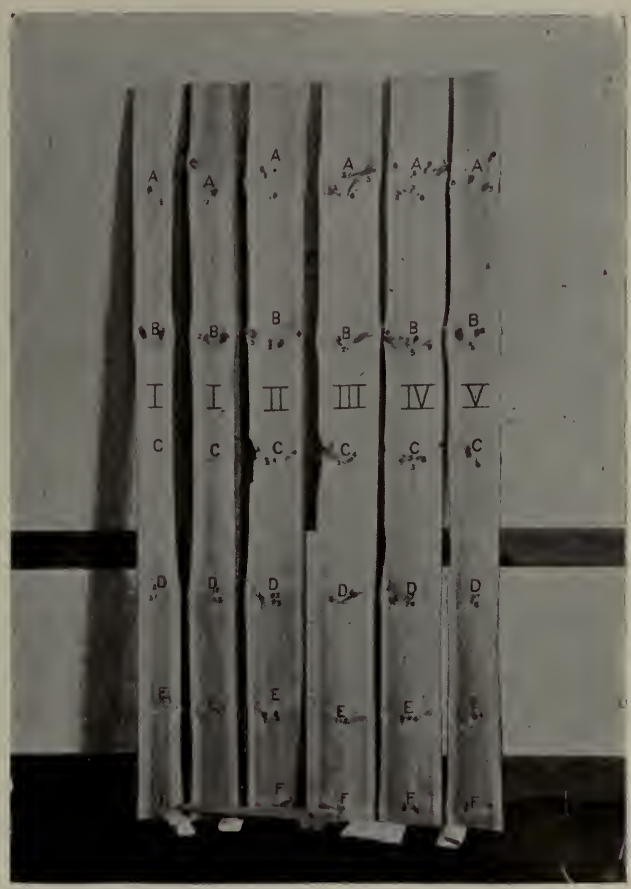

Fig. 40. - The results of pruning in producing clear lumber. The tree from which this lumber came was pruned up to, but not including, the set of knots marked $B$.

or a heavy stick will often do the work. On the higher limbs and where the limbs are small, pruning hooks do the best work. Where larger limbs are found, a saw is needed. The cuts should be smooth, and close to the trunk, so that they may readily heal over. 


\section{CHAPTER VI.}

\section{INJURIES FROM ANIMALS.}

THE forest as a whole suffers relatively little from animals, their influence on its character being much less important than that of insects. Probably the most destructive wild animal is the porcupine, which in the northern woods girdles a great many trees, especially spruce. As these animals are very fond of old pork barrels they are often found in the vicinity of abandoned lumber camps, and, although, in some states there is a reward for killing them, it is a question whether more harm is done by the porcupines or by the class of men who profit by this reward and are responsible for many forest fires.

While deer may damage some farm crops in parts of New England and often eat the leaders of white pine when planted in the spruce region where it is not common, it will be a long time before our forest management will reach that degree of intensiveness which has been reached in Germany and which takes remedial measures against the occasional nipping of a forest bud or stripping of the bark from a sapling.

Squirrels, rabbits, and mice often nibble the bark from young trees and occasionally girdle them. The writers have seen plantations of locust and Scotch, white and pitch pines in Connecticut killed in this way. Moles also injure the roots of trees and wounds of this kind furnish an easy entrance point for fungous spores. The greatest damage from these rodents is, however, in the forest nursery, where the seeds are often eaten in large numbers, especially the nuts and larger pine seed. Small birds such as sparrows and goldfinches frequently cause serious damage in forest nurseries by eating the seed just after germination and thus destroying the young plants. Provision against such damage can be made by coating the seed before sowing with red lead, 
a powder which will remain on the seed for a year and which is distasteful to birds. In the large commercial nurseries where birds are a serious menace the seedbeds are covered with a wire netting of three-fourths inch mesh. Moles and mice in a nursery can be trapped. One of the simplest methods is to sink pails half full of water and covered with grain in the paths of the nursery,

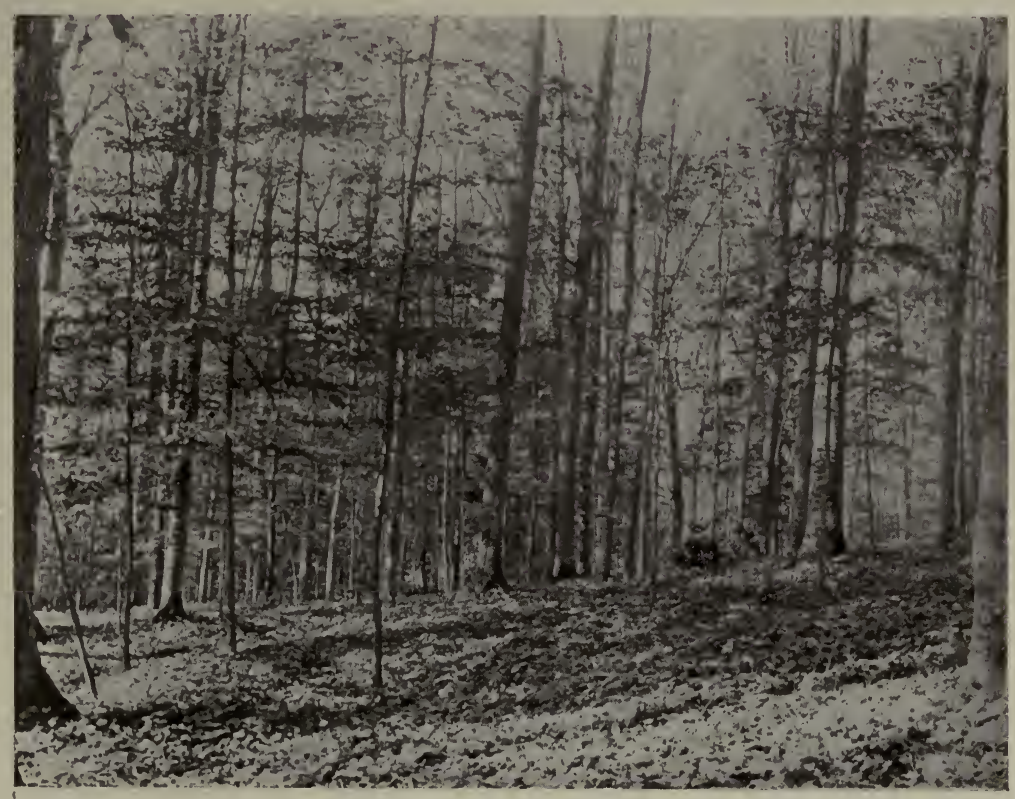

Fig. 4I. - A fine stand of hard maple and beech. Note absence of reproduction owing to heavy grazing and compare with next figure.

where the rodents will soon fall into them. Woodchucks, squirrels, and crows frequently damage seedlings in plantations, especially where nuts have been planted. Much of this injury can be obviated by coating the nuts with tar before planting.

More a matter of interest than of economic importance is the service squirrels sometimes render in helping in the collection of forest seeds. The Shakers of Enfield, Connecticut, used to seed down an area of sand plain each year to pine and buckwheat. 
After taking of the crop of buckwheat they allowed the area to grow up to pine, and gathered the pine cones from the piles which the squirrels had collected in the woods.

Throughout New England much land formerly pastured is now growing up to brush and trees. For a long time this land was kept clean by cattle and sheep, but the rapid decline in the amount of live stock raised in the East has allowed the reversion of many pastures to forests. Where forest seedlings have come

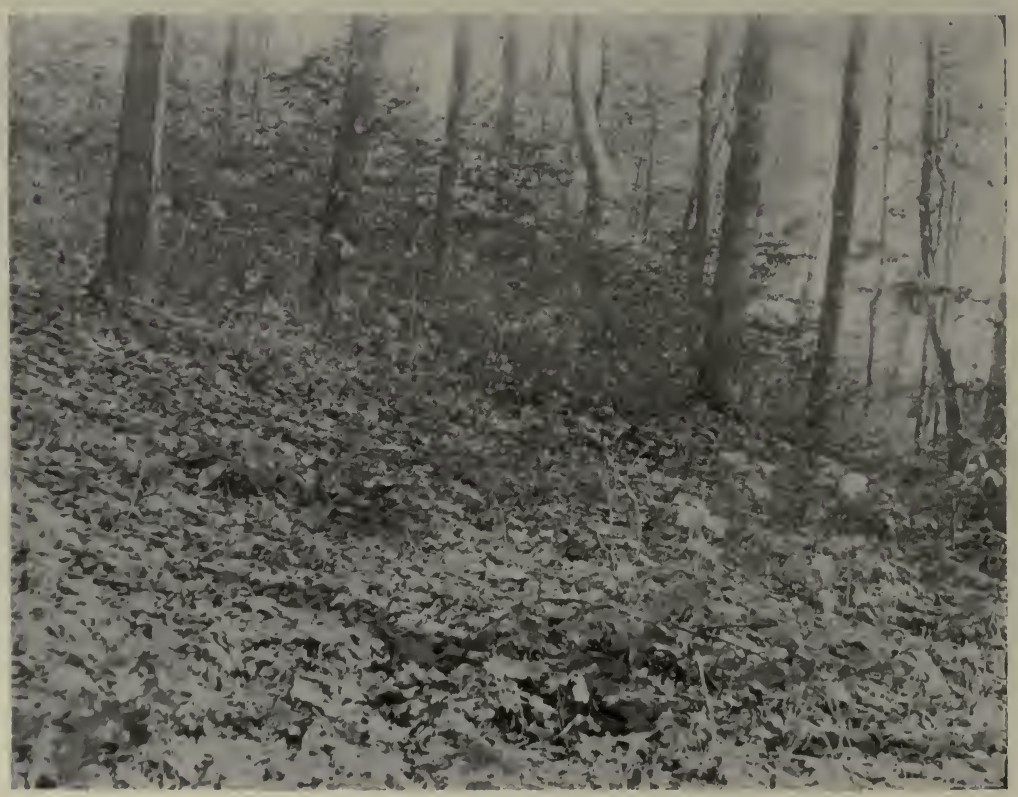

Fig. 42. - A pure stand of hard maple ready for a selection cutting. Note the abundance of hard maple seedlings and saplings which have started owing to protection from grazing.

up in land still pastured, examination will show that many of them have been eaten or broken off by the animals. A common practice is to allow domestic animals to pasture in wood lots, where they do a great deal of damage, the character of which depends on the kind of animal.

Cattle are more inclined to rub against little pines and other 
conifers and thus break off their tops than to eat them. Sheep and goats will often strip all foliage as high as they can reach. On steep slopes the trampling of the animals, overturning stones and cutting up the soil, results in preventing young seedlings from becoming established. Hogs destroy forest seedlings and eat the mast of nut trees and, in some sections of the West, this forms an important part of their diet. There may be times when the introduction of hogs into a forest is rather beneficial than otherwise. They will do much by their rooting to prepare the soil for germination before a heavy seed crop and it may even be advantageous for them to eat an undesirable kind of seed, as beech nuts, to keep down the percentage of a poor species. They also destroy innumerable grubs, many of which, like that of the June bug, are serious enemies of forest and nursery.

The presence of grass in a forest is a sign of poor management, as grass can only grow in openings exposed to sunlight and these openings should not exist in the forest. Grass more than anything else transpires moisture and tends to dry out the soil.

Another result of pasturing wood lots is a total absence of young seedlings and the consequent decline of the forest. This is especially serious in connection with the sugar orchards of northern New England, which are such important portions of many farms. The lack of young maples due to cattle threatens the discontinuance of the industry in many places.

No area which has been planted to forest, or which has been covered with a natural growth of seedlings, should be pastured until the trees are ten feet high. If the stand is of proper density there will not then be sufficient browse to pay for pasturage. In other words, forestry and grazing can rarely be practiced on the same land to their mutual advantage. 
CHAPTER VII.

\section{FOREST INSECTS AND FUNGI.}

THERE are numerous insects and fungi which attack the leaves, branches, trunks or roots of forest trees. Some restrict their attack to dead or dying trees, while a smaller number are able to prey upon living healthy trees.

The insects and fungi, considered in this chapter, have been selected because they are among the most destructive to living forest trees. From the practical standpoint, the forester is less interested in enemies which prey only upon dead or badly injured trees.

For a complete list of the insect and fungous enemies of the New England forests, reference must be made to more advanced entomological and pathological works.

\section{A. INSECTS.}

White-pine Weevil (Pissodes strobi).

This pest is found generally wherever the white pine grows.

Form of Damage. - The weevil invariably works in the main terminal shoot and causes it to wither, but seldom kills the tree. Depredations begin in July or early August. The next year one of the side branches straightens up and forms the leader, but there is always a slight crook in the tree. In badly infested regions the same tree may be attacked repeatedly, and numerous crooks will give it a deformed and stunted appearance. For timber purposes the value of the pine is much diminished. The insect seems to prefer trees under 30 feet in height, but it occasionally attacks taller ones, and those in old fields and open woods are more severely attacked than those in closed stands. The injurious effects are worse in the southern range of the species. 
Appearance. - In its adult stage it is a reddish-brown beetle about one-quarter inch long with a pronounced snout. The pupa is creamy white and about the same length as the adult, and the grub is also white and of varying length up to onequarter inch, according to development. The infested top of the tree is badly decayed at the close of the season and is riddled with tunnels that are filled with the borings. The wilting of the needles is the first evidence of the weevil's presence.

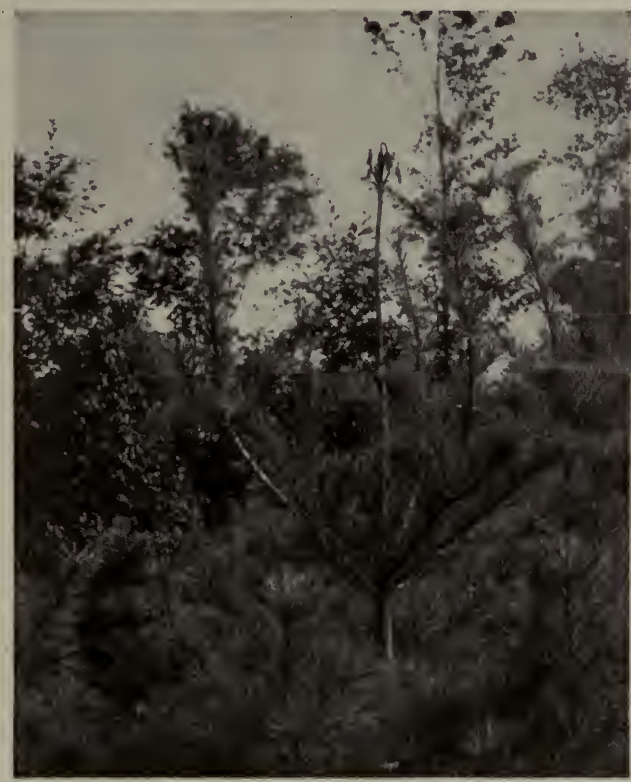

By permission of the U.S. Forest Service.

Fig. 43. - Leader of a young white pine killed by the white-pine weevil. Several of the side branches have already begun to take the place of the leader.

Life History. - The beetles deposit their eggs under the bark of the main shoots in May or June, and the grubs, which hatch after a week or two, begin to bore inward and in a downward direction to the pith. In the grub stage they are greatly reduced in numbers by natural enemies, mostly parasitic insects. The transformation into pupæ and adults takes place during 
July and August, after which the imprisoned beetles bore a way out to freedom and seek suitable abodes in which to pass the winter.

Treatment. - The best way to fight this enemy is to cut off the infested top during June, July or early August, before the beetles have escaped. The surest way of extermination is to burn these tops, but as they often are the habitat of minute insects which prey upon the weevil, a modification has been suggested by Dr. Hopkins of the United States Bureau of Entomology. Obtain a perfectly tight box or barrel with but one opening (a large metal can is still better). In this, place the infested tops, and cover the opening with a very fine-wire mesh (one which an ordinary pinhead cannot pass through). The beetles cannot escape, but the parasites easily make their way out and attack other weevils. The box must not be exposed to the weather as it will check and allow the weevils to escape. Either form of treatment must be repeated several successive years as it is impossible to exterminate them in a single season.

In order to prevent the injured trees from developing two or more main stems, all of the side branches of the top whorl, except one, should be cut off close to the main stem. This one side branch will straighten and develop into the trunk of the tree.

\section{PINE-BARK APHID (Chermes pinicorticis).}

Form of Damage. - This plant louse is sometimes present in such large numbers on pine stems as to weaken the vitality of the tree by sucking the sap. A sickly condition and occasionally death, in the case of young trees, results. This aphid occurs everywhere throughout the range of the white pine.

Appearance. - A cottony appearance on the twigs and sometimes over the trunk of the tree betrays the presence of the insect. It is sometimes mistaken for the exudations of the pitch.

The eggs occur in downy balls near the base of the needles and vary in number from five to sixty or more in each cluster. They are oval, and of a reddish yellow color. As insects some are 
winged and some wingless. The young of the latter are oval in shape, somewhat flattened, and of a yellowish-brown tint. As these develop they become darker colored, and finally almost black. The wool-like covering serves to hide the insect and

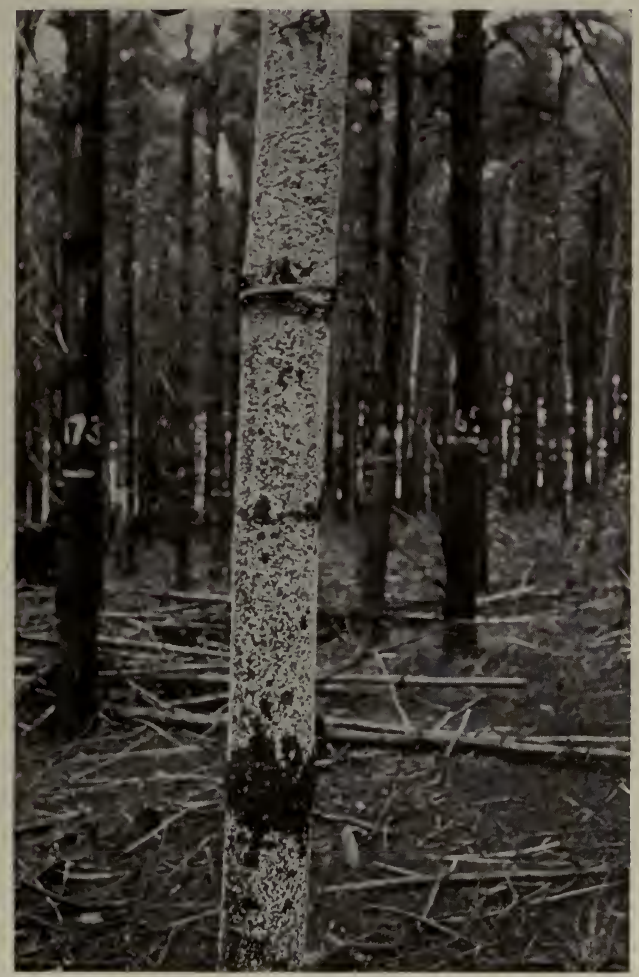

By permission of the Connecticut State Forester.

Fig. 44. - A white pine tree 27 years old seriously attacked by the white-pine aphid.

gives it the appearance of a ball of down. The winged species are of a light-reddish tinge; their white wings expanding rapidly become transparent, but the bodies become almost black.

Life History. - The eggs laid by the wingless females begin to hatch early in May, and the young emerging in large numbers from the bulbs of woolly matter, spread over the bark at the base 
of the needles. Individually they are almost too small to be seen with the naked eye, but their number at this stage is legion. They soon attach themselves to the tender bark of young twigs, increase rapidly in size and darken down to brown or black, and all the while exude a substance which nearly conceals them. Maturity is reached about the last of May when the females deposit eggs for another brood. During the summer there may be several broods and at last females with wings appear.

Treatment. - The aphid has several natural enemies, the most effective being certain varieties of lady bugs. Where a hydrant is near the insects can be washed off by a forcible stream of cold water. A spray of kerosene emulsion or whale-oil soap is efficient. One pound of the soap to four gallons of water makes a good mixture. However, in forestry it is usually impracticable as well as unnecessary to use preventive measures.

\section{The European Pine-shoot Moth (Evetria buoliana). ${ }^{1}$}

Form of Damage. - This insect attacks all species of pine, eating the inside of new buds and killing or deforming the young twigs. In severe attacks repeated for several years hardly a single bud escapes and the trees are stunted into small bushes. When slightly attacked the terminal shoots are badly deformed.

Trees between six and fifteen years are commonly attacked, although both younger and older ones are not immune. Trees over thirty years of age are not often seriously affected.

The pine-shoot moth is considered in Europe one of the most injurious forest insects. Introduced into this country several years ago it is now reported from twenty localities in the states of Illinois, Ohio, W. Virginia, Pennsylvania, New York, New Jersey, Connecticut, Rhode Island and Massachusetts. As yet it has been found only in nurseries and in private parks. This may be due to lack of complete investigation or to the slow spread of the insect.

1 See U. S. Dept. of Agriculture Bulletin 170. Contributed by the Bureau of Entomology. "The European Pine-Shoot Moth - A Serious Menace to Pine Timber in America." 
Appearance. - The moth is a small orange-red insect about one-half inch long with three-quarters inch wing spread and may be observed in July and August. In the buds and new shoots a dark brown larva with a black head can be found. When mature it is two-thirds of an inch in length. The dying shoots with larva inside are the best indication of the presence of the insect.

Life History. - The moths in the late summer lay eggs singly on new buds for next year's growth. Ordinarily the terminal cluster of buds are selected. A minute larva soon hatches and eats into the bud and hollows out a cell inside. It may devour the inside of one bud and tunnel into another adjoining. The larva winters in one of the buds. As soon as the sap starts in the spring the larva resumes work and eats more buds, and, as the buds develop, the inside of the young shoots. Since only very young and tender shoots can be devoured, some may not be killed but are injured on one side. They bend over at the injured point and form a permanent crook in the tree. Finally the larva builds a chamber in one of the hollow shoots and pupates. In about three weeks the moth emerges.

Treatment. - Removal of the infested twigs and buds is the best method of control. This work may be done at any time in fall, winter or early spring. Fall and winter are best. Buds containing larva can be identified by small exudations of pitch near the base of the bud. In the spring injured shoots can be easily found. Since the pine-shoot moth spreads slowly the work of extermination may be possible. It should be attempted immediately on location of an infestation. In Europe several parasites prey on the pine-shoot moth. Several native species of shoot moths are known to injure pines, but none are so voracious and dangerous as the European variety.

\section{The Spruce-Destroying Beetle ${ }^{1}$ (Dendroctomus piceaperda).}

Form of Damage. - This insect, which has been prevalent in New England and New York since I8I8, has destroyed much

${ }^{1}$ See "Some of the Principal Insect Enemies of Coniferous Forests in the United States," by A. D. Hopkins, from Yearbook, U. S. Dept. of Agriculture, r9o2. 
spruce timber by its borings in the cambium, the living tissue just beneath the bark. Here it makes its primary galleries and lays its eggs. As soon as the eggs hatch the young broods make transverse galleries which effectually girdle the tree, and in time the withering leaves proclaim the death of the tree. The falling leaves are an outward sign of the damage; by removing the bark the galleries made by the insects may be plainly seen.

Appearance. - The adult is a reddish-brown or black beetle, varying in length from three-sixteenths to one-quarter of an inch. The egg, small and nearly white, is not distinguishable from that of other bark beetles. The larva, at first a minute white grub, becomes about one-quarter inch long. The pupa is nearly white and of about the same size and form as the adult; - it is found in cavities in the bark.

Life History. - Simultaneously a large number of beetles will attack the lower part of a large-sized spruce. Trees over ten inches in diameter may be attacked. They bore through the bark and deposit their eggs in the galleries as already described. The eggs soon hatch and each larva bores its individual gallery where it matures. The period of development from egg to mature larva varies according to the season, from two to nine months, but the adult seldom develops sufficiently to emerge until another spring. The result is, when activity ceases in October, that a tree may contain the insect in all its stages of growth.

Treatment. - Nothing can be done to save a tree once infested with this borer, but much can be done to prevent the spread to other trees. Theoretically the best method is to make trap trees by hack girdling them in May or June. The beetles are thus led to concentrate on these weakened trees, and these are to be destroyed in the fall, winter or early spring, either by the removal of the timber from the forest or by felling and removing the bark before the insects emerge. Intelligent lumbering of the areas of infected trees, and of all mature trees, is the most practicable way of keeping this insect in check. 


\section{The Spruce Budworm (Tortrix fumiferana).}

The spruce budworm is an insect which, within recent years at least, has not attracted widespread attention among foresters and landowners in New England. Extensive killing of the spruce about thirty-five years ago along the Maine coast is attributed largely by Packard to this insect. However, in Canada, in the neighboring province of Quebec, it is now a serious pest, and there is reason to believe that in New England also it may become dangerous.

Form of Damage. - The insect feeds in its caterpillar stage on the buds of the spruce, and after these are destroyed it eats off the needles, attacking them at the base. Besides the spruce, other conifers may be attacked.

Trees may be killed outright by the spruce budworm, if defoliated repeatedly, but in the majority of cases the result is the checking of the growth of the tree and the weakening of its vitality. Indirectly this is of importance, since the weakening of the tree's vitality results in its falling an easy prey to the spruce-destroying bark beetle, which is a much more dangerous enemy. Branches attacked by the spruce budworm have a reddish-brown appearance, due to the bare twigs and to the dead leaves, which the caterpillars have fastened together to serve as a place in which to live.

Dr. C. Gordon Hewitt, F.E.S., Dominion Entomologist of Ottawa, Canada, has studied the spruce budworm and the following account of its life history is taken from one of his addresses published in the Report of the Canadian Forestry Convention for I9II:

"The winter is passed in the caterpillar stage, as a very small caterpillar, we believe, in a little shelter constructed near a bud. In the spring, when the buds begin to swell, the caterpillar begins to feed and becomes full-grown towards the end of May and beginning of June. They are then four-fifths of an inch long, of a reddish-brown color, and have small light-yellow warts on each segment of the body; the sides of the caterpillar are lighter 
in color. They transform into brown chrysalids inside the loosely made shelters. In six to ten days the small brown moth emerges from the chrysalis, dragging the empty case partially out of the larval shelter. The moths are found from the middle of June to the end of July. Shortly after emergence, they deposit their peculiar pale-green scale-like eggs in small oval patches on the undersicles of the needles, and they are not conspicuous. The eggs hatch in about a week or ten days, and the young larva feed for a short time on the terminal shoots of the branches before hibernating. During July when the moths are flying, they occur in enormous numbers about the electric and other lights.... They are carried considerable distances by the wind, and this method of dispersal accounts for the rapid spread of the insect."

Treatment. - No practicable method of directly combating the spruce budworm is as yet known. Its greatest damage is done in connection with the spruce bark-destroying beetle. This beetle can be controlled as already described. Where the spruce budworm is found in abundance, especial watch should be kept to see whether the bark-destroying beetle has attacked the weakened trees.

\section{The Gipsy Мотн (Porthetria dispar).}

Form of Damage. - Since its importation into Massachusetts, the damage done by this insect has been most serious - damage, by the way, not confined either to forest or fruit trees, for it also attacks other forms of vegetation. The damage done is by defoliation which weakens the tree, and if repeated for two or three successive seasons results in its death.

The gipsy moth prefers such trees as the oak and maple, but conifers are not immune. ${ }^{1}$ It does little damage to the compound leaf species, as the ash, hickory and butternut. Experts, therefore, advise the encouragement in the infected regions, so far as possible, of species with compound leaves.

A ppearance. - The presence of this insect is always apparent in the latter part of the season from the defoliation of the trees,

1 The red pine is thought to be immune. 
but identification is easiest by the discovery of the large egg masses which are oval in shape, about an inch wide and two inches long, of a buff color and presenting much the appearance of a piece of sponge. These may be found on the bark of trees or under leaves on the ground. The young caterpillar is about one-tenth inch long on emerging from the egg; when full grown it is from two to two and a half inches in length. It has a double row of tubercles down the back, eight blue and twelve red. The pupa is dark brown and from three-fourths to one and a half inches long. The male and the female moth differ widely in appearance. The former is small and of a brown color, with a wing spread of one and a half inches. The female, of a white or buff color, and with a wing spread of about two inches, is too heavy to fly.

Life History. - In this country as well as in Europe this insect has but one generation a year. The minute eggs are laid in clusters of from four hundred to five hundred eggs each. Yellowish hairs give to these clusters a sponge-like appearance, and although they are usually on the trunk of the tree, or the side of a $\log$, they are often concealed in crevices and under rocks. Eggs are laid in the latter part of the summer and usually do not hatch into caterpillars until the following spring, from the end of April until the middle of June. The caterpillars reach full growth in about ten days, spin filmy cocoons usually on the trunks of trees, and finally emerge as moths in late July or August. Most of the damage is done in the caterpillar stage, and the dissemination of the insect is also due largely to the activity of the caterpillar. Eggs and caterpillars are distributed by artificial means, as on cars, automobiles, etc.

Treatment. - The conspicuous color of the egg mass and the long duration of the insect in this stage make this the most vulnerable stage to combat. The masses may be collected and burned, or, as is most generally done now, they may be treated with a coating of creosote. In the woods, extreme vigilance is necessary to find these clusters. All brush, especially near stone walls, should first be removed. 
Several methods of destroying the caterpillars are employed. During the month just after hatching - from the middle of May to the middle of June - the trees may be sprayed effectively with arsenate of lead. This spray will not injure the tenderest foliage when diluted with water in the ratio ten pounds to one hundred gallons of water. One method of preventing the caterpillars from climbing trees is to scrape the bark in a belt around the tree and apply a coating of tanglefoot. The caterpillars cannot cross this band if it is stirred up every week or ten days to keep it sticky. Another kind of band, used as a trap, consists of a strip of common burlap a foot wide which is tied around the trunk with a single string at its middle and about four feet from the ground. The upper part of the burlap is turned down over the twine, thus making a double fold around the tree. The caterpillars eat the foliage in the night, crawl down the tree and conceal themselves on the burlap through the day. Squads of men going through the forest crush them in these hiding places. Burlap bands are being used less and less, due principally to the expense involved.

Rubbish heaps and all breeding places should be destroyed. An effective method of protecting conifers is to remove all hardwoods, especially those with simple leaves. A number of parasitic insects have been introduced from Europe and set free in Massachusetts, and it is confidently hoped that they will in time obtain the mastery.

The gipsy moth has spread constantly, year by year, despite all the efforts that have been made to control it. At one time it was nearly under control when unfortunately Massachusetts politics interfered, appropriations for suppressing the insect were cut down and the evil spread unhindered. It now appears throughout eastern and central Massachusetts, through southern Maine and the southern half of New Hampshire, throughout Rhode Island and eastern Connecticut. The United States Department of Agriculture is now coöperating with the various states mentioned in an attempt to suppress this evil, and is laying special emphasis on the introduction of foreign parasites and enemies. 


\section{BROWN-TAIL MOTH (Euproctis chrysorrhoea).}

Form of Damage. - Like the gipsy moth this insect defoliates both forest and fruit trees, but apparently does not attack conifers. Of forest trees, it prefers oak, maple and elm. Besides the damage to trees the hairs from the caterpillars are exceedingly irritating and poisonous to some people, and often cause severe illness.

Appearance. - The most conspicuous indication of this insect's presence, and one which distinguishes it at once from the gipsy moth, is the webs on the terminal twigs in which the partly grown caterpillars spend the winter. The male moth is pure white with a wing spread of about one and a fourth inches, and has a conspicuous reddish-brown tuft at the tip of the abdomen from which it gets its name. The female is somewhat larger, but is the same color as the male except that the tuft is larger and of lighter color. The full-grown caterpillars range from one to one and a fourth inches in length.

Life History. - The winter is passed in the partly grown caterpillar stage as indicated above. These begin work early in the spring feeding downward from the tips of the branches, and leaving the naked twigs and their gray tents as evidence of their sojourn. When numerous, they will devour green fruit as well as leaves and buds and blossoms. A number of caterpillars frequently pupate in a common cocoon of dry leaves at the tips of the branches and sometimes in masses under fences, clapboards or on the trunks of trees. They pupate in June usually. Their webs may be distinguished from those of the tent caterpillar which are always at the forks of the branches. The eggs are laid during July in masses composed of two hundred to three hundred, usually on the under side of leaves. These eggs which are covered with fine brown hairs hatch in a short time and the young marauders live on the foliage until it is time for them to make their winter tents.

Treatment. - As their hibernating nests are conspicuous, 
particularly in early spring, they can then be cut off and burned. The species is killed also by spraying with arsenical mixtures. The range of this insect is similar to that of the gipsy moth, but is more widespread, extending farther west and north.

\section{The Larch Sawfly (Nematus erichsonii).}

This insect is distributed through the range of the tamarack, on the leaves of which it feeds. Complete defoliation often results from the attack of the sawfly, and the tamarack over a large region may be killed. In the early 8o's, great destruction of the native larch was caused in New England. The insect will also attack the European larch.

The following account of the appearance and life history of the insect is quoted from an article by Dr. C. Gordon Hewitt, F.E.S., Dominion Entomologist of Ottawa, Canada, and published in the Report of the Canadian Forestry Convention for I9I I :

"The habits and life history of the insects are such as to render it injurious in both the caterpillar or worm stage, and the fly stage. The winter is passed by the larva in a cocoon under the turf round the base of the tree. In May the larva transform into the perfect insect and the flies begin to emerge during that month. An interesting feature of the productive powers of the larch sawfly is that it can reproduce parthenogenetically; this means that the females can deposit eggs which, although they have not been fertilized by the males, are not infertile but produce larvæ of the sawfly. This interesting phenomenon, which also occurs in certain other insects, is of importance as the productive power of the species is increased when the necessity of the female meeting a male is dispensed with. Shortly after emerging the females begin to deposit their eggs. The eggs are always deposited in the terminal green shoots of the larch and never on any other part of the tree. In laying the eggs the female sawfly makes an incision in the tender stem of the shoot by means of a pair of saw-like instruments at the end of the body, and into this incision the egg is pushed. The eggs are usually deposited in a double row in the shoot and as many as 
forty or fifty eggs may be found on a single green shoot. As they are usually deposited along one side of the shoot the injuries inflicted by the saw-like appendages of the female cause the shoot as it grows to curl. In many cases the injuries are so severe as to kill the shoot and the presence of the dead and reddish-brown shoots often serves as an indication of the presence of the insect. In about a week to ten days after deposition the eggs hatch and the young pale-green caterpillars emerge and immediately begin to feed upon the green verticles of the leaves. As they become older they feed in masses, sometimes as many as fifty or sixty caterpillars in a single cluster and, feeding in this manner, they completely strip the branches of all green leaves which gives the tree a winter aspect in the middle of summer. The caterpillars are full grown in three to four weeks and, during their lives, they cast their skins five times. ... The full-grown caterpillar measures about two-thirds of an inch in length. Its color is bluish or glaucous green, the lower surface being a lighter green. The head and three pairs of thoracic legs are jet black. It also possesses seven pairs of abdominal legs. When the caterpillars are full-grown they either crawl down or drop from the tree and penetrate the turf round the base of the tree to the depth of a few inches. There they spin a brown oval cocoon about two-fifths of an inch in length, and in this the winter is passed, the caterpillar transforming into the perfect insect in the following year as previously described. The sawflies are black with the middle portion of the hind body or abdomen a bright resin red, and they measure about half an inch in length."

Treatment. - The prevention of the ravages of this insect must be left to natural factors, especially to various parasites which prey upon the sawfly. So completely does an outbreak of the sawfly destroy the larch, that the supply of food for the insect becomes scarce and it falls a victim of its own rapacity.

In Europe birds have been found to be important enemies of the sawfly, and special steps are taken to increase their numbers, but this will hardly be practicable as yet in this country, as the native larch is most abundant in sections where only extensive methods of management can be applied. 
The Pine Sawfly (Diprion simile). ${ }^{1}$

Dr. W. E. Britton, State Entomologist of Connecticut in I9I4, first discovered the presence of the insect in the United States. It must have been introduced on nursery stock from Europe, where it is one of the most injurious sawflies. The insect is now established in Connecticut, New York and New Jersey.

Form of Damage. - The larva feed on pine needles and may completely defoliate trees. Probably all species of pine can be attacked.

Appearance. - The insect is most easily recognized in the larva or caterpillar stage. The caterpillars are greenish yellow in color with black head and a double stripe of brown on the back. Their length ranges from one to one and an eighth inches.

Life History. - The eggs are laid by the sawfly in slits along one edge of the needles. From these eggs larva hatch and feed on the foliage. There may be at least two broods of larva in one season. The summer brood of larva make cocoons on the branches of the tree, while the second brood deposit their cocoons in the litter beneath the tree. In the spring sawflies emerge from the cocoons.

Treatment. - No practical method of combating this insect in the forest is known. Several active parasites have already been found in this country. It is still too early to say how injurious the pine sawfly will become.

\section{Elm-Leaf Beetle (Galerucella luteola).}

Form of Damage. - The elm leaves are skeletonized and this gives the crown of the tree a brown, scorched appearance which detracts greatly from its beauty. If a tree is defoliated two or three seasons in succession it is sure to die. The elms of southern New England, especially those in cities and towns, have suffered tremendously from this pest.

1 See Fifteenth Report of the State Entomologist of Connecticut, p. Ir8. 
Appearance. - The damage is always done before its extent is apparent. By the middle of summer the infested trees are entirely defoliated. The beetle is about one-fourth inch long with head and wings marked with yellow. The yellow eggs are usually deposited in irregular rows on the under surface of the leaf. The full-grown caterpillar is about one-half inch long with a broad, yellowish stripe down the center and a narrower stripe of the same color on each side. The pupa is a bright orange yellow about one-fifth of an inch long.

Life History. - The transformations of this insect follow each other so rapidly that unless one knows just what to look for he is apt in combating the pest to do the wrong thing at the wrong time. The beetles pass the winter in sheds, attics and in other sheltered places and emerge in the first warm spring weather. Late in April or with the appearance of elm leaves the beetles fly into the trees and begin defoliating. Before the latter part of June when the eggs are all laid, much damage may be done. Early in June the young grubs hatch out and begin to eat the leaves. They complete this stage in about three weeks and then pupate, developing into the beetle in a few days. As there are usually two broods in a season the foliage may be destroyed, renewed, and again destroyed, which is very weakening to the tree.

Treatment. - Many of these insects are killed by a fungus and by parasites. The success of any treatment depends on accurate observations. Much can be accomplished by spraying the under side of the leaves in early spring with arsenical poisons when the grubs begin to feed. There should be no delay in this work. When the caterpillars crawl down the trunk, large numbers of them may be killed by spraying with kerosene emulsion, soap solution or by pouring boiling water on them. Banding the trees is of no use in combating the insect since it works down the tree instead of up. The successful method of fighting the elm-leaf beetle cannot be used in forestry work on account of the expense. 
Forest Tent Caterpillar ${ }^{1}$ or Maple Worm (Malacosoma disstria).

Form of Damage. - A few years ago this insect caused a great deal of damage throughout the northeast by defoliating sugarmaple trees. Many sugar orchards were completely stripped of leaves by the caterpillar, resulting in the death of numerous trees, and an injury to sugar productivity which has not yet been fully compensated, after a period of ten years. The defoliation occurs for the most part in the early summer. While the insect prefers the foliage of the maple, it does not confine its ravages to this tree, but eats the foliage of oak, linden, locust, peach, plum, cherry, apple, elm, poplar, birch and some of the shrubs.

Appearance. - The damage is done by the caterpillar which is blue-headed, with a line of silvery diamond-shaped spots down the middle of the back. When not feeding, they assemble in clusters on the sides of the larger limbs and trunks. This insect may be distinguished from the common tent caterpillar, Malacosoma americana, by the fact that it does not spin a conspicuous web tent as does the latter. The egg belts containing about i 50 eggs encircle the slender twigs and have a brownish protective covering. The white or yellowish-white cocoons are spun in the leaves on the tree or on the ground, in crevices of the bark, under stones, in fence corners, etc. In the cocoons are dark-brown pupas. The moths are light, buff colored and active. The males are smaller than the females and of rich coloring.

Life History. - This insect passes the winter in the egg stage as a well-developed larva. In the warm weather of spring the young caterpillars emerge and await the unfolding of the leaves. As the young increase in size they molt leaving their cast-off skins on the bark. The larva are found in clusters on the limbs when not feeding. When the limb is jarred they are easily knocked off. Early in June when the caterpillars are

1 See New York State Museum Memoir 8, "Insects Affecting Park and Woodland Trees." 
nearly full grown they may be seen in great numbers crawling over walks, piazzas and the sides of buildings. The insect remains in the pupa stage about two weeks, and emerges as moth about the last of June or in July, when the eggs are deposited.

Natural Enemies. - This insect is sometimes attacked by a fungous disease. It is also a favorite item of diet for robins, orioles, chipping sparrows, catbirds, cuckoos, cedar birds and nuthatches.

Treatment. - Something can be done by collecting and burning the egg masses in winter, but the method is of no great value. Many of the caterpillars can be brushed off the trees and crushed, or burned on the trees with a torch. Bands of tar paper or fly paper tied around the trees prevent the caterpillars from ascending. The masses of caterpillars on the trunks can also be killed by spraying with kerosene emulsion, whale-oil-soap solution (one pound to four gallons), or with the ordinary poisonous insecticides, as the arsenical sprays. In June great numbers of cocoons can be collected with little trouble. In some New York towns rewards have been paid the school children for collecting these cocoons. These methods are too expensive for use in forestry, except in the care of valuable sugar orchards.

\section{The June Bug (Lachnosterna). ${ }^{1}$}

The June bug as a forest pest has gained prominence in New England only in the last few years since forest planting has been started on a large scale. For years it has been recognized as injurious to certain crops, particularly grass, its ravages being much worse in some localities than in others. During the last three years the attention of foresters has been directed to this bug because of the havoc it has wrought in certain nurseries.

Appearance. - The June bug in the pupa stage, as a whitish grub, eats the roots and bark on the roots of seedlings, trans-

1 This is the generic name. There are ten or more species of the genus found in New England. 
plants, and trees in plantations. Only the smallest and tenderest roots can be consumed, but larger roots, up to at least one-eighth inch in diameter, may be partially or completely stripped of their bark. The greatest damage is to seedlings where the entire root system may be consumed by this grub. Three- and four-year old transplants in nurseries may lose all but a single main root and become so weakened that finally they die. In plantations the loss is less noticeable than in nurseries. No thorough study of the loss has been made so far as is known. Often the slow and stunted growth of certain trees may be traced to root injuries due to this insect.

Only plantations in open land not recently under forest are liable to the injury, as the June bug is not found commonly in forested soil.

When once familiar with its devastations, its presence can be readily detected. In seedbeds of very young plants the grub often eats off the roots and draws the stem of the plant into the ground leaving the top to rest on the surface. When these tops are taken out the roots are found to have been eaten entirely away. Older seedlings and transplants show the injury by wilting and turning yellow, when their tops are pulled up easily. An uninjured plant being held by its small roots offers resistance when pulled.

Life History. - The June bug appears in the beetle form during the latter part of the spring. In June or July it lays eggs in the ground, one to six inches below the surface. Open land and fields of old sod are its habitat. In the daytime the beetle prefers to remain in trees and at night to fly out into the adjoining fields where it lays its eggs. Fields bordered with shade trees which offer a shelter in the daytime are pretty sure to furnish numerous June-bug grubs. The eggs soon hatch into slender, whitish grubs, which at first are less than one-fourth of an inch in length; sometimes they grow to be over one and a half inches long. It is in this grub or pupa stage that the injury is done. The grubs are sluggish, work slowly, and never appear above ground. They do not remain at one depth, but in sum- 
mer work from near the surface to ten or twelve inches below; in late fall and winter they bore much deeper and remain there until frost leaves the ground. They work at night and will be found nearer to the surface then than during the daytime.

In August or September the grubs begin to change into beetles, and as such remain in the ground until spring, when they emerge and are a familiar sight. Many remain in the grub stage for more than one season, and do not change into beetles until the second August or September. This gives them a longer time to feed, and as they grow in size they become more injurious. Often they work until the ground is frozen and start in early again when it thaws in the spring.

Treatment. - A simple and cheap method of combating the June bug has not yet been worked out. At present in forest nurseries, when the grubs are found to be abundant, they are dug out by hand, the spot where they are working being easily determined by the appearance of the injured plants. This method can be used in transplant beds, but in thick beds of seedlings it is hardly practicable. Where land known to be infested with the grub is to be used for a nursery or a plantation, it is a good thing to turn in swine. They will uproot and eat the grubs thoroughly. After that the field can be used safely.

Inasmuch as old sod and grass land is preferred by the beetles as a meeting place, such land should not be put into nursery use until after a year or two of preliminary cultivation.

In the case of a similar species, trapping and killing the beetles has been tried in Europe sometimes very successfully. In one section where the insects abounded, the cost of planting was in eight years reduced from the abnormal figure of $\$ 53$ per acre to between $\$_{3}$ and $\$_{4}$ per acre. In this case trap trees of a species which the beetles preferred were left in the open, and then the beetles, when in the trees, were shaken down upon sheets and destroyed. 
B. FUNGI.

\section{Chestnut Bark Disease (Diaporthe parasitica).}

Without doubt this is one of the most threatening fungous diseases which ever attacked a forest tree. It is one of the few diseases which cause the certain death of healthy, vigorous trees. So virulent is it that the chestnut, on which it preys, has been practically exterminated in portions of New England, New York, Pennsylvania and New Jersey. The worst injury has been done on Long Island, and in the vicinity of New York City, from which as a center it is spreading. Only since 1905, has the disease been generally recognized, and in New England it was little noticed until I907. Southwestern Connecticut is the most seriously infected region here; and in Fairfield and New Haven counties the chestnut has been nearly all killed. As we proceed from southwestern Connecticut, through that state and then into Massachusetts and northern New England, the number of infected trees is less and less noticeable. But the disease may be found practically over the entire New England range of the species.

The chestnut bark disease attacks and kills the cambium layer, which lies between the bark and the wood. This is the growing layer of the tree, and when it is girdled, death of the portion above the injured place results. As the disease is distributed by the spores (virtually seeds) which are easily blown by winds, or carried by birds, its spread is rapid. These spores cannot attack a tree except through a wound, but as every tree has many slight wounds or openings in its bark, it is rarely that a tree is exempt from the disease. When a spore finds lodgment it quickly develops a fungous growth spreading in the cambium layer at first in a somewhat elliptical form until finally it girdles the branch or trunk. It may also work up and down the trunk.

Trees of all ages from the young sprout to those of lumber value are attacked. In an old tree with thick bark the disease usually enters at the top and works downward. On young trees, 
with easily wounded bark, the disease may start at any point. When old trees are injured by fire, even to a very slight extent, the disease will find entrance at the base.

There are several ways in which the work of this fungus can

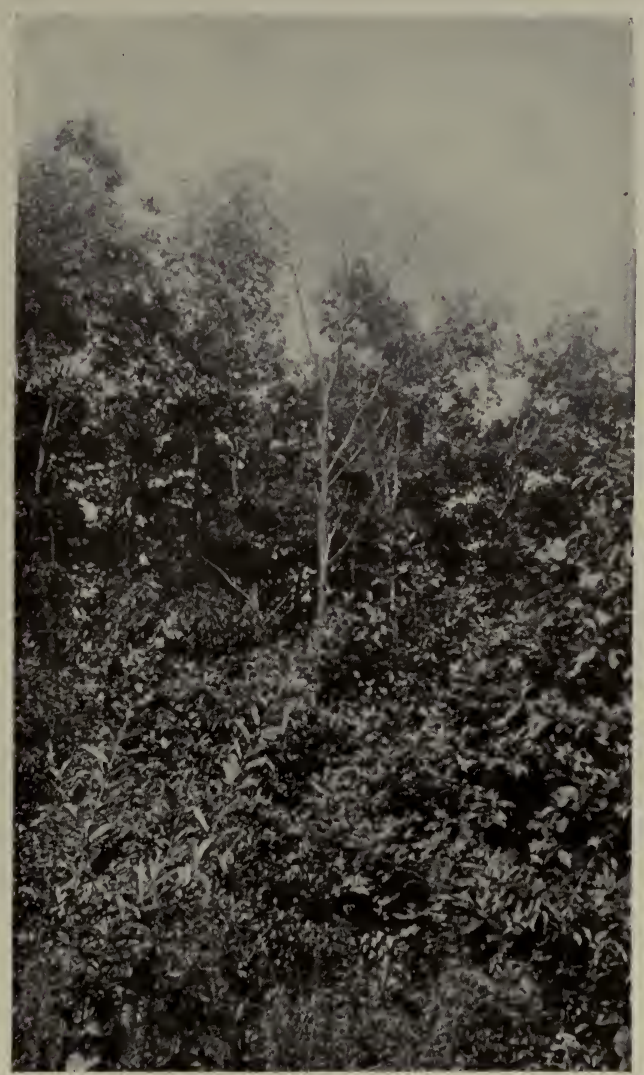

Fig. 45. - A forest-grown chestnut on the edge of a recent cutting killed the previous season by the chestnut bark disease.

be recognized. The spots or cankers are apt to have an elliptical form, and the bark over the injured part is somewhat reddish and sometimes appears sunken. Pustules, of a yellowish or orange color, containing the spores can often be seen pro- 
truding through the bark. These fruiting bodies are the only part of the fungus visible to the naked eye, and usually occur in the crevices of the bark. Often they may be seen-near the base of a mature tree, which to the observer appears otherwise sound. These pustules are an unmistakable sign of the disease. When the trees are in foliage, diseased individuals may be recognized by their bare branches, or branches with partly shriveled leaves or burrs. Frequently half a tree or a limb here and there may be dead, and the remainder of the tree be in full foliage.

Another sign of the disease is the presence of thrifty oneyear sprouts on the trunks of fairly large trees. Usually on close examination near or above these sprouts can be found a spot with other characteristic symptoms.

As yet no method of successfully combating the chestnutbark disease is known. When a tree in the forest is attacked it is virtually doomed. In the case of valuable shade trees, cutting out the infected parts has in some cases been successful. The exposed face of the cutting must be covered with paint or tar. If this is done and all infected spots are completely removed, the tree may be saved. Such treatment is, of course, out of the question in handling forests on account of the expense. The fungus cannot be reached by spraying as it is protected by the bark of the tree. Several pathologists who have studied its ravages, predict the extermination of the chestnut unless something unforeseen stops the disease.

If all the infected trees, in a section where the disease is just beginning to spread, could be cut down and the brush and infected bark burned, this evil might be checked in that locality, but unfortunately all injured trees cannot be found. In a forested region it is doubtful if any method will be successful.

\section{RED Rot (Trametes pini).}

Trametes pini is a fungus attacking practically all the important conifers of New England; red and white spruce, white pine, hemlock, larch and balsam. Von Schrenk considers larch most 
susceptible to its attacks, the spruces next and the balsam least. It is a common and extremely dangerous disease, entering living trees, old enough to form heartwood, through wounds or any opening in the bark and continuing to grow even after the tree is dead where moisture conditions are favorable. From the point of entry it spreads up and down the trunk, working both in the heartwood and the sapwood, except in white pine, where it flourishes only in the heartwood. Finally even the roots and the larger branches may be infected. As the wood is not entirely destroyed by the fungus the tree remains standing, but is so weakened that eventually it is broken off by a strong wind. The lumber value of the infected portion is entirely destroyed.

The fungus can be identified because the diseased wood is honeycombed and is filled with small holes. These holes often have a shiny white lining, and between the holes will be thin layers of wood only partially destroyed. The best outward indication of the disease is the pitch which exudes on the bark, sometimes in considerable quantities.

The fungus ${ }^{1}$ is spread by spores blown by the wind.

These come from fruiting bodies located usually at old knot holes and on the stubs of dead branches, although on spruce at least the fruiting bodies may form in dry crevices of the bark.

The light reddish-brown color of the lower surface of the fruiting bodies is characteristic, but their form varies from a bracket shape to that of a plate, following the configuration of the trunk or branch.

There is no practical method for use in forestry of combating Trametes pini. Diseased trees, as soon as discovered, should be cut and utilized, but as such trees are often scattered it is not always possible to remove them. If all diseased trees could be discovered quickly and removed the loss from this fungus would be greatly lessened. Since the disease is worse in crowded

1 A detailed description of Trametes pini will be found in U. S. Division of Vegetable Physiology and Pathology, Bull. 25, entitled, "Some Diseases of New England Conifers," by Von Schrenk, and Vt. Exp. Sta. Bull. 19r. The Red Rot of Conifers, by F. H. Abbott. 
stands thinnings are advisable to reduce the proportion of diseased trees and strengthen those that remain. The practice which has been inaugurated by some lumbermen of leaving for seed purposes trees diseased with red rot is unsafe because it tends to perpetuate the disease, not through the seed of the old trees, but by the fungus upon them.

\section{Polyporus schweinitzii.}

This fungus is common on balsam, red and white spruce, white pine and arborvitæ; it attacks living trees of all ages and causes extensive losses.

The fungus first enters underground, through the root system, but soon spreads to the trunk, up which it may extend its growth for forty feet or more. Diseased trees are ordinarily found in groups, because the fungus spreads from tree to tree through the ground. As the disease progresses the root system and trunk become weakened and finally the tree is uprooted or broken off near the base.

Like Trametes pini this fungus destroys the lumber value of the infected portion. Probably the greatest loss is found in the balsam, of which species nearly all the older trees are attacked.

Wood attacked by Polyporus schweinitzii ${ }^{1}$ has a cheesy consistency, is yellowish in color and is easily powdered when dry. In the last stages of decay it is very brittle. These characteristics of the diseased wood and the large, brightly colored fruiting bodies are the best means of field identification. The fruiting bodies when young are a yellowish-brown color, but in a few days become reddish brown. The underside is sometimes rose colored, and if bruised, quickly turns dark red. They take the form of brackets, ordinarily several in number, fastened one above the other, usually arising from the roots of the tree, near the base of which they may be seen growing, in the months

${ }^{1}$ For a more detailed description of the fungus see Bull. 25, U. S. Division of Vegetable Physiology and Pathology, entitled, "Some Diseases of New England Conifers," by Von Schrenk. 
of July and August. Occasionally the fruiting bodies are borne on the trunk of the tree. Fully grown specimens range from four inches in diameter to about fourteen inches.

On account of its spreading underground, and entering the tree unseen, the fungus is hard to detect, until in the advanced stages, and hence difficult to combat. A European practice is to surround infected trees and groups with a deep trench which prevents the further spread of the fungus. Such a method is as yet impracticable in New England, and the best that can be done is to utilize diseased trees before their value is entirely gone.

\section{The White-pine Blister Rust, or European Currant Rust (Peridermium strobi). ${ }^{1}$}

Other species of Peridermium have been common in New England on pitch pine and Scotch pine, as well as other plants, but until recently the white pine was exempt.

As a result of the growing enthusiasm for forest planting which has spread so rapidly during the past few years, a large quantity of nursery stock was imported from Europe: In June, I909, some of the stock thus imported into New York state was found to be infected with this fungus and on examination it was discovered that stock imported into other states was likewise diseased. In fact the fungus has been found on trees imported several years previous to I909. In nearly all cases the diseased stock has been traced to one European nursery, that of J. Heins Söhne, of Halstenbek, Germany.

The disease has spread widely from several of the diseased plantations and many new sources of infection have been located in the last two years as a result of systematic search in the eastern and northern states. The disease is now known to be scattered (on currants at least) over New England with the exception of northern New Hampshire and Maine. Serious infections have been located in New York, Michigan, Minnesota

${ }^{1}$ See U. S. Department of Agriculture Farmers Bulletin No. 742, "The Whitepine Blister Rust," by Perley Spaulding. 
and Canada, while diseased pines have been found in New Jersey, Pennsylvania and Ohio. ${ }^{1}$

In Europe this species of Peridermium has long been common on Pinus cembra, or stone pine, which is the European variety of white pine. Of late years with the multiplication of plantations of our American species throughout Europe the disease has attacked these. In some regions it has caused much havoc, especially in nurseries. In certain places, notably, in Holland; at Oldenburg, Germany; and at Moscow, Russia; the disease is so serious that the cultivation of white pine has been abandoned. Young trees are killed outright by the disease, and the small branches of large trees are killed.

The affected seedlings have a peculiarly stunted appearance, and the stem is abnormally enlarged and swollen in places. New growth is very short. The orange fruiting bodies on the stem, which, however, occur only in the spring, furnish the best means of identification.

This fungus is one stage of the blister rust of currants and gooseberries known as Cronatium rubicola. In other words, like the wheat rust, cedar apple, and many similar fungi, it is a fungus which requires two hosts to complete its life history. The spores from an infested currant or gooseberry bush are blown to a neighboring white pine tree. Here they germinate and the mycelium vegetates in the inner bark until the second spring after infection. Then the diseased bark thickens and the stem becomes swollen. The fruiting bodies break through the bark sometime between the middle of April and June, according to the locality and the season. They are of a light, orange color and project from the stem about one-eighth of an inch. They soon break open and the spores are scattered by the wind. After the spores are gone, the remains of the fruiting bodies are washed off, leaving empty fissures in the bark to show where they were. The spores from the pine, if they chance to fall upon currant leaves, infect them in turn. On

${ }^{1}$ See Bull. 15, Conservation Commission, State of New York, "The Pine Blister," by B. H. Paul, State Forester. 
these leaves in fifteen to forty days new fruiting bodies are formed, the spores of which may infect either currant or pine. The spores produced on the pine cannot directly infect pine, but must first infect currants. On the pine the fungus remains alive as long as the stem on which it grows; but in the currant it is not thought to be perennial.

A second kind of spores produced on the currant and gooseberry bushes are able to infect other currants and gooseberries. In this way the disease may travel from currant to currant for many miles in one season.

Definite knowledge as to how far spores may travel from currant to pine, from pine to currant and from currant to currant is still lacking. The best opinion indicates that distances of one-eighth to one mile render infection difficult and very likely impossible in the case of currant to pine and pine to currant. Spores carrying from currant to currant may presumably go farther.

The best means of combating the disease are:

(I) To exterminate currant and gooseberry bushes in the neighborhood of plantations.

(2) To stop making pure white pine plantations, but instead plant mixtures of white and Norway pines.

If the white pine is later on kilied by the blister rust there will still remain a full stand of Norway pine.

(3) To inspect annually for several years all white pines located near infected currant bushes and burn all that show infection.

White-heart Rot. False-tinder Fungus, Poplar Disease (Fomes igniarius). ${ }^{1}$

The principal diseases of deciduous forest trees are caused by a group of fungi which grow in the heartwood of trees. This species is characteristic of the group. It is impossible to recognize the presence of the fungus during the early stages of the

1 See Bull. 149, U. S. Department of Agriculture Bureau of Plant Industry. "Diseases of Deciduous Forest Trees." 
disease, in fact not until the fruiting bodies form on the exterior of the trunk. When these appear the tree is thoroughly diseased for two or three feet above and below the fruiting bodies. In its final stages the heartwood is completely destroyed so that the tree is weakened and liable to be broken off by windstorms. On examination the center of the tree will be found of a pulpy consistency definitely limited on the outside by one or more narrow black layers.

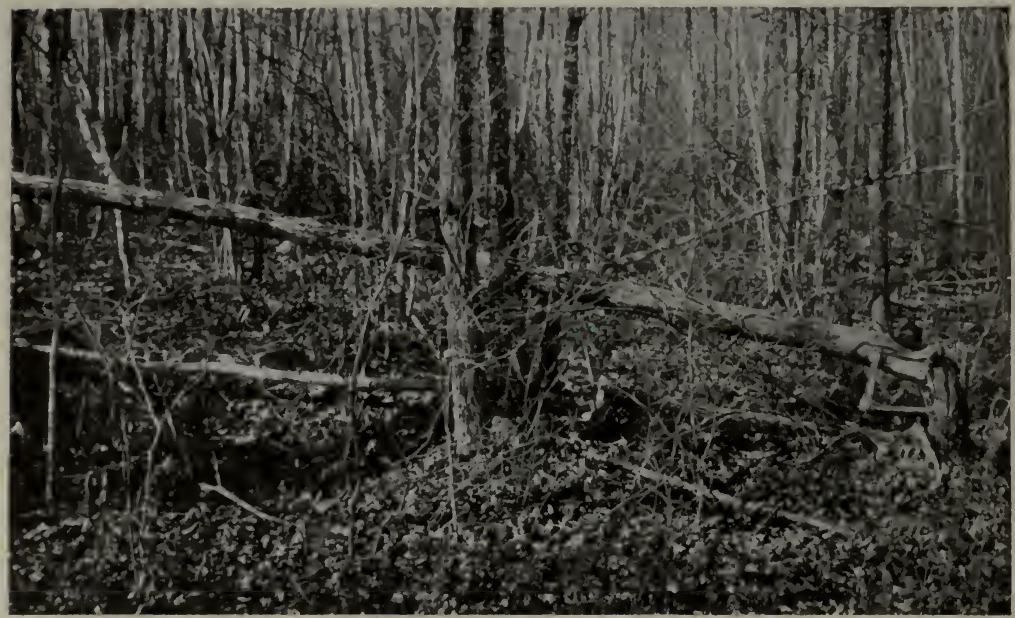

Fig. 46. - The fallen chestnut, now 6 inches in diameter, was formerly injured by fire which allowed a fungus to enter. This fungus hollowed out the stem for over 2 feet from the ground leaving untouched a mere shell of wood on the outside. The first heary wind broke the tree.

This disease causes greater damage to poplar than to other. trees, but is by no means confined to the poplar. It occurs on more species of broadleafs than any similar fungus. It has been found on poplar from Maine to Oregon and from Canada to New Mexico, and undoubtedly exists wherever poplar lives. In New York and New England the beech also is very commonly affected.

It is one of the most conspicuous of our so-called punks, or shelf fungi, which grow upon living trees. The fruiting body is 
commonly more or less hoof shaped, the thickness being about equal to the width. The upper surface, at first smooth, becomes concentrically marked with age. They grow to great age as indicated approximately by the number of layers. The lower surface is gray to reddish brown; the edge yellowish brown.

The spores enter the tree trunk through some wound, as an old branch stub. The fruiting bodies usually form at the point of original infection. It is not uncommon to find a dozen of these bodies on the trunk of an aspen. Examinations by Spaulding have proved that the fungus continues to thrive after the death of its host.

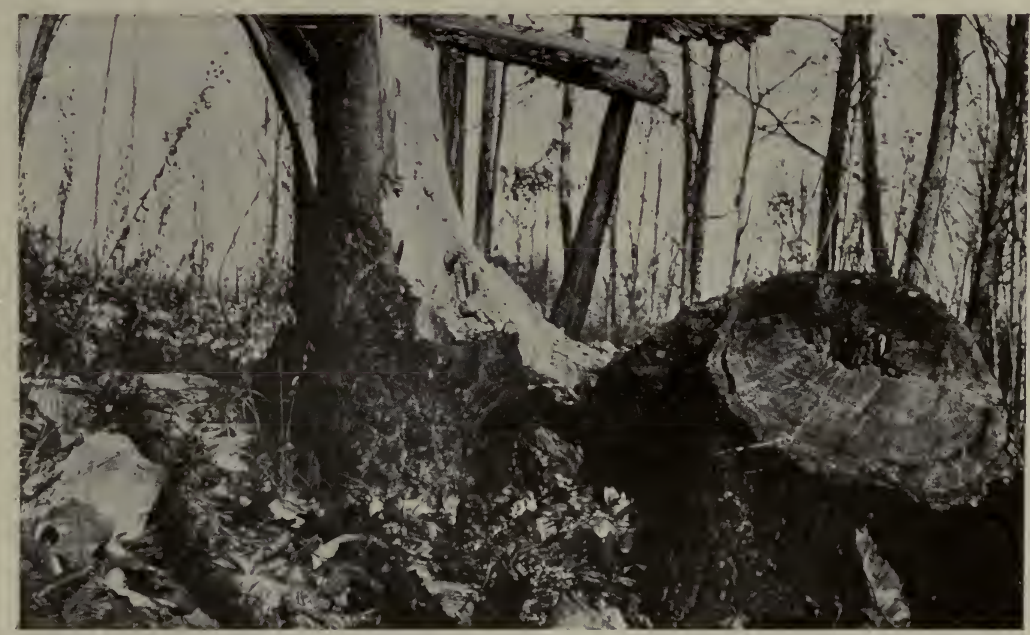

Fig. 47. - An oak broken off by the wind. The base of the tree was honeycombed by a fungus which entered through old fire scars. Wind cannot uproot an oak but frequently breaks off weakened trees.

A tree affected with white rot may live for a number of years, especially such long-lived species as oak and beech. But with such trees as aspen where the disease may encroach upon the sapwood, the trees may be killed by the disease. The death of trees is a minor result of the disease compared with the great destruction of wood which it causes.

Two methods of prevention are possible: one consists in the 
prevention of wounds, and the other in the removal of the sources of infection. The former method is impracticable except in the case of ornamental trees. Infected trees should always be removed as soon as the disease is apparent. Usually this will be soon enough to save part of the wood or lumber. It is of no avail to destroy the fruiting bodies alone as the fungus will continue to grow in the tree and produce other punks.

\section{White Pine Blight.}

It is now plain that this injury is not due to any insect, and apparently not to any fungus, but probably is caused by unfavorable weather conditions, such as winter injury due to extremely cold weather without much snow, or to extremely dry summers, or a combination of the two. This blight is characterized by the death of the end tips of the needles, from one-fourth to one-third thereof turning a bright reddish brown. Sometimes the whole needle dies, giving the tree a brown appearance, but the tip of the needle is always affected first. Trees that have been attacked look as if they had been scorched by fire. Young trees are more susceptible to this form of injury than old ones. On young trees, often the needles will wither and curl up much as if scorched, and very frequently the twigs also are killed back. In Maine ${ }^{1}$ in exposed localities, acres of young trees which were apparently healthy in the fall of 1907 , were entirely dead by the last of May, I908. Usually the injury was confined almost entirely to the north and northwest sides of the young trees. Injury here was not limited to pines, but spruces, firs and other conifers showed the same trouble and in the same manner.

In most parts of New England the disease was first noticed in 1907. It was particularly widespread during the summer of 1907 , and many feared the pine forests were doomed. It was thoroughly advertised throughout New England and many young pine stands were unnecessarily cut. Few trees died,

1 See Report of Forest Commissioner of Maine, 1909, pp. 22-24. 
however, and conditions were much better the next year. By r 909 it had practically disappeared in most sections of New England, but curiously enough was much worse in certain localities, as, for example, in the region about Burlington, Vermont. 


\section{CHAP'TER VIII.}

\section{FOREST FIRES.}

THIs chapter deals with forest fires in general. In Volume II under each region the particular fire problems of that region are discussed at length.

\section{Kinds of Fires and Damage Done.}

American forests have suffered more from fires than those of any other country and few regions have entirely escaped. The character of these fires and the damage done by them depends very largely upon the type of forest. It is only in coniferous forests that fires assume immense proportions and become entirely uncontrollable and for this reason Maine, with its rolling hills of spruce, has from its earliest history suffered more from fires than most parts of New England. In these coniferous forests, fires often sweep through the tops of the trees, and, driven along by strong winds, advance over several miles of forest in a day. These are called "crown fires." Most of the evergreen trees are killed; but here and there a clump sometimes escapes. The fire may jump from one side of a ravine to the other leaving the trees in the bottom uninjured, and while the hardwoods adjoining conifers are usually severely scorched, large areas of these deciduous trees form an effective check to the spread of the flames in the tops.

The dry sand plains of Plymouth County, Massachusetts, have been an incessant breeding ground for forest fires as the cranberry growers of the region have, until recently, taken little care for the forest. Fires burn over thousands of acres annually and the result has been that the forest growth has continually deteriorated until it is of very little value. 
The hardwood forests of Connecticut and Massachusetts are largely composed of oak, which has a tendency to retain its foliage over winter. The result is that in the dry season, which usually comes in April and May, these leaves form a ready tinder for the innumerable little fires of the region. These fires confined to the leaves and underbrush are called "surface fires." The birch and maple of Vermont and New Hampshire shed their leaves in the fall; they are matted down and rotted by the winter

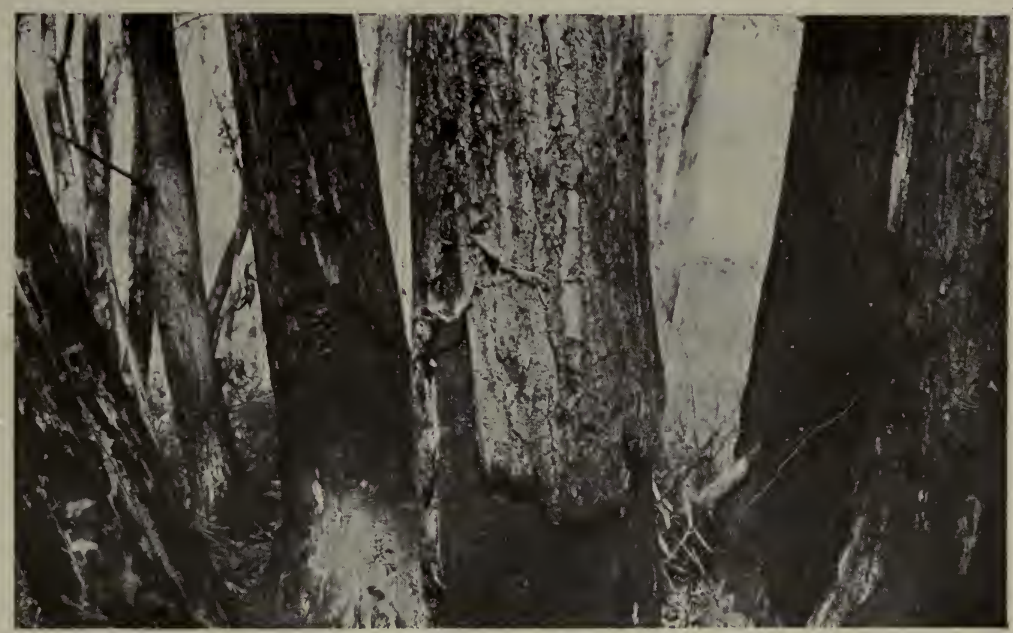

Fig. 48. - A group of chestnuts killed outright by surface fires.

snows, which are much heavier than in southern New England, and the result is that these states, with few unbroken areas of conifers, are more free from forest fires than any other part of New England.

These surface fires seldom kill the trees of a forest outright, but wound them so severely that they become infested with fungous diseases, make little growth, and eventually die. The severity of the wounds inflicted depends very largely upon the strength of the wind at the time of the fire, the amount of inflammable material on the ground, and the kind and size of trees in the forest. With a strong wind the flames often lap around the trunk of a 
tree and, in the case of a conifer, leap into the top. Some farmers claim that annual fires are a good thing, because the ground is thus kept free of material which would make a really hot fire. This, however, is not true, for every fire, in New England at any rate, does more harm than good. Some trees, as the chestnut, are much more easily damaged by fire than others, like the oak, hickory, and birch; and practically all trees are more tender in youth than later when the bark has thickened.

Besides the crown fire which leaps from tree top to tree top, and the surface fire which runs over the ground burning the litter, underbrush, etc., a third class of fire occurs in the coniferous forests of the north. In the forests composed of such trees as spruce and fir the ground is often covered with a thick layer of decaying vegetable matter, such as needles and twigs, which in seasons of drought become very dry. If a fire once starts in this "duff" as it is called, it may smolder for weeks on a small area of less than a half acre. At any time such a "ground fire" is apt to flare up, if a strong wind arises, and may become a serious surface or even a crown fire.

Besides the damage to grown trees one of the worst effects of a forest fire is the killing of the small forest seedlings and saplings. This is a damage which is often overlooked and it is more responsible for the present worthless condition of millions of acres in the United States than any other cause. Forest seedlings, especially those of the evergreens, are practically sure to be destroyed by any fire passing through them. We do not realize the relatively long time required for seedlings to grow the first ten feet in height, as compared to that of subsequent growth. It requires from ten to twenty years for most trees to reach the height of ten feet, while many suppressed spruce and hemlock are fifty years old before they reach it. The destruction of seedlings, therefore, retards the growth of the forest. It often happens, too, that the seed trees have been removed in the meantime or are killed by the same fire. In this case natural reproduction of that species will be prevented for many years and the land will either be covered with a worthless tangle of brush or be 
seeded in by some light-seeded tree, such as the paper birch or poplar, or must be planted.

The composition of a New England forest is invariably injured by fire, for it happens that the trees which first come up on burned areas in addition to huckleberry, raspberry, and other shrubs, are inferior, such as poplar, birch, and bird cherry. In northern New England these often form pure forests after a fire. Seedlings of the original conifers may finally come in and in the course

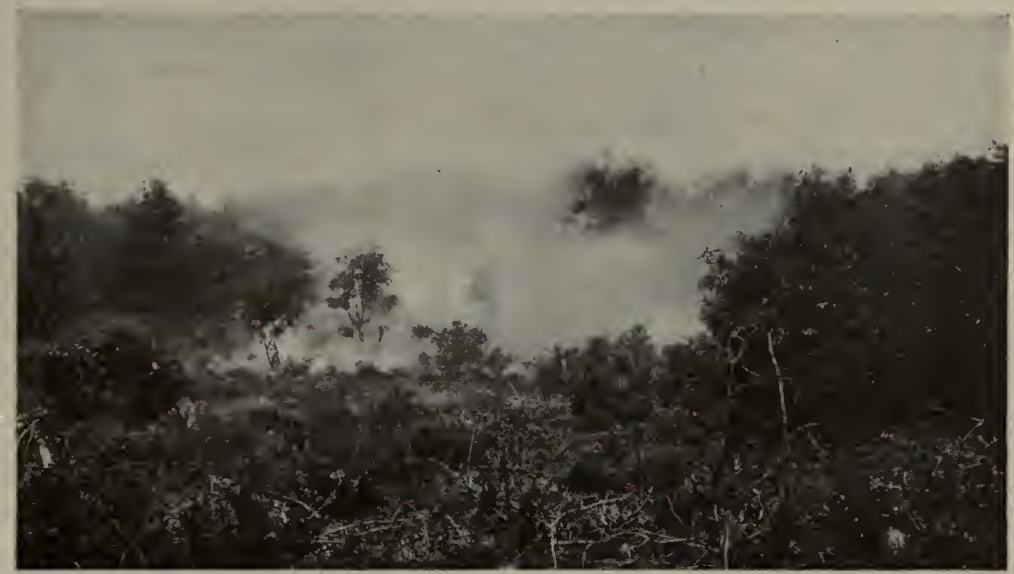

By permission of the Massachusetts State Forester.

Fig. 49. - The start of a forest fire on dry, sandy and brushy land. This could easily be put out now by a patrolman, but if left alone soon will develop into a serious conflagration.

of fifty or one hundred years the original character of the forest reasserts itself. In regions where trees sprout after being killed back by fire the character of the forest is not so greatly changed, but the quality is seriously injured.

The question often arises why it is that softwoods so frequently succeed hardwoods when the latter are cut or burned off and vice versa. It is largely a matter of seed supply, as may be easily demonstrated by proper cutting of a forest. Softwoods can be made to succeed themselves by leaving enough seed trees at the time of cutting, and this is one of the most interesting problems 
of the forester about which the various methods of reproduction described in the third chapter have developed. A careful examination of any softwood forest will reveal a great many deciduous seedlings on the ground. These, together with the old hardwoods that the ordinary lumberman would leave, are amply able to change the appearance of a softwood to hardwood forest when the former is cut off, or when the evergreens are burned.

In a cleciduous forest a surface fire may pass through and in a few hours burn out except in a few dead stumps. But in a coniferous forest, when a fire once gets in the duff, it becomes a ground fire which may smo'der for weeks or months and eventually be fanned into a serious blaze by a strong wind.

An examination of the soil just under the "duff" or leaf litter of a forest will show that the mineral particles are mixed with decomposed vegetable materials. The percentage of those materials grows less the deeper down one digs. This top soil is called humus, and it is very valuable both as fertilizer, on account of the nitrogen it contains, and because of its water-absorbing power. One of the most serious effects of a forest fire is the burning out of this humus, ${ }^{1}$ resulting in a drying out of the soil. On steep slopes, especially when this binding and absorptive agent has been removed, the soil is frequently washed off, leaving bare ledges which will probably never again be reclothed with soil. In such situations the snow melts rapidly in the spring and the water flows off immediately, so that, indirectly, these fires have an important bearing on water flow and freshets.

The most severe forest fires occur on tracts which have been lumbered, where the ground is covered with the tops of pines and other conifers. For this reason it is very desirable that these tops should be destroyed at the time of cutting, either by careful burning or by lopping off the branches so that they will at once come in contact with the soil and be rotted.

Fires are not as common in New England as formerly. The

1 Where there is considerable soil with the humus and the fire is not very severe, the humus may not burn, but the removal of the litter prevents formation of more humus. If fires are repeated the humus may entirely disappear. 
great forestry educational movement has done much to make people more careful; still there is room for a great deal of improvement, and not until the danger of fire is largely eliminated will land owners be induced to practice forestry extensively. Up to the present time, forest fire risk is so great that no insurance company in this country will insure standing timber. ${ }^{1}$ Every landowner must furnish his own insurance by introducing the preventive measures which are described under the different forest regions.

\section{Causes of Fires.}

In the different sections of the United States, the causes of forest fires differ according to the nature of the country. In large, unbroken forest areas, like the Adirondacks and the Maine woods, probably the largest percentage of fires has been set by locomotives on the railroads crossing the region. Heavy freight trains ascending steep grades are particularly apt to throw out live cinders which readily start a fire in the dry leaves and grass beside the right of way. On every railroad there are certain places where there is special danger, as, for example, on sharp curves between high banks, particularly if on a steep grade, where the engine is so much tipped that its cinders fall on the bank before they have had time to cool. No effective spark arrester has thus far gained general use, but extensive and very satisfactory experiments ${ }^{2}$ have recently been conducted with new inventions in this line by the Chicago and Northwestern Railroad at Chicago and by the American Spark Arrester Company of Indianapolis at Purdue University. The best way of preventing these railroad fires is to keep the right of way as clean as possible, and during dry seasons to thoroughly patrol it. One man in a hand car closely following every freight train during such seasons can put out a great many incipient fires. In New York the State Public Utilities Commission has required the railroads operating

1 One company has incorporated for the purpose of insuring forest property; and will start (I9I7) with headquarters at Boston, Mass., to write selected risks.

2 See Report State Forester of Wisconsin, I909-IO, p. I I9. 
in the Adirondacks and Catskills to burn only oil in their locomotives during certain months of the year.

In certain seasons in these large forest sections many fires are started by the carelessness of hunters and fishermen. Probably the most common kind of fires set by this class is due to abandoned camp fires. One cannot be too careful in the building of a fire in the woods to surround it with a ditch dug down to mineral soil, so that the fire cannot spread in the duff. When leaving a camp fire one should be certain that it is completely out. Hunters and fishermen, as well as others, also start a good

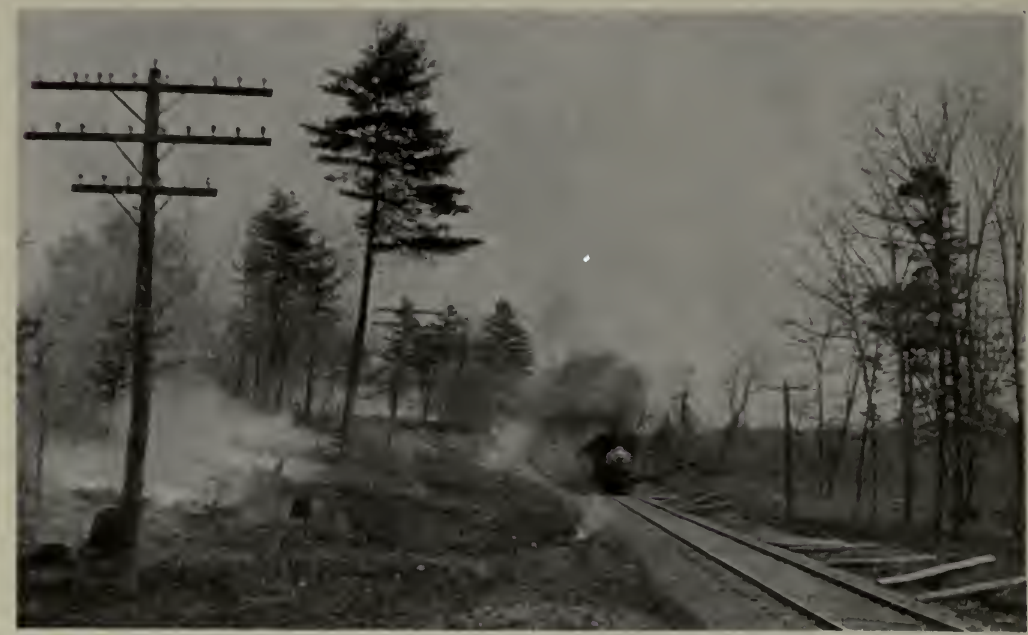

By permission of the Conneclicul State Forester.

Fig. 5o. - A train on an upgrade casting sparks on the adjoining woodland. Fortunately this has been burned over and is in condition to act as a fire line. At the left the work of burning over a strip next the track is in progress.

many fires by carelessly throwing down lighted stubs of cigars or cigarettes and burning, matches. It is hard to realize how easily a fire may be set in this way in dry weather. Hunters after hedgehogs and coons in the north and possums in the south, often start forest fires in trying to smoke the animals out of hollow trees.

In farm communities most forest fires start through careless- 
ness in burning brush. Many people seem to be entirely lacking in common sense in selecting a time and place for burning brush or rubbish. Such fires should never be started when there is a strong wind or in dry weather, wind or no wind.

In manufacturing communities mill hands in the woods on holidays and Sundays are responsible for starting numerous fires.

Besides these fires, due to various forms of carelessness, there is a class far more common than the uninitiated would suppose, namely, incendiary fires. In almost every sparsely-settled region of New England there are certain communities of run-out stock where a few characters, often of doubtful parentage, sometimes half-witted and less frequently vicious, hold the surrounding farmers in continual terror. They start forest fires either from a wild delight in seeing them burn or for spite, and, if interfered with, will wreak vengeance by next burning a barn or poisoning a horse. The better element in the community is usually too much afraid to furnish evidence that might lead to conviction. Not until this class is weeded out of our hill towns and a thrifty, self-respecting population is substituted, will the rural problem of New England be on a fair way to settlement. Here is the common field for forester and missionary; - for remunerative work, which in many of these regions can be furnished only by the forester, is a necessary accompaniment of better teaching.

In the West many forest fires are started by lightning, and occasional fires in New England arise from this cause. It is maintained that fires are sometimes started by the sun's rays reflected from broken bottles and unquestionably they have been set by fire balloons and other fireworks.

\section{Fire Prevention.}

Forest fires spread very rapidly if there is any wind, with an ever-increasing front, so that each hour wasted in attacking them increases many times the difficulty and expense of extinguishing. The most efficient method of preventing damage by forest fire is, therefore, to provide some means of attacking 
them at once before they have time to spread. Watchmen in lookout stations or patrolling in dangerous localities are necessary in order to give notice immediately on the discovery of fire. A definite policy of establishing lookout stations on the summits of prominent mountains has been inaugurated in the New England States and in New York. Massachusetts, for example, is thoroughly covered by a network of 28 stations.

Lookout stations range from costly steel towers roo feet high down to inexpensive wooden shelters. They are connected by telephone with the nearest fire warden. At each station there should be a watchman constantly on duty during the fire season. His equipment should include at the least a good map of the surrounding country, field glasses and conipass. Much more elaborate outfits are often provided. Upon discovery of a fire the watchman gets the compass bearing and the closest possible location of the fire. This is telephoned down to the warden and a crew is at once sent to extinguish the fire.

While a watchman located in one of these fire stations can overlook a large area, 50,000 to 200,000 acres according to the topography, in clear weather, the efficiency of such stations in smoky. weather may be very low. The lookouts should be supplemented by a system of fire patrols, although one patrolman can of necessity protect only a small portion of the area that can be overlooked from a fire station. There are various methods of patrolling according to the nature of the country and the kind of fire danger.

A very efficient method of patrolling railroads is to follow every train on a hand car or motor. As there is most danger from freights the patrolman should follow directly after these, if it is impossible to follow all trains. Following as closely as this the patrolman will discover fires while they are still so small that he can extinguish them alone.

In a well-watered country where there is special danger from campers and fisherman, as in northern Maine, a patrol of the streams by boat or canoe is easiest and most efficient. The patrolman takes the names and addresses of all campers, and in 
that way not only has good evidence in case of subsequent fires, but warns parties so that they are more careful.

In many wooded sections well provided with trails a patrolman on horseback can cover considerable country, and in farm communities provided with roads he may be mounted on a bicycle.

In other regions where trails are lacking it is necessary for the patrolman to go on foot, but in any case the patrol must be so

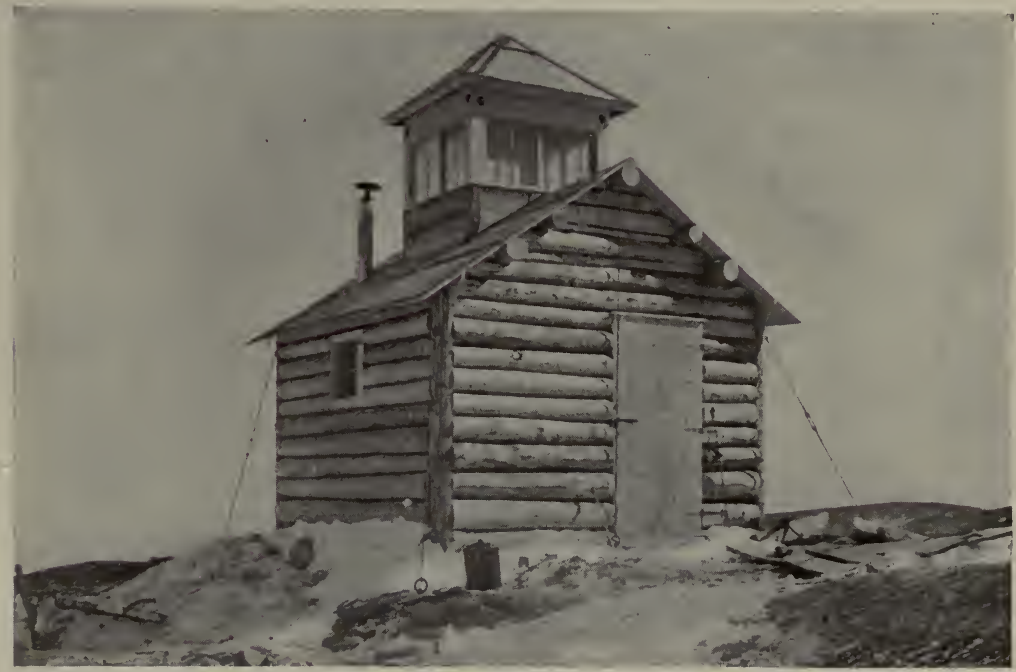

Fig. 51. - Fire station on Bald Mountain, Maine. A constant watch for forest fires is maintained during the dangerous season.

located as to provide inspection of the places most in danger of fire.

In the so-called "Weeks' Bill," which was passed by the United States Congress in the spring of I9I I, to provide for the acquisition of national forests in the East, provision was also made for the expenditure of $\$ 200,000^{1}$ in coöperation with the various states in the prevention of forest fires. Under this law any state which has an organized system for the prevention of forest fires, and which has forests protecting the headwaters of navigable

1 The original appropriation has been exhausted but other appropriations have been made and the work has been continued up to date. 
rivers, may call upon the national government for some of this money. The federal government is authorized to appropriate to any state only so much as the state is expending in similar work in the same fiscal year. All the New England states with the exception of Rhode Island are eligible for this assistance, and received in 1915 over $\$ 16,000$. In the same year these states appropriated themselves over $\$ 146,000$ for fire protection. This federal money can be spent solely for hiring men to be employed either in patrol or lookout duty. The wages paid are fixed in an agreement between the state and national forest service. During wet weather when there is no immediate danger of forest fires these men may be employed in constructing trails and fire lines or in any other way that will tend toward fire protection.

Much can be accomplished toward preventing fires by improving the condition of the forest. As previously stated, most of our worst fires occur or, at least, gain their headway in cut-over coniferous forests where the ground is covered with dry, inflammable tops. In New York State a law has been enacted compelling lumbermen to lop the branches from these tops so that the material will at once come in contact with the ground and be rotted out by the snows of a few winters. Experience of lumbermen in the Adirondacks has demonstrated that this operation can be done for twelve to fifteen cents per cord of pulpwood cut. It was also found that many tops after being lopped were worth taking out; these would otherwise have been left in the woods, so there was considerable saving to the operators. In our large lumber operations, especially in spruce forests where the tops are very branching, some such lopping measure will be the best and most practical preventive. However, in smaller operations especially in the small pine wood lots of New England the more efficient measure can be adopted of burning the branches, either at the time of lumbering or soon afterwards. The cost of this work has been found to vary from twenty-five to fifty cents per thousand feet of lumber cut according to the size of the trees. Of course, in many parts of New England the wood cut from the limbs has a sale value sufficient to more than pay for cutting, and 
in this way close utilization may considerably reduce or render unnecessary the cost of brush burning.

While the conditions are such that measures of this sort are not always feasible, it may readily be seen that if this inflammable material is cleared from certain belts in the forest it would be comparatively easy to check a fire. Belts of this kind are called fire lines.

\section{Fire Lines.}

A fire line or fire lane is a strip kept free from inflammable material, so that a fire will either go out of itself on reaching it, or can easily be extinguished at this line by a crew of fire fighters.

Fire lines may be of various widths and made in different ways according to the forest and kinds of fire likely to occur. Investigation of the Vermont fires of 1908 showed that crown fires occurred only in coniferous forests, and that practically all of the worst fires started in slash made by lumbermen.. One effective form of fire line could, therefore, be made by burning all the tops and dead-and-down timber and removing all conifers from the strip in question.

Of course surface fires would cross such a strip, if unprotected, upon the leaves and underbrush. It would, therefore, be well to cut from a narrow strip all growth of trees and brush and to burn the leaves annually.

This can be made still more effective by grubbing out the stumps and plowing a few furrows.

As an ideal fire line for mixed forests, we would suggest the following:

(a) A strip one hundred feet wide from which all coniferous trees and all underbrush and all dead-and-down timber are removed to prevent crown fires.

(b) One-third of this or a strip thirty-three feet wide to be annually burned over to prevent surface fires.

(c) A portion of this or a strip six to ten feet wide, to be grubbed out, and, if possible, plowed to prevent ground fires. 
The cost of a fire line of this kind would vary, according to the topography, the nature of the forest, and the thoroughness with which it is made, from $\$_{25}$ to $\$_{100}$ a mile. The maximum

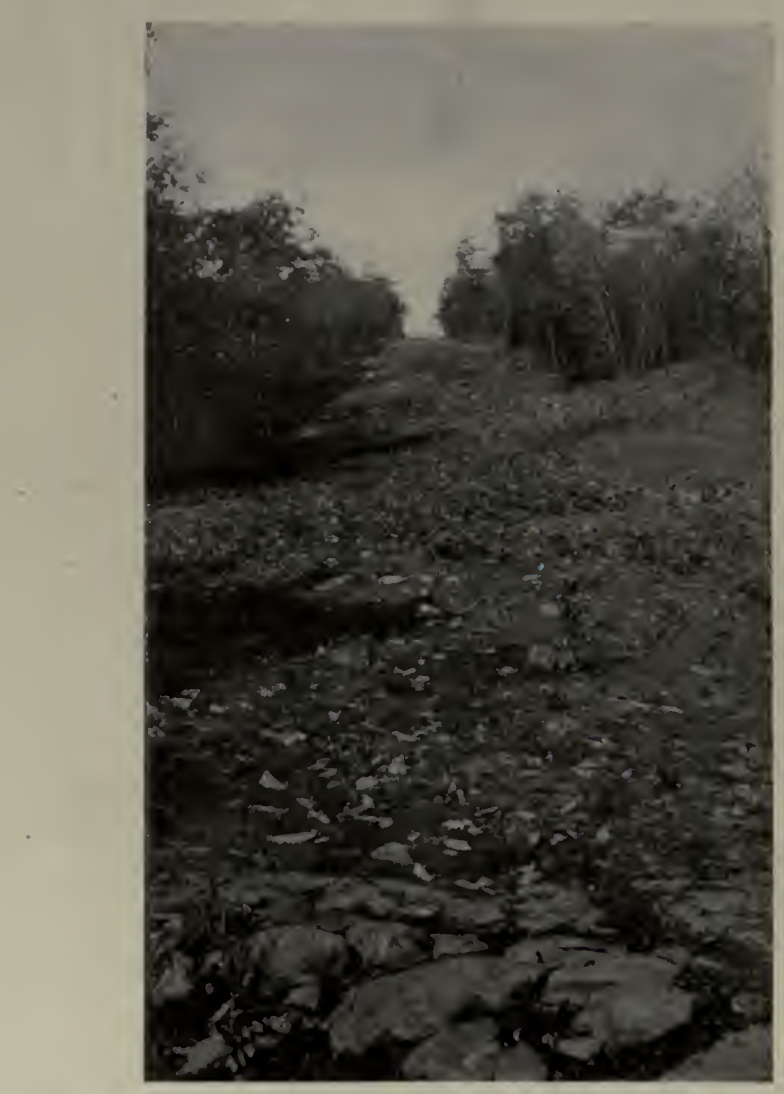

Fig. 52. - A completely cleared fire line in a stand of mixed hardwoods on ground too rocky to plow. The line has recently been cleared of leaves and occasional sprouts from the old stumps. This is done twice a year.

expenditure could hardly be justified except in the case of very valuable forests in extremely exposed situations, but there are few forest areas that it would not pay to protect with some such kind of fire line. 
On level, sandy soils, where fires run frequently and easily, forests should be divided into relatively small areas of from three hundred to six hundred acres in extent by fire lines. All extensive plantations should also be protected by fire lines. These lines need be only ten to fifteen feet wide. They should have all growth removed except trees over four inches in diameter, breast high, and the mineral soil exposed. Frequently this can be accomplished by cutting out the brush and small trees

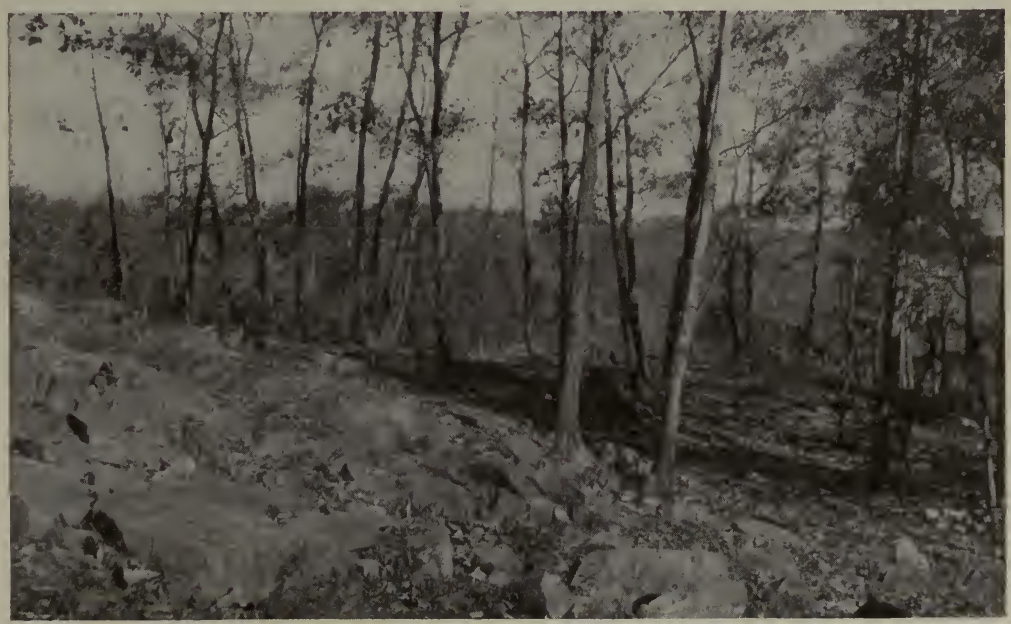

Fig. 53. - A ground cleared fire line with the larger trees left standing on the line. The shade checks the growth of grass and herbs which is apt to spring up on an open line.

and then plowing the line. Once established in a sandy soil such a line can be cheaply maintained by an occasional harrowing. If plowing is impossible a clear line can be secured by burning over the line or by hoeing and raking away the litter. If burned over great care must be taken to prevent the escape of the fire. Narrow lines should be raked free of litter on each edge of the fire line and then the area inside burned over on a quiet day. Roads make the best kind of a fire line and can, in many cases, be utilized for this purpose. The original cost of construction will vary greatly with the amount and character of the growth 
to be cleared, and whether the line is plowed, burned over, or raked. Under the best conditions a ten to fifteen-foot line cannot be constructed for less than \$io per mile, while in less favorable places the cost may easily run up to $\$_{5}$ or $\$_{75}$ per mile. After it is constructed the cost of maintenance should be below \$ro per mile per annum.

The location of fire lines is largely controlled by natural condi-

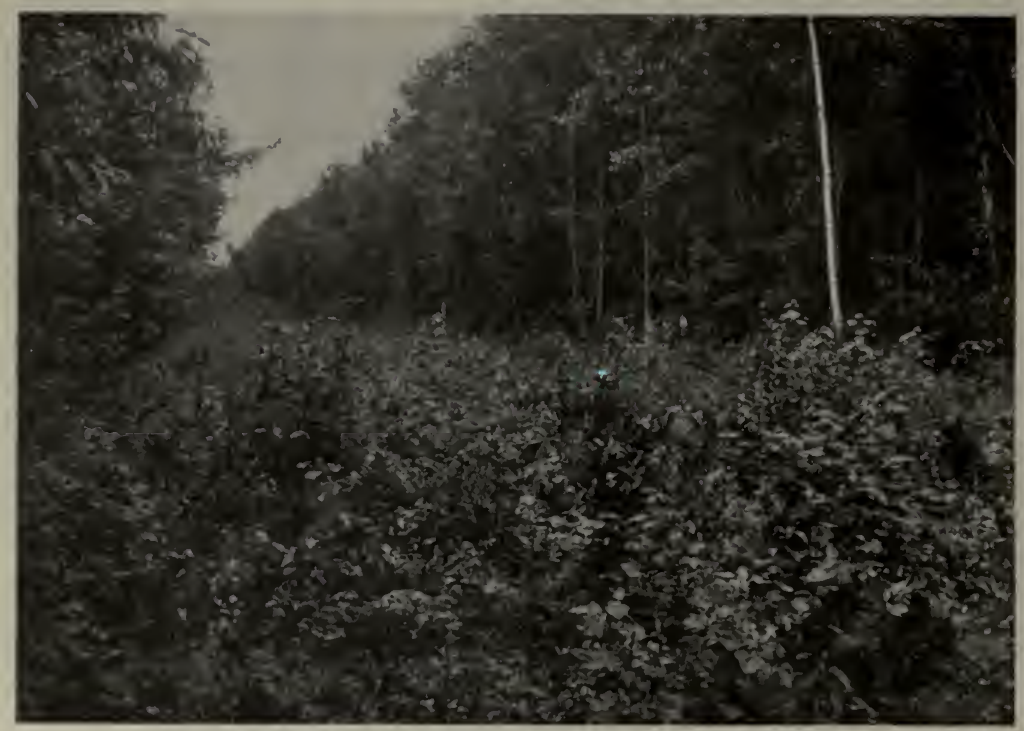

By permission of the U. S. Forest Scrice.

Fig. 54. - Fire line cleared through a hardwood stand. The line has not been properly maintained and is covered with a thick growth of weeds. The fire hazard is now greater on the line than in the forest.

tions. It is well to take advantage of brook beds which form a barrier in themselves and where water can be obtained for fighting fires; also of roads and trails; and especially of ridge tops. Fires burn downhill very slowly and can, therefore, be most easily checked at the top of a ridge. 


\section{ROADS AND TRAILS.}

Roads and trails are of great benefit in the prevention of fires, not only serving for fire lines but furnishing means of communication between various parts of a forest. A large forest area without such roads is very hard to protect, as a long time may be wasted before men and tools can reach the source of danger.

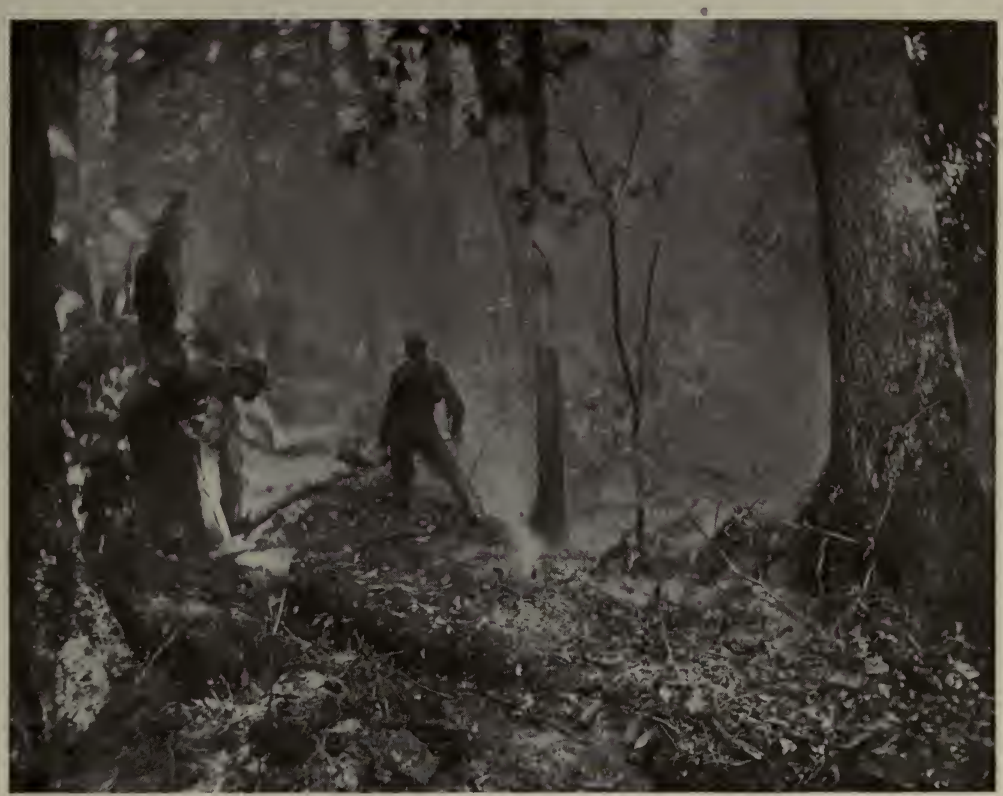

By permission of the U. S. Forest Service.

Fig. 55. - Fighting a ground fire by trenching through the thick duff to mineral soil.

\section{Extinguishing Fires.}

We have considered already the most efficient means of so improving the condition of the forest that not only fires will burn with less severity but that men can gain access to them more easily. Even under the most favorable conditions a wellorganized fighting crew is also necessary, under the leadership of someone who understands fire fighting. Certain equipment can 
be of great service and should be kept at vantage points in the forest where it is easily obtainable in case of fire.

The best tools to be kept for such purposes are: long-handled shovels, rakes, axes, mattocks, brooms, pails, and spray pumps. Chemical fire extinguishers are also of great value for surface fires, and it is a much-discussed question whether such extinguishers or spray pumps are more efficient in extinguishing forest fires. The chemical extinguishers employed for this purpose are

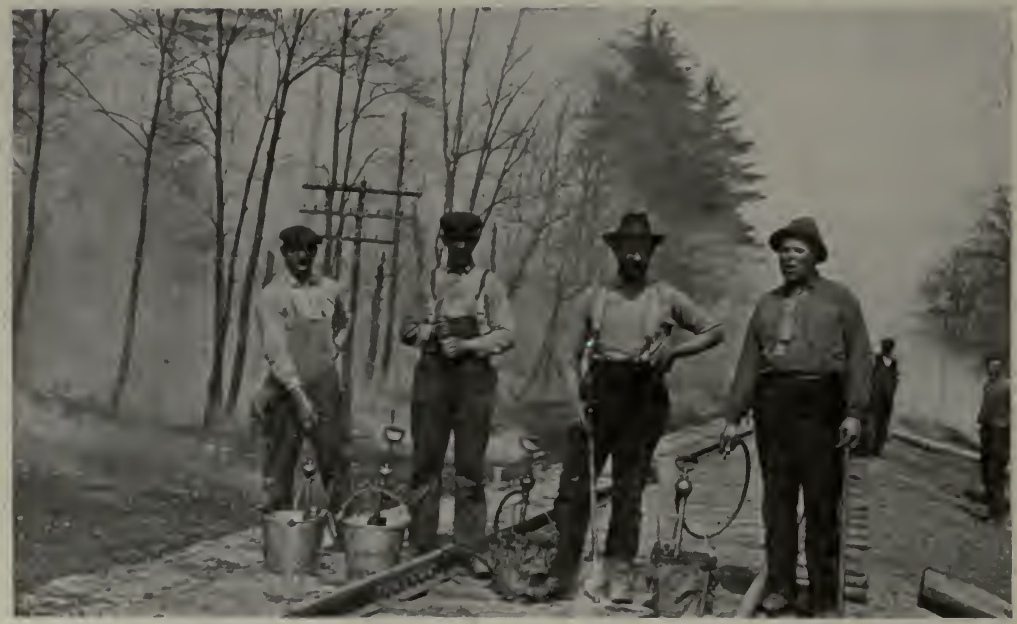

By permission of the Connecticut State Forester.

Fig. 56. - The fire wardens of a Connecticut town and their fire fighting outfit of bucket pumps. They have been burning over a fire line adjacent to the railroad track.

fairly light, portable ones, weighing about thirty-seven pounds when charged, and provided with a short hose and nozzle. Various makes of extinguishers are on the market but all based on the same principle. Briefly, the extinguisher contains in the top a small bottle of sulphuric acid, while beneath is a mixture of water and bicarbonate of soda. In working the extinguisher it is inverted and the sulphuric acid mixes with the liquid, resulting in the formation of carbonic acid gas and calcium sulphate. The chemical reaction forces out through the hose a mixture of water and carbonic acid gas, which, theoretically, stops combus- 
tion quicker than water alone. 'The bucket or spray pump is a small suction pump fitted with a hose and nozzle, and with a clamp so that the pump can be securely fastened into a large pail. The pail should be covered with a wire netting or cloth to strain the water and keep out sticks and dirt. Both the extinguisher and bucket pump are used in the same way in fighting a surface fire. The operator walks rapidly along the line of the fire and deadens the blaze. A helper, who beats

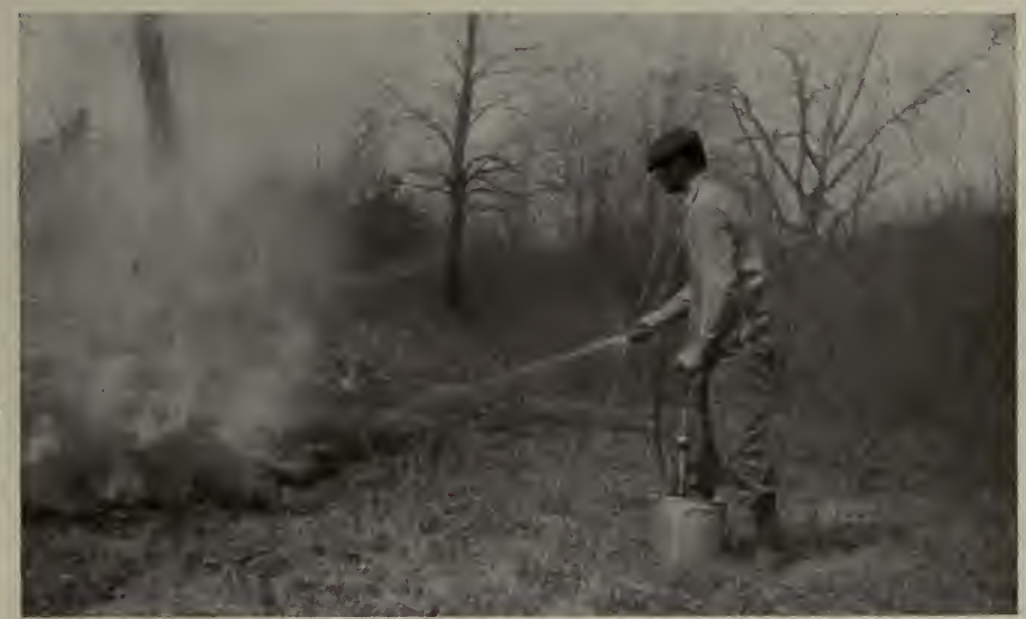

By permission of the Connecticut State Forester.

Fig. 57. - Fighting a surface fire with a bucket pump.

out with a shovel the last remnants of the fire, should come behind him.

Both are extremely effective methods of extinguishing surface fires, even of such severity that beating out, shoveling on dirt, etc., cannot be employed alone.

Which is the better, bucket pump or chemical extinguisher? Each has its supporters and usually in a locality where one is employed the other is not used. Each has its advantages and disadvantages, which have been placed in two parallel columns for the purpose of comparison. 


\section{COMPARATIVE EFFICIENCY OF CHEMICAL EXTINGUISHER AND SPRAY PUMP.}

\begin{tabular}{|c|c|c|}
\hline & Bucket pump. & Chemical extinguisher. \\
\hline $\begin{array}{l}\text { Cost } \\
\text { Capacily }\end{array}$ & $\begin{array}{l}\text { Depends on size of pail. } \\
\text { Should use large pail hold- } \\
\text { ing } 3 \text { to } 4 \text { gallons. }\end{array}$ & Between $2 \frac{1}{2} \stackrel{\text { and }}{3}$ gallons. \\
\hline $\begin{array}{l}\text { Weight when } \\
\text { full. }\end{array}$ & $\begin{array}{l}\text { A 4-gallon galvanized, pail, } \\
\text { with pump, containing } 3 \\
\text { gallons of water, weighs } \\
\text { under } 35 \text { pounds. }\end{array}$ & $\begin{array}{l}\text { Approximately } 37 \text { pounds. It } \\
\text { is a much harder article } \\
\text { to carry than pail and } \\
\text { pump. }\end{array}$ \\
\hline $\begin{array}{l}\text { Length of line } \\
\text { of fire put } \\
\text { out. }\end{array}$ & $\begin{array}{l}50 \text { to } 150 \text { feet. } \\
\text { Skill of operator in using only } \\
\text { a little water in the right } \\
\text { spot governs the length of } \\
\text { line which can be put out. }\end{array}$ & $\begin{array}{l}50 \text { to } 200 \text { feet. } \\
\text { This depends mainly on how } \\
\text { fast the operator walks } \\
\text { and his skill. }\end{array}$ \\
\hline & $\begin{array}{l}\text { The severity of the fire influes } \\
\text { If very carefully handled ar } \\
\text { over, making rapid walkin } \\
\text { should put out a longer }\end{array}$ & $\begin{array}{l}\text { aces length of line with both. } \\
\text { ad the country is easy to get } \\
\text { ig possible, the extinguisher } \\
\text { f fire than the bucket pump. }\end{array}$ \\
\hline $\begin{array}{l}\text { Material } \\
\text { used. }\end{array}$ & Water. & $\begin{array}{l}\text { Water, sulphuric acid, bi- } \\
\text { carbonate of soda. }\end{array}$ \\
\hline & $\begin{array}{l}\text { Practically same amount of w } \\
\text { of the two. }\end{array}$ & ter needed to recharge either \\
\hline $\begin{array}{l}\text { Cash outlay } \\
\text { for recharg- } \\
\text { ing. }\end{array}$ & Nothing. & Io to 25 cents per charge. \\
\hline $\begin{array}{l}\text { Accompany- } \\
\text { ing equip- } \\
\text { ment. }\end{array}$ & \multicolumn{2}{|c|}{$\begin{array}{l}\text { In order to make either the bucket pump or chemical extin- } \\
\text { guisher most effective there must be facilities for refilling. } \\
\text { Several empty cans (big milk cans are among the best) } \\
\text { or pails for bringing water are necessary. Besides this for } \\
\text { the chemical extinguisher there must be extra supplies of } \\
\text { sulphuric acid and bicarbonate of soda. }\end{array}$} \\
\hline
\end{tabular}

The statement is frequently made that the chemical extinguisher is forty times as effective as water in extinguishing fire, i.e., one hundred and twenty gallons of water would be needed to do the work which one charge (three gallons) of the chemical extinguisher accomplishes. Whether this is so in the case of a fire in a building in which a great volume of fire is concentrated in a comparatively small space, the authors do not know, but 
it is certain that nothing so disproportionate exists in the case of the ordinary forest fire, which extends as a narrow line. Here the extinguisher is not even twice as effective.

The lower cost (both the initial cost and that of maintenance) and freedom from trouble in recharging with chemicals, make the bucket pump more desirable for general use than the chemical

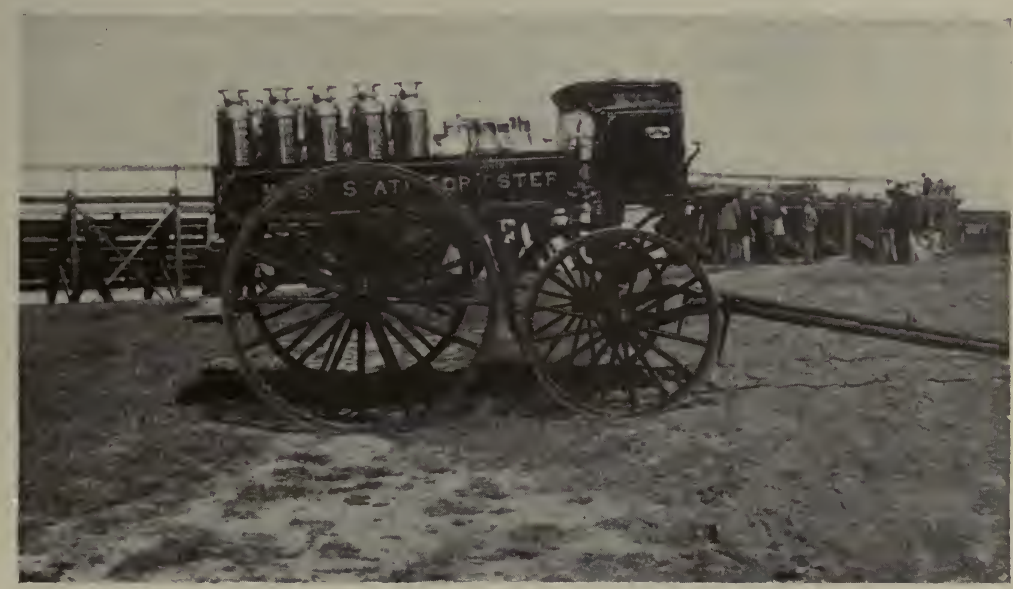

By permission of the Massachusetts State Forester.

Fig. 58. - Special forest fire wagon; small size for one horse.

extinguisher, although the latter can put out a somewhat longer line of fire.

There are special circumstances under which the chemical extinguisher is preferable, as when water is extremely scarce, for it uses a little less water; or where all parts of a tract are accessible by good roads, for then a wagon can go along and transport a supply of extra chemicals easily and without danger of breakage.

The most intensive development of this method of fire fighting is found in certain Massachusetts towns, located mainly through the eastern part of the state and especially in the level, sandy southeastern section, where transportation by wagon is easy. In these towns, special forest fire wagons are maintained. They 
vary in style somewhat in different towns, but two types built by the state forester of Massachusetts as special forest fire-wagons may be considered as standard. The following quotation from the Seventh Annual Report of the State Forester of Massachusetts briefly describes the two wagons and their equipment.

"The larger wagon is intended for two horses and costs, all equipped, about \$450. The equipment consists of fourteen chemical extinguishers; fourteen galvanized cans, each holding two extra charges of water and chemicals; shovels, rakes, mattocks, and spare chemical charges. This equipment is carried in racks and cases, not only so that it will ride safely, but also so that it can be conveniently carried into the woods. Eight men can find accommodation on this wagon.

"The smaller wagon, drawn by one horse, has all the equipment of the larger, but less in amount. It will carry four men and costs, all equipped, about $\$ 300$."

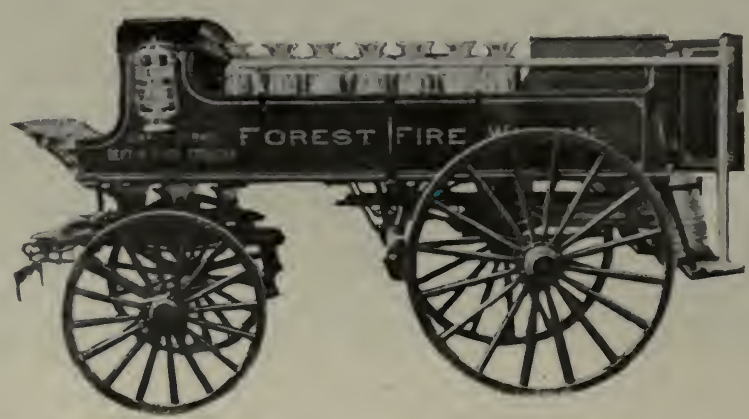

By permission of the Massachusetts State Forester.

Fig. 59. - Special forest fire wagon; large size for two horses.

Raking the leaves and litter away from the advancing flames is another good way of checking surface fires. This makes a rough sort of fire line where the fire stops for lack of inflammable material.

Perhaps the most common method of checking a fire, and the most effective under certain conditions, is beating it out with brooms or evergreen boughs or bran sacks. These sacks when wet can be used to good advantage.

One experience in fighting fire will suggest the best methods for certain conditions. The chief thing to remember is that a fire is not out when the flames are stopped. It will often smolder for a long time in some old stump and finally blaze 
out again, perhaps after several days. Fire wardens should remember this and always have someone to watch a fire for some time after it is supposedly out.

The most effective time to fight fire is in the night when there is usually less wind and the ground is damp with dew. A small force of men can often accomplish more at this time than a large force in the daytime.

It is easier to put out a fire spreading downhill than in the opposite direction, because hot air rises and an ascending fire is fanned by the draft which it creates.

Fortunately crown fires are not very common in New England. About the only way to prevent a serious crown fire with a strong wind is by "back firing," but this should never be resorted to except as a last resort and at points of vantage. To have a back fire effective it must be started far enough ahead of the main fire to clear a considerable strip of all inflammable material before the main fire reaches it. This distance, therefore, depends upon the rate of advance of the main fire. A fire advancing at the rate of a mile an hour could probably be checked by a back fire set one-half mile ahead; while to check one traveling at twice that rate a greater distance would be required. Great care must be used in starting a back fire that this does not escape with the wind and go tearing through the forest, increasing the damage done by the main fire.

The purpose is to burn back against the wind toward the main fire and thus destroy all inflammable material in the track of the main fire and cause its death through lack of fuel. A back fire should only be started on the side of a road, brook, ledge, or some other obstacle which would help to control it.

\section{Estimating the Damage Done by Forest Fires.}

In almost all states persons who set forest fires are responsible for damages, and civil suit for such may be brought against them. From the first part of this chapter it will be seen that fires seldom kill standing timber outright and that the damage thereto is often small compared to that done the younger growing stock, 
the reproduction, and the soil itself. Inasmuch as this young growth seldom has any market value until of lumber, or at least of cordwood, size, it has been quite common to overlook these more serious forms of damage in appraising the results of a fire. Neither is it an easy matter to determine the damage to young growth and soil. The only just method of determining this damage is to estimate, $(a)$ what the forest would have been worth after a given length of time if not burned, and $(b)$ what it will be worth in that same time now that it has been burned and deduct the latter from the former. The result is the amount of damage at the end of this period caused by the present fire In order to determine the present value of this damage it is necessary to discount the amount to the present time, at the same rate of interest as the forest is yielding on the capital invested. To illustrate:

Suppose on a tract of twenty acres of spruce burned over this year, 200,000 feet of lumber were destroyed worth $\$ 7$ per M. The damage to timber is $\$ 1400$. If it is estimated that the young growth would have produced 200,000 feet more in thirty years without the fire and will now not produce over 30,000 feet in that time; and it is estimated that stumpage will be worth \$1 o per M. in thirty years, the damage at the end of the period would be equivalent to 170,000 feet at $\$$ IO $=\$ 1700$. From tables of interest it is found that the present value of $\$$ I 700 discounted at five per cent for thirty years is $\$ 390$. Therefore the total present damage is $\$ 1400+\$ 390=\$ 1790$. To execute the field work necessary for an estimate of this sort of the damages done by fire the chapter on timber estimating must be understood. As a rule our New England fires do not destroy the trees, so it is possible after a fire to estimate the amount of lumber killed just as live timber is estimated. To determine the damage to reproduction is somewhat more difficult, depending on whether the young seedlings are wholly destroyed or simply killed. If they are still present it is possible to estimate the percentage of the area which was stocked. If they have been destroyed it will be necessary to judge the former condition of the reproduction 
by that on similar adjoining tracts which have not been burned over. After ascertaining the percentage of the area formerly stocked it will be possible by the use of yield tables, discussed in Chapter $\mathrm{X}$, to estimate what the yield would have been had the land escaped fire.

It will be realized that there are many opportunities for inaccuracies in determining damage in this way, especially in our American forests where so little is known as yet of exact rate of growth and the future value of stumpage. One of the main chances for mistake is in selecting the rate of interest. In the example given it will be seen that the present value of $\$$ I 700 discounted at 4 per cent for 30 years would be $\$ 525$, or, at 5 per cent, $\$ 295$, making the total damage respectively $\$ 1925$ or $\$ 1695$ instead of $\$ 1790$. Of course where forests are managed under scientific working plans, as is the case in many European forests, and only a portion of the forest is removed equal to the amount grown in that time, a definite income is derived. In such a forest the rate of interest corresponds fairly well to the income divided by the capital. For example, in a forest having an estimated stand of 40 cords per acre in which there is an annual growth of one cord and where wood is worth \$I per cord, the rate of interest at which the forest is growing would be onefortieth $=$ two and one-half per cent. In this country the rate of interest used will usually be not less than that paid by savings banks since our forest management is in such an unsettled state.

It is only recently that the destruction of reproduction has been recognized by the courts as a damage for which reimbursement could be claimed. Hitherto damages allowed by courts have been based entirely on the stumpage value of the timber destroyed. This, however, is only a part of the actual damage, as the young growth and productive capacity of the soil is also injured. For this reason a recent decision of the United States Circuit Court at Deadwood, South Dakota, is of interest.

"The government in the summer of I9I0, won a signal victory in the case against the receiver of the Missouri River and Northwestern Railroad Company, in which damages were claimed for 
the destruction of timber by sparks from the defendant's locomotives. The jury brought in a verdict for the plain tiff allowing practically the full amount asked. The total sum demanded was $\$_{3728 . \$_{5}}$ and the verdict was for $\$_{3} 659.45$, a difference of but $\$ 69.45$. This item was the alleged value of the cordwood destroyed, amounting to $231 \frac{1}{2}$ cords at 30 cents per cord. The government claimed that the wood before the fire was worth 60 cents per cord and as it was subsequently sold for 30 cents they claimed the difference, which was not allowed.

"The important feature of the case was the allowing of $\$_{12}$ per acre for reproduction and the suit was unique in that this establishes a precedent of the greatest value to the Forest Service. It is the first time that a court in the United States has decided that trees of such immature growth have a value that may be determined and for which damage may be estimated and allowed.

"The item of reproduction in this case was $\$$ I094.40 or $\$$ I 2 per acre for 91.2 acres and it was allowed by the jury in full. The other item allowed was for the partial destruction of 675,000 feet of mature timber, originally valued at $\$ 6$ per thousand, but a credit of $\$ 2.20$ per thousand was allowed the defendant as the fire-killed timber was subsequently sold at that price. This added $\$_{25} 65$ to the reproduction allowance.

"The basis for the valuation of the reproduction were the figures derived from the actual operations of this kind in the Black Hills National Forest during the past season, when I 500 acres were reforested by seeding. Thus the forest officers, in their testimony, were able to give exact figures for the work already performed and thereby put a definite value on young trees, which to practical lumbermen would be worthless." 1

${ }_{1}$ This quotation is taken from Forestry Quarterly, Vol. VIII, p. 566. 


\section{CHAPTER IX. \\ TIMBER ESTIMATING AND MARKETING.}

METHODs of timber estimating are numerous and of varying degrees of accuracy. The method which should be employed depends very largely upon conditions. Usually there is not the same need of exactness in estimating timber on a large tract that there is on a small one, since the large tracts, as a rule, do not have a very heavy average yield per acre, and they are situated in remote regions where the stumpage price is comparatively low. Some small tracts, on the other hand, are worth from $\$ 100$ to $\$ 500$ per acre, on account of heavy yield and proximity to the market. Naturally one would employ more exact methods of estimating the stand on a fifty-acre tract priced at \$5000 than on a ten-thousand-acre tract valued at $\$ 100,000$. As a general thing the more valuable the timber the greater the need of an accurate and elaborate estimate.

Estimating lumber is like every other business; the more experience a man has in it, the more accurately he can estimate and the simpler the methods he can use. Many lumbermen, or, more correctly, timber cruisers can go over a large tract in a casual way and estimate fairly well the total amount of timber upon it. They are able to do this because they have had experience in cutting off many similar tracts and know the amount of lumber taken from them. The roughest method is simply to compare in one's mind the tract under consideration with those with which one has had experience. 'This method is liable to errors of twenty-five per cent even when used by experienced men. Stumpage prices of timber have now advanced so much and competition is so great that practically all cruisers now use some more accurate system.

It should be said at the outset that the land owner or pro. I6I 
spective purchaser can usually secure the services of a timber cruiser, but as the business of estimating offers unequaled opportunity for dishonesty, the employer should be sure that the estimator is working for his interests. It must also be borne in mind that most of these men look at the forest from the lumberman's rather than the forester's standpoint, and are, therefore, not inclined to place much value on young growth or to appreciate the probable rise in prices. For these reasons they are more likely to underestimate than overestimate and their judgment is worth more to the purchaser than to the seller.

As the purpose of this chapter is to point out methods of estimating which can be applied by one of little experience, rather than to describe the cruisers' methods, the latter will be omitted.

\section{A. estimating timber on SMALL WoOd LOTS.}

The most accurate way of estimating timber and one wholly practicable on small wood lots, as areas of less than one hundred acres, is to measure the diameters of all the trees and the heights of as many as will establish an average. The diameters are measured with calipers, always at breast height. Heights may be measured accurately with an instrument known as a hypsometer, ${ }^{1}$ or, after a little practice, may be estimated fairly accurately. This work can be done best by two men crossing and recrossing the wood lot on parallel strips. To avoid mistakes it is well to mark the trees measured with a piece of carpenter's chalk.

The most convenient form of tallying the trees measured under this system is to use a sheet ruled horizontally and vertically; the vertical columns for the various species, the horizontal lines for diameters. A dot is made for each tree measured and after four dots are made under the same diameter and species, the next trees are designated by connecting lines and diagonal lines until ten trees are tallied. The following table illustrates this method:

1 There are several kinds of hypsometers. The one commonly used in this country is called the Faustman and can be purchased from Keuffel \& Esser Co. of New York. 


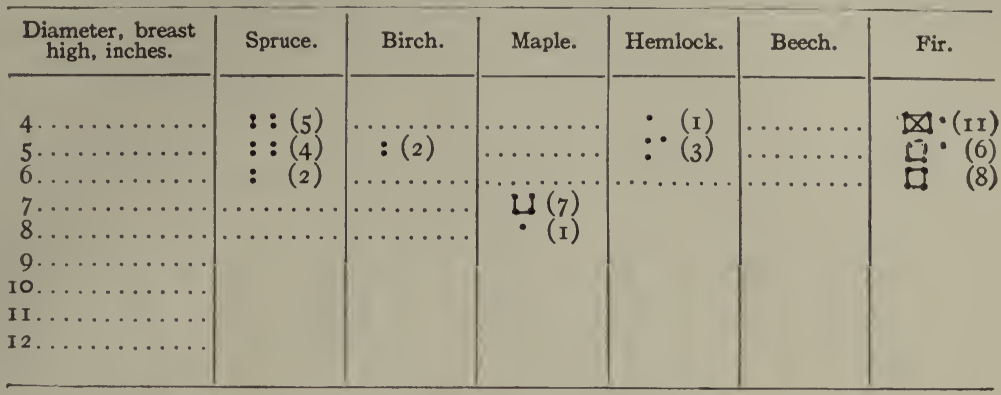

On the area tallied there was one hemlock 4 inches, one maple 8 inches, two spruces 6 inches, two birches 5 inches, three hemlocks 5 inches, four spruces 5 inches, etc.

After all the trees on a lot have been measured in this way their volumes can be best ascertained by the use of "volume tables," if they are available. . Volume tables have now been constructed for many of our important species. They are based on the measurements taken in lumber jobs of several hundred felled trees and give the average volume, either in board feet or some other unit, for trees of different diameters and heights. With such tables the total volume of each species on the lot is obtained separately, a table being constructed similar to the one below.

In the application of volume tables it will be seen that some give cubic feet instead of fractions of a cord or board feet. The number of cords can be secured by dividing the number of cubic feet by 90 on the principle that a cord of wood (I 28 stacked cubic feet) contains 70 per cent solid wood, which amounts virtually to 90 cubic feet. Board feet can be converted to cords by allowing 500 board feet as the equivalent of a cord. This varies from 400 feet for small logs to 600 feet for large ones; but it must be remembered that the rule will not always work backwards, for a cord of wood may be composed of sticks too small to be sawed.

1 A number of such tables are included at the back of the book. 
TABLE SHOWING THE APPLICATION OF A VOLUME TABLE TO SECURE THE STAND OF SPRUCE ON A WOOD LOT.

\begin{tabular}{c|c|c|c}
\hline $\begin{array}{c}\text { Diameter, breast } \\
\text { high, inches. }\end{array}$ & Number of trees. & $\begin{array}{c}\text { Volume } 1 \text { per tree in board } \\
\text { feet, from volume table. }\end{array}$ & $\begin{array}{c}\text { Total volume, board } \\
\text { feet. }\end{array}$ \\
\cline { 2 - 4 } 5 & 500 & 6 & 3,000 \\
6 & 420 & 12 & 5,040 \\
7 & 430 & 18 & 7,740 \\
8 & 300 & 38 & 11,400 \\
9 & 170 & 61 & 10,370 \\
I0 & 200 & 98 & 15,600 \\
II & 220 & 110 & 21,120 \\
I2 & I40 & & 15,400 \\
Total........ & 2,380 & & 89,670 \\
\hline
\end{tabular}

1 Volumes taken from volume table by T. S. Woolsey, Jr., made in Grafton, N. H.

In the case of trees for which no volume tables have been constructed a table should be made. A rough table that will be fairly accurate for any wood lot can be made by cutting on the tract a number of trees of different diameters of the species in question, only taking care that a good range of diameters from the smallest to the largest is included. After these sample trees are felled they are measured into log lengths, and the logs of each tree scaled by the log rule in general use in the community. A $\log$ rule is a table, generally laid out on a measuring stick, which gives the number of feet, board measure, in logs of different diameters and lengths. A number of such $\log$ rules $^{1}$ are in use in different parts of the country. The most common rules ${ }^{2}$ used in New England are the Doyle, the Scribner, the Bangor or Maine, the Blodgett, and the Vermont. After scaling the logs of a tree their volumes are added to give the volume of the whole tree. The volumes of the various felled sample trees are then plotted on cross-section paper, and a curve is drawn designating the average, as shown below. Of the five trees measured in this case, the 7 -inch tree contained 30 board feet; one of the 9 -inch trees 40 , and the other 60 board feet, etc.

1 See Woodman's Handbook, Bulletin 36 , U. S. Forest Service.

2 Copies of these rules are given in the back of the book. 
From this curve it is possible to make the rough volume table (called a "local" volume table) as follows:

\section{LOCAL VOLUME TABLE.}

\begin{tabular}{|c|c|}
\hline $\begin{array}{c}\text { Diameter, } \\
\text { breast high, } \\
\text { inches. }\end{array}$ & $\begin{array}{c}\text { Volume, board } \\
\text { feet. }\end{array}$ \\
\hline 6 & I5 \\
7 & 30 \\
8 & 35 \\
9 & 50 \\
IO & 65 \\
I I & 85 \\
I 2 & I 20 \\
\hline
\end{tabular}

With such a volume table the total contents of the trees on the wood lot of this species are obtained as already explained.

Still another method of obtaining the volume of the stand without the use of any volume table is based on estimating, at the same time with the breast high diameters, the top diameter of every 16 -foot $\log$. To do this accurately requires some practice in judging 16 -foot lengths and diameters at different distances. As a result of this method the note keeper has not only the diameter of each tree but also the estimated top diameter of each log. The volumes of logs of different diameters are given by the log rules, and the total amount of lumber for the tract is obtained by multiplying the volume of the log of each diameter by the number of logs of that diameter, and adding all together. The following table illustrates the final result by this method.

\begin{tabular}{|c|c|c|c|}
\hline $\begin{array}{c}\text { Top diameter of } \\
\text { I6-foot logs, } \\
\text { inches. }\end{array}$ & $\begin{array}{c}\text { Number of } \\
\text { logs. }\end{array}$ & $\begin{array}{c}\text { Volume per } \\
\text { log, } \\
\text { board feet. }\end{array}$ & $\begin{array}{c}\text { Total volume, } \\
\text { board feet. }\end{array}$ \\
\cline { 1 - 2 } 8 & 50 & 32 & I600 \\
9 & 62 & 36 & 2232 \\
I0 & 70 & 60 & 4200 \\
\hline
\end{tabular}




\section{B. estimating timber ON LARGE WOOD LOTS.}

On large wood lots, as those over one hundred acres in extent, very likely it would be impracticable to measure all the trees. A system somewhat less accurate can be applied in such cases depending upon two operations carried on together, as follows:

I. Count all the trees on the lot.

2. Measure all the trees on certain plots.

Two men by walking through a forest on a compass course can very rapidly count the trees on a strip four rods wide. Those on the outside should be marked so as to avoid confusion when returning on the parallel strip. At regular distances, as every two hundred paces, a plot is laid off and all the trees on this plot measured as described under $A$. Circular plots are conveniently laid off by pacing from the center the distance of the required radius in different directions. A circle with a radius of 59 feet contains a quarter acre; with a radius of 85 feet, a half acre. After all the trees on the wood lot have been counted in this way, and the trees on several sample plots have been measured, the volumes of the various sample plots are worked up by one of the methods described under $A$. The total volume of the lot is obtained by ratio:

$$
X: V:: N: n
$$

in which

$$
\begin{aligned}
X & =\text { total volume of the wood lot. } \\
V & =\text { volume of the sample plots. } \\
N & =\text { total number of trees on the wood lot. } \\
n & =\text { number of trees on the sample plots. }
\end{aligned}
$$

\section{ESTIMATING TIMBER ON LARGE FOREST TRACTS.}

The methods described above rely upon a census of the total number of trees on the wood lot. In the case of large timber tracts such an enumeration is impossible, and some method must be employed based on an accurate estimate of certain parts of the tract and a knowledge of what proportion these areas form of the 
whole. In order to determine this proportion a map is necessary, from which the total area of each portion or type can be obtained. For example, a 10,000-acre tract in northern New England might be found to comprise 2000 acres of second-growth pine, I000 acres abandoned pastures, 4000 acres mixed birch, beech, and maple, and 3000 acres second-growth spruce. A knowledge of the area of each of these types is necessary. There might also be subdivisions according to age, which would have to be estimated separately. Thus in the second-growth spruce and pine types, certain blocks might occur containing timber twenty to fifty years old, while the remainder was less than twenty years of age. The only accurate way to determine these areas is to map them, and consequently a map must be secured by the estimator. ${ }^{1}$ In an open country, undoubtedly, it is better to map the area first with a plane table and do the estimating separately, but there can be no question that for those sections of New England where large forests occur, the so-called "strip system," or "valuation survey," devised by the United States Forest Service, is unsurpassed. By this method the data for making the map are secured at the same time that measurements of the timber are being taken. To carry out this method a crew of four men is best, although it can be done with a smaller or a larger number. The necessary equipment is a surveyor's chain, a hand compass (for more accurate work a staff compass), two pairs of calipers, a tally board, some record sheets or a notebook, and a pencil. A hypsometer is a valuable addition as will be explained later. The crew may be arranged in various ways. The main object is to run a straight compass course through the forest and this is done by the head man. The other two men carry the calipers and measure the diameters of all trees for a distance of one-half chain length, two rods on either side. At first this distance should be checked frequently, by carrying the chain out to the side or by pacing; but with practice the men soon are able to judge very closely, and the few inaccuracies

1 For methods of mapping forests, see "A Manual for Northern Woodmen," by Austin Cary, published by Harvard University, Cambridge, Igog. 
balance themselves. The trees on this strip, 66 feet long and 66 feet wide, are calipered and tallied as described under $A$.

This square of 66 feet each way is one-tenth of an acre. When all the trees on this area have been measured the crew moves on another chain length in the fixed compass direction. The chains are tallied after moving forward. Ten chains complete the acre, which is all that is tallied on one sheet. A description of the

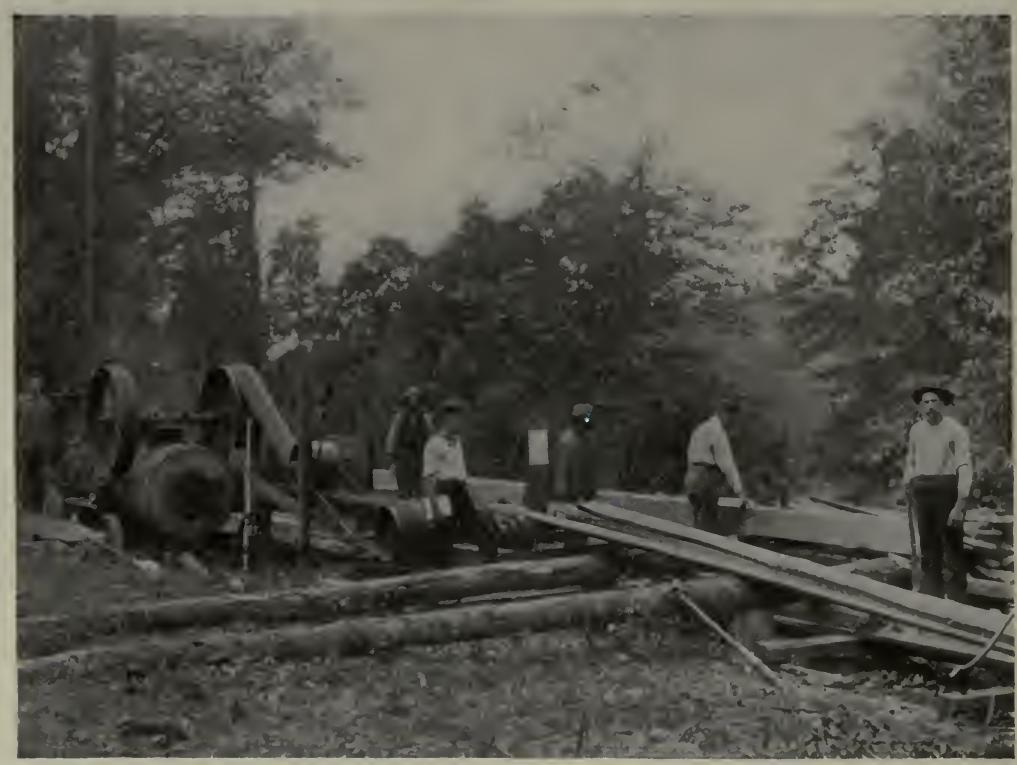

By permission of the Connecticut State Forester.

Fig. 6o. $-\Lambda$ portable sawmill of small capacity, such as is commonly used in southern New England.

forest is written on the back of the sheet with special reference to the type, so that all acres measured in a certain type can be averaged together. If there is a marked change in type in the course of an acre, it is better to start a new sheet, the tally of chains showing that this sheet represents .6 or .8 of an acre, etc., as the case may be. A continuous strip of eight acres covers a mile of distance: $66 \times 10 \times 8=5280$ feet. The tract is gridironed with these strips. The distance apart of the lines depends 
upon the intended accuracy of the estimate. Lines run one mile apart give a measurement of one and one-quarter per cent of the entire area; one-half mile apart two and five-tenths per cent; one-quarter mile apart five per cent; one-eighth mile ten per cent, etc. However, in practice, the lines are rarely run nearer than one-quarter mile, and usually two and five-tenths per cent of the area is considered sufficient. By making note of changes of type, topography, streams, etc., it is possible to make a fairly accurate map of the tract. The areas of the different types can be determined from this map. Along with the survey the crew should take the height measurements of a few hundred trees of the most important species, to obtain the average height for each diameter class.

When all the required valuation surveys have been secured there remains a large amount of work to be done. In the first place, the tally sheets are assorted according to the type of land they represent. Of the 500 acres measured in the 10,000-acre tract, suppose 100 fall into the second-growth pine type, I50 into mixed hardwoods, 200 into second-growth spruce, and 50 into abandoned pasture. The sheets representing each of these types are averaged together, giving an average acre for each type. This shows the average number of trees of each diameter and species for the type, and the contents can be obtained from volume tables as discussed under $A$. The total volume of each species is then multiplied by the number of acres in the whole type, giving a total for the type.

The valuation survey method of estimating, described above, undoubtedly surpasses, for accuracy and cheapness, any other method and admits of considerable variation in detail. There are now forestry companies whose main business is to estimate timber, and, as far as known, they all use some modification of this system.

Another method applicable for large tracts, by which the data for a map are secured along with the estimate, is a combination of the strip system and the circular plot method outlined under $B$. The chief advantage of this method is that it can be done 
by one man. In principle it does not differ from the method just described. The estimator secures his distances by pacing, guiding his course by a pocket compass. Instead of measuring the timber in a continuous strip he takes measurements only at certain points, as at the end of every quarter mile. At these points circular plots are laid off as described under $B$. In open forest and with mature timber it soon becomes possible to locate the boundaries of the plot by the eye. The trees are either

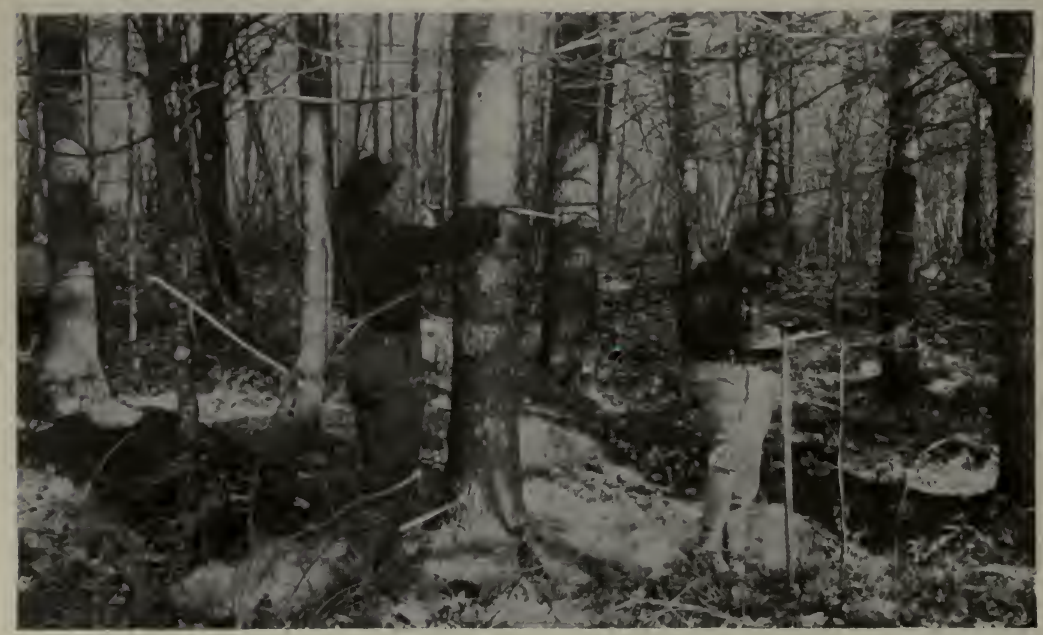

Fig. 6r. - Estimating timber by use of the strip method.

calipered and the volume of the types ascertained, as in the valuation survey method, or after sufficient practice the volume of each tree can be estimated and tallied. After the volumes of all the sample plots in a type have been found, the average volume per acre is obtained and this is multiplied by the number of acres in the type, as secured from the map.

\section{The Money Value of Standing Timber.}

After the amount of standing timber or wood on a given tract has been estimated, the final object usually is to determine its money value. 
Timber is bought and sold under so many different conditions that when a price is mentioned it is always necessary to define the conditions under which the price applies. Timber standing is spoken of as stumpage, and the price paid for trees standing is called stumpage price, which is expressed generally as so much per thousand board feet, cord, or other unit. It is customary in European practice, and in some cases in this country, to sell logs in the woods when piled alongside the logging road. In America this is spoken of as being on the skidway. Again, the transaction may be of logs delivered at the mill, or loaded on a car, or skidded on the bank of a river.

Naturally the price of stumpage is lowest, that paid for logs delivered at the mill is highest; other prices range between the two. The value of timber may also be figured at its price when manufactured and placed on the market. This, of course, is the highest of all, but is the easiest to arrive at and should serve as the basis from which the value of the standing timber can be computed as described below.

The market value of manufactured lumber fluctuates considerably with national supply and demand. In years of business depression, like 1908 and 1914 , when there is less building or exporting, prices decline. As a general tendency, however, the prices of lumber are rising. Prices paid for lumber, wood, and other forest products, as for everything else, vary according to local conditions, and the first step in valuation of timber is to ascertain the prices that can be secured either for the manufactured article or for the logs delivered at the mill. Where there are special industries requiring a large amount of any special timber, the prices paid for that species are higher. As we have stated, a timber owner having had his logs sawed may sell the manufactured lumber. Sawmill owners usually charge from $\$ 2.50$ to $\$ 3$ per thousand feet, board measure, for sawing softwood lumber and from $\$_{3}$ to $\$ 4$ for hardwoods. These figures indicate the possible profit of selling manufactured lumber over logs, but the owners should realize that it is often difficult for them to find a ready market, while the millmen are in constant communication with dealers. 
Lumbering is a form of business in which there are many chances of loss and in which experience and the judgment acquired thereby are of great value. Without these there is a large chance of failure. The inexperienced man may well prefer to pay a lumberman a commission on an operation, which he practically does when he sells the stumpage, instead of acting as his own lumberman. In determining the value of stumpage

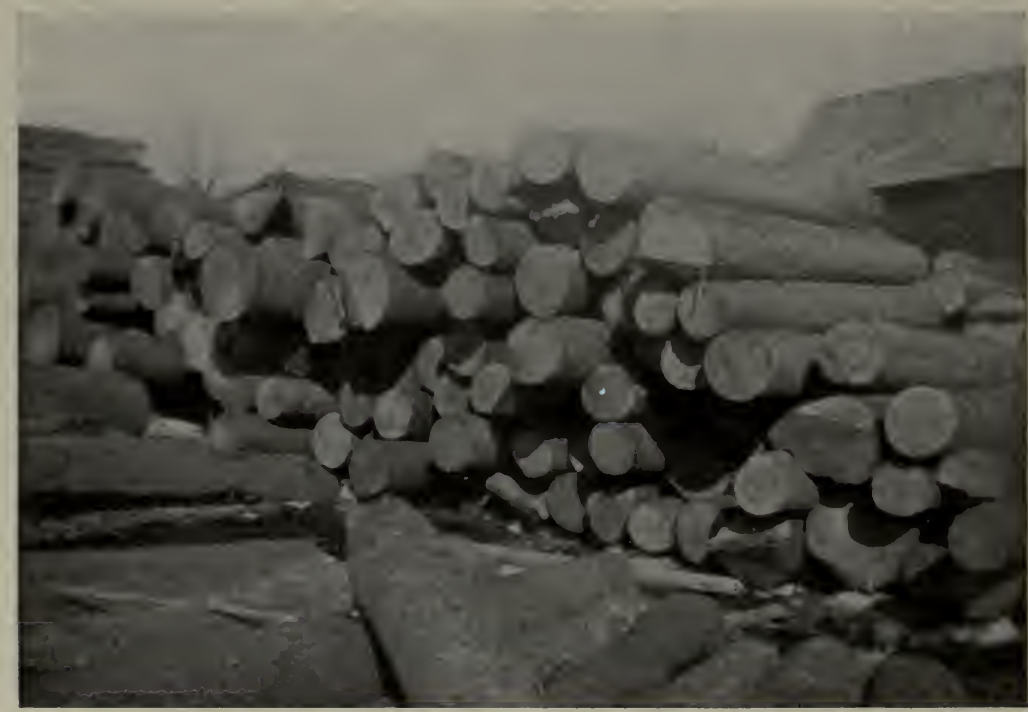

Fig. 62. - A selected lot of the best grade spruce logs for manufacture into clapboards.

it is necessary to make a distinction between the price which the owner could get for it if he sold to a lumberman or jobber, and what he could realize if he acted as his own jobber. If successful in the latter capacity he would have the additional profit which the lumberman would expect to make by the operation.

In most communities there are men who make a business in winter of hauling logs and wood. They will take a contract to haul the given distance at a certain price per thousand feet or per cord. The prices charged are usually based on a fair day's wage for men and teams, and this, of course, varies in different 
sections. The margin for profit is so small that unless the landowner has plenty of men and teams this contract method will be cheaper for him. For a six-mile haul in northern New England the price is usually about $\$ 3$ per thousand, or from $\$$ I.50 to $\$ 2.00$ a cord. For short hauls, where two trips a day can be made, the cost will be about half these figures. By deducting the cost of haul from the price to be received at the mill, the value of the felled timber is obtained. If it is to be transported by railroad or river, the further charges for such freightage must be added. In southern New England most of the lumbering is done with portable sawmills. In this case the price paid for logs at the mill is less because the manufactured lumber has to be transported to the railway or market.

To obtain the value of standing timber, a further deduction for the cost of cutting and logging is necessary. It usually costs about $\$$ I.25 per thousand board feet for cutting the trees. Logging ${ }^{1}$ in the north woods, where the logs are piled on skids near the cutting, is cheap - usually not over $\$ \mathrm{I} .50$ per $\mathrm{M}^{2}$ - but logging to the portable mill averages about \$2 per M. Cutting cordwood costs from 90 cents to $\$ 1.25$ per cord.

As said before, when the cost of cutting, logging, and hauling has been deducted from the price to be received for the logs, the stumpage value is secured, which is the value to the owner acting as his own jobber. A lumberman would not pay so much as this, as he must necessarily make his own profit also, which may be considered as a commission paid the lumberman by the owner.

The commission paid to a lumberman when stumpage is sold him varies considerably, but averages about one-half the net value of the standing timber. For example, if logs are worth \$1 a thousand feet at the mill and it costs $\$ 6$ to get them to the mill, they will be worth to the owner about $\$ 6$, if he is a successful lumberman. If he sells the stumpage, however, he will

1 Logging as here used refers to the operation of removing the log from the place where the tree grew to the skidway or portable mill; it does not include cutting or hauling from the skidway to the permanent mill or railroad.

${ }^{2} \mathrm{M}$ stands for thousand feet, board measure. 
rarely receive over $\$_{3}$ per thousand. In other words, he pays a commission of $\$_{3}$ to the lumberman.

The following is a summary of prices and costs for an average lumber operation, when the price of logs at the mill is $\$$ I 2 and for sawed lumber delivered is $\$ 20$ per M.

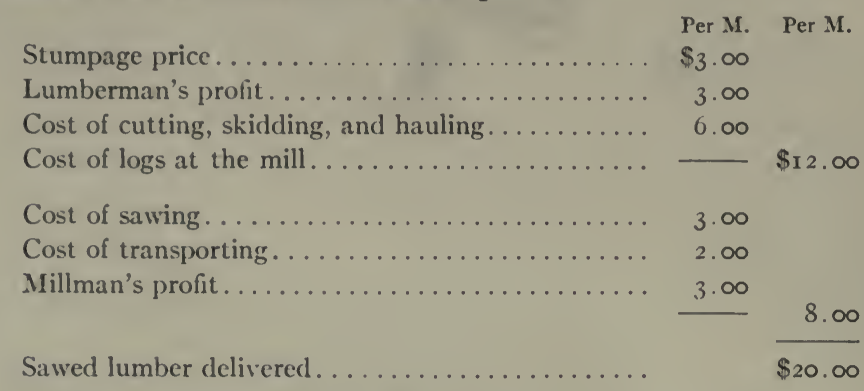

In the future this method will largely give way to that of selling at a definite rate per thousand feet, board measure (or other unit), based on the actual cut at the mill.

When the stumpage value per thousand feet and per cord has been ascertained, it is an easy matter to determine the value of the standing timber on a lot by simply multiplying by the amount obtained in the estimate.

In many cases when lumbermen make an offer for the stumpage the computations above referred to will be useful to ascertain whether offers are satisfactory or not. The experienced lumberman does not make these detailed computations but knows from past experience about what he can give for stumpage to make a fair profit.

Most timber in the past has been sold by the lot and not by stumpage price, but even in this case both the purchaser and the seller have their estimates of the amount of lumber on the lot, and regulate their prices accordingly. 


\section{CHAPTER $\mathrm{X}$.}

\section{UTILIZATION OF FOREST PRODUCTS.}

THE names "evergreen" and "conifers" are used interchangeably in common practice although some conifers, as the cypress and tamarack, are not evergreen but deciduous. In the same way the wood of the conifers is commonly called "softwood" although longleaf pine wood is harder than that of poplar and basswood. The term "hardwood" as it is usually used refers to the wood of the broad-leaved or deciduous species, and hence includes with the maple, oak, hickory, etc., some woods such as chestnut, willow, and poplar which are much softer.

The factors which influence the value of lumber are size and quality. Large, straight pine trees have been known to sell for $\$ 100$ apiece for derrick sticks because of their size. White pine lumber is also valued because of its soft workable wood. Pine planks free from knots and sawed from straight-grained old trees, have been sold as high as $\$ 300$ per thousand feet for pattern stock. When these prices are compared with the price of ordinary pine box boards, which are cut from second growth, crooked, sap pine, $\$ 20$ to $\$ 30$ per M., it will be seen that there is a great variation in value even for the same species.

There is nothing which detracts from the value of lumber more than the presence of knots, for they not only seriously interfere with its strength, but with its use for many special purposes. Lumber which is free from knots is called "clear."

Lumber Grades. - For the purpose of grading lumber for the market the various lumber dealers' associations have established uniform rules for grading so that a purchaser can know just what quality of lumber he is buying for a certain price.

The Maple Flooring Manufacturers' Association, ${ }^{1}$ for example,

1 Forest Service Bul. 7r. Rules and Specifications for Grading of Lumber, compiled by E. R. Hodson, r 906 . 
recognizes three grades: Clear, No. I, and factory flooring. The standard grades of hardwood lumber, as established by the National Hardwood Lumber Association, are: First, second, No. I, common, No. 2, common, and No. 3, common. Standard lengths are 6,8 , I0, I2, I4 and I6 feet, except as otherwise specified. Standard thicknesses are $\frac{3}{8}, \frac{1}{2}, \frac{5}{8}, \frac{3}{4}, \mathrm{I}, \mathrm{I} \frac{1}{4}, \mathrm{I} \frac{1}{2}, 2,2 \frac{1}{2}, 3$, and 4 inches. Standard defects are one knot $1 \frac{1}{4}$ inches in diameter; two sound knots not exceeding in extent or damage one.I $\frac{1}{4}$ inch knot; one inch of bright sap; one split not diverging more than I inch to the foot, etc. The way in which these rules are applied in grading is shown in the following: Maple firsts must be 8 inches or over wide, I0, I2, I 4 and I6 feet long, and free from all defects, except in pieces ro inches or over wide, which may have one sound standard defect.

There are several lumber associations in the country and each has its intricate grading rules. The result is that the grading of lumber, rapidly as it leaves the saw, requires an expert who knows the rules and applies them instinctively. The man who can do this can always command good wages. For this reason the small portable mill operator is usually unable to employ a trained grader and sells his lumber without grading ("log-run"). Many lumber wholesalers reap considerable profits from buying lumber in this way and grading it, because the price paid for a mixed lot is always low. Another difficulty in grading in small operations is that buyers will not take less than a carload lot of any one grade. It is undoubtedly feasible for two or more small operators to coöperate in the employment of a grader and in the shipping of their lumber. In fact, the day of the Coöperative Sawmill, which shall correspond to the Coöperative Creamery, may not be far off.

Log Grades. - It has not been customary in the past to grade logs and there are no standard grades, but as lumber becomes more valuable, especially for special uses, there is a tendency to distinguish various grades of logs. When a landowner can secure a higher rate for sound, straight logs than for the same number of board feet of inferior logs, there is undoubtedly an incentive 
for the practice of forestry. As an example of log grading, the following specifications of a Vermont manufacturer may be given:

Pine:

$$
\text { Log Grading Rules - Season igi2-I9I3. }
$$

No. I pine shall be at least $\mathrm{I} 2$ inches in diameter and free from knots and all defects, except that not to exceed 3 or 4 small hard knots may be admitted.

No. 2 pine shall include all logs of fair quality, 9 inches and above in diameter not included in No. I grade.

No. 3 pine shall include all logs less than 9 inches in diameter and all logs which, by reason of defects of any kind, are not included in the other grades. No log measured under 6 inches.

PRICES PAID FOR LOGS AT BRISTOL MILLS.

\begin{tabular}{|c|c|c|c|}
\hline & No. I. & No. 2. & No. 3. \\
\hline Pine........ & $\$ 18$ & \$I6 & \$I2 \\
\hline
\end{tabular}

For pine No. I and No. 2, cut I4 feet long, \$I more is paid than the above prices.

Lumber is spoken of as "sawed alive," or "through and through," when the log is not turned over in sawing, and both edges of each board have the bark on. In distinction to this is "square edged" lumber when the log is turned over in sawing so that the slabs are removed before the boards are sawed out.

In the marketing of lumber a careful study should be made of what each kind of lumber is best adapted for and where the best prices can be secured. To assist the timber owner the following partial list of wood-using industries is included.

Veneer. - The manufacture of veneer requires logs of the best quality. They must be at least ro inches in diameter inside the bark and must be sound so that they can be firmly held in the machine. Practically all the veneer made from native species is made by revolving the log against a knife. Because of the 
size required only old growth trees can be marketed in this way, and only the better logs of these. Several companies transport veneer logs considerable distances by rail. The farmer should not ship logs to a veneer mill without first ascertaining how poor a $\log$ will be accepted. Standard log lengths with a minimum of eight feet, are usually required. Nearly all native species are used for veneer. Basswood and elm veneer is chiefly used for the manufacture of boxes, crates, and other packages. Birch, maple, beech, and oak veneer is used in furniture and interior finish. The heart of the large yellow birch is commonly called "red birch" in the trade, and is used on a large scale for imitating mahogany.

Planing Mill Products. - Most of the sugar maple, yellow birch and beech cut in New England is used for planing mill products, mainly for flooring. The birch and maple are particularly adapted to this purpose. While beech wears well, it is used more for factory and mill flooring than in private residences. Only the better grades, those free from defects, are suitable for this purpose. For this reason, only old growth trees are at present used. Flooring is usually made in connection with other products, so that the poorer and smaller pieces can be used in their manufacture.

Sounding Boards and Clapboards. - The manufacture of piano sounding boards is important in some sections because it offers the best market for very high-grade spruce. Old spruce trees which have made an even and fairly good growth, and are absolutely free from knots have a quality of resiliency which especially commends it for violin stock and sounding boards. This market for spruce corresponds somewhat with the veneer market for hardwoods. Clapboard manufacture requires spruce next in quality to that used in sounding boards. Clapboards are made by sawing radially in toward the center of a $\log$, and the $\log$ must, therefore, have a diameter greater than the width of two clapboards, for a core is left in the center which is held by the machine. Only old growth logs are merchantable for this purpose. In many localities the butt logs are used for this 
purpose, while the inferior logs are used for ordinary lumber or pulp.

Chairs and Furniture. - Yellow birch, sugar maple, beech and oak are the chief lumbers used in these industries. Small pieces, especially in chair rungs, make close utilization possible, and small crooked logs are serviceable. Many mills simply make chair stock, which is shipped to a chair factory.

Boxes and Crates. - White pine is the leading box material and the poorer grades are used. Small trees, though often very knotty, make good shipping boxes, and much second growth timber is used. The light weight of pine is an important item in figuring on freight rates. Spruce is second to pine. It is odorless and tasteless and is therefore suitable as a container of food products such as butter, cheese and fruits. Because it is also a stainless wood it is used in large quantities for crating marble. Balsam and hemlock are also used extensively for boxes. Basswood and poplar are finer woods and go into boxes for carrying food products, and lock-corner boxes.

Shuttles, Spools and Bobbins. - Paper birch is the wood most preferred for this purpose, especially for spools. Sugar maple, yellow birch and beech are also used for many turned products. One great advantage derived from a market for these purposes is that the poorer grades may be used. There is no trouble anywhere in marketing first quality old hardwoods; but it is not everywhere possible to market crooked logs or logs with imperfections. Wherever this industry exists there should be an opportunity to market these poorer materials, and the industry should, therefore, be a benefit to the community.

Handles. - The factories manufacturing wooden handles of various kinds are one of the very best markets for hardwood. Hickory and ash bring the highest prices, but maple and beech furnish the greatest amount of raw material. Other species such as basswood, cherry, and applewood, are used in small amounts. The form of raw material required by establishments manufacturing different kinds of handles naturally differs a great deal. ${ }^{1}$

1 "Selling Woodlot Products on Michigan Farms," by E. H. Frothingham. 
Hickory, for example, goes into short and medium length handles, such as axe, pick, and hammer handles; ash is used for longer handles requiring greater stiffness, such as those for forks, hoes, and rakes. Broom handles take a larger part of the maple and beech logs. Small tool handles are made of a variety of woods; plane handles, for example, are made largely of applewood. Where strength is a requisite, second growth wood is often specified. In the manufacture of cant hooks and peaveys, for example, second growth maple and rock elm are usually required.

Vehicles and Vehicle Parts. - Two classes of wood are demanded by vehicle makers. One must possess strength and rigidity and goes into axles, braces, and frames; the other need not be particularly strong or rigid, and is worked into bodies. The frame woods include oak, ash, maple, birch, beech and elm; while the body woods are such species as basswood, yellow poplar, balsam fir, and red spruce.

\section{Bolts AND Billets.}

Bolts are short sections of logs. Billets are obtained by halving, quartering, or otherwise splitting or sawing bolts lengthwise. Under former conditions billets were often split or rived, but because of the greater waste from this method and the present high values most billets are now sawed out. A cord of average sized hickory bolts that will yield only about 700 rived spoke billets may be sawed into 900 billets. $^{1}$

Bolts and billets are used for cooperage, wood pulp, excelsior, wooden ware (pails and tubs), handles, vehicle parts, some agricultural implements, fruit and vegetable packages, athletic goods, etc.

Bolts are measured and sold by the cord, by linear feet, and by board feet. If they are 12 inches or over in diameter, they are usually sold by board measure. Billets are frequently sold by the piece or count, particularly if sawed and of uniform size, or are stacked and measured in cords, either standard or short cords of specified width.

\footnotetext{
1 Farmers' Bulletin 715, by W. R. Mattoon.
} 
Cooperage Stock. - The grades and specifications used in slack cooperage are very numerous, but the forms and qualities for tight-cooperage stock, including staves, hoops, and heading, are much restricted. The white oaks are practically the only woods used in tight-cooperage; but many different kinds of wood may be made into barrels for flour, sugar, vegetables, salt, cement, lime, etc. Among the chief species used for these are pine, beech, elm, maple, birch, basswood, spruce, ash, oak, cottonwood, tamarack, hemlock, chestnut and sycamore. For hoops the chief species used are elm, beech, ash, oak, maple and basswood.

Stock used for the manufacture of shuttles, spools and bobbins, handles and vehicle parts are purchased either in logs or bolts.

Railroad Ties. - Since the average life of an untreated railroad tie is only about seven years, and 3000 ties per mile of track are required, there is always a market for ties, although the price fluctuates somewhat. Ties are either sawed or hewed. In the case of the second growth stands of chestnut and oak in southern New England they are frequently hewed. In the case of large oak trees it is probably more profitable to saw good logs into lumber than to have them sawed into ties, but those which will not make high-grade lumber can better be used for ties. About 33 average first class railroad ties are equivalent to rooo board feet of lumber. A No. I tie is 8 or $8 \frac{1}{2}$ feet long, 8 inches wide and 6 inches thick. Switch ties are 7 by 9 inches in end dimensions and of different lengths. The best prices are paid for oak ties, which are used without preservative treatment, and on the parts of the track where there is the greatest strain.

Cedar and chestnut ties are used in large quantities. "Treatment ties" are mostly of beech, birch, hard maple and tamarack. Before using they are treated with a wood preservative.

Poles and Posts. - In southern New England chestnut is the chief species used for poles and posts. Red cedar and the various oaks are also favorite post timbers. In northern New England white cedar or arborvitæ is the chief tree used for poles and posts. Cedar poles cut and peeled during the late fall and winter should be laid in a single layer on a pair of skids to allow them to dry 
out. Posts are usually 7 or 8 feet long; and standard telegraph, telephone and electric poles are 25 feet or longer. Practically all species are used for fence posts, the prices varying according to the durability of the wood. Butternut and ash are in special demand in localities where the above species are lacking.

Piling. - The classification or grading of piling and the species. accepted depends largely upon its use, whether in fresh water, salt water, or on land, and upon its form and size. Specifications usually require piles to be fairly straight, sound, cut from live trees, and without defects that will impair durability. A top diameter of at least six inches is required. Butts of piles under 30 feet in length are required to have a diameter of from 12 to I6 inches; and butts of piles from 30 to 50 feet in length from 12 to 8 inches. Piling is sold at a stated price per linear foot for specified dimensions and kinds of wood. The price increases rapidly with increase in length and desirability of form.

Excelsior. - The chief woods used for excelsior manufacture are poplar and basswood. Although the latter is the preferred wood, this market is more important in connection with poplar since that is a much more common tree, and one which has fewer uses. Within 25 or 30 years after a fire poplar is large enough for excelsior bolts, although it will be found more profitable to leave stands a few years longer. Excelsior wood is bought in bolts 4 feet or 4 feet 6 inches long, either peeled or unpeeled. The poplar is usually cut in the early summer and peeled. Bolts from 4 to 8 inches in diameter are taken unsplit; from 8 to 2 inches in diameter they should be split in two; and when over I 2 inches they should be split into pieces 6 to 8 inches wide on the bark side. Bolts less than 4 inches in diameter are not accepted.

Wood for Distillation. - Since the beginning of the war wood alcohol and acetate have increased in value so much that several new manufacturing establishments have been built, some of them in the East. The products of hardwood distillation in the order of their importance are acetate of lime, wood alcohol and charcoal. A large amount of cordwood of maple, beech and birch is 
used in distillation and this offers a means of disposing of the top wood, small trees and low-grade material. This material is taken with the bark on in lengths of 4 feet or 50 inches, and to minimum diameters of usually 3 or 4 inches. Pieces over 6 inches are required to be split. Most wood for this purpose comes from the tops of trees in large lumber operations. Formerly charcoal was made by the slow burning of wood in pits. Large amounts of charcoal made in this way were used in the early iron and brass industries of New England. Charcoal was the chief product, but under present methods of distillation it has been relegated to a position of least importance. Burning charcoal in the old way has become almost a lost art, and it can hardly be made in that way, to compete with distillation charcoal.

Pulpwood. - A very large amount of wood is used annually for the production of paper (over 4,000,000 cords in the United States in I909). Of the total amount used, 60 per cent was spruce, and I 5 per cent hemlock. Pulpwood dealers buy either unsplit bolts by the cord, of I $28 \mathrm{cu}$. $\mathrm{ft}$., or logs by the thousand board feet, $\mathrm{o}^{*}$ cord. The wood is taken either peeled or unpeeled, most companies paying $\$ \mathrm{I} .00$ more per cord for peeled wood. Bolts are bought in 4 -foot lengths with a minimum diameter of 4 inches. Since the beginning of the war paper prices have been steadily advancing, and the prices paid for wood have also increased though not in proportion to the price of paper. In some localities prices paid for pulpwood have become so high that it pays better to put ordinary spruce into pulp than into lumber, but this is not usually the case.

Two general methods of manufacturing pulp are recognized: mechanical and chemical. Practically the entire supply of "ground-wood" pulp, as the product of the first method is called, is made from spruce. Much of the cheaper paper, such as newsprint, is made from this kind of pulp. The finer and stronger grades of paper are made from chemical pulp. Besides the spruce, hemlock, balsam, poplar, white and jack pine and tamarack can be used for chemical pulp. One cord of wood makes approximately one ton of ground-pulp; or one-half ton 
of chemical pulp. The reason that less chemical pulp is made from the same amount of wood is that the lignin is dissolved by this process.

Three chemical processes are in use: "sulphite," which is most extensively used in this country and is adapted for not too resinous conifers; "soda," which is well-established and adapted for either deciduous or highly resinous woods; and the "sulphate," which is at present little used in this country, but promises to be successful for very resinous woods.

Firewood. - The poorest products of the forest find a market for fuel, but the prices paid are so low that there is usually only a narrow margin of profit. Although there is an immense amount of wood used annually for fuel it is not a serious drain upon the forest, because it is made up mostly of material which cannot be used for other purposes. In many parts of New England the demand for cordwood, and the price paid for it is less than it was seventy-five years ago, because there is so much more land growing this class of material, because the rural population has declined, and because coal has so largely taken the place of wood as fuel. The price of firewood is regulated not by the supply of wood, except locally, but by the supply of coal. In the year of the great coal strike, for example, the price of wood advanced materially. In the same way the phenomenal industrial development of the country since the beginning of the war in Europe, and the shortage of cars, has brought about a coal shortage and is raising the value of wood.

In selling wood there are two units, both called "cords," which are apt to be confused. The "standard" cord is made up of wood cut 4 four feet long; while the "stove-wood" or "running" cord, as it is called in northern New England, or "run" for short, is made up of wood 16 inches long. Each is a pile 8 feet long and 4 feet high. It will be seen that the standard cord contains I 28 cubic feet, while the "run" contains only one-third as much. Since the shorter the pieces, the less amount of crookedness, a cord of stovewood actually contains a little more than one-third the volume of a standard cord. Cords made up of thick pieces 
contain more wood than those of small pieces, while round sticks give a higher wood volume than split ones of about the same size. The relative price of various kinds of wood depends upon its heating value and the rate at which it burns. Compared with coal, the heating value of different species is about as follows: one ton of coal is equal to a standard cord of hickory, oak, beech, birch, hard maple, ash, elm, locust or cherry; a cord and a half of soft maple; and two cords of cedar, poplar, or basswood. For fire places old applewood is in great demand, and brings a high price.

Lime kilns and brick yards use a great deal of wood, which they buy in four- or five-foot lengths. They can use very low-grade material and, therefore, do not pay high prices for it. In northern New England and New York the poorest of all wood, namely dead and down trees, can be used to a large extent in boiling sap. "Sugar wood," as it is called, has practically no stumpage value. In fact, in most woodlots there is much of this kind of material going to waste; and the owner would be benefited if he could give it away.

Tanning Bark. - The purpose of tanning is to render the skin permanently supple and durable by impregnation with tannin. There are several methods of tannage in use including that employing "vegetable tanning," " of which the forest produces several products. Chief of these are hemlock and oak bark, and chestnut wood. Hemlock bark has a tannin percentage of $\mathrm{I}_{3}$ per cent; chestnut oak bark, I 2 per cent; chestnut wood, 8 per cent. There is no tannin in the corky outer layers of bark. Fresh bark contains on an average, 45 per cent water and shrinks heavily during the drying process. While oak bark must be peeled in the spring immediately when the sap begins to rise, hemlock bark may be peeled at any time from May to September, peeling best in July. Dying trees will not peel. One cord of bark is produced on an average from 1500 board feet of hemlock. Bark is sold by the cord, but by a "cord" is meant 2240 pounds.

${ }^{1}$ Logging and Lumbering or Forest Utilization, by C. A. Schenck. 
Maple Sugar and Syrup. - Vermont, New York, and New Hampshire are among the six leading states of the country for the making of maple products, and in certain sections these are important factors in woodlot management. Maple sugar is formed from starch, which is formed in the leaves under the influence of sunlight and stored in certain sapwood cells. The best sap flow occurs in the early spring when there is an alternation of cold nights and warm days. Three pounds of sugar per tree is a good, although not extreme, yield. Sugar is worth from ro to 25 cents a pound, according to the quality and way it is put up.

There is little use in stating prices paid for different materials, since they vary so considerably from year to year. The following prices are, therefore, included not for the sake of indicating what any particular material will sell for, but to show the relative value of logs and wood for different markets. The prices given below are for logs delivered at the mill, or for wood delivered to the consumer.

PRICES PAID FOR LOGS, PER THOUSAND FEET, DELIVERED AT THE MILL.

\begin{tabular}{|c|c|c|}
\hline Species. & No. $\mathrm{I}$. & No. 3. \\
\hline 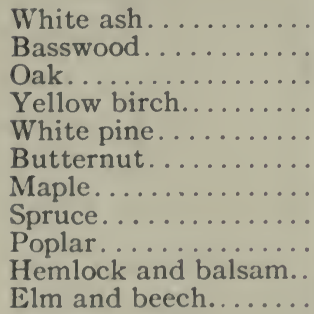 & $\begin{array}{l}\$ 25 \text { (tennis raquetstock) } \\
\$ 20 \text { (veneer grade) } \\
\$_{20} \text { (veneer grade) } \\
\text { I8 (veneer grade) } \\
\text { I8 } \\
\text { I } 5 \\
\text { I } 4 \\
\text { I } 4 \text { (clapboard stock) } \\
\text { I3 } \\
\text { I } 2 \\
\text { I } 2\end{array}$ & $\begin{array}{l}\text { \$1 } 2 \\
\text { \$ } 2 \\
7 \text { (cooperage stock) } \\
\text { I0 } \\
\text { I } 2 \text { (cooperage stock) } \\
\text { I0 } \\
7 \text { (cooperage stock) } \\
\text { I0 } \\
9 \\
8\end{array}$ \\
\hline
\end{tabular}

PRICES PAID FOR EXCELSIOR WOOD AND PULPWOOD, PER CORD, DELIVERED AT THE MILI.

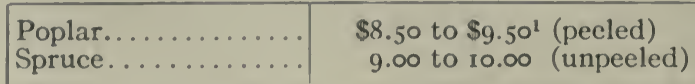

I N. H. For. Dept. Educational Circular, Mar. 12, 1917. 
PRICES PAID FOR RAILROAD TIES DELIVERED AT THE RAILROAD.

\begin{tabular}{|c|c|c|}
\hline Species. & No. 1. & No. 2. \\
\hline 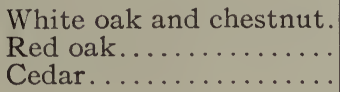 & $\begin{array}{c}\text { \$o.75 } \\
\cdots \cdots \\
0.50\end{array}$ & $\begin{array}{r}\text { \$o. } 62 \frac{1}{2} \\
0.42 \frac{1}{2}\end{array}$ \\
\hline
\end{tabular}

Chestnut poles are in demand at prices ranging from $\$ 2.50$ for 25 -foot lengths up to $\$ 18$ for the 6o-foot lengths.

In the winter of I916-17, cordwood delivered in 4-foot lengths at New England cities or villages brought from $\$ 3.50$ to $\$ 6.50$ per cord. The better qualities of cleft hardwood, such as white birch, maple and beech, brought $\$ 5.50$ to $\$ 6.50$ per cord. Even the poorer woods, such as gray birch and soft maple, brought from $\$ 3.50$ to $\$ 5$ per cord.

Hemlock bark until recently, sold for about $\$ 7$ a "cord" at the tannery. Since the war has interfered with the supply of Quebracho from South America, the demand for hemlock bark has greatly increased and it brings now, 1917, from \$10 to \$12 per cord. 


\section{CHAPTER XI. \\ GROWTH OF TREES AND FORESTS.}

THE study of the growth of trees and forests is, perhaps, the most difficult one in forestry and it is not proposed to attempt any complete presentation of the subject here. Several technical works, ${ }^{1}$ in English and in other languages, can be consulted for detailed information. The purpose of this chapter is rather to indicate the various kinds of growth and the general methods of study. For convenience the chapter is divided into two sections: $A$. Growth of trees; $B$. Growth of stands. A knowledge of the latter must rest upon a knowledge of the former.

For scientific purposes foresters speak of increase in volume of a tree or stand as "increment"; and the increase in diameter, sectional area, or height, as "accretion"; but ordinarily "growth" is used to cover both terms. The growth of a tree or stand may be the growth of a specific year, when it is called "current annual growth"; or of a specified period of years, called "periodic growth." By dividing the total volume by the age the "mean annual growth" is obtained.

\section{A. GROWTH OF TREES.}

There are many incentives for the study of tree growth, the chief being to establish a basis for forest-growth studies. For the forester to have a knowledge of the relative rates of growth of the more important species with which he deals is not only interesting, but very necessary. It is also advisable to know something of the relative growth of the same species under different conditions. Height growth is the best indication of

1 The most important American book dealing with this subject is, "Forest Mensuration," by Graves. Wiley \& Sons. 
the quality of the soil for any species, and consequently a table showing the average height of trees of different diameters and on different sites furnishes a ready means of determining the relative value of the sites for the species in question. In fact the three quality sites commonly recognized are usually determined by a classification of heights.

\section{Age of Trees.}

The age of a second-growth pine tree and of some other species up to fifty or sixty years can be obtained with fair accuracy by counting the whorls of branches, since the pine makes but one whorl each year. The buds of winter develop in the spring into branches and leader. Height growth is made entirely at the top. One can only approximate the age of most trees without cutting and counting the rings on the stump. Every fall, in our climate, the growth ceases and the tree remains at rest until spring. When activity in the cambium (the tissue just inside the bark) recommences, large wood cells are made with comparatively thin walls. Throughout the growing season new layers of cells are formed, but as the season advances these cells become smaller and their walls relatively thicker. On account of this difference in structure the wood formed in spring and early summer is lighter colored than that formed at the end of the season. A sharp, well-defined line in most species separates the dark growth of the fall from the light growth of the next spring, and the belt between these dark lines is called the annual ring. In the tropics where there are no welldefined seasons, no distinct rings occur, and the age of trees cannot be ascertained in this way. The distinctness of the rings in trees varies with the texture of the wood. In such woods as the spruce, pine, oak, ash, and chestnut the rings are easily distinguishable, although slow growth in some cases may require the use of a magnifying glass. With such fine-grained trees as beech, birch and maple, on the other hand, it is often very difficult to distinguish the rings. In obtaining the age of a tree by counting the rings on the stump it must be remembered 
that seedlings grow very slowly at first, especially under shade, and that a number of years may have been required for the seedling to reach the height of the stump. For this reason stumps to be analyzed should be cut as low as possible. The

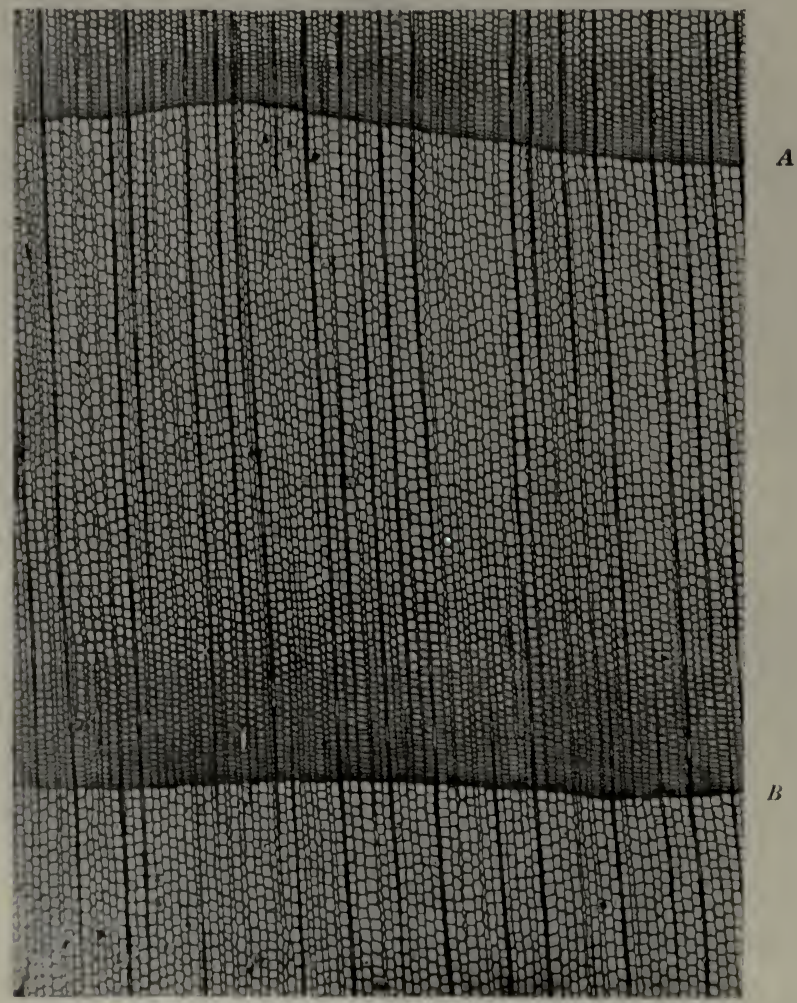

By permission of $S$. J. Record.

Fig. 63. - Cross section of a conifer (hemlock) highly magnified showing the annual rings of growth. $A$ to $B$ is one season's growth.

average period required by different species to reach stump height can be ascertained by studying the ages of a few seedlings of the desired height. The average age thus obtained should be added to the age of the tree as found on the stump. Thus, if there are one hundred and sixty rings on a hemlock stump, two feet high, and a study has shown that it requires fifteen years 
for hemlock under similar conditions to reach the height of two feet, then the total age of the tree will be estimated to be one hundred and seventy-five years.

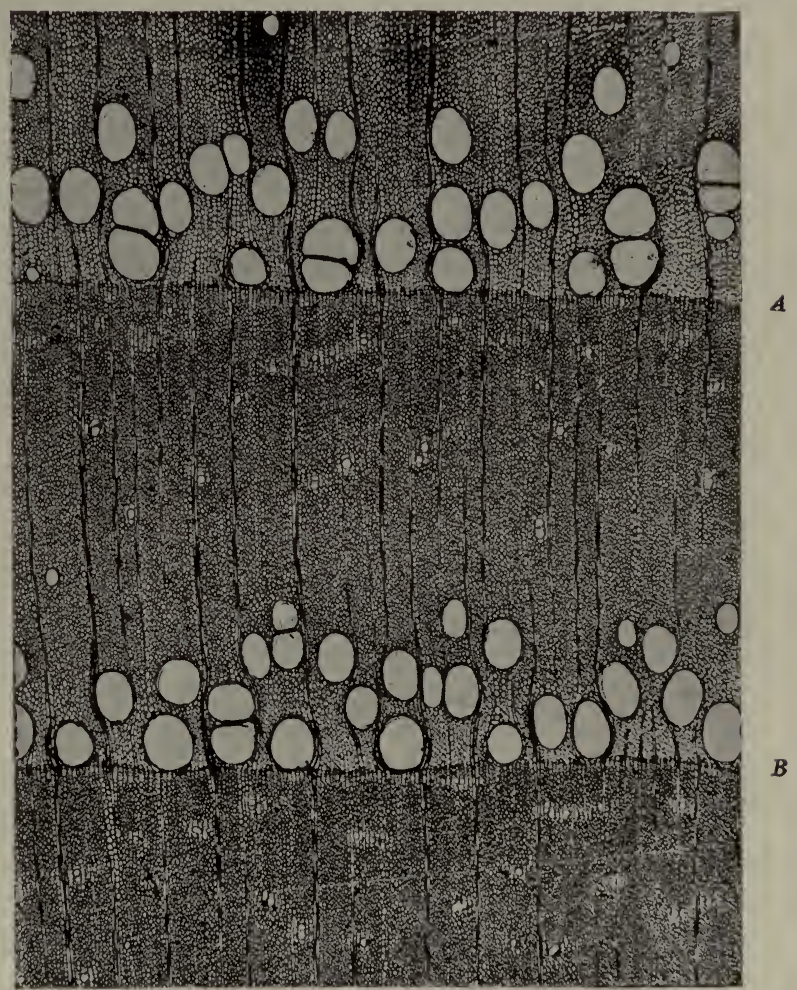

By permission of S.J. Record.

Fig. 64. - Cross section of a hardwood (black ash) highly magnified showing the annual rings of growth. $A$ to $B$ is one season's growth.

\section{Diameter Growth.}

For scientific purposes diameter growth should always be studied at a cross section taken at breast height, but as a matter of fact it is usually studied on the stumps of trees cut for lumbering. As the growth near the swelling of the roots is slightly greater than that higher up, the results are not entirely accurate. 
The rings should be counted and the growth measured on the average radius, in order to secure the average growth on all sides. The results of a study of this kind may be expressed in various ways as, for example: the average diameter of trees of different ages; the average age of trees of different diameters; the number of rings in the last inch of radius for trees of different diameters; the number of years required for each diameter inch class to increase one inch. Frequently confusion arises among amateurs between the first and the second of these expressions. They are apt to infer because the average diameter of a species fifty years old is fifteen inches that conversely the average age of trees of that species fifteen inches in diameter is fifty years. It is impossible to use the tables in this way, since one is made by averaging all trees that are fifteen inches in diameter, and the other is made by averaging a different set of trees that happen to be fifty years old. Among these, many that have been suppressed may be only eight or ten inches in diameter, and others that have grown rapidly may be correspondingly larger.

\section{Height Growth.}

By means of a hypsometer, ${ }^{1}$ the heights of standing trees can be rapidly and easily obtained. A table made from these results will show the average height of trees of different diameters, and as the method of determining the average age of different diameters has already been given, the average height growth can be ascertained by combining the two in the following manner.

\begin{tabular}{|c|c|c|c|}
\hline $\begin{array}{c}\text { Diameter, } \\
\text { breast high, } \\
\text { inches. }\end{array}$ & $\begin{array}{c}\text { Average height, } \\
\text { feet. }\end{array}$ & $\begin{array}{c}\text { Average age } \\
\text { of diameter } \\
\text { classes, years. }\end{array}$ & $\begin{array}{c}\text { Height growth } \\
\text { per year, } \\
\text { feet. }\end{array}$ \\
\hline & 25 & 20 & $\ldots$ \\
5 & 32 & 26 & I. I \\
6 & 40 & 32 & I.3 \\
7 & 48 & 40 & I.0 \\
8 & 57 & 44 & 2.2 \\
9 & 69 & 50 & 2.0 \\
I0 & & 50 \\
\hline
\end{tabular}

1 See note, page, 162. 
The height growth of individual trees can be obtained by counting the rings at the various sections into which thestree is cut. The number of rings on the stump represents the total age of the portion of the tree above the stump cut. Obviously a tree two hundred years old would have that number of rings at its.base, but it would have only one ring at the very tip for the growth made the last year. . Since the first ring is made by the leader, the number of rings in any section of the tree represents the number of years since the leader reached that point. Each section cut from the base up has, therefore, a diminishing. number of rings. This difference in age at various sections is the number of years required by the tree to grow the distance between the sections. By cutting felled trees into sections it is possible to read the record of their height growth.

\section{Volume Growth.}

To compute the mean annual growth of a tree after the volume and age are obtained, one divides the volume by the total age. The figures below, which are actual measurements of a few trees of different species, illustrate this method.

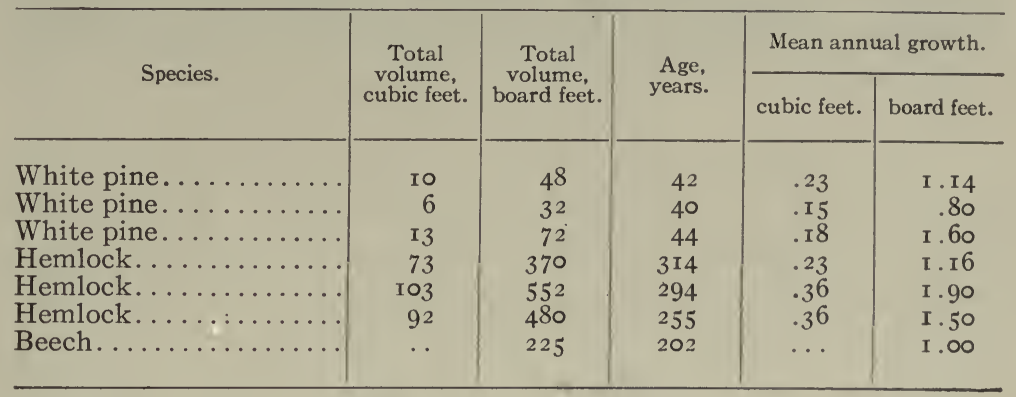

In the life of most trees, there are periods of slow growth due to suppression by neighboring trees, or to other causes. For this reason the mean annual growth is always low. Foresters sometimes speak of the economic age of a tree as referring to that part of the tree's life during which it made a normal growth. 
The chief purpose of studying tree volume growth is to be able to predict future growth for a coming period. This can best be done by a study of periodic growth made under conditions similar to those which are likely to obtain during the period to be predicted. Unless there is a radical change of conditions, the rate of growth during the ten coming years may fairly be expected to approximate that of the past ten years. The growth

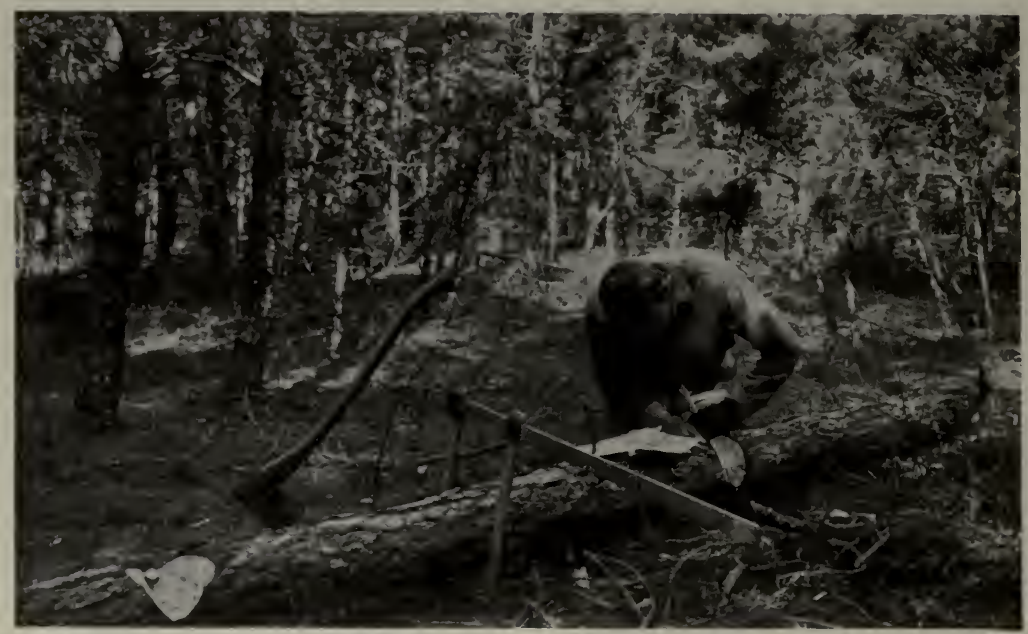

Fig. 65. - A study of the growth of an individual pitch pine tree is in progress.

of a past period is easily obtained, ( $\mathrm{I}$ ) by determining the present volume of the tree; (2) by counting the desired number of rings from the bark inward at both ends of the logs, and obtaining the volume of the tree at the beginning of the period; (3) by subtracting the second volume from the first. If the percentage of growth is desired, this remainder is divided by the volume at the beginning of the period. For example, a red oak sixty years old had a volume of 8.4 cubic feet. Its volume ten years ago was 6 cubic feet, and the tree grew at the rate of $\frac{2.4}{6}$ or 40 per cent. But the annual growth was .24 cubic foot, and hence its annual rate was 4 per cent. Usually the rate of growth of a 
tree in percentage falls with increasing age, in spite of the fact that it lays on more wood each year even if the width of the rings remains the same. Although the actual amount of wood made may increase, this increase is an ever-decreasing proportion of the total volume of the tree. Suppose, for example, that the red oak mentioned above grew 3 cubic feet during the decade between sixty and seventy years, the percentage of growth would be $\frac{3}{8.4}$ or 35 per cent.

The growth of standing trees can be conveniently studied by the use of a Pressler's increment borer. With this instrument a core of wood may be removed showing the width of the outside rings. By means of Schneider's formula which was devised in I 853 the percentage of growth, which the tree has been making, can be determined. This formula is:

$$
p=\frac{400}{n d}
$$

in which

$p=$ percentage of growth,

$n=$ number of rings in the last inch of radius,

$d=$ diameter at breast height.

This formula is applicable only to mature or nearly mature trees which have completed their height growth.

\section{B. GROWTH OF STANDS.}

Thus far the growth of individual trees has been considered; it is important for many purposes to ascertain the growth of stands or whole forests. Forest management depends very largely on this knowledge, especially the more intensive forms of management, such as are in use in.Europe. In Austria, for example, the policy is to cut and reproduce a stand as soon as it ceases to yield a satisfactory rate of interest. This is called the financial maturity of the stand. In Baden and other countries the forest working plans prescribe the cutting of an equal amount of wood each year, while in Württemberg, an equal area 
is cut over annually. A knowledge of the growth of the different stands is essential for the Baden system. In our own country, forestry which aims at a permanent income must rest on this kind of knowledge.

Just as we have considered the growth in diameter, height and volume of individual trees, so the growth of whole stands should be discussed under similar headings.

\section{Age of Stands.}

The age of a stand is usually considered to coincide with the age of the tree of average size in the stand. Such a tree is selected and its age ascertained as already described. This result is taken as the average age of the stand. Such a figure has more value in even-aged than in uneven-aged stands.

\section{Diameter Growth.}

The only accurate method of determining the diameter growth of a stand is to measure carefully all the trees in a stand, mark the points at which the measurements are taken, and remeasure after a series of years. Usually, for accurate purposes of this kind, the circumferences are measured and the diameter growth calculated from the growth in circumference. This, of course, is impracticable for immediate purposes. Fairly accurate data may be obtained from the mean sample tree or tree of average diameter. If the growth for the whole life of the stand is desired, the sample tree is felled and the rings counted and measured; but if the growth for the past few years only is required, a gash can be cut in an inch or so and the radial growth measured. The measurements from this sample tree are considered as representing the diameter growth of the average tree in the stand. Care must be taken that the average tree is normal in other respects as well as diameter.

\section{Height Growth.}

The height growth of a second-growth pine forest can easily be obtained by counting the whorls of branches of a few average 
trees. With other species it is necessary to cut and measure a few trees of average height.

\section{Volume Growth.}

One of the simplest methods of determining the volume growth of a stand is to obtain the growth per cent of a mean sample tree, that is, a tree of average size, and apply this per cent to the total estimated volume of the stand. Thus, if the sample tree is growing at the rate of 4 per cent and the total volume of the stand per acre is 20 cords, the growth of the stand may be considered as .8 of a cord per acre.

Often the mean annual growth of a stand is found and used as a basis for predicting the future growth. To secure this the stand is carefully estimated, and the total volume divided by the average age, which may be considered as the age of the average sized tree. For example, a stand which has produced forty cords to the acre in thirty years may be expected to produce about one and one-third cords per acre a year, for the next few years. This method of predicting growth is only approximate, because the growth of a stand is not uniform throughout its life. During the first part of its life the annual growth would exceed the mean annual growth, but in later years it would be less.

As a basis of forest management to indicate what different types of forest can produce under various conditions and at different ages, so-called yield tables ${ }^{1}$ are in use. Comparatively few of these have as yet been constructed in this country, but their construction is one of the most important lines of forestry research open to the forester. These tables are based on the measurements of many stands of a given type at different ages, and express the average volume per acre that can be expected at different ages. Such tables may be "local," if based on stands in a single community, or "general," when the data is secured over a large area, as a whole forest region. It will be

1 Several yield tables are included at the back of the book. 
readily seen that yield tables, for even-aged stands, not only are more easily made, but are of wider application than those for uneven-aged stands. Since the chief use of yield tables is to predict what forests will produce under favorable circumstances, they are based usually on the measurements of fully stocked stands, and then are called "normal." Often it is impossible in our irregular forests to find acres that are fully stocked, and consequently fractions of acres are measured rather than entire acres which include open areas. Three classes of forests need to be studied for the construction of such yield tables: $(a)$ unthinned pure forests; $(b)$ unthinned mixed forests; (c) thinned stands. Thus far all of the yield tables made in this country have been for the first and second classes, especially for pure forests, and do not indicate what these forests can produce when properly treated. In the future this last $(c)$ class of yield tables will be chiefly needed, especially in forest regions with the best market conditions.

Normal yield tables cannot be made for uneven-aged forests, since cuttings in such forests are made at regular intervals when only a part of the stand is removed. For rough yield tables with which to estimate the growth of such stands, it is customary in this country to designate in tabular form the number of years required for each diameter inch class to grow one inch, and from this to estimate the amount of timber that can be produced in a given period. Since the rate of growth is based almost entirely on conditions different from those which will prevail in the future, these tables should not be taken too seriously. 


\section{TABLES.}

It has been the aim of the authors to gather together all the reliable tables at present available, which contain figures showing volumes and growth for the important commercial trees and types. The principal log rules used in the region have also been included. In connection with the practice of forestry such tables are of great value, and it is unfortunate that as yet, owing to the recent rise of the movement, more information has not been obtained. The field is very incompletely covered and indeed for many species data is entirely lacking. For white pine, comparatively full studies have been made and many valuable tables are available.

Except for Tables X, XV, XX, XXV, XXXII, XLV, XLVI, LXVI and LXXV, none of the tables given here are original, but have been taken from various sources, of which acknowledgment has been made in the preface. Also, in connection with each table will be found a statement as to the source from which it was secured. 



\section{LIST OF TABLES.}

\section{LOG RULES.}

I. Scribner $\log$ rule. .....................................

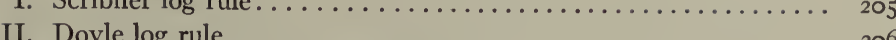

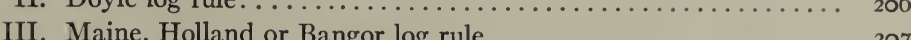

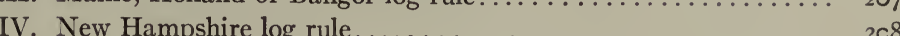

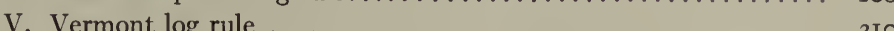

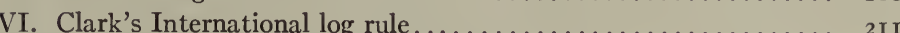

VII. Log rule for white pine, r-inch boards. ...

IX. Log rule for second-growth hardwoods, southern New Hampshire........................... 213

X. Log rule for chestnut in ties. . . . . . . . . . . . . . . . 213

XI. Humphrey decimal cord measure ............... 2I4

XII. Solid contents of $\operatorname{logs}$ in cubic feet................ 215

XIII. Stacked cubic feet in logs of given dimensions.......... 2 I6

\section{VOLUME TABLES.}

XIV. White ash, volume in board feet................ 217

$\mathrm{XV}$. White ash, volume in cubic feet................ 218

XVI. Aspen, merchantable volume in cubic feet............ 219

XVII. Aspen, merchantable volume in cords.............. 220

XVIII. Basswood in the Lake States, volume in board feet........ $22 \mathrm{I}$

XIX. Beech in New Hampshire, volume in board feet........... 222

XX. Beech, volume in cubic feet.................... 223

XXI. Paper birch, merchantable volume in cubic and board feet by diameters and heights...................... 224

XXII. Paper birch, merchantable volume in cubic and board feet by diameters and merchantable lengths............. 225

XXIII. Paper birch, solid contents per stacked cord for spoolwood bolts. . 226

XXIV. Yellow birch in New Hampshire, volume in board feet......... 226

XXV. Yellow birch in New Hampshire, volume in cubic feet....... 227

XXVI. Chestnut, volume in cubic feet for sprout trees, New Hampshire.. 227

XXVII. Chestnut, volume in cubic feet, Connecticut............ 228

XXVIII. Chestnut, volume in board feet, Connecticut. . . . . . . . . . 229

XXIX. Chestnut, volume in ties, Connecticut.............. 230

XXX. Red maple, volume in standard cords............. $23 \mathrm{I}$

XXXI. Sugar maple in New Hampshire, volume in board feet....... 232

XXXII. Sugar maple, volume in cubic feet............... 233

XXXIII. Red oak, volume in cubic and board feet, New Hampshire. . . . . 234 
XXXIV. Red, black and scarlet oaks, volume in cubic feet......... 235

XXXV. Red, black and scarlet oaks, volume in board feet......... 236

XXXVI. Red, black and scarlet oaks, volume in ties............. 237

XXXVIF. White oak, volume of cordwood in cubic feet............ $23 \mathrm{~S}$

XXXVIII. White and chestnut oaks, volume in cubic feet.......... 239

XXXIX. White and chestnut oaks, volume in board feet......... 240

XL. White and chestnut oaks, volume in ties............. 240

XLI. Cordwood converting factors . . . . . . . . .

XLII. Balsam fir in Maine and New York, volume in cords. . . . . . . . 242

XLIII. Balsam fir in New Hampshire, merchantable volume in cords. . 242

XLIV. Hemlock, volume in cubic and board feet, New Hampshire.... 243

XLV. Hemlock, volume in board feet, Vermont............ 244

XLVI. Hemlock bark, volume in stacked cords............. 245

XLVII. Norway pine, volume in board feet.............. 246

XLVIII. White pine, volume in board feet, New Hampshire........ 247

XLIX. White pine, volume in board feet, Massachusetts. . . . . . . 248

L. White pine, merchantable volume in cords............ 249

LI. White pine, volume in cubic feet............... 250

LII. Red spruce, volume in board feet, New Hampshire........ 25 I

LIII. Red spruce, volume in board feet, New Hampshire......... 252

LIV. Red spruce, volume in cubic feet of entire stem .......... 253

LV. Red spruce, volume in cords.................. 253

LVI. Red spruce, volume of unpeeled pulpwood in cubic feet...... 254

LVII. Number of trees of each size required to yield.......... 255

LVIII. Approximate amounts of various forest products contained in a standard car.................................... ${ }_{25} 6$

LIX. Approximate weights of various forest products......... 257

\section{GROIVTH OF INDIVIDUAL TREES.}

LX. White ash, diameter and height growth.............. 258

LXI. Aspen, diameter and height growth............... 259

LXII. Paper birch, height, diameter and volume growth........ 259

LXIII. Balsam fir and red spruce, comparative growth in height and

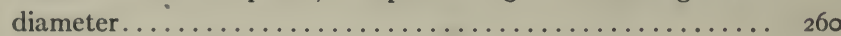

LXIV. Balsam fir in New York, volume growth in cubic feet....... 26 I

LXV. Balsam fir in Maine, volume growth in cubic feet........ 262

LXVI. Hemlock in Vermont. Diameter and volume growth........ 262

\section{YIELD TABLES.}

LXVII. White ash, yield of pure even-aged, well-stocked stands...... 263

LXVIII. Paper birch, yield per acre pure (roo per cent) stands........ 264

LXIX. Chestnut type. Growth in height, diameter and number of

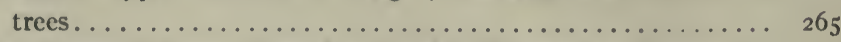

LXX. Oak-chestnut type. Growth in height, diameter and number of

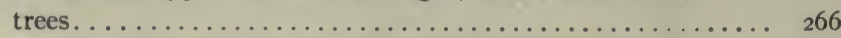

LXXI. Oak type. Growth in height, diameter and number of trees.... 267 
LXXII. Yield in cords for three types and qualities of soil, Connecticut... 268

LXXIII. Chestnut type. Yield in lumber and additional cordwood... . . 269

LXXIV. Chestnut type. Yield in ties and additional cordwood...... 269

LXXV. Mixed second-growth hardwood Vermont. Yield per acre.... 270

LXXVI. White pine. Yield per acre for pure even-aged second-growth stands............................... $27 \mathrm{r}$

LXXVII. White pine. Yield per acre in lumber for pure even-aged secondgrowth stands.......................... 272

LXXVIII. White pine. Yield per acre in board feet, cords and cubic feet... 272

LXXIX. White pine. Average annual growth per acre.......... 273

LXXX. Red spruce. Yield per acre for pure even-aged stands....... 274 

LOG RULES.

TABLE I. - SCRIBNER LOG RULE. ${ }^{\prime}$

(Decimal "C " $)^{2}$

\begin{tabular}{|c|c|c|c|c|c|c|c|}
\hline \multirow{3}{*}{$\begin{array}{c}\text { Diameter } \\
\text { in } \\
\text { inches. }\end{array}$} & \multicolumn{6}{|c|}{ Length in feet. } & \multirow{3}{*}{$\begin{array}{c}\text { Diameter } \\
\text { in } \\
\text { inches. }\end{array}$} \\
\hline & 6 & 8 & I0 & I2 & 14 & 16 & \\
\hline & \multicolumn{6}{|c|}{ Contents in board feet. } & \\
\hline 6 & 0.5 & 0.5 & I & I & I & 2 & 6 \\
\hline 7 & 0.5 & I & I & 2 & 2 & 3 & 7 \\
\hline 8 & I & I & 2 & 2 & 2 & 3 & 8 \\
\hline 9 & I & 2 & 3 & 3 & 3 & 4 & 9 \\
\hline I0 & 2 & 3 & 3 & 3 & 4 & 6 & I0 \\
\hline II & 2 & 3 & 4 & 4 & 5 & 7 & II \\
\hline I 2 & 3 & 4 & 5 & 6 & 7 & 8 & I 2 \\
\hline I3 & 4 & 5 & 6 & 7 & 8 & I0 & I3 \\
\hline I4 & 4 & 6 & 7 & 9 & IO & II & I4 \\
\hline I 5 & 5 & 7 & 9 & II & I 2 & I 4 & I5 \\
\hline 16 & 6 & 8 & IO & I 2 & I4 & I6 & I6 \\
\hline I7 & 7 & 9 & I 2 & I4 & 16 & I8 & I7 \\
\hline I8 & 8 & II & I3 & 16 & I9 & $2 \mathrm{I}$ & I8 \\
\hline I9 & 9 & I 2 & $I_{5}$ & I8 & $2 \mathrm{I}$ & 24 & I9 \\
\hline 20 & II & I4 & I7 & $2 \mathrm{I}$ & 24 & 28 & 20 \\
\hline $2 \mathrm{I}$ & I 2 & I5 & I9 & 23 & 27 & 30 & $2 \mathrm{I}$ \\
\hline 22 & I3 & I7 & $2 \mathrm{I}$ & 25 & 29 & 33 & 22 \\
\hline 23 & I4 & I9 & 23 & 28 & 33 & 38 & 23 \\
\hline 24 & I 5 & $2 I$ & 25 & 30 & 35 & 40 & 24 \\
\hline 25 & I7 & 23 & 29 & 34 & 40 & 46 & 25 \\
\hline 26 & I9 & 25 & $3 I$ & 37 & 44 & 50 & 26 \\
\hline 27 & $2 I$ & 27 & 34 & $4 I$ & 48 & 55 & 27 \\
\hline 28 & 22 & 29 & 36 & 44 & $5^{I}$ & $5^{8}$ & 28 \\
\hline 29 & 23 & $3 \mathrm{I}$ & $3^{8}$ & 46 & 53 & $6 I$ & 29 \\
\hline 30 & 25 & 33 & $4 \mathrm{I}$ & 49 & 57 & 66 & 30 \\
\hline $3 \mathrm{I}$ & 27 & 36 & 44 & 53 & 62 & $7 \mathrm{I}$ & $3 \mathrm{I}$ \\
\hline 32 & 28 & 37 & 46 & 55 & 64 & & 32 \\
\hline 33 & 29 & 39 & 49 & 59 & 69 & 78 & 33 \\
\hline 34 & 30 & 40 & $5^{\circ}$ & 60 & 70 & 80 & 34 \\
\hline 35 & 33 & 44 & 55 & 66 & 77 & 88 & 35 \\
\hline 36 & 35 & 46 & $5^{8}$ & 69 & $8 I$ & 92 & 36 \\
\hline
\end{tabular}

1 Taken from "The Woodsman's Handbook."

2 The total scale is obtained by multiplying the figures in this table by ro. Thus the contents of a 6-inch 8-foot $\log$ are given as 0.5 , so the total scale is 5 board feet. A 30 -inch 16 -foot $\log$ is given as 66 , or a total scale of 660 board feet. 
TABLE II. - DOYLE LOG RULE.

\begin{tabular}{|c|c|c|c|c|c|}
\hline \multirow{3}{*}{$\begin{array}{l}\text { Diameter in } \\
\text { inches. }\end{array}$} & \multicolumn{5}{|c|}{ Length in feet. } \\
\hline & 8 & 10 & 12 & 14 & 16 \\
\hline & \multicolumn{5}{|c|}{ Contents in board feet. } \\
\hline 6 & 2.0 & $2 \cdot 5$ & 3.0 & $3 \cdot 5$ & 4.0 \\
\hline 7 & $4 \cdot 5$ & 5.6 & 6.8 & $7 \cdot 9$ & 9.0 \\
\hline 8 & 8 & 10 & I 2 & I 4 & I6 \\
\hline 9 & I 2 & I6 & 19 & 22 & 25 \\
\hline 10 & I 8 & 23 & 27 & 32 & 36 \\
\hline I I & 24 & $3 I$ & 37 & 43 & 49 \\
\hline I 2 & 32 & 40 & 48 & 56 & 64 \\
\hline I3 & 40 & 50 & $6 I$ & 71 & $8 \mathrm{I}$ \\
\hline 14 & 50 & 62 & 75 & 88 & 100 \\
\hline I5 & 60 & 75 & $9 I$ & Io6 & I 2 I \\
\hline 16 & 72 & 90 & 108 & I 26 & I 44 \\
\hline 17 & 84 & 106 & 127 & 148 & 169 \\
\hline I 8 & 98 & 122 & I 47 & I 71 & I96 \\
\hline 19 & II 2 & I $4 \mathrm{I}$ & I 69 & I 97 & 225 \\
\hline 20 & 128 & 160 & 192 & 224 & $25^{6}$ \\
\hline $2 I$ & I 44 & I $8 \mathrm{I}$ & 217 & 253 & 289 \\
\hline 22 & 162 & 202 & 243 & 283 & 324 \\
\hline 23 & 180 & 226 & 271 & 313 & 359 \\
\hline 24 & 200 & 250 & 300 & 350 & 400 \\
\hline 25 & 220 & 276 & 331 & 386 & $44 \mathrm{I}$ \\
\hline 26 & 242 & 302 & $3^{6}{ }_{3}$ & 423 & 484 \\
\hline 27 & 264 & 330 & 397 & 463 & 530 \\
\hline 28 & 288 & 360 & 432 & 504 & 576 \\
\hline 29 & 312 & 391 & 469 & 547 & 625 \\
\hline 30 & 338 & 422 & 507 & 591 & 676 \\
\hline $3 I$ & 364 & 456 & 547 & 638 & 729 \\
\hline 32 & $39^{2}$ & 490 & 588 & 686 & 784 \\
\hline 33 & 420 & 526 & $63 x$ & 736 & $84 \mathrm{I}$ \\
\hline 34 & 450 & 562 & 675 & 787 & 900 \\
\hline 35 & 480 & 601 & 721 & $84 \mathrm{I}$ & 961 \\
\hline 36 & 512 & 640 & 768 & 896 & I, 024 \\
\hline
\end{tabular}


TABLES

TABLE III. - MAINE, HOLLAND, OR BANGOR LOG RULE. ${ }^{1}$

\begin{tabular}{|c|c|c|c|c|c|c|c|c|c|c|}
\hline \multirow{3}{*}{$\begin{array}{l}\text { Length in } \\
\text { feet. }\end{array}$} & \multicolumn{10}{|c|}{ Diameter in inches. } \\
\hline & & 6 & 7 & 8 & 9 & Io & II & 12 & 13 & 14 \\
\hline & \multicolumn{10}{|c|}{ Contents in board feet. } \\
\hline \multicolumn{2}{|l|}{ IO } & I 2 & I9 & 27 & 32 & 42 & $5^{I}$ & 65 & 75 & 89 \\
\hline \multicolumn{2}{|l|}{ II } & I4 & $2 \mathrm{I}$ & 30 & 36 & 46 & 57 & 70 & $8 \mathrm{I}$ & 98 \\
\hline \multicolumn{2}{|l|}{ I 2} & I 5 & 23 & 33 & 39 & $5^{I}$ & 62 & 78 & 90 & 107 \\
\hline \multicolumn{2}{|l|}{ I3 } & I 7 & 25 & 36 & 43 & 55 & 67 & 85 & 98 & I I 5 \\
\hline \multicolumn{2}{|l|}{ I4 } & I 8 & 27 & 39 & 46 & 59 & 72 & 92 & 105 & I 24 \\
\hline \multicolumn{2}{|l|}{ I5 } & I9 & 29 & $4 I$ & 49 & 64 & 78 & 98 & II 3 & I33 \\
\hline \multicolumn{2}{|l|}{ I6 } & 20 & $3 I$ & 44 & 52 & 68 & 83 & 105 & 120 & 142 \\
\hline \multicolumn{2}{|l|}{ I 7} & 22 & 33 & 47 & 56 & 72 & 88 & III & I 28 & I $5 \mathrm{I}$ \\
\hline \multicolumn{2}{|l|}{ I8 } & 23 & 35 & 50 & 59 & 76 & 93 & II 8 & I35 & 160 \\
\hline \multicolumn{2}{|l|}{19} & 24 & 37 & $5^{2}$ & 62 & $8 I$ & 98 & I 24 & I 43 & I69 \\
\hline \multicolumn{2}{|l|}{20} & 25 & 39 & 55 & 65 & $8_{5}$ & IO3 & I3I & I 50 & I 78 \\
\hline \multicolumn{2}{|l|}{$2 \mathrm{I}$} & 27 & $4 I$ & $5^{8}$ & 69 & 89 & 109 & I37 & $15^{8}$ & I 86 \\
\hline \multicolumn{2}{|l|}{22} & 28 & 43 & $6 \mathrm{I}$ & 72 & 94 & I I 4 & I 44 & 165 & I95 \\
\hline \multicolumn{2}{|l|}{23} & 29 & 45 & 63 & 75 & 98 & II9 & I $5^{\circ}$ & I 73 & 204 \\
\hline \multicolumn{2}{|l|}{24} & 30 & 47 & 66 & 78 & 102 & I 24 & I 57 & 180 & 213 \\
\hline \multicolumn{2}{|l|}{25} & 32 & 49 & 69 & 82 & 106 & I 29 & I64 & I 88 & 222 \\
\hline \multicolumn{2}{|l|}{26} & 33 & 50 & 72 & 85 & I I I & I34 & I 70 & I95 & $23 I$ \\
\hline 27 & & 34 & $5^{2}$ & 74 & 88 & I I 5 & I 40 & I 77 & 203 & 240 \\
\hline 28 & & 36 & 54 & 76 & 92 & II9 & I 45 & 183 & 210 & 249 \\
\hline 29 & & 37 & 56 & 79 & 95 & 123 & I 50 & I90 & 218 & 258 \\
\hline 30 & & 38 & $5^{8}$ & 82 & 98 & I 28 & I 55 & I96 & 225 & 266 \\
\hline & & & & & amete & inche & & & & \\
\hline $\begin{array}{l}\text { Length } \\
\text { in feet. }\end{array}$ & I5 & 16 & 17 & 18 & 19 & 20 & 21 & 22 & 23 & 24 \\
\hline & & & & & tents ir & oard fe & & & & \\
\hline IO & IOI & I I I & I 28 & I 45 & 169 & I 89 & 210 & 227 & 250 & 274 \\
\hline II & I I I & I 23 & 142 & 160 & I 87 & 209 & 232 & $25^{\circ}$ & 274 & 298 \\
\hline I2 & I $2 I$ & I 34 & I 54 & I 74 & 203 & 227 & 252 & 272 & 300 & 327 \\
\hline I3 & I3I & I 45 & 167 & 189 & 220 & 246 & 273 & 295 & 326 & 357 \\
\hline I4 & I4I & I 57 & I 79 & 203 & 237 & 265 & 294 & 318 & $35 \mathrm{I}$ & 384 \\
\hline I5 & ${ }^{I} 5^{I}$ & 168 & 192 & 218 & 254 & 284 & 315 & 340 & 376 & 412 \\
\hline 16 & I6I & I 79 & 205 & 232 & 271 & 302 & 336 & 363 & 401 & 439 \\
\hline 17 & I $7 \mathrm{I}$ & I90 & 218 & 247 & 288 & 321 & 357 & 386 & 426 & 466 \\
\hline I 8 & $\mathrm{I} 8 \mathrm{I}$ & 201 & $23 I$ & $26 \mathrm{I}$ & 305 & 340 & 378 & 408 & $45^{I}$ & 494 \\
\hline I9 & 192 & 212 & 243 & 276 & 322 & 359 & 399 & $43 I$ & 476 & . $52 \mathrm{I}$ \\
\hline 20 & 202 & 223 & 256 & 290 & 339 & 378 & 420 & 454 & 501 & 549 \\
\hline $2 I$ & 212 & 235 & 269 & 305 & $35^{6}$ & 397 & $44 \mathrm{I}$ & 476 & 526 & 576 \\
\hline 22 & 222 & 246 & 282 & 319 & 373 & 415 & 462 & 499 & $55^{\mathrm{I}}$ & 604 \\
\hline 23 & 232 & 257 & 295 & 334 & 390 & 4,35 & 483 & 522 & 576 & $63 I$ \\
\hline 24 & 242 & 268 & 307 & 348 & 407 & 454 & 504 & 545 & 601 & 659 \\
\hline 25 & $25^{2}$ & 279 & 320 & $36_{3}$ & 424 & 473 & 525 & 567 & 626 & 686 \\
\hline 26 & 262 & $29 I$ & 333 & 378 & $44 \mathrm{I}$ & $49 I$ & 545 & 590 & $65 \mathrm{I}$ & 713 \\
\hline 27 & 272 & 302 & 346 & 392 & $45^{8}$ & 510 & 566 & $6{ }_{3}$ & 676 & $74 \mathrm{I}$ \\
\hline 28 & 282 & 3 I 3 & 359 & 407 & 475 & 529 & $5^{87}$ & 635 & 701 & 768 \\
\hline 29 & 292 & 324 & 371 & $42 I$ & 492 & 548 & 608 & 658 & 726 & 796 \\
\hline 30 & 302 & 335 & 384 & 436 & 509 & 567 & 629 & $68 I$ & $75^{I}$ & 823 \\
\hline
\end{tabular}

1 Taken from "A Manual for Northern Woodsmen." 
TABLE IV. - NEW HAMPSHIRE LOG RULE. ${ }^{1}$

\begin{tabular}{|c|c|c|c|c|c|c|c|c|c|c|c|c|c|c|c|}
\hline \multirow{3}{*}{$\begin{array}{l}\text { Length } \\
\text { in feet. }\end{array}$} & \multicolumn{15}{|c|}{ Diameter in inches. } \\
\hline & 4 & 5 & 6 & 7 & 8 & 9 & I0 & II & 12 & 13 & 14 & 15 & 16 & 17 & 18 \\
\hline & \multicolumn{15}{|c|}{ Contents in board feet. } \\
\hline 12 & . & I & & & 3 & & & & 7 & 8 & 9 & I I & I 2 & & 15 \\
\hline I3 & & & & & $\ldots$ & 4 & 5 & 6 & & & I0 & II & I3 & 15 & $\ldots \ldots$ \\
\hline I4 & & & 2 & & & & & .. & 8 & 9 & I I & I 2 & 14 & & \\
\hline 15 & & & $\ldots$ & & $\ldots$ & ... & 6 & 7 & & I0 & & 13 & 15 & $\ldots$ & $\ldots$ \\
\hline 16 & I & . & $\ldots$ & 3 & 4 & 5 & & & 9 & $\ldots$ & I 2 & I4 & I6 & & 20 \\
\hline 17 & ... & & $\ldots$ & $\ldots$ & $\ldots$ & $\ldots$ & .. & 8 & & II & I3 & I 5 & I 7 & & $\ldots$ \\
\hline 18 & .. & & $\ldots$ & $\ldots$ & & & 7 & & 10 & I 2 & 14 & 16 & I8 & 20 & \\
\hline 19 & .. & $\cdots$ & $\ldots$ & & $\ldots$ & 6 & & 9 & & & $\ldots$ & I 7 & 19 & $\ldots$ & $\ldots$ \\
\hline 20 & .. & 2 & $\ldots$ & $\ldots$ & 5 & $\ldots$ & 8 & & I I & 13 & 15 & 18 & 20 & & 25 \\
\hline 21 & .. & $\ldots$ & 3 & 4 & $\ldots$ & & $\ldots$ & 10 & I 2 & 14 & . 6 & I 8 & $2 \mathrm{I}$ & $\ldots$ & $\ldots$ \\
\hline 22 & .. & & ... & $\ldots$ & $\ldots$ & 7 & $\ldots$ & $\ldots$ & $\ldots$ & $\ldots$ & I7 & 19 & 22 & 25 & ..... \\
\hline 23 & .. & & $\ldots$ & 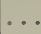 & & & 9 & II & I3 & 15 & & 20 & 23 & & \\
\hline 24 & & & & & 6 & & & $\ldots$ & ... & 16 & I 8 & $2 \mathrm{I}$ & 24 & & 30 \\
\hline 25 & .. & & & & $\ldots$ & 8 & $\ldots$ & 12 & I4 & $\ldots$ & I9 & 22 & 25 & & ..... \\
\hline 26 & & & & 5 & & $\ldots$ & IO & & ${ }^{\circ}$ & 17 & 20 & 23 & 26 & & \\
\hline 27 & . . & & .. & 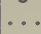 & $\ldots$ & $\ldots$ & $\ldots$ & 13 & 15 & 18 & $2 \mathrm{I}$ & 24 & 27 & 30 & ..... \\
\hline 28 & & & 4 & .. & 7 & 9 & II & $\ldots$ & I6 & $\ldots$ & $\ldots$ & 25 & 28 & & 35 \\
\hline 29 & .. & . & $\ldots$ & .. & $\ldots$ & $\ldots$ & $\ldots$ & $\ldots$ & $\ldots$ & 19 & 22 & 25 & 29 & $\ldots$ & ..... \\
\hline 30 & & & . & & & & & 14 & I7 & 20 & 23 & 26 & 30 & $\ldots .$. & \\
\hline 31 & . . & 3 & & 6 & & . & I 2 & $\ldots$ & $\ldots$ & $\ldots$ & 24 & 27 & $3 I$ & 35 & \\
\hline 32 & 2 & & & 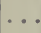 & 8 & 10 & $\ldots$ & I5 & I8 & 21 & $\ldots$ & 28 & 32 & $\ldots .$. & 40 \\
\hline 33 & .. & & & & .. & $\ldots$ & I3 & & $\ldots$ & 22 & 25 & 29 & 33 & & \\
\hline 34 & .. & & • & & .. & $\ldots$ & $\ldots$ & I6 & I9 & $\ldots$ & 26 & 30 & 34 & $\ldots$ & 43 \\
\hline 35 & & & .. & & $\ldots$ & II & $\ldots$ & $\ldots$ & $\ldots$ & 23 & 27 & 31 & 35 & 40 & ..... \\
\hline 36 & & & 5 & $\cdots$ & 9 & $\ldots$ & I4 & 17 & 20 & 24 & & 32 & 36 & & \\
\hline 37 & & & $\ldots$ & 7 & ... & $\ldots$ & $\ldots$ & $\ldots$ & $2 \mathrm{I}$ & $\ldots$ & 28 & 32 & 37 & $\ldots$ & $\ldots$ \\
\hline $3^{8}$ & & & & & ... & I 2 & 15 & I8 & $\ldots$ & 25 & 29 & 33 & 38 & $\therefore$ & $4^{8}$ \\
\hline 39 & & & & & $1 .$. & $\ldots$ & & $\cdots$ & 22 & 26 & 30 & 34 & 39 & $\ldots \ldots$ & $\ldots$ \\
\hline 40 & & & & & I0 & & I6 & I9 & & $\ldots$ & $3 \mathrm{I}$ & 35 & 40 & 45 & 50 \\
\hline
\end{tabular}

1 Taken from "A Manual for Northern Woodsmen." 
TABLE IV. - NEW HAMPSHIRE LOG RULE. - Continued.

\begin{tabular}{|c|c|c|c|c|c|c|c|c|c|c|c|c|c|c|c|c|c|c|}
\hline \multirow{3}{*}{$\begin{array}{l}\text { Length } \\
\text { in feet. }\end{array}$} & \multicolumn{18}{|c|}{ Diameter in inches. } \\
\hline & I9 & 20 & $2 \mathrm{I}$ & 22 & 23 & 24 & 25 & 26 & 27 & 28 & 29 & 30 & $3 \mathrm{I}$ & 32 & 33 & 34 & 35 & 36 \\
\hline & \multicolumn{18}{|c|}{ Contents in board feet. } \\
\hline I 2 & . & $\ldots$ & $2 \mathrm{I}$ & & 25 & 27 & 29 & 32 & 34 & 37 & 39 & 42 & 45 & 48 & $5 I$ & 54.0 & 57 & $6 I$ \\
\hline I3 & $\cdots$ & 20 & $\ldots$ & 25 & $\ldots$ & 29 & $\ldots$ & $\ldots$ & 37 & 40 & 43 & 46 & 49 & 52 & 55 & $5^{8} .0$ & 62 & 66 \\
\hline I4 & 20 & .. & $\ldots$ & $\cdots$ & $\cdots$ & $\cdots$ & 34 & 37 & 40 & 43 & 46 & 49 & 53 & 56 & 60 & 63.0 & 67 & 71 \\
\hline I5 & $\cdots$ & $\cdots$ & 26 & $\cdots$ & $3 I$ & $\cdots$ & $\cdots$ & $\cdots$ & 43 & 46 & 49 & 53 & 56 & 60 & 64 & 6.8 .0 & 72 & 76 \\
\hline I6 & $\cdots$ & 25 & $\cdots$ & 30 & $\cdots$ & 36 & 39 & $\ldots$ & 46 & 49 & 53 & $5^{6}$ & 60 & 64 & 68 & 72.0 & 77 & $8 I$ \\
\hline I7 & $\ldots$ & $\ldots$ & $\ldots$ & $\ldots$ & 35 & ... & $\ldots$ & 45 & 48 & $5^{2}$ & 56 & 60 & 64 & 68 & 72 & 77.0 & $8 I$ & 86 \\
\hline I8 & 25 & $\ldots$ & $3 I$ & & ... & 40 & 44 & $\ldots$ & $5 \mathrm{I}$ & 55 & 59 & 63 & 68 & 72 & 77 & $8 \mathrm{I} .0$ & 86 & $9 I$ \\
\hline I9 & $\ldots$ & 30 & $\ldots$ & 36 & 39 & $\ldots$ & $\ldots$ & 50 & 54 & $5^{8}$ & 62 & 67 & $7 \mathrm{I}$ & 76 & $8 I$ & 86.0 & $9 I$ & 96 \\
\hline 20 & $\cdots$ & $\ldots$ & $\ldots$ & $\cdots$ & $\cdots$ & 45 & 49 & $\ldots$ & 57 & $6 I$ & 66 & 70 & 75 & 80 & 85 & 90.0 & 961 & IOI \\
\hline $2 I$ & 30 & $\ldots$ & 36 & 40 & $\ldots$ & $\ldots$ & $\ldots$ & & 60 & 64 & 69 & 74 & 79 & 84 & 89 & 95.01 & 1001 & I06 \\
\hline 22 & $\cdots$ & $\cdots$ & $\ldots$ & $\ldots$ & 45 & 49 & $\ldots$ & $5^{8}$ & 63 & 67 & 72 & 77 & 83 & 88 & 94 & 99.01 & 1051 & I I I \\
\hline 23 & $\ldots$ & 36 & 40 & & $\ldots$ & $\ldots$ & $5^{6}$ & $\ldots$ & 65 & 70 & 76 & $8 \mathrm{I}$ & 86 & 92 & 98 & IO4.0 & I IO I & II 6 \\
\hline 24 & $\cdots$ & ... & $\ldots$ & 45 & 50 & & $\cdots$ & & 68 & 74 & 79 & 84 & 90 & 96 & IO2 & 108.0 & I I 5 & I 2 I \\
\hline 25 & 35 & 39 & $\ldots$ & $\ldots$ & $\ldots$ & $5^{6}$ & $6 I$ & 66 & $7 I$ & 77 & 82 & 88 & 94 I & 100 & 106 & II3.0 & 1201 & 126 \\
\hline 26 & ... & $\ldots$ & 45 & 49 & $\ldots$ & $\ldots$ & $\ldots$ & $\ldots$ & 74 & 80 & 85 & $9 \mathrm{I}$ & 98 I & IO4 & I I I & 117.0 & 125 & 132 \\
\hline 27 & $\ldots$ & $\ldots$ & $\ldots$ & $\cdots$ & 56 & & 66 & $\ldots$ & 77 & 83 & 89 & 95 & IOI 1 & 108 & I 5 & 122.0 & 129 & 137 \\
\hline 28 & 40 & & $\ldots$ & & & $6_{3}$ & $\ldots$ & 74 & 80 & 86 & 92 & 98 & 1051 & I I 2 & I I9 & I 26.0 & I34 I & 142 \\
\hline 29 & $\ldots$ & 45 & 50 & 55 & 60 & 65 & 71 & $\ldots$ & 83 & 89 & 95 & IO2 & rog 1 & I 16 & I 23 & 131.01 & I39 & 143 \\
\hline 30 & $\cdots$ & $\ldots$ & $\cdots$ & ... & $\ldots$ & $\ldots$ & $\cdots$ & & 85 & 92 & 99 & 105 & II 3 & 120 & 128 & 135.01 & 144 & 152 \\
\hline $3 I$ & $\ldots$ & $\cdots$ & $\cdots$ & $\because$ & 64 & $\ldots$ & $\cdots$ & 82 & 88 & 95 & 102 & IO9 & I 6 & I 24 & 132 & 140.0 & 148 & I 57 \\
\hline 32 & 45 & 50 & 55 & 60 & $\ldots$ & 72 & 78 & $\ldots$ & $9 \mathrm{I}$ & 98 & 105 & II 2 & I 20 & I 28 & 136 & 145.0 I & I 53 & 162 \\
\hline 33 & $\cdots$ & $\cdots$ & $\cdots$ & $\cdots$ & $\cdots$ & 74 & & $\ldots$ & 94 & IOI & 108 & II 6 & I 24 & I32 & 140 & I $49.0 \mathrm{I}$ & I 58 & 167 \\
\hline 34 & $\ldots$ & $\cdots$ & & 64 & 70 & $\ldots$ & 83 & 90 & 97 & IO4 & I I 2 & II9 & I 28 & 136 & I 45 & I 54.0 I & 163 & 172 \\
\hline 35 & 49 & 55 & 60 & $\ldots$ & $\ldots$ & $\ldots$ & & $\ldots$ & 100 & 107 & II 5 & 123 & I3I & 140 & I 49 & 158.01 & 167 & 177 \\
\hline 36 & $\ldots$ & $\ldots$ & $\ldots$ & $\ldots$ & 74 & $8 \mathbf{I}$ & 88 & 95 & 102 & I 10 & I I 8 & 126 & 135 & I44 & I 53 & 162.5 & 172 & 182 \\
\hline 37 & $\ldots$ & $\cdots$ & $\cdots$ & 70 & $\ldots$ & $\ldots$ & $\ldots$ & $\ldots$ & 105 & II 3 & 122 & I3O & 139 & 148 & I 57 & I $67.0 \mathrm{I}$ & 177 & I 87 \\
\hline 38 & $\cdots$ & $\cdots$ & 65 & $\cdots$ & $\cdots$ & $\cdots$ & $\ldots$ & 100 & 108 & 116 & I 25 & I33 & I 43 & 152 & 162 & I $72.0 \mathrm{I}$ & I82 & 192 \\
\hline 39 & 55 & $6 I$ & $\ldots$ & $\cdots$ & $8 I$ & $\cdots$ & 95 & $\ldots$ & I I I & I 20 & I 28 & I37 & 146 & I 56 & I66 & I 76.01 & I87 & I97 \\
\hline 40 & $\ldots$ & ... & $\cdots$ & 75 & $\cdots$ & 90 & $\cdots$ & 106 & I I 4 & 123 & I3I & 140 & I 50 & 160 & I 70 & I 81.0 & I9I & 202 \\
\hline
\end{tabular}


TABLE V. - VERMONT LOG RULE.

\begin{tabular}{|c|c|c|c|c|c|c|c|c|c|c|c|c|c|}
\hline \multirow{3}{*}{$\begin{array}{l}\text { Length } \\
\text { in feet. }\end{array}$} & \multicolumn{13}{|c|}{ Diameter in inches. } \\
\hline & 6 & 7 & 8 & 9 & 10 & II & 12 & 13 & 14 & 15 & I6 & 17 & I8 \\
\hline & \multicolumn{13}{|c|}{ Contents in board feet. } \\
\hline 8 & I 2 & I6 & $2 \mathrm{I}$ & 27 & 33 & 40 & 48 & $5^{6}$ & 65 & 75 & 85 & 96 & 108 \\
\hline 9 & I3 & I8 & 24 & 30 & 37 & 45 & 54 & 63 & 73 & 84 & 96 & 108 & I 2 I \\
\hline IO & I5 & 20 & 27 & 34 & 42 & 50 & 60 & 70 & 82 & 94 & 107 & I 20 & I 35 \\
\hline II & I6 & 22 & 29 & 37 & 46 & 55 & 66 & 77 & 90 & 103 & I I 7 & I32 & I 43 \\
\hline I 2 & I8 & 24 & 32 & 40 & 50 & 60 & 72 & 84 & - 98 & I I 2 & I 28 & I 44 & I 62 \\
\hline \multirow{3}{*}{$\begin{array}{l}\text { Length } \\
\text { in feet. }\end{array}$} & \multicolumn{13}{|c|}{ Diameter in inches. } \\
\hline & 19 & 20 & $2 I$ & 22 & 23 & & 24 & 25 & 26 & 27 & 25 & 29 & 30 \\
\hline & \multicolumn{13}{|c|}{ Contents in board feet. } \\
\hline 8 & 120 & I33 & I 47 & $16 I$ & I7 & 76 & I92 & 208 & 225 & 243 & $26 I$ & 280 & 300 \\
\hline 9 & I 35 & 150 & 165 & I 8I & I9 & & 216 & 234 & 253 & 273 & 294 & 315 & 337 \\
\hline IO & 150 & 167 & 184 & 202 & 22 & 20 & 240 & 260 & 282 & 304 & 327 & $35^{\circ}$ & 375 \\
\hline I I & 165 & 183 & 202 & 222 & 24 & 42 & 264 & 286 & 310 & 334 & 359 & 385 & $4 \mathrm{I} 2$ \\
\hline I 2 & 180 & 200 & 220 & 242 & & & 288 & 312 & 338 & 364 & $39^{2}$ & 420 & $45^{\circ}$ \\
\hline
\end{tabular}


TABLE VI. - CLARK'S INTERNATIONAL LOG RULE. ${ }^{1}$

\begin{tabular}{|c|c|c|c|c|c|c|c|c|c|c|c|c|c|}
\hline \multirow{3}{*}{$\begin{array}{l}\text { Diam- } \\
\text { eter in } \\
\text { inches. }\end{array}$} & \multicolumn{13}{|c|}{ Length in feet. } \\
\hline & 8 & 9 & Io & II & 12 & 13 & $I_{4}$ & 15 & 16 & 17 & 18 & I9 & 20 \\
\hline & \multicolumn{13}{|c|}{ Contents in board feet. 2} \\
\hline 6 & Io & Io & Io & I5 & I5 & I 5 & 20 & 20 & 20 & 25 & 25 & 30 & 30 \\
\hline 7 & I 5 & I 5 & I5 & 20 & 20 & 25 & 25 & 30 & 30 & 35 & 35 & 40 & 45 \\
\hline 8 & 20 & 20 & 25 & 25 & 30 & 35 & 35 & 40 & 45 & 45 & 50 & 55 & 60 \\
\hline 9 & 25 & 30 & 30 & 35 & 40 & 45 & 50 & 50 & 55 & 60 & 65 & 70 & 75 \\
\hline Io & 30 & 35 & 40 & 45 & 50 & 55 & 60 & 65 & 70 & 75 & 85 & 90 & 95 \\
\hline II & 40 & 45 & 50 & 55 & 65 & 70 & 75 & 80 & 90 & 95 & 105 & IIO & II 5 \\
\hline I 2 & 50 & 55 & 65 & 70 & 75 & 85 & 90 & 100 & 105 & I I 5 & I 25 & I30 & I40 \\
\hline I3 & 60 & 65 & 75 & 85 & 90 & 100 & IIo & I 20 & I 30 & I 40 & 145 & I55 & 165 \\
\hline 14 & 70 & 80 & 90 & 100 & I IO & I 20 & I30 & 140 & 150 & 160 & I 75 & 185 & 195 \\
\hline I 5 & 80 & 90 & 105 & I I 5 & I 25 & I 40 & I 50 & I60 & I 75 & I 85 & 200 & 215 & 225 \\
\hline 16 & 95 & 105 & I 20 & 130 & I 45 & 160 & I 70 & 185 & 200 & $2 \mathrm{I} 5$ & 230 & 245 & 260 \\
\hline I 7 & 105 & I 20 & I 35 & I 50 & I65 & 180 & I95 & 210 & 225 & 245 & 260 & 275 & 295 \\
\hline 18 & 120 & I35 & I 55 & 170 & 185 & 205 & 220 & 240 & 255 & 275 & 295 & 3 IO & 330 \\
\hline I9 & I 35 & 155 & 175 & I9O & 210 & 230 & $25^{\circ}$ & 270 & 290 & 310 & 330 & 350 & 370 \\
\hline 20 & 150 & 170 & I95 & 215 & 235 & 255 & 275 & 300 & 320 & 345 & 365 & 390 & $4 \mathrm{IO}$ \\
\hline 21 & I 70 & I90 & 215 & 235 & 260 & 285 & 305 & 330 & 355 & 380 & 405 & 430 & 455 \\
\hline 22 & 185 & 210 & 235 & 260 & 285 & 3 I 5 & 340 & 365 & 390 & 420 & 445 & 475 & 500 \\
\hline 23 & 205 & 230 & 260 & 285 & 315 & 345 & 370 & 400 & 430 & 460 & 49 & & $55^{\circ}$ \\
\hline 24 & 225 & 255 & 285 & 315 & 345 & 375 & 405 & 440 & 470 & 500 & 53 & 565 & 600 \\
\hline 25 & 245 & 275 & 3 IO & 345 & 375 & 4IO & 445 & 475 & $5^{10}$ & 545 & & 615. & $65^{\circ}$ \\
\hline 26 & 265 & 300 & 335 & 370 & 405 & 445 & 480 & 520 & 555 & 59 & 630 & 670 & 705 \\
\hline 27 & 290 & 325 & 365 & 405 & 440 & 480 & $5^{20}$ & 560 & 600 & 640 & 680 & 725 & 765 \\
\hline 28 & 310 & $35^{\circ}$ & 395 & 435 & 475 & $5^{20}$ & $5^{60}$ & 605 & 645 & 690 & 735 & 780 & 825 \\
\hline 29 & 335 & 380 & 425 & 470 & 510 & 560 & 605 & $65^{\circ}$ & 695 & 740 & 790 & 835 & 885 \\
\hline 30 & 360 & 405 & 455 & 500 & $55^{\circ}$ & 600 & 645 & 695 & 745 & 795 & 845 & 895 & $95^{\circ}$ \\
\hline $3 \mathrm{I}$ & 385 & 435 & 485 & 540 & 590 & 640 & 695 & 745 & 800 & 850 & 905 & 960 & 1015 \\
\hline 32 & $4 \mathrm{IO}$ & 465 & 520 & 575 & 630 & 685 & .740 & 795 & $85^{\circ}$ & 910 & 965 & 1025 & 1080 \\
\hline 33 & 440 & 495 & 555 & 610 & 670 & 730 & 790 & 850 & Q05 & 970 & 1030 & 1090 & II $5^{\circ}$ \\
\hline 34 & 470 & 530 & 590 & $65^{\circ}$ & 715 & 775 & 840 & 900 & 965 & 1030 & & I I 60 & 1225 \\
\hline 35 & 495 & $5^{60}$ & 625 & 690 & 755 & 825 & 890 & $955 \mathrm{I}$ & 1025 & 1095 & 1160 & I 230 & 1300 \\
\hline 36 & 525 & 595 & 665 & 735 & 800 & 875 & $945 \mathrm{I}$ & IOI 5 & 1085 & II 60 & 1230 & 1305 & I 375 \\
\hline 37 & 560 & 630 & 705 & 775 & $85^{\circ}$ & $925 \mathrm{I}$ & 1000 I & $1075 \mathrm{I}$ & II 50 & I 225 & I 300 & I380 & I 455 \\
\hline 38 & 590 & 665 & 745 & 820 & 895 & $975 \mathrm{I}$ & $1055 \mathrm{I}$ & II 35 I & I 210 & I 295 & I 375 & I 455 & I 535 \\
\hline 39 & 620 & 705 & 785 & 865 & 945 & $1030 \mathrm{I}$ & I I IO I & & I 280 & & & & \\
\hline 40 & 655 & 740 & 825 & 910 & 995 & $1085 \mathrm{I}$ & I I 70 I & 12601 & I345 & I 435 & 1525 & I6I 5 & 1705 \\
\hline $4 \mathrm{I}$ & 690 & 780 & 870 & 9601 & 10501 & I I 40 I & I $230 \mathrm{I}$ & $1325 \mathrm{I}$ & I 415 & & & & 1795 \\
\hline 42 & 725 & 820 & 915 & IOIO & I 100 & I 200 I & I 295 I & I 390 & 1490 & 1585 & 1685 & I 785 & 1885 \\
\hline 43 & 760 & 860 & 960 & 1060 & II 55 & I 260 I & I 360 I & 14601 & 1560 & 1665 & I $77^{\circ}$ & I870 & I975 \\
\hline 44 & 800 & 9001 & 1005 & I I I I ? & I 215 & & I $425 \mathrm{I}$ & 15301 & I635 & I 745 & 1855 & 1960 & 20 \\
\hline 45 & 835 & 945 & 1055 & 1160 & 1270 & I 380 I & I $490 \mathrm{I}$ & 1600 & 1715 & 1825 & I940 & 2050 & 2165 \\
\hline 46 & 875 & 990 & I 100 & I 215 & 13301 & I 445 I & I 560 I & I675 & I 790 & I9Io & 2030 & 2145 & 2265 \\
\hline 47 & $9 \mathrm{I} 5$ & 1035 & II 50 & I 270 & I 390 & 15101 & $1630 \mathrm{I}$ & I $75^{\circ}$ & 1870 & 1995 & 2120 & 2240 & 2365 \\
\hline 48 & 955 & 1080 & 1205 & 1325 & $145^{\circ}$ & I 575 & $\mathrm{I} 700 \mathrm{I}$ & 1830 & 1955 & 2085 & 2210 & 2340 & 2470 \\
\hline
\end{tabular}

3 By permission of Judson F. Clark.

2 The contents are for logs sawn with band saws cutting one-eighth inch kerf. 
TABLE VII. - LOG RULE FOR WHITE PINE, I-INCH BOARDS. ${ }^{1}$

Based on the measurement of $I 209$ logs sawed in Massachusetts mills. Circular saw, $\frac{1}{4}$-inch kerf.

\begin{tabular}{|c|c|c|c|c|c|c|c|c|c|}
\hline \multirow{3}{*}{$\begin{array}{l}\text { Diameter, } \\
\text { inside bark } \\
\text { at small } \\
\text { end, in } \\
\text { inches. }\end{array}$} & \multicolumn{4}{|c|}{ Length of log, feet. } & \multirow{3}{*}{$\begin{array}{l}\text { Diameter, } \\
\text { inside bark } \\
\text { at small } \\
\text { end, in } \\
\text { inches. }\end{array}$} & \multicolumn{4}{|c|}{ Length of $\log$, feet. } \\
\hline & Io & 12 & I4 & 16 & & I0 & 12 & 14 & I6 \\
\hline & \multicolumn{4}{|c|}{ Contents in board feet. } & & \multicolumn{4}{|c|}{ Contents in board feet. } \\
\hline 4 & 9 & I3 & I 7 & $2 I$ & I5 & 104 & I 29 & 150 & 180 \\
\hline 5 & 13 & 17 & $2 I$ & 26 & 16 & II 7 & 146 & 170 & 205 \\
\hline 6 & 17 & 22 & 27 & 32 & 17 & I3I & 165 & 192 & 230 \\
\hline 7 & 23 & 29 & 35 & 40 & I 8 & $\ldots \ldots$ & 184 & 220 & 256 \\
\hline 8 & 30 & 37 & 44 & $5^{I}$ & 19 & $\ldots \ldots$ & 206 & 243 & 288 \\
\hline 9 & 39 & 47 & 55 & 64 & 20 & $\ldots \ldots$ & 230 & 272 & $\ldots \ldots$ \\
\hline ro & 48 & $5^{8}$ & 68 & 79 & $2 I$ & $\ldots \ldots$ & 255 & 300 & $\ldots \ldots$ \\
\hline II & $5^{8}$ & 70 & 82 & 98 & 22 & & 280 & 330 & $\ldots \ldots$ \\
\hline 12 & 69 & 83 & 97 & I I 5 & 23 & $\ldots \ldots$ & 310 & ...... & $\ldots \ldots$ \\
\hline I3 & 80 & 96 & II3 & 136 & 24 & & 340 & $\ldots .$. & $\ldots \ldots$ \\
\hline 14 & 92 & III & I3I & 158 & & & & & \\
\hline
\end{tabular}

1 Taken from "Forest Mensuration of the White Pine in Massachusetts."

TABLE VIII. - LOG RULE FOR SECOND-GROWTH WHITE PINE. ${ }^{1}$ - SOUTHERN NEW HAMPSHIRE.

(Cut into both square and round-edged boards; circular saw, $\frac{1}{4}$-inch kerf.) Based on measurements of 5177 logs.

\begin{tabular}{|c|c|c|c|c|c|c|c|}
\hline \multirow{4}{*}{$\begin{array}{l}\text { Diameter, } \\
\text { inside bark } \\
\text { at small end } \\
\text { of log, } \\
\text { in inches. }\end{array}$} & \multicolumn{3}{|c|}{ Length of log, feet. } & \multirow{4}{*}{$\begin{array}{l}\text { Diameter, } \\
\text { inside bark } \\
\text { at small end } \\
\text { of log, } \\
\text { in inches. }\end{array}$} & \multicolumn{3}{|c|}{ Length of $\log$, feet. } \\
\hline & I0 & 12 & 14 & & 10 & 12 & 14 \\
\hline & $\begin{array}{c}\text { Basis, } \\
\text { 6I3 logs. }\end{array}$ & $\begin{array}{l}\text { Basis, } \\
\text { I9I5 logs. }\end{array}$ & $\begin{array}{c}\text { Basis, } \\
2649 \text { logs. }\end{array}$ & & $\underset{\text { 6r3 logs. }}{\text { Basis, }}$ & $\begin{array}{l}\text { Basis, } \\
\text { I9I5 logs. }\end{array}$ & $\begin{array}{c}\text { Basis, } \\
2649 \text { logs. }\end{array}$ \\
\hline & \multicolumn{3}{|c|}{ Contents in board feet. } & & \multicolumn{3}{|c|}{ Contents in board feet. } \\
\hline 3 & 5 & 7 & 9 & 14 & 89 & I I 2 & I 34 \\
\hline 4 & 8 & ro & 12 & I5 & 102 & I30 & 155 \\
\hline 5 & I3 & I5 & I 7 & I6 & $\ldots \ldots$ & 149 & I 76 \\
\hline 6 & I8 & $2 I$ & 24 & 17 & $\ldots \ldots$ & 169 & I98 \\
\hline 7 & 24 & 28 & 33 & I 8 & $\ldots \ldots$ & 189 & 222 \\
\hline 8 & 30 & 36 & 42 & 19 & $\ldots \ldots$ & 2 II & 247 \\
\hline 9 & $3^{8}$ & 46 & 52 & 20 & $\ldots \ldots$ & 235 & 275 \\
\hline IO & 47 & 56 & 65 & $2 I$ & $\ldots \ldots \ldots$ & 260 & 304 \\
\hline II & 56 & 68 & 80 & 22 & $\ldots \ldots$ & 284 & 333 \\
\hline 12 & 66 & $8 I$ & 97 & 23 & $\ldots \ldots$ & $\ldots \ldots \ldots$ & 364 \\
\hline I3 & 77 & 96 & II 5 & 24 & $\ldots \ldots$ & $\ldots \ldots \ldots$ & 398 \\
\hline
\end{tabular}

1 Taken from Biennial Report of the New Hampshire Forestry Commission for the years $1905-1906$. 
TABLE IX. - LOG RULE FOR SECOND-GROWTH HARDWOODS. ${ }^{1}$ - SOUTHERN NEW HAMPSHIRE.

(Cut into $\mathrm{I} \frac{1}{8}$-inch, round-edged boards; circular saw, $\frac{1}{4}$-inch kerf.) Based on I83I I 2-foot logs.

\begin{tabular}{|c|c|c|c|c|c|c|c|}
\hline \multirow{3}{*}{$\begin{array}{c}\text { Diameter, } \\
\text { inside bark } \\
\text { at small end } \\
\text { of log, } \\
\text { in inches. }\end{array}$} & \multicolumn{3}{|c|}{ Length of log, feet. } & \multirow{3}{*}{$\begin{array}{l}\text { Diameter, } \\
\text { inside bark } \\
\text { at small end } \\
\text { of log, } \\
\text { in inches. }\end{array}$} & \multicolumn{3}{|c|}{ Length of $\log$, feet. } \\
\hline & I0 & I2 & I4 & & Io & 12 & 14 \\
\hline & \multicolumn{3}{|c|}{ Contents in board feet. } & & \multicolumn{3}{|c|}{ Contents in board feet. } \\
\hline 4 & 6 & 8 & IO & I2 & 68 & 82 & 96 \\
\hline 5 & 9 & II & I3 & I3 & 83 & 100 & II 7 \\
\hline 6 & I3 & I6 & I9 & I4 & 100 & I 20 & 140 \\
\hline 7 & I8 & 22 & 26 & I5 & II 7 & I4I & $16_{5}$ \\
\hline 8 & 25 & 30 & 35 & I6 & I37 & 165 & I93 \\
\hline 9 & 32 & 39 & 46 & I7 & 160 & I92 & 224 \\
\hline IO & 42 & $5 \mathrm{I}$ & 60 & I8 & I 85 & 222 & 259 \\
\hline II & 54 & 65 & 76 & & & & \\
\hline
\end{tabular}

1 Taken from Biennial Report of the New Hampshire Forestry Commission for the years I905-I906.

TABLE X. - LOG RULE GIVING VOLUME OF CHESTNUT LOGS 8 FEET LONG IN TIES. ${ }^{1}$

\begin{tabular}{c|c|c||c|c|c}
\hline $\begin{array}{c}\text { Diameter, out- } \\
\text { side bark at } \\
\text { small end, in } \\
\text { inches. }\end{array}$ & $\begin{array}{c}\text { Number of } \\
\text { ties. }\end{array}$ & Class. & $\begin{array}{c}\text { Diameter, out- } \\
\text { side bark at } \\
\text { small end, in } \\
\text { inches. }\end{array}$ & $\begin{array}{c}\text { Number of } \\
\text { ties. }\end{array}$ & Class. \\
\hline & I & Second & I6 & 2 & First \\
7 & I & Second & I7 & 2 & First \\
8 & I & First & I8 & 3 & First \\
9 & I & First & I9 & 3 & First \\
I0 & I & First & 20 & 4 & First \\
II & I & First & $2 I$ & 4 & First \\
I2 & I & First & 22 & 5 & First \\
I3 & 2 & First & 23 & 6 & First \\
I4 & 2 & First & 24 & 7 & First \\
I5 & 2 & I9 & & \\
\hline
\end{tabular}

1 Taken from Bull. I54 of the Connecticut Agricultural Experiment Station. 
TABLE XI. - THE HUMPHREY DECIMAL CORD MEASURE.

\begin{tabular}{|c|c|c|c|c|c|c|c|c|c|}
\hline \multirow{3}{*}{$\begin{array}{l}\text { Diameter } \\
\text { at middle } \\
\text { outside } \\
\text { bark, } \\
\text { inches. }\end{array}$} & \multicolumn{9}{|c|}{ Length of $\log$ in feet. } \\
\hline & 8 & 9 & 10 & II & 12 & 13 & 14 & 15 & 16 \\
\hline & \multicolumn{9}{|c|}{ Volume in $\mathrm{I} / \mathrm{rooths}$ cords. } \\
\hline 3 & 0.4 & 0.4 & 0.5 & 0.5 & 0.6 & 0.6 & 0.7 & 0.7 & 0.8 \\
\hline 4 & 0.7 & 0.8 & 0.9 & I. 0 & 1.0 & I.I & I. 2 & I. 3 & I. 4 \\
\hline 5 & I. I & I. 2 & I. 4 & I. 5 & 1. 6 & I. 7 & I. 9 & 2.0 & 2.2 \\
\hline 6 & I. 6 & 1.8 & 2.0 & 2.2 & $2 \cdot 3$ & 2.5 & 2.7 & 2.9 & 3.1 \\
\hline 7 & 2.1 & 2.4 & 2.7 & 2.9 & 3.2 & 3.4 & $3 \cdot 7$ & 4.0 & $4 \cdot 3$ \\
\hline 8 & 2.8 & 3.1 & $3 \cdot 5$ & $3 \cdot 9$ & $4 \cdot 2$ & 4.6 & $4 \cdot 9$ & 5.2 & 5.6 \\
\hline 9 & $3 \cdot 5$ & 4.0 & $4 \cdot 4$ & $4 \cdot 9$ & $5 \cdot 3$ & $5 \cdot 7$ & 6.2 & 6.6 & 7.1 \\
\hline 10 & 4.4 & 4.9 & 5.4 & 6.0 & 6.5 & 7.1 & 7.6 & 8.2 & 8.7 \\
\hline I I & 5.2 & 5.9 & 6.7 & 7.2 & 7.9 & 8.5 & 9.2 & 9.8 & 10.5 \\
\hline 12 & 6.3 & $7 \cdot 1$ & 7.8 & 8.6 & 9.4 & 10.2 & II.O & II. 8 & 12.5 \\
\hline 13 & $7 \cdot 3$ & 8.2 & 9.2 & IO.I & II.O & II .9 & 12.9 & I 3.8 & 14.7 \\
\hline I4 & 8.5 & 9.6 & 10.7 & II.7 & I 2.8 & 13.8 & I4. 9 & 16.0 & 17.1 \\
\hline I5 & 9.8 & II.O & 12.2 & I 3.4 & $14: 7$ & 15.9 & 17.1 & 18.4 & I9.6 \\
\hline 16 & II II & 12.5 & I3.9 & I $5 \cdot 3$ & 16.7 & 18.1 & 19.5 & 20.9 & 22.3 \\
\hline I 7 & I 2.6 & 14.2 & 15.7 & 17.3 & 18.9 & 20.5 & 22.0 & 23.6 & 25.2 \\
\hline I8 & I4. I & I 5.9 & I 7.6 & I 9.4 & 21.2 & 23.0 & 24.7 & 26.5 & 28.3 \\
\hline I9 & $15 \cdot 7$ & 17.7 & 19.7 & 21.6 & 23.6 & 25.6 & 27.5 & 29.5 & $31 \cdot 5$ \\
\hline 20 & I 7.4 & 19.6 & 21.8 & 24.0 & 26.2 & 28.4 & 30.6 & 32.8 & 34.9 \\
\hline $2 \mathrm{I}$ & 19.2 & 21.7 & 24.0 & 26.5 & 28.8 & $3 \mathrm{I} \cdot 3$ & 33.6 & 36.1 & 38.5 \\
\hline 22 & $2 \mathrm{I} . \mathrm{I}$ & 23.7 & 26.4 & 29.0 & 31.6 & $34 \cdot 3$ & 36.9 & $39 \cdot 5$ & 42.2 \\
\hline 23 & $23 \cdot I$ & 26.0 & 28.8 & 31.7 & 34.6 & 37.5 & 40.4 & $43 \cdot 3$ & $46 . I$ \\
\hline 24 & $25 \cdot 1$ & 28.2 & 3 I. 4 & $34 \cdot 5$ & 37.6 & 40.8 & $43 \cdot 9$ & $47 \cdot I$ & 50.2 \\
\hline 25 & $27 \cdot 3$ & 30.6 & $34 . \mathrm{I}$ & $37 \cdot 5$ & 40.9 & $44 \cdot 3$ & 47.7 & $5 \mathrm{I} . \mathrm{I}$ & 54.5 \\
\hline 26 & 29.5 & 33.2 & 36.9 & 40.5 & 44.2 & 47.8 & 51.6 & 55.2 & 59.0 \\
\hline 27 & 31.8 & 35.8 & 39.7 & 43.7 & $47 \cdot 7$ & 51.7 & $55 \cdot 7$ & 59.7 & 63.7 \\
\hline 28 & 34.2 & $3^{8} \cdot 5$ & 42.7 & 47.0 & 5 I. 2 & $55 \cdot 5$ & 59.8 & 64.2 & 68.4 \\
\hline 29 & 36.7 & $4 \mathrm{I} \cdot 3$ & 45.8 & 50.3 & 55.0 & 59.5 & 64.1 & 68.7 & $73 \cdot 3$ \\
\hline 30 & 39.2 & $44 \cdot I$ & 49.0 & 54.0 & 58.8 & 63.7 & 68.6 & 73.5 & 78.5 \\
\hline $3 I$ & 4 I. 9 & 47.2 & 52.4 & 57.5 & 62.9 & 68.1 & 73.2 & 78.6 & 83.8 \\
\hline 32 & 44.6 & 50.2 & 55.8 & 61.3 & 66.9 & $72 \cdot 3$ & 78.0 & 83.7 & $89 . \mathrm{I}$ \\
\hline 33 & 47.5 & 53.4 & 58.3 & 65.2 & 71.2 & 77.1 & 83.1 & 89.0 & 95.0 \\
\hline 34 & 50.4 & 56.6 & 63.0 & 69.2 & $75 \cdot 5$ & 81.9 & 88.2 & 94.0 & 102.0 \\
\hline 35 & $53 \cdot 3$ & 60.0 & 66.7 & $73 \cdot 3$ & 80.0 & 86.7 & 93.0 & 100.0 & 107.0 \\
\hline 36 & $5^{6.5}$ & 63.6 & 70.6 & 77.8 & 84.9 & 92.0 & 99.0 & 106.0 & II 3.0 \\
\hline 37 & 59.8 & 67.1 & 74.6 & 82.1 & 89.4 & $97 . \circ$ & 104.0 & 112.0 & II 9.0 \\
\hline 38 & 63.0 & 70.8 & 78.7 & 86.4 & 94.0 & 102.0 & I 10.0 & 118.0 & $\mathrm{I} 26.0$ \\
\hline 39 & 66.2 & 74.4 & 82.8 & $9 \mathrm{I}$. I & 99.0 & 108.0 & II 6.0 & I 24.0 & 132.0 \\
\hline 40 & 69.7 & 78.4 & $87 . \mathbf{I}$ & 96.0 & 105.0 & II 3.0 & I 22.0 & I 31.0 & I 39.0 \\
\hline
\end{tabular}




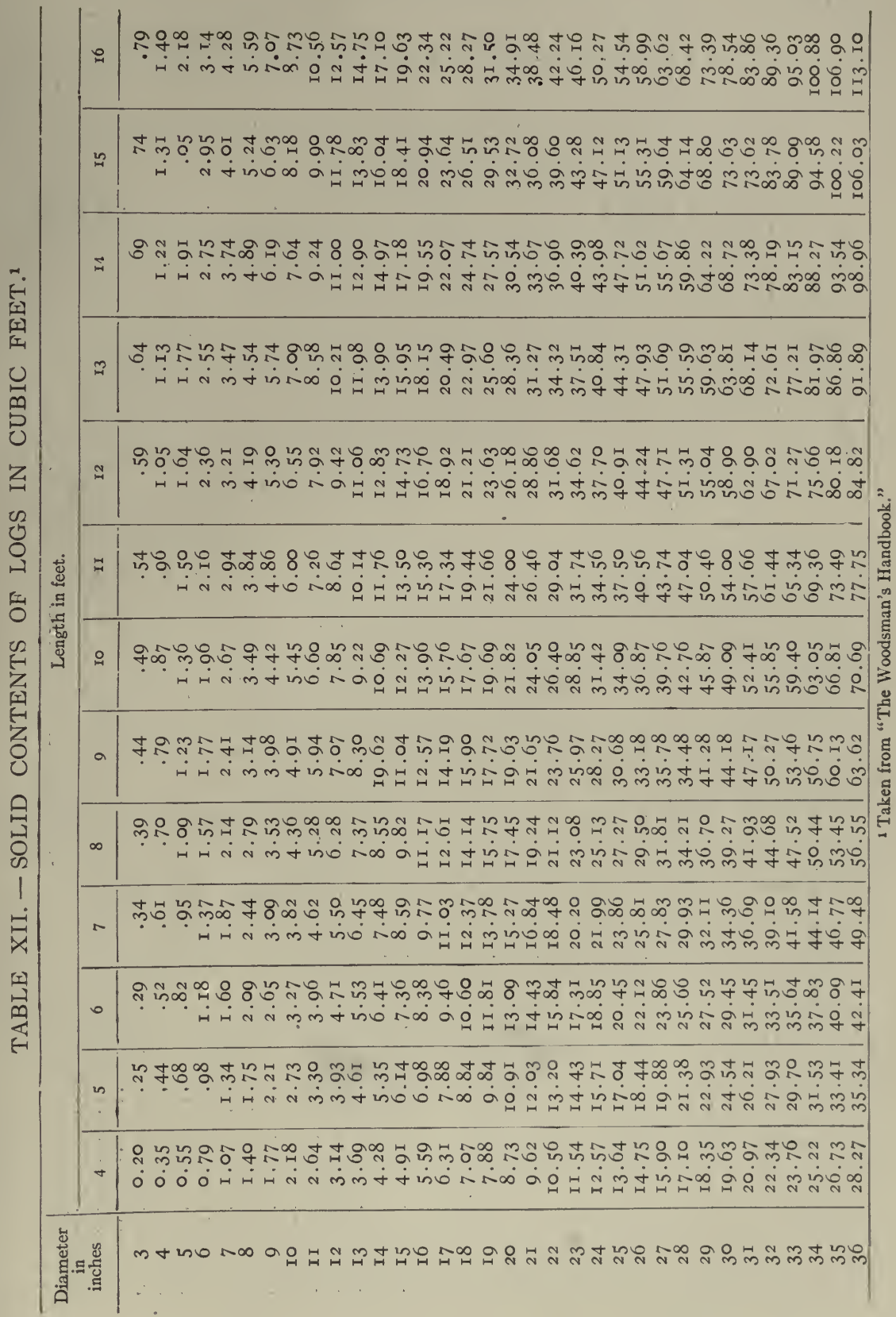




\begin{tabular}{|c|c|c|c|}
\hline & & \& & 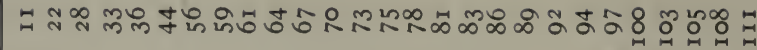 \\
\hline & & $\stackrel{2}{a}$ & 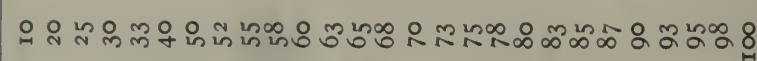 \\
\hline & & $\stackrel{\infty}{\infty}$ & 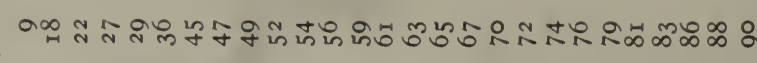 \\
\hline$\frac{0}{2}$ & & $=$ & 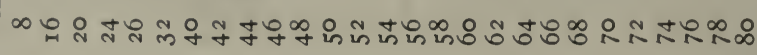 \\
\hline$\sum_{0}^{0}$ & & 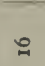 & 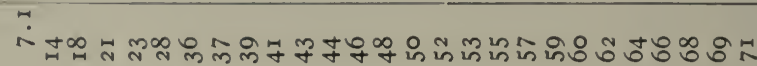 \\
\hline$\sum_{\rightarrow=1}^{\circ} \stackrel{\leftrightarrow}{0}$ & & $\approx$ & 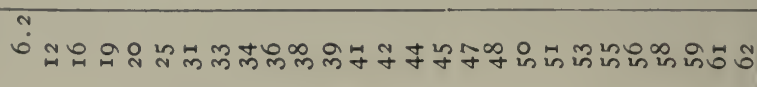 \\
\hline 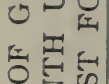 & & \pm & 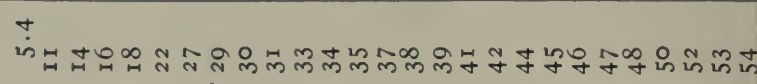 \\
\hline 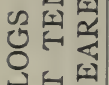 & 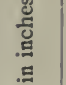 & $\approx$ & 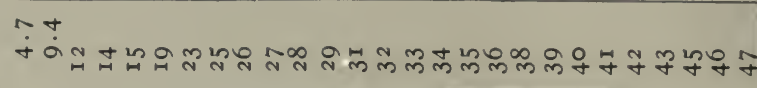 \\
\hline z & $\stackrel{0}{\frac{0}{0}}$ & $\simeq$ & $+\infty$ 에 \\
\hline$\Leftrightarrow$ & 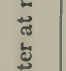 & $=$ & 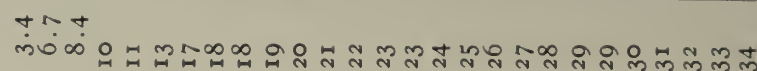 \\
\hline $0 \stackrel{0}{0}$ & है & 요 & 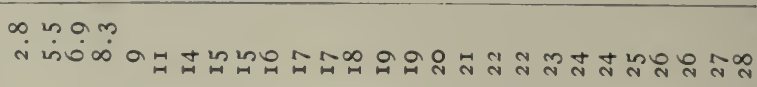 \\
\hline 记象吕 & & a & 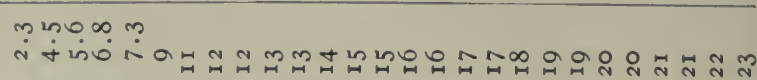 \\
\hline 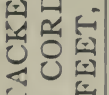 & & $\infty$ & 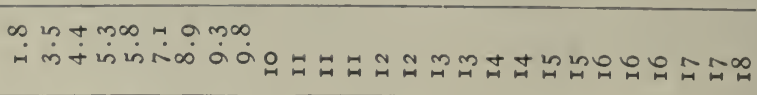 \\
\hline$i^{2}<$ & & $n$ & 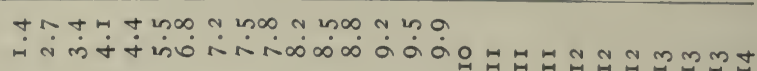 \\
\hline$\equiv \frac{\overline{3}}{2}$ & & $\bullet$ & 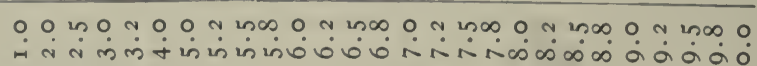 \\
\hline & & in & 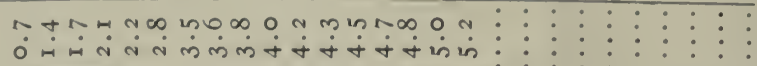 \\
\hline & & $\rightarrow$ & 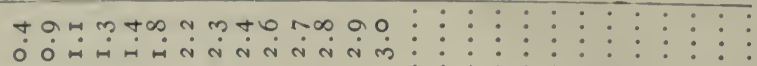 \\
\hline & & m & 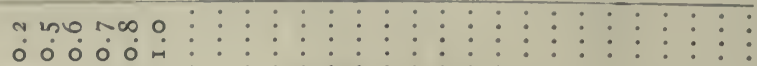 \\
\hline & & & 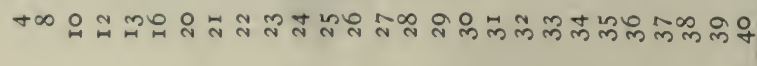 \\
\hline
\end{tabular}


VOLUME TABLES.

\section{TABLE XIV. - WHITE ASH. ${ }^{1}$ VOLUME IN BOARD FEET FOR TREES UNDER 75 YEARS. SCALED BY THE SCRIBNER LOG RULE.}

(Based on taper curves; scaled mostly in 16.3 -foot logs, with a few shorter logs where necessary. Height of stump, I foot. Measurements taken in Vermont, New York, Michigan, Indiana, and Tennessee.)

\begin{tabular}{|c|c|c|c|c|c|c|c|c|c|c|}
\hline \multirow{3}{*}{$\begin{array}{l}\text { Diam- } \\
\text { eter, } \\
\text { breast } \\
\text { high. }\end{array}$} & \multicolumn{8}{|c|}{ Number of 16 -foot logs. } & \multirow{3}{*}{$\begin{array}{c}\text { Diam- } \\
\text { eter } \\
\text { inside } \\
\text { bark of } \\
\text { top. }\end{array}$} & \multirow{3}{*}{ Basis. } \\
\hline & $I_{\frac{1}{2}}$ & 2 & $2 \frac{1}{2}$ & 3 & $3 \frac{1}{2}$ & 4 & $4 \frac{1}{2}$ & 5 & & \\
\hline & \multicolumn{8}{|c|}{ Volume - board feet. } & & \\
\hline Inches. & & & & & & & & & Inches. & Trees. \\
\hline 8 & 25 & 38 & 50 & $\ldots \ldots$ & $\ldots \ldots$ & $\ldots \ldots$ & $\ldots \ldots$ & $\ldots \ldots$ & 6 & 80 \\
\hline 9 & 27 & $4 \mathrm{I}$ & 54 & 72 & $\ldots \ldots$ & $\ldots \ldots$ & $\ldots \ldots$ & $\ldots \ldots$ & 6 & 57 \\
\hline IO & 30 & 44 & 60 & 79 & IOO & $\ldots \ldots$ & $\ldots \ldots$ & $\ldots \ldots$ & 6 & 63 \\
\hline II & 32 & 48 & 67 & 88 & I IO & $\ldots \ldots$ & $\ldots \ldots$ & $\ldots \ldots$ & 6 & 54 \\
\hline I 2 & 35 & 54 & 75 & IOO & I 20 & I 50 & $\ldots \ldots$ & $\ldots \ldots$ & 6 & 45 \\
\hline I3 & $\ldots \ldots$ & 62 & 85 & I IO & I 40 & I 70 & $\ldots \ldots$ & $\ldots \ldots$ & 6 & 33 \\
\hline I4 & $\ldots \ldots$ & 70 & 95 & 120 & I50 & I9o & 220 & $\ldots \ldots$ & 6 & 28 \\
\hline I5 & $\ldots \ldots$ & 80 & IIO & 140 & I 70 & 210 & 240 & $\ldots \ldots$ & 6 & I9 \\
\hline I6 & $\ldots \ldots$ & 92 & I 20 & 150 & I9o & 230 & 270 & $\ldots \ldots$ & 6 & I4 \\
\hline I 7 & $\ldots \ldots$ & $\ldots \ldots$ & 140 & I 70 & 210 & 250 & 300 & $\ldots \ldots$ & 6 & IO \\
\hline I8 & $\ldots \ldots$ & $\ldots \ldots$ & 150 & I9o & 230 & 280 & 330 & 380 & 6 & 6 \\
\hline I9 & $\ldots \ldots$ & $\ldots \ldots$ & I 70 & 220 & 260 & 310 & 370 & 420 & 6 & 6 \\
\hline 20 & $\ldots \ldots$ & $\ldots \ldots$ & 200 & 240 & 290 & 350 & 4IO & 470 & 6 & 3 \\
\hline $2 I$ & $\ldots \ldots$ & $\ldots \ldots$ & 220 & 270 & 320 & 390 & $45^{\circ}$ & 520 & 7 & 4 \\
\hline 22 & $\ldots \ldots$ & $\ldots \ldots$ & 240 & 300 & 360 & 430 & 490 & 570 & 7 & I \\
\hline 23 & $\ldots \ldots$ & $\ldots \ldots$ & 270 & 330 & 390 & 470 & 540 & 620 & 8 & $\ldots .$. \\
\hline \multirow[t]{2}{*}{24} & $\ldots \ldots$ & $\ldots \ldots$ & 300 & 370 & 430 & 510 & 580 & 670 & 8 & $\ldots \ldots$ \\
\hline & & s. & & & & & & & & 423 \\
\hline
\end{tabular}

1 Taken from The Ashes: Their Characteristics and Management, by W. D. Sterret. U. S. Department of Agriculture, Bulletin No. 229. 
TABLE XV. - SECOND-GROWTH WHITE ASH. ${ }^{2}$ VOLUME IN CUBIC FEET BASED ON MEASUREMENTS OF 200 TREES.

\begin{tabular}{|c|c|c|c|c|c|c|c|}
\hline \multirow{3}{*}{$\begin{array}{c}\text { Diameter, } \\
\text { breast } \\
\text { high, } \\
\text { inches. }\end{array}$} & \multicolumn{6}{|c|}{ Total height in feet. } & \multirow{3}{*}{$\begin{array}{c}\text { Limb } \\
\text { wood alone. }\end{array}$} \\
\hline & 40 & 50 & 60 & 70 & 80 & 90 & \\
\hline & \multicolumn{6}{|c|}{ Total volume, trunk and limbs, cubic feet. } & \\
\hline 3 & 0.9 & $\ldots \ldots$ & $\ldots \ldots \ldots$ & $\ldots \ldots \ldots$ & $\ldots \ldots \ldots$ & $\ldots \ldots \ldots$ & $\ldots \ldots \ldots$ \\
\hline 4 & I. 5 & 2.0 & 2.3 & $\ldots \ldots \ldots$ & $\ldots \ldots \ldots$ & $\ldots \ldots \ldots$ & $\ldots \ldots \ldots$ \\
\hline 5 & 2.4 & $3 \cdot \mathrm{I}$ & 3.6 & 3.8 & $\ldots \ldots \ldots$ & $\ldots \ldots \ldots$ & $\ldots \ldots \ldots$ \\
\hline 6 & $3 \cdot 4$ & $4 \cdot 5$ & $5 \cdot 2$ & 5.9 & $\ldots \ldots \ldots$ & $\ldots \ldots \ldots$ & $\ldots \ldots \ldots$ \\
\hline 7 & $4 \cdot 7$ & $6 . \mathrm{I}$ & $7 \cdot 1$ & $8 . \mathrm{I}$ & $\ldots \ldots \ldots$ & $\ldots \ldots \ldots$ & 0.2 \\
\hline 8 & $\ldots \ldots$ & 8. I & 9.2 & 10.6 & I 2.1 & $\ldots \ldots \ldots$ & 0.4 \\
\hline 9 & $\ldots \ldots$ & $\ldots \ldots$ & I I . 5 & 13.6 & I 5.9 & $\ldots \ldots \ldots$ & 0.6 \\
\hline Io & $\ldots \ldots$ & $\ldots \ldots$ & 14.0 & 17.0 & 19.0 & 20.9 & 0.8 \\
\hline I I & $\ldots \ldots$ & $\ldots \ldots$ & I6.7 & 21.2 & $23 \cdot 3$ & 26.0 & I . 2 \\
\hline I 2 & $\ldots \ldots$ & $\ldots \ldots$ & I9. 4 & 25.2 & 28.4 & $3 I \cdot 5$ & I. 5 \\
\hline I3 & $\ldots \ldots$ & $\ldots \ldots$ & 22.5 & 29.6 & $33 \cdot I$ & 36.9 & I. 8 \\
\hline I 4 & $\ldots \ldots$ & $\ldots \ldots$ & $\ldots \ldots \ldots$ & 33.8 & $35 \cdot 5$ & 42.7 & 2.2 \\
\hline I 5 & $\ldots \ldots$ & $\ldots \ldots$ & $\ldots \ldots \ldots$ & 38.4 & 42.8 & 49.1 & 2.8 \\
\hline I6 & $\ldots \ldots$ & $\ldots \ldots$ & $\ldots \ldots \ldots$ & $43 \cdot 3$ & $48 \cdot 5$ & $56 . x$ & $3 \cdot 5$ \\
\hline 17 & $\ldots \ldots$ & $\ldots \ldots$ & $\ldots \ldots \ldots$ & 48.8 & 52.9 & $64 \cdot I$ & $4 \cdot 5$ \\
\hline I 8 & $\ldots \ldots$ & $\ldots \ldots$ & $\ldots \ldots \ldots$ & $53 \cdot 4$ & 58.8 & 72.2 & 6.0 \\
\hline 19 & $\ldots \ldots$ & $\ldots \ldots$ & $\ldots \ldots \ldots$ & 58.1 & $6_{5} \cdot 5$ & 80.0 & $7 \cdot 5$ \\
\hline 20 & $\ldots \ldots$ & $\ldots \ldots$ & $\ldots \ldots \ldots$ & 62.9 & 70.5 & 89.2 & 9.0 \\
\hline $2 \mathrm{I}$ & $\ldots \ldots$ & $\ldots \ldots$ & $\ldots \ldots \ldots$ & $\ldots \ldots \ldots$ & $\cdots$ & $\ldots \ldots \ldots$ & 10.5 \\
\hline
\end{tabular}

1 Taken from The Management of Second Growth Hardwoods in Vt., by A. F. Hawes and B. A. Chandler. Vt. Forest Service Publication, No. I3. 


\section{TABLE XVI. - ASPEN. ${ }^{1}$ MERCHANTABLE VOLUME, ${ }^{2}$ IN CUBIC FEET.}

Based on measurements of 362 trees.

\begin{tabular}{|c|c|c|c|c|c|c|c|}
\hline \multirow{3}{*}{$\begin{array}{l}\text { Diameter, out- } \\
\text { side bark, } \\
\text { breast high, } \\
\text { in inches. }\end{array}$} & \multicolumn{7}{|c|}{ Height of tree in feet. } \\
\hline & 30 & 40 & 50 & 60 & 70 & 80 & 90 \\
\hline & \multicolumn{7}{|c|}{ Volume in cubic feet. } \\
\hline 5 & 0.5 & I.O & I. 5 & 2.0 & $3 \cdot 0$ & $\cdots \cdots \cdots$ & $\ldots \ldots \ldots$ \\
\hline 6 & 2.0 & $2 \cdot 5$ & 3.0 & $3 \cdot 5$ & $4 \cdot 5$ & 6.0 & $\ldots \ldots \ldots$ \\
\hline 7 & $3 \cdot 5$ & 4.0 & $4 \cdot 5$ & $5 \cdot 5$ & 7.0 & 8.5 & $\ldots \ldots \ldots$ \\
\hline 8 & $5 \cdot 5$ & 6.0 & 7.0 & 8.0 & IO. 0 & I I $\cdot 5$ & I3. 0 \\
\hline 9 & $\ldots \ldots$ & 8.0 & $9 \cdot 5$ & II.O & I2. 5 & $\mathbf{I} 4 \cdot 5$ & I6. 5 \\
\hline IO & $\ldots \ldots$ & 10.5 & I 2.0 & 14.0 & 16.0 & I8. 0 & 20.0 \\
\hline I I & $\ldots \ldots$ & $\ldots \ldots$ & 15.0 & 17.0 & I9.0 & $2 I \cdot 5$ & 25.0 \\
\hline I2 & $\ldots \ldots$ & $\ldots \ldots$ & 18.0 & 20.5 & 23.0 & $26 \cdot 5$ & 30.0 \\
\hline$I_{3}$ & $\ldots \ldots$ & $\cdots \cdots$ & $\ldots \ldots \ldots$ & 24.0 & 27.0 & $3 I \cdot 5$ & 36.0 \\
\hline I4 & $\ldots \ldots$ & $\ldots \ldots$ & $\ldots \ldots \ldots$ & $28 \cdot 5$ & 32.0 & 37.0 & 43.0 \\
\hline I5 & $\ldots \ldots$ & $\cdots \cdots$ & $\ldots \ldots$ & 32.0 & 37.0 & $43 \cdot 0$ & $5 I .0$ \\
\hline I6 & $\ldots \ldots$ & $\ldots \ldots$ & $\ldots \ldots$ & 37.0 & 43.0 & 50.0 & 59.0 \\
\hline 17 & $\ldots \ldots$ & $\ldots \ldots$ & $\ldots \ldots$ & 43.0 & $49 \cdot 5$ & 57.0 & 68.0 \\
\hline I8 & $\ldots \ldots$ & $\ldots \ldots$ & $\ldots \ldots$ & $\ldots \ldots \ldots$ & 57.0 & 66.0 & 76.0 \\
\hline I9 & $\cdots \cdots$ & $\ldots \ldots$ & $\ldots \ldots$ & $\ldots \ldots \ldots$ & 65.0 & 75.0 & 85.0 \\
\hline 20 & $\ldots \ldots$ & $\ldots \ldots$ & $\ldots \ldots \ldots$ & $\ldots \ldots \ldots$ & 74.0 & 84.0 & 95.0 \\
\hline
\end{tabular}

1 Taken from U. S. Forest Service Bull. 93.

2 Merchantable volume includes that portion of the bole between a stump I foot high and a minimum upper diameter of 4 inches inside bark and all branches 4 inches and over inside bark. The volumes do not include bark. 
TABLE XVII. - ASPEN. ${ }^{1}$ MERCHANTABLE VOLUME. ${ }^{2}$ IN CORDS AND NUMBER OF TREES PER CORD.

Based on measurements of 362 trees.

\begin{tabular}{|c|c|c|c|c|c|c|}
\hline \multirow{3}{*}{$\begin{array}{l}\text { Diameter. } \\
\text { breast high. }\end{array}$} & \multicolumn{6}{|c|}{ Height of tree in feet. } \\
\hline & \multicolumn{2}{|c|}{30} & \multicolumn{2}{|c|}{40} & \multicolumn{2}{|c|}{50} \\
\hline & Volume. & $\begin{array}{l}\text { Trees per } \\
\text { cord. }\end{array}$ & Volume. & $\begin{array}{l}\text { Trees per } \\
\text { cord. }\end{array}$ & Volume. & $\begin{array}{l}\text { Trees per } \\
\text { cord. }\end{array}$ \\
\hline Inches. & Cords. & Number. & Cords. & Number. & Cords. & Number. \\
\hline 5 & 0.01 & 100.0 & 0.02 & 50.0 & 0.03 & $33 \cdot 3$ \\
\hline 6 & .03 & $33 \cdot 3$ & .04 & 25.0 & .05 & 20.0 \\
\hline 7 & .05 & 20.0 & .06 & 16.7 & .07 & $14 \cdot 3$ \\
\hline 8 & .08 & I 2.5 & .09 & II . I & . 10 & 10.0 \\
\hline 9 & $\ldots \ldots \ldots$ & $\ldots \ldots \ldots$ & . II & $9 . I$ & .12 & 8.3 \\
\hline I0 & $\ldots \ldots \ldots$ & $\ldots \ldots \ldots$ & .14 & $7 \cdot 1$ & . 55 & 6.7 \\
\hline I I & $\ldots \ldots \ldots$ & $\ldots \ldots \ldots$ & $\ldots \ldots \ldots$ & $\ldots \ldots$ & .18 & 5.6 \\
\hline I 2 & $\ldots \ldots \ldots$ & $\ldots \ldots \ldots$ & $\ldots \ldots \ldots$ & $\ldots \ldots$ & .21 & 4.8 \\
\hline
\end{tabular}

\begin{tabular}{|c|c|c|c|c|c|c|c|c|}
\hline \multirow{3}{*}{$\begin{array}{c}\text { Diameter, } \\
\text { breast } \\
\text { high. }\end{array}$} & \multicolumn{8}{|c|}{ Height of tree in feet. } \\
\hline & \multicolumn{2}{|r|}{60} & \multicolumn{2}{|r|}{70} & \multicolumn{2}{|r|}{80} & \multicolumn{2}{|c|}{90} \\
\hline & Volume. & $\begin{array}{l}\text { Trees per } \\
\text { cord. }\end{array}$ & Volume. & $\begin{array}{l}\text { Trees per } \\
\text { cord. }\end{array}$ & Volume. & $\begin{array}{l}\text { Trees per } \\
\text { cord. }\end{array}$ & Volume. & $\begin{array}{l}\text { Trees per } \\
\text { cord. }\end{array}$ \\
\hline Inches. & Cords. & Number. & Cords. & Number. & Cords. & Number. & Cords. & Number. \\
\hline $\begin{array}{l}5 \\
6\end{array}$ & 0.03 & $33 \cdot 3$ & $\ldots .$. & $\cdots \cdots$ & $\begin{array}{c}\cdots \cdots \\
0 .\end{array}$ & $\cdots \cdots \cdots$ & $\cdots \cdots$ & $\cdots \cdots$ \\
\hline 6 & $\begin{array}{l}.06 \\
.08\end{array}$ & I0.7 & 0.07 & I 4.3 & 0.10 & 10. 0 & $\cdots \cdots$ & $\ldots \ldots$ \\
\hline $\begin{array}{l}7 \\
8\end{array}$ & .08 & I 2.5 & IO & $\begin{array}{r}10.0 \\
7.1\end{array}$ & $\begin{array}{r}.13 \\
\times 6\end{array}$ & $\begin{array}{l}7 \cdot 7 \\
6.3\end{array}$ & $\cdots \cdots$ & $\cdots \ldots$ \\
\hline $\begin{array}{l}8 \\
0\end{array}$ & .114 & $\begin{array}{l}9.1 \\
7.1\end{array}$ & $\begin{array}{r}.14 \\
\text { I6 }\end{array}$ & $\begin{array}{l}7.1 \\
6.3\end{array}$ & & $\begin{array}{l}0.3 \\
5.3\end{array}$ & $\cdots \cdots \cdot$ & $\cdots \ldots \ldots$ \\
\hline 9 & .14 & 7.1 & & 0.3 & .19 & $5 \cdot 3$ & $\cdots \cdots$ & $\cdots \ldots$ \\
\hline Io & & 5.6 & .20 & 5.0 & .23 & $4 \cdot 3$ & 0.25 & $4 \cdot 0$ \\
\hline I I & .20 & 5.0 & .23 & $4 \cdot 3$ & .26 & 3.8 & .30 & $3 \cdot 3$ \\
\hline I 2 & .24 & 4.2 & .27 & $3 \cdot 7$ & .31 & 3.2 & .34 & 2.9 \\
\hline I3 & .27 & $3 \cdot 7$ & .30 & $3 \cdot 3$ & .35 & 2.9 & .40 & 2.5 \\
\hline 14 & $\cdot 31$ & 3.2 & .35 & 2.9 & .40 & $2 \cdot 5$ & .46 & 2.2 \\
\hline I5 & $\ldots \ldots$ & $\ldots \ldots \ldots$ & .39 & 2.6 & .45 & 2.2 & .53 & I. 9 \\
\hline I6 & $\ldots \ldots$ & $\ldots \ldots \ldots$ & .44 & $2 \cdot 3$ & $\cdot 5^{2}$ & I. 9 & .60 & I. 7 \\
\hline I 7 & $\ldots \ldots$ & $\ldots \ldots \ldots$ & $\ldots \ldots$ & $\ldots \ldots \ldots$ & .57 & I. 8 & .68 & I. 5 \\
\hline I 8 & $\ldots \ldots$ & $\ldots \ldots \ldots$ & $\ldots \ldots$ & $\ldots \ldots \ldots$ & .65 & I. 5 & .75 & I. 3 \\
\hline 19 & $\ldots \ldots$ & $\ldots \ldots \ldots$ & $\ldots \ldots$ & $\ldots \ldots \ldots$ & $\ldots \ldots$ & $\ldots \ldots \ldots$ & .82 & I. 2 \\
\hline 20 & $\ldots \ldots$ & $\ldots \ldots \ldots$ & $\ldots \ldots$ & $\ldots \ldots \ldots$ & $\ldots \ldots$ & $\ldots \ldots \ldots$ & .90 & I. I \\
\hline
\end{tabular}

1 Taken from U. S. Forest Service Bull. 93.

2 See footnote 2 under Table XV. 
TABLE XVIII. - BASSWOOD ${ }^{1}$ IN THE LAKE STATES, ${ }^{2}$ VOLUME IN BOARD FEET.

Average top diameters.

\begin{tabular}{|c|c|c|c|c|c|c|c|c|}
\hline \multirow{3}{*}{$\begin{array}{c}\text { Diameter, } \\
\text { breast } \\
\text { high. }\end{array}$} & \multicolumn{6}{|c|}{ Number of 16 -foot logs. } & \multirow{3}{*}{$\begin{array}{c}\text { Diameter } \\
\text { inside } \\
\text { bark of } \\
\text { top. }\end{array}$} & \multirow{3}{*}{ Basis. } \\
\hline & 2 & $2 \frac{1}{2}$ & 3 & $3 \frac{1}{2}$ & 4 & $4 \frac{1}{2}$ & & \\
\hline & \multicolumn{6}{|c|}{ Volume - board feet. } & & \\
\hline $\begin{array}{c}\text { Inches. } \\
8\end{array}$ & 30 & 47 & 60 & $\ldots \ldots$ & $\ldots \ldots$ & $\ldots$ & $\begin{array}{c}\text { Inches. } \\
6\end{array}$ & $\begin{array}{c}\text { Trees. } \\
6\end{array}$ \\
\hline 9 & 36 & 53 & 69 & $\ldots \ldots$ & $\ldots \ldots$ & $\ldots \ldots \ldots$ & 6 & 9 \\
\hline IO & 44 & 60 & 79 & 100 & I30 & $\ldots \ldots \ldots$ & 6 & 7 \\
\hline I I & 53 & 70 & 90 & I IO & I 40 & $\ldots \ldots \ldots$ & 6 & 8 \\
\hline I 2 & 63 & 80 & 100 & I30 & 160 & $\ldots \ldots \ldots$ & 7 & 7 \\
\hline I3 & 75 & 94 & I 20 & I 50 & I80 & 220 & 7 & 9 \\
\hline I4 & 89 & I IO & 140 & I 70 & 200 & 240 & 7 & 7 \\
\hline I 5 & IOO & I3O & I6o & I9c & 230 & 270 & 8 & 17 \\
\hline I 6 & I 20 & I 50 & I80 & 220 & 260 & 300 & 8 & 17 \\
\hline I 7 & $\ldots \ldots$ & I 70 & 210 & 250 & 290 & 340 & 9 & 20 \\
\hline I 8 & $\ldots \ldots$ & I90 & 240 & 280 & 330 & 380 & 9 & I 8 \\
\hline I9 & $\ldots \ldots$ & 210 & 270 & 320 & 370 & 430 & IO & I4 \\
\hline 20 & $\ldots \ldots$ & 240 & 300 & 360 & 420 & 480 & Io & $3 I$ \\
\hline $2 I$ & $\ldots \ldots$ & 270 & 340 & 400 & 470 & 540 & I I & $2 I$ \\
\hline 22 & $\ldots \ldots$ & 300 & 380 & 450 & 520 & 600 & 12 & I4 \\
\hline 23 & $\ldots \ldots$ & 340 & 420 & 500 & $5^{80}$ & 670 & 12 & 17 \\
\hline 24 & $\ldots \ldots$ & 380 & 470 & 560 & 650 & 750 & I3 & I9 \\
\hline 25 & $\ldots \ldots$ & 410 & 520 & 620 & 720 & 830 & I 4 & I4 \\
\hline 26 & $\ldots \ldots$ & 450 & 570 & 680 & 790 & 920 & I5 & I 7 \\
\hline 27 & $\ldots \ldots$ & 500 & 620 & 750 & 870 & roro & I5 & 8 \\
\hline 28 & $\ldots \ldots$ & 540 & 680 & 820 & 960 & I I OO & I6 & 9 \\
\hline 29 & $\ldots \ldots$ & 590 & 740 & 890 & 1040 & I I90 & I7 & 6 \\
\hline 30 & $\ldots \ldots$ & 640 & 800 & 970 & $\operatorname{II} 30$ & I 290 & 17 & 4 \\
\hline $3 I$ & $\ldots \ldots$ & 690 & 870 & 1050 & 1220 & 1400 & I8 & 8 \\
\hline 32 & $\ldots \ldots$ & 750 & 940 & II30 & I3IO & I 500 & I8 & 3 \\
\hline 33 & $\ldots \ldots$ & 810 & IOIO & I 210 & I4IO & I6ro & I9 & 3 \\
\hline 34 & $\ldots \ldots$ & 870 & 1080 & I 290 & I 500 & I720 & 20 & 4 \\
\hline 35 & $\ldots \ldots$ & 940 & $\operatorname{II} 5^{\circ}$ & 1380 & 1600 & 1830 & 20 & I \\
\hline 36 & $\ldots \ldots$ & roro & 1240 & 1470 & I 700 & I950 & $2 I$ & $\ldots \ldots \ldots$ \\
\hline 37 & $\ldots \ldots$ & 1080 & 1320 & I560 & 1800 & 2060 & 22 & I \\
\hline $3^{8}$ & $\ldots \ldots$ & I I 50 & I 410 & 1650 & I900 & 2180 & 22 & $\ldots \ldots \ldots$ \\
\hline 39 & $\ldots \ldots$ & I 220 & I 490 & I750 & 2000 & 2300 & 23 & $\ldots \ldots \ldots$ \\
\hline \multirow[t]{2}{*}{40} & $\ldots \ldots$ & 1300 & I 570 & I850 & 2100 & 2420 & 24 & $\ldots \ldots \ldots$ \\
\hline & & & & & & & & 3 I9 \\
\hline
\end{tabular}

Height of stump, $\mathrm{x}$ foot, scaled from taper curves, by the Scribner Decimal C rule; mostly in I6.3-foot logs, with a few shorter logs where necessary. Average utilization.

1 Taken from The Northern Hardwood Forest, etc., by E. H. Frothingham. U. S. Dept. of Agr. Bul. 285 .

2 Charlevoix and Kalkaska Counties, Mich.; Iron and Price Counties, Wis. 


\section{TABLE XIX. - BEECH ${ }^{1}$ IN NEW HAMPSHIRE, ${ }^{2}$ VOLUME IN BOARD FEET.}

\begin{tabular}{|c|c|c|c|c|c|c|c|c|c|c|}
\hline \multirow{3}{*}{$\begin{array}{l}\text { Diam- } \\
\text { eter, } \\
\text { breast } \\
\text { high. }\end{array}$} & \multicolumn{7}{|c|}{ Number of 16 -foot logs. } & \multirow{3}{*}{$\begin{array}{c}\text { Diam- } \\
\text { eter } \\
\text { inside } \\
\text { bark of } \\
\text { top. }\end{array}$} & \multirow{3}{*}{$\begin{array}{l}\text { Stump } \\
\text { height. }\end{array}$} & \multirow{3}{*}{ Basis. } \\
\hline & $\frac{1}{2}$ & I & $I^{\frac{1}{2}}$ & 2 & $2 \frac{1}{2}$ & 3 & $3 \frac{1}{2}$ & & & \\
\hline & \multicolumn{7}{|c|}{ Volume - board feet in tens. } & & & \\
\hline Inches. & & & & & & & & Inches. & Feet. & Trees. \\
\hline 7 & I & I & 2 & $\ldots \ldots$ & $\ldots \ldots$ & $\ldots \ldots$ & $\ldots \ldots$ & 6 & I. 8 & I \\
\hline 8 & I & 2 & 3 & $\ldots \ldots$ & $\ldots \ldots$ & $\ldots \ldots$ & $\ldots \ldots$ & 6 & I. 8 & 3 \\
\hline 9 & 2 & 3 & 4 & 5 & $\ldots \ldots$ & $\ldots \ldots$ & $\ldots \ldots$ & 7 & I . 9 & 4 \\
\hline I0 & 2 & 4 & 5 & 6 & $\ldots \ldots$ & $\ldots \ldots$ & $\ldots \ldots$ & 8 & I .9 & I I \\
\hline I I & 3 & 4 & 6 & 8 & 9 & $\ldots \ldots$ & $\ldots \ldots$ & 8 & 2.0 & 24 \\
\hline I 2 & 3 & 6 & 8 & 9 & I I & $\ldots \ldots$ & $\ldots \ldots$ & 9 & 2.0 & 35 \\
\hline I3 & 4 & 7 & 9 & I I & I3 & I 5 & $\ldots \ldots$ & IO & 2.0 & 45 \\
\hline I4 & 5 & 8 & II & I3 & I6 & I 8 & $\ldots \ldots$ & I I & $2 . I$ & $4 I$ \\
\hline 15 & 6 & IO & I3 & 16 & I9 & $2 \mathrm{I}$ & 24 & I I & $2 . I$ & 45 \\
\hline I6 & $\ldots \ldots$ & I I & I5 & I9 & 22 & 26 & 29 & I 2 & $2 . I$ & 43 \\
\hline 17 & $\ldots \ldots$ & I3 & I7 & 22 & 26 & 30 & 34 & I3 & 2.2 & 37 \\
\hline I8 & $\ldots \ldots$ & $\ldots \ldots$ & 20 & 26 & 30 & 35 & 39 & I3 & 2.2 & 28 \\
\hline I9 & $\ldots \ldots$ & $\ldots \ldots$ & 23 & 30 & 35 & 40 & 44 & I4 & 2.2 & Io \\
\hline 20 & $\ldots \ldots$ & $\ldots \ldots$ & $\ldots \ldots$ & 34 & 39 & 44 & 49 & I 5 & 2.2 & I 8 \\
\hline $2 I$ & $\ldots \ldots$ & $\ldots \ldots$ & $\ldots \ldots$ & 38 & 44 & 49 & 54 & I 5 & 2.2 & I I \\
\hline 22 & $\ldots \ldots$ & $\ldots \ldots$ & $\ldots \ldots$ & 42 & 48 & 53 & 59 & I 6 & $2 \cdot 3$ & I I \\
\hline 23 & $\ldots \ldots$ & $\ldots \ldots$ & $\ldots \ldots$ & 46 & 52 & $5^{8}$ & 64 & I 7 & $2 \cdot 3$ & 8 \\
\hline \multirow[t]{2}{*}{24} & $\ldots \ldots$ & $\ldots \ldots$ & $\ldots \ldots$ & 49 & 56 & 62 & 69 & I7 & $2 \cdot 3$ & $\mathbf{I}$ \\
\hline & & & & & & & & & & 376 \\
\hline
\end{tabular}

Logs scaled as cut, 10 to 16 feet long, by the Scribner Decimal $\mathrm{C}$ rule. Utilization as close as form of tree allowed.

1 Taken from The Northern Hardwood Forest, etc., by E. H. Frothingham. U. S. Dept. of Agr. Bul. 285.

3 Grafton County. 
TABLES

TABLE XX. - SECOND-GROWTH BEECH. ${ }^{1}$ VOLUME IN CUBIC FEET BASED ON MEASUREMENTS OF 200 TREES.

\begin{tabular}{|c|c|c|c|c|c|c|}
\hline \multirow{3}{*}{$\begin{array}{l}\text { Diameter } \\
\text { breast high, } \\
\text { inches. }\end{array}$} & \multicolumn{5}{|c|}{ Total height in feet. } & \multirow{3}{*}{$\begin{array}{l}\text { Limb } \\
\text { wood alone. }\end{array}$} \\
\hline & 30 & 40 & 50 & 60 & 70 & \\
\hline & \multicolumn{5}{|c|}{ Total volume, trunk and limbs, cubic feet. } & \\
\hline - 3 & 0.8 & 0.8 & $\ldots \ldots \ldots$ & $\ldots \ldots$ & $\ldots \ldots$ & $\ldots \ldots \ldots$ \\
\hline 4 & I. 3 & I. 6 & I. 7 & $\ldots \ldots \ldots$ & $\ldots \ldots \ldots$ & $\ldots \ldots \ldots$ \\
\hline 5 & $\ldots \ldots \ldots$ & $2 \cdot 5$ & 2.8 & $\ldots \ldots \ldots$ & $\ldots \ldots \ldots$ & 0.1 \\
\hline 6 & $\ldots \ldots \ldots$ & $3 \cdot 7$ & $4 \cdot 3$ & 5.2 & $\ldots \ldots \ldots$ & 0.2 \\
\hline 7 & $\ldots \ldots \ldots$ & $4 \cdot 7$ & 6.0 & $7 \cdot 3$ & $\ldots \ldots \ldots$ & 0.4 \\
\hline $8^{\circ}$ & $\ldots \ldots \ldots$ & $5 \cdot 7$ & 8.1 & 10.0 & $\ldots \ldots \ldots$ & 0.8 \\
\hline 9 & $\ldots \ldots \ldots$ & $7 \cdot 3$ & 10.5 & 13.0 & $\mathrm{r} 4.8$ & I. 4 \\
\hline Io & $\ldots \ldots \ldots$ & $\ldots \ldots \ldots$ & 12.3 & r6. 6 & I9.9 & 2.4 \\
\hline II & $\ldots \ldots \ldots$ & $\ldots \ldots \ldots$ & I6.9 & 2 I.O & 25.6 & $3 \cdot 9$ \\
\hline 12 & $\ldots \ldots \ldots$ & $\ldots \ldots \ldots$ & $\ldots \ldots \ldots$ & 26.4 & $3 I . I$ & $6 . I$ \\
\hline I3 & $\ldots \ldots \ldots$ & $\ldots \ldots \ldots$ & $\ldots \ldots \ldots$ & $3 I \cdot 5$ & 36.9 & 8.3 \\
\hline I4 & $\ldots \ldots \ldots$ & $\ldots \ldots \ldots$ & $\ldots \ldots \ldots$ & 36.7 & 42.8 & IO. 5 \\
\hline
\end{tabular}

1 Taken from The Management of Second Growth Hardwoods in Vt., by A. F. Hawes and B. A. Chandler. Vt. Forest Service Publication No. I3. 
TABLE XXI. - PAPER BIRCH. ${ }^{1}$ MERCHANTABLE VOLUME IN CUBIC AND BOARD FEET BY DIAMETER AND HEIGHT.

Based on measurements of 445 trees.

\begin{tabular}{|c|c|c|c|c|c|c|c|c|c|c|c|}
\hline \multirow{4}{*}{$\begin{array}{l}\text { Diam- } \\
\text { eter, } \\
\text { breast } \\
\text { high. } \\
\text { Inches. }\end{array}$} & \multicolumn{10}{|c|}{ Height of tree in feet. } & \multirow{4}{*}{ 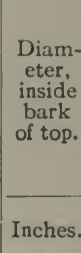 } \\
\hline & \multicolumn{2}{|c|}{50} & \multicolumn{2}{|c|}{60} & \multicolumn{2}{|c|}{70} & \multicolumn{2}{|c|}{80} & \multicolumn{2}{|c|}{90} & \\
\hline & \multicolumn{10}{|c|}{ Volume. } & \\
\hline & Cu. ft. & $\mathrm{Bd} . \mathrm{ft}^{2}$ & Cu. ft. & Bd. ft. & Cu. ft. & $\begin{array}{l}\text { Bd. } \\
\text { ft. }\end{array}$ & Cu. ft. & $\begin{array}{l}\text { Bd. } \\
\text { ft. }\end{array}$ & Cu. ft. & $\begin{array}{l}\mathrm{Bd} . \\
\mathrm{ft} .\end{array}$ & \\
\hline 5 & 2.7 & I6 & 3.2 & I9 & $3 \cdot 7$ & 23 & $\ldots$ & $\ldots$ & $\ldots$ & $\ldots$ & $3 \cdot 3$ \\
\hline 6 & 3.8 & 22 & 4.6 & 26 & $5 \cdot 4$ & 30 & 6.2 & 35 & $\ldots$ & $\ldots$ & 3.7 \\
\hline 7 & 5.2 & 28 & 6.3 & 34 & $7 \cdot 3$ & 40 & 8.5 & 46 & 9.6 & 52 & 4.2 \\
\hline 8 & 6.8 & 38 & 8.2 & 45 & $9 \cdot 5$ & $5^{2}$ & II.O & 60 & I 2.4 & 68 & $4 \cdot 5$ \\
\hline 9 & 8.7 & 48 & 10.4 & 57 & I 2.2 & 67 & 14.0 & 76 & I 5.5 & 86 & 4.8 \\
\hline ro & 10.9 & 60 & 13.0 & 72 & I 5.2 & 85 & I 7.4 & 95 & 19.3 & I08 & $5 . \mathrm{I}$ \\
\hline I I & 13.4 & 73 & 16.0 & 88 & I 8.8 & 104 & $2 \mathrm{I} .4$ & II 7 & 24.0 & 132 & $5 \cdot 3$ \\
\hline 12 & 16.3 & 88 & 19.5 & 106 & 22.8 & I 24 & 26.I & $14 \mathrm{I}$ & $29 \cdot 3$ & 160 & $5 \cdot 5$ \\
\hline I3 & 19.8 & 106 & $23 \cdot 3$ & 127 & $27 \cdot 3$ & 148 & $3 I .3$ & I69 & 35.0 & I9I & 5.6 \\
\hline 14 & $\ldots \ldots$ & $\ldots \ldots$ & $27 \cdot 7$ & 150 & $32 \cdot 3$ & 176 & 37.0 & 201 & $4 \mathrm{I} .5$ & 226 & 5.8 \\
\hline 15 & $\ldots \ldots$ & $\ldots \ldots$ & 32.5 & I 77 & 37.8 & 207 & 43.2 & 236 & 48.5 & 266 & 5.9 \\
\hline 16 & $\ldots \ldots$ & $\ldots \ldots$ & $\ldots \ldots$ & 206 & 43.8 & 242 & 50.0 & 276 & 56.3 & 310 & 6.0 \\
\hline I7 & $\ldots \ldots$ & $\ldots \ldots$ & $\ldots \ldots$ & $\ldots \ldots$ & 50.3 & 280 & 58.0 & 320 & 64.9 & 360 & 6.1 \\
\hline I8 & $\ldots \ldots$ & & $\ldots \ldots$ & $\ldots \ldots$ & $57 \cdot 4$ & 320 & $\ldots \ldots$ & 366 & ...... & 412 & 6.1 \\
\hline
\end{tabular}

1 Taken from U. S. Forest Service Circular $16{ }_{3}$

2 New Hampshire rule. 
TABLE XXII. - PAPER BIRCH. ${ }^{1}$ MERCHANTABLE VOLUME IN CUBIC AND BOARD FEET BY DIAMETER AND MERCHANTABLE LENGTH.

Based on measurements of 396 trees.

\begin{tabular}{|c|c|c|c|c|c|c|c|c|c|c|c|c|c|c|}
\hline \multirow{4}{*}{$\begin{array}{c}\text { Diam- } \\
\text { eter, } \\
\text { breast } \\
\text { high. }\end{array}$} & \multicolumn{14}{|c|}{ Merchantable length in feet. } \\
\hline & \multicolumn{2}{|c|}{12} & \multicolumn{2}{|r|}{16} & \multicolumn{2}{|l|}{20} & \multicolumn{2}{|c|}{24} & \multicolumn{2}{|c|}{28} & \multicolumn{2}{|c|}{32} & \multicolumn{2}{|c|}{36} \\
\hline & \multicolumn{14}{|c|}{ Volume. } \\
\hline & $\begin{array}{l}\mathrm{Cu} . \\
\mathrm{ft} .\end{array}$ & $\begin{array}{c}\mathrm{Bd} . \\
\mathrm{ft} .\end{array}$ & $\begin{array}{l}\mathrm{Cu} . \\
\text { ft. }\end{array}$ & $\begin{array}{c}\text { Bd. } \\
\text { ft. }\end{array}$ & Cu. ft. & $\begin{array}{l}\text { Bd. } \\
\text { ft. }\end{array}$ & Cu. ft. & $\begin{array}{l}\text { Bd. } \\
\text { ft. }\end{array}$ & Cu. ft. & $\begin{array}{c}\text { Bd. } \\
\text { ft. }\end{array}$ & Cu. ft. & Bd. ft. & Cu. $\mathrm{ft}$. & $\begin{array}{l}\text { Bd. } \\
\text { ft. }\end{array}$ \\
\hline 5 & I. 7 & 7 & 2.0 & Io & 2.3 & I3 & 2.6 & I5 & 2.9 & I 8 & 3.2 & $2 I$ & $\ldots$ & $\ldots$ \\
\hline 6 & 2.4 & I 2 & 2.9 & I6 & $3 \cdot 4$ & I9 & 3.9 & 22 & $4 \cdot 3$ & 25 & 4.8 & 28 & 5.4 & $3 I$ \\
\hline 7 & $3 \cdot 3$ & I 7 & $3 \cdot 9$ & $2 \mathrm{I}$ & .4 .6 & 25 & $5 \cdot 3$ & 29 & $5 \cdot 9$ & 33 & 6.5 & 37 & 7.2 & $4 I$ \\
\hline 8 & 4.2 & 23 & 5.2 & 28 & 6.0 & 32 & 6.8 & 37 & 7.6 & 42 & 8.4 & 47 & 9.2 & 52 \\
\hline 9 & $5 \cdot 3$ & 29 & 6.6 & 34 & $7 \cdot 5$ & $40^{\circ}$ & 8.5 & 46 & $9 \cdot 5$ & $5 \mathrm{I}$ & 10.5 & 57 & II. 4 & 64 \\
\hline IO & $\ldots$ & 35 & 8. I & $4 \mathrm{I}$ & 9.2 & 48 & 10.3 & 55 & II .5 & $6 \mathrm{I}$ & I 2.7 & 68 & I 3.8 & 76 \\
\hline I I & $\ldots$ & $\ldots$ & $\ldots$ & 49 & II. 0 & 56 & I 2.2 & 64 & I 3.5 & $7 I$ & I 5.0 & 80 & I 6.4 & 89 \\
\hline I 2 & . & $\ldots$ & $\ldots$ & $\ldots$ & $\ldots \ldots$ & $\ldots$ & $\ldots \ldots$ & 73 & I 5.7 & 82 & 17.5 & $9^{2}$ & I9. 2 & I03 \\
\hline I3 & ... & . & $\ldots$ & $\ldots$ & $\ldots \ldots$ & $\ldots$ & $\ldots \ldots$ & $\ldots$ & $\ldots \ldots$ & $\ldots$ & 20.I & 105 & 22.7 & I 20 \\
\hline I 4 & $\ldots$ & .. & $\ldots$ & $\ldots$ & $\ldots \ldots$ & $\ldots$ & & $\ldots$ & $\ldots \ldots$ & $\ldots$ & $\ldots \ldots$ & I 18 & 27.0 & I3 8 \\
\hline
\end{tabular}

\begin{tabular}{|c|c|c|c|c|c|c|c|c|c|c|c|c|}
\hline \multirow{4}{*}{$\begin{array}{c}\text { Diam- } \\
\text { eter, } \\
\text { breast } \\
\text { high. }\end{array}$} & \multicolumn{12}{|c|}{ Merchantable length in feet. } \\
\hline & \multicolumn{2}{|l|}{40} & \multicolumn{2}{|l|}{44} & \multicolumn{2}{|l|}{48} & \multicolumn{2}{|l|}{52} & \multicolumn{2}{|l|}{56} & \multicolumn{2}{|l|}{60} \\
\hline & \multicolumn{12}{|c|}{ Volume. } \\
\hline & Cu. ft. & Bd. ft. & Cu. ft. & Bd. ft. & Cu. $\mathrm{ft}$. & $\begin{array}{l}\mathrm{Bd} \text {. } \\
\mathrm{ft} .\end{array}$ & Cu. ft. & $\begin{array}{l}\mathrm{Bd} \text {. } \\
\mathrm{ft} .\end{array}$ & Cu. ft. & $\begin{array}{l}\mathrm{Bd} . \\
\mathrm{ft} .\end{array}$ & Cu. ft. & $\begin{array}{l}\mathrm{Bd} . \\
\mathrm{ft} .\end{array}$ \\
\hline 5 & $\cdots \cdots$ & $\cdots$ & $\cdots \cdots$ & $\ldots$ & $\cdots$ & $\ldots$ & $\ldots \ldots$ & $\cdots$ & $\ldots \ldots$ & $\cdots$ & $\ldots \ldots$ & $\ldots$ \\
\hline 6 & 5.8 & 35 & 6.3 & $\ldots \ldots$ & $7 \cdot 0$ & $\cdots$ & $\ldots \ldots$ & $\cdots$ & $\ldots \ldots$ & $\ldots$ & $\ldots \ldots$ & $\ldots$ \\
\hline 7 & $7 \cdot 9$ & 45 & 8.4 & 49 & $9 \cdot 3$ & 53 & 9.9 & $5 i$ & $\ldots \ldots$ & $\ldots$ & $\ldots \ldots$ & $\ldots$ \\
\hline 8 & I0.0 & 57 & 10. 8 & 62 & I1 . 6 & 67 & 12.4 & 72 & I3. 2 & 76 & 14.0 & 80 \\
\hline 9 & 12.3 & 69 & I $3 \cdot 3$ & 75 & $\mathrm{I} 4.2$ & $8 I$ & I 5.2 & 86 & I6.I & 92 & 17.1 & 99 \\
\hline IO & I 4.9 & 83 & 16.0 & 90 & I 7.2 & 97 & I8. 4 & 104 & I9. 4 & I I I & 20.6 & II 8 \\
\hline I I & 17.8 & 97 & I9. 3 & 107 & 20.7 & II 5 & 22.2 & I 24 & 23.6 & I 34 & 25.2 & I 42 \\
\hline I 2 & 21.0 & I I 4 & 23.0 & I 25 & 24.8 & I 37 & 26.7 & I 48 & 28.6 & 160 & 30.6 & 168 \\
\hline I3 & $24 \cdot 9$ & I 33 & $27 \cdot 4$ & 146 & 29.8 & 160 & $32 \cdot 3$ & I 74 & $34 \cdot 9$ & I 87 & $37 \cdot 5$ & 200 \\
\hline I 4 & 30.0 & I 54 & 33.0 & I 70 & 35.9 & I 85 & 39.1 & 201 & $4 I \cdot 5$ & $\cdots$ & $\ldots \ldots$ & $\ldots$ \\
\hline
\end{tabular}

1 Taken from U. S. Forest Service Circular 163. 
TABLE XXIII. - PAPER BIRCH. ${ }^{1}$ SOLID CONTENTS PER STACKED CORD FOR SPOOLWOOD BOLTS. IN THE ROUND.

\begin{tabular}{|c|c|c|c|c|c|}
\hline $\begin{array}{l}\text { Average diam- } \\
\text { eter of stick. }\end{array}$ & $\begin{array}{l}\text { Sticks per } \\
\text { cord. }\end{array}$ & $\begin{array}{l}\text { Solid wood per } \\
\text { cord. }\end{array}$ & $\begin{array}{l}\text { Average diam- } \\
\text { eter of stick. }\end{array}$ & $\begin{array}{l}\text { Sticks per } \\
\text { cord. }\end{array}$ & $\begin{array}{l}\text { Solid wood per } \\
\text { cord. }\end{array}$ \\
\hline Inches. & Number. & Cubic feet. & Inches. & Number. & Cubic feet. \\
\hline $\begin{array}{l}5 \\
6 \\
7 \\
8\end{array}$ & $\begin{array}{r}135 \\
\text { I06 } \\
85 \\
69\end{array}$ & $\begin{array}{l}S_{2} .0 \\
\text { So. } \\
91.4 \\
96.0\end{array}$ & $\begin{array}{r}9 \\
\text { IO } \\
\text { I I } \\
\text { I } 2\end{array}$ & $\begin{array}{l}57 \\
47 \\
39 \\
32\end{array}$ & $\begin{array}{l}\text { IO0.0 } \\
\text { IO2.8 } \\
\text { IO4.6 } \\
\text { I05.2 }\end{array}$ \\
\hline
\end{tabular}

${ }_{1}^{1}$ Taken from U. S. Forest Service Circular 163.

TABLE XXIV. - YELLOW BIRCH ${ }^{1}$ IN NEW HAMPSHIRE, ${ }^{2}$ VOLUME IN BOARD FEET.

\begin{tabular}{|c|c|c|c|c|c|c|c|c|c|c|}
\hline \multirow{3}{*}{$\begin{array}{l}\text { Diam- } \\
\text { eter, } \\
\text { breast } \\
\text { high. }\end{array}$} & \multicolumn{7}{|c|}{ Number of 16 -foot logs. } & \multirow{3}{*}{$\begin{array}{l}\text { Diam- } \\
\text { eter } \\
\text { inside } \\
\text { bark } \\
\text { of top. }\end{array}$} & \multirow{3}{*}{$\begin{array}{l}\text { Stump } \\
\text { height. }\end{array}$} & \multirow{3}{*}{ Basis. } \\
\hline & $\frac{1}{2}$ & I & $I \frac{1}{2}$ & 2 & $2 \frac{1}{2}$ & 3 & $3 \frac{1}{2}$ & & & \\
\hline & \multicolumn{7}{|c|}{ Volume - board feet in tens. } & & & \\
\hline Inches. & & & & & & & & Inches. & Feet. & Trees. \\
\hline 7 & I & I & 2 & 3 & $\cdots$ & $\ldots$ & $\ldots \ldots$ & 6 & $2 . I$ & 2 \\
\hline 8 & $\mathbf{I}$ & 2 & 2 & 3 & 4 & $\ldots$ & $\ldots \ldots$ & 6 & $2 . I$ & 8 \\
\hline 9 & $\mathbf{I}$ & 2 & 3 & 4 & 5 & $\ldots$ & $\ldots \ldots$ & 7 & 2.2 & 24 \\
\hline Io & 2 & 3 & 4 & 5 & 6 & ... & $\ldots \ldots$ & 7 & 2.2 & 43 \\
\hline II & 2 & 4 & 5 & 6 & 8 & $\ldots$ & $\ldots \ldots$ & 8 & 2.2 & 44 \\
\hline I 2 & 3 & 5 & 6 & 8 & 9 & $\ldots$ & $\ldots \ldots$ & 8 & 2.2 & 45 \\
\hline I3 & 3 & 6 & 8 & 9 & I I & $\ldots$ & $\ldots \ldots$ & 9 & 2.2 & 36 \\
\hline I4 & 4 & 7 & 9 & I I & I3 & 14 & $\ldots \ldots$ & 9 & 2.3 & 35 \\
\hline 15 & 4 & 8 & I I & I 3 & I 5 & I 6 & $\ldots \ldots$ & IO & 2.3 & 47 \\
\hline 16 & 5 & IO & I 3 & I 5 & 17 & I 8 & $\ldots \ldots$ & I I & $2 \cdot 3$ & 40 \\
\hline I 7 & 6 & I I & 15 & I 8 & 20 & $2 I$ & $\ldots \ldots$ & II & 2.4 & 32 \\
\hline I8 & 7 & I3 & 17 & 20 & 23 & 25 & $\ldots \ldots$ & I 2 & 2.4 & $3^{8}$ \\
\hline I9 & 8 & I 4 & 20 & 23 & 26 & 28 & $\ldots \ldots$ & 13 & 2.4 & $3^{6}$ \\
\hline 20 & 9 & I 6 & 22 & 26 & 30 & 33 & $3^{6}$ & I3 & 2.5 & 39 \\
\hline $2 I$ & 10 & I 8 & 25 & 30 & 34 & 37 & $4 I$ & I4 & 2.5 & 28 \\
\hline 22 & I I & 20 & 27 & 33 & 38 & 42 & 47 & I 5 & 2.6 & $2 I$ \\
\hline 23 & I3 & 23 & 30 & 36 & 42 & 48 & 53 & I 5 & 2.6 & 24 \\
\hline 24 & I4 & 25 & 33 & 40 & 47 & 53 & 59 & I 6 & 2.7 & $2 I$ \\
\hline 25 & I 5 & 27 & 36 & 44 & $5 I$ & $5^{8}$ & 64 & I 6 & $2 \cdot 7$ & 23 \\
\hline 26 & $\ldots$ & 30 & 40 & 48 & $5^{6}$ & 63 & 70 & I 7 & 2.8 & 17 \\
\hline 27 & $\ldots$ & 33 & 44 & 52 & 61 & 69 & 76 & I 8 & 2.9 & 14 \\
\hline 28 & & 36 & 48 & 57 & 66 & 74 & 82 & I 8 & 2.9 & 17 \\
\hline 29 & $\ldots \ldots$ & $\ldots .$. & $5^{2}$ & 62 & 71 & 80 & 88 & I9 & 3.0 & 7 \\
\hline 30 & $\ldots$. & $\ldots$. & 57 & 67 & 77 & 86 & 95 & 20 & 3.0 & $\ldots$ \\
\hline $3 I$ & $\ldots \ldots$ & $\ldots \ldots$ & .... & 72 & 82 & 92 & IOI & 20 & 3.1 & 5 \\
\hline 32 & $\ldots$ & & $\ldots$ & 78 & 88 & 98 & 108 & $2 I$ & 3.1 & 5 \\
\hline & & & & & & & & & & $6_{51}$ \\
\hline
\end{tabular}

Logs scaled as cut, 10 to 16 feet long, by Scribner Decimal C rule. Utilization as close as form of tree allowed.

1 Taken from The Northern Hardwood Forest, etc., by E. H. Frothingham. U. S. Dept. Agr. Bul. 285 . 


\section{TABLE XXV. - SECOND-GROWTH YELLOW BIRCH.1 VOLUME IN CUBIC FEET.}

Based on measurements of 200 trees.

\begin{tabular}{|c|c|c|c|c|c|}
\hline \multirow{3}{*}{$\begin{array}{c}\text { Diameter, } \\
\text { breast } \\
\text { high, } \\
\text { inches. }\end{array}$} & & Total hei & ght in feet. & & \multirow{3}{*}{$\begin{array}{c}\text { Limb } \\
\text { wood alone. }\end{array}$} \\
\hline & 40 & 50 & 60 & 70 & \\
\hline & \multicolumn{4}{|c|}{ Total volume, trunk and limbs, cubic feet. } & \\
\hline 3 & 0.7 & 0.9 & I. I & $\ldots$ & $\ldots \ldots$ \\
\hline 4 & I. 7 & $2 . I$ & $2 \cdot 3$ & $\ldots \ldots \ldots$ & 0.1 \\
\hline 5 & 2.9 & $3 \cdot 3$ & $4 \cdot 0$ & $\ldots \ldots \ldots \ldots$ & 0.3 \\
\hline 6 & 4.0 & 4.8 & 5.8 & 6.4 & 0.5 \\
\hline 7 & $\ldots \ldots \ldots$ & 6.5 & $7 \cdot 5$ & 8.9 & 0.8 \\
\hline 8 & $\ldots \ldots \ldots$ & 8.6 & $9 \cdot 7$ & II . 2 & $\mathbf{I} \cdot 3$ \\
\hline 9 & $\ldots \ldots \ldots$ & II .O & I 2.4 & I 4.4 & 2. I \\
\hline 10 & $\ldots \ldots \ldots$ & $\ldots \ldots \ldots \ldots$ & I 5.2 & 17.7 & 2.9 \\
\hline II & $\ldots \ldots \ldots$ & $\ldots \ldots \ldots \ldots$ & $\ldots \ldots \ldots \ldots$ & $2 I .4$ & 3.8 \\
\hline I2 & $\ldots \ldots \ldots$ & $\ldots \ldots \ldots \ldots$ & $\ldots \ldots \ldots \ldots$ & $24 \cdot 9$ & 4.6 \\
\hline I3 & $\ldots \ldots \ldots$ & $\ldots \ldots \ldots$ & $\ldots \ldots \ldots$ & 28.8 & $5 \cdot 5$ \\
\hline I4 & $\ldots \ldots \ldots$ & $\ldots \ldots \ldots \ldots$ & $\ldots \ldots \ldots \ldots$ & $3^{2} \cdot 4$ & 6.3 \\
\hline I5 & $\ldots \ldots \ldots$ & $\ldots \ldots \ldots \ldots$ & $\ldots \ldots \ldots \ldots$ & $\ldots \ldots \ldots$ & 7.1 \\
\hline
\end{tabular}

3 Taken from The Management of Second Growth Hardwoods in Vt., by A. F. Hawes and B. A. Chandler. Vt. Forest Service Publication No. I3.

\section{TABLE XXVI. - CHESTNUT. ${ }^{1}$ VOLUME IN CUBIC FEET FOR SPROUT TREES, PISGAH, NEW HAMPSHIRE. \\ Based on measurements of 658 trees.}

\begin{tabular}{|c|c|c|c|c|c|}
\hline \multirow{3}{*}{$\begin{array}{l}\text { Diameter, } \\
\text { breast high, } \\
\text { in inches. }\end{array}$} & \multicolumn{5}{|c|}{ Height in feet. } \\
\hline & 60 & 70 & 80 & 90 & 100 \\
\hline & \multicolumn{5}{|c|}{ Volume of used length, including bark, in cubic feet. } \\
\hline 8 & $7 \cdot 7$ & 8.5 & $9 \cdot 7$ & $\ldots \ldots \ldots$ & $\ldots \ldots$ \\
\hline 9 & 10.0 & II.I & 13.0 & 14.4 & $\ldots \ldots$ \\
\hline IO & I 2.4 & I4. I & I6. 4 & I8.0 & $\ldots \ldots \ldots$ \\
\hline II & 15.0 & $17 \cdot 3$ & 20.0 & 22.0 & $25 \cdot 4$ \\
\hline I2 & I8.0 & 20.9 & 24.0 & 26.5 & 30.2 \\
\hline I3 & $2 \mathrm{I} . \mathrm{I}$ & $24 \cdot 7$ & 28.0 & 31.0 & 35.1 \\
\hline I4 & $24 \cdot 4$ & 28.3 & 32.0 & $35 \cdot 7$ & 40.0 \\
\hline I5 & 28.0 & 32.7 & $3^{6} .5$ & 40.6 & $45 \cdot I$ \\
\hline 16 & 32.0 & 36.8 & $4 I .0$ & 45.6 & 50.3 \\
\hline I7 & 36.0 & 40.8 & 45.9 & 50.8 & 56.1 \\
\hline I8 & $39 \cdot 9$ & 45.0 & 51.0 & $56 . I$ & 62.0 \\
\hline I9 & $43 \cdot 7$ & $49 \cdot 5$ & 56.4 & 62.0 & 68.3 \\
\hline 20 & $\ldots \ldots \ldots$ & 54.0 & 62.0 & 68.0 & 74.8 \\
\hline $2 I$ & $\ldots \ldots \ldots$ & & 68. I & 74.4 & $8 \mathrm{I} \cdot 3$ \\
\hline
\end{tabular}

1 Taken from Biennial Report of the New Hampshire Forestry Commission for $1905-1906$. 


\section{TABLE XXVII. - CHESTNUT. ${ }^{2}$ VOLUME IN CUBIC FEET, LITCHFIELD AND MIDDLESEX COUNTIES, CONNECTICUT.?}

Based on measurements of 218 trees.

\begin{tabular}{|c|c|c|c|c|c|c|c|c|}
\hline \multirow{3}{*}{$\begin{array}{c}\text { Diameter, } \\
\text { breast } \\
\text { high, } \\
\text { in inches. }\end{array}$} & \multicolumn{8}{|c|}{ Height of tree in feet. } \\
\hline & 20 & 30 & 40 & 50 & 60 & 70 & 80 & 90 \\
\hline & \multicolumn{8}{|c|}{ Volume in cubic feet. } \\
\hline 2 & 0.2 & 0.3 & $\ldots \ldots$ & $\ldots \ldots$ & $\ldots \ldots$ & $\ldots \ldots \ldots$ & $\ldots \ldots \ldots$ & $\ldots \ldots \ldots$ \\
\hline 3 & .4 & $\cdot 7$ & 0.9 & $\ldots \ldots$ & $\ldots \ldots$ & $\ldots \ldots \ldots$ & $\ldots \ldots \ldots$ & $\ldots \ldots$ \\
\hline 4 & $\ldots \ldots$ & I. 2 & I. 6 & $2 . I$ & $\ldots \ldots$ & $\ldots \ldots \ldots$ & $\ldots \ldots \ldots$ & $\ldots \ldots$ \\
\hline 5 & $\ldots \ldots$ & I.9 & 2.6 & $3 \cdot 3$ & $\ldots \ldots$ & $\ldots \ldots \ldots$ & $\ldots \ldots \ldots$ & $\ldots \ldots$ \\
\hline 6 & $\ldots \ldots$ & $\ldots \ldots$ & $3 \cdot 7$ & 4.6 & 5.6 & $\ldots \ldots \ldots$ & $\ldots \ldots \ldots$ & $\ldots \ldots$ \\
\hline 7 & $\ldots \ldots$ & $\ldots \ldots$ & 5.0 & 6.2 & $7 \cdot 3$ & $\ldots \ldots \ldots$ & $\ldots \ldots \ldots$ & $\ldots \ldots$ \\
\hline 8 & $\ldots \ldots$ & $\ldots \ldots$ & 6.5 & $7 \cdot 9$ & $9 \cdot 4$ & II.O & $\ldots \ldots \ldots$ & $\ldots \ldots \ldots$ \\
\hline 9 & $\ldots \ldots$ & $\ldots \ldots$ & 8.4 & IO. I & I 1.8 & I3.6 & $\ldots \ldots \ldots$ & $\ldots \ldots$ \\
\hline IO & $\ldots \ldots$ & $\ldots \ldots$ & 10.5 & 12.5 & $14 \cdot 5$ & I6. 6 & 17.8 & I9.0 \\
\hline I I & $\ldots \ldots$ & $\ldots \ldots$ & 12.8 & I5. 3 & 17.9 & 20.7 & 22.6 & $24 \cdot 3$ \\
\hline 12 & $\ldots \ldots$ & $\ldots \ldots$ & I5. 4 & 18.4 & $21 \cdot 5$ & 25.0 & $27 \cdot 4$ & 30.0 \\
\hline 13 & $\ldots \ldots$ & $\ldots \ldots$ & I8. 2 & 19.7 & 25.2 & 29.1 & 32.1 & $35 \cdot 3$ \\
\hline 14 & $\ldots \ldots$ & $\ldots \ldots$ & $\ldots \ldots$ & 25.0 & 29.2 & 33.8 & 37.7 & $4 I \cdot 3$ \\
\hline I 5 & $\ldots \ldots$ & $\ldots \ldots$ & $\ldots \ldots$ & 28.8 & 33.6 & $3^{8} .8$ & $43 \cdot 4$ & 48.0 \\
\hline I6 & $\ldots \ldots$ & $\ldots \ldots$ & $\ldots \ldots$ & 32.6 & $3^{8} . \mathrm{I}$ & 44.0 & $49 \cdot 5$ & 55.0 \\
\hline I 7 & $\ldots \ldots$ & $\ldots \ldots$ & $\ldots \ldots$ & $3^{6} \cdot 5$ & 42.7 & $49 \cdot 5$ & 56.0 & 63.0 \\
\hline 18 & $\ldots \ldots$ & $\ldots \ldots$ & $\ldots \ldots$ & 40.5 & 47.4 & $55 \cdot 5$ & $6_{3} .0$ & 70.5 \\
\hline I9 & $\ldots \ldots$ & $\ldots \ldots$ & $\ldots \ldots$ & $44 \cdot 3$ & $5 \mathrm{I} \cdot 4$ & $6 \mathrm{I} \cdot 5$ & 70.0 & 79.0 \\
\hline 20 & $\ldots \ldots$ & $\ldots \ldots$ & $\ldots \ldots$ & 49.0 & $5^{8} \cdot 5$ & 68.5 & 78.0 & 85.0 \\
\hline $2 I$ & ..... & $\ldots \ldots$ & $\ldots \ldots$ & $\ldots \ldots$ & 65.0 & $75 \cdot 5$ & 86.0 & 97.0 \\
\hline 22 & $\ldots \ldots$ & $\ldots \ldots$ & $\ldots \ldots$ & $\ldots \ldots$ & 71.0 & 83.0 & 95.0 & 106.5 \\
\hline 23 & $\ldots \ldots$ & $\ldots \ldots$ & $\ldots \ldots$ & $\ldots \ldots$ & 78.0 & 91.0 & 104.0 & II 7.0 \\
\hline 24 & $\ldots \ldots$ & ..... & $\ldots \ldots$ & $\ldots \ldots$ & $85 \cdot 5$ & $99 \cdot 5$ & I I 4.0 & I 28.0 \\
\hline 25 & ..... & ..... & $\ldots \ldots$ & $\ldots \ldots$ & 93.0 & 108.5 & I 24.0 & 140.0 \\
\hline
\end{tabular}

Volumes include stem and topwood, with bark, up to a minimum diameter of 2 inches. Average stump heights vary from 6 inches for small trees to $2 x$ inches for large ones.

1 Taken from U. S. Forest Service Bull. 96.

${ }^{2}$ For volume of trees under 8 inches diameter, breast high, twenty-one measurements made in 1905 at Hyde Park, N. X., by Mr. J. G. Peters, were combined with those made in Connecticut. 


\section{TABLE XXVIII. - CHESTNUT. ${ }^{1}$ VOLUME IN BOARD FEET,} LITCHFIELD COUNTY, CONNECTICUT.

By Internationa1 ${ }^{2}$ Log Rule. Based on measurements of 118 trees.

\begin{tabular}{|c|c|c|c|c|c|c|c|c|c|c|c|}
\hline \multirow{4}{*}{$\begin{array}{l}\text { Diam- } \\
\text { eter, } \\
\text { breast } \\
\text { high. }\end{array}$} & \multicolumn{10}{|c|}{ Height of tree in feet. } & \multirow{4}{*}{$\begin{array}{l}\text { Diam- } \\
\text { eter } \\
\text { (inside } \\
\text { bark) } \\
\text { of top. }\end{array}$} \\
\hline & \multicolumn{2}{|c|}{50} & \multicolumn{2}{|c|}{60} & \multicolumn{2}{|c|}{70} & \multicolumn{2}{|c|}{80} & \multicolumn{2}{|c|}{90} & \\
\hline & \multicolumn{10}{|c|}{ Volume. } & \\
\hline & Stem. & $\begin{array}{l}\text { Top- } \\
\text { wood. }\end{array}$ & Stem. & $\begin{array}{l}\text { Top- } \\
\text { wood. }\end{array}$ & Stem. & $\begin{array}{l}\text { Top- } \\
\text { wood. }\end{array}$ & Stem. & $\begin{array}{l}\text { Top- } \\
\text { wood. }\end{array}$ & Stem. & $\begin{array}{l}\text { Top- } \\
\text { wood. }\end{array}$ & \\
\hline Inches. & $\overline{\text { Bd. ft. }}$ & Cu. ft. & $\overline{\text { Bd. ft. }}$ & Cu. ft. & $\overline{\text { Bd. ft. }}$ & Cu. ft. & Bd. ft. & Cu. ft. & $\overline{\text { Bd. } \mathrm{ft}}$. & Cu. ft. & Inches. \\
\hline 9 & IO & 5.8 & I5 & 6.9 & 22 & 8.0 & $\ldots$ & $\ldots$ & $\ldots$ & $\ldots$ & 7 \\
\hline IO & 26 & 5.2 & 32 & 6.2 & 40 & $7 \cdot 1$ & $4^{8}$ & 6.9 & $5^{6}$ & 6.6 & 7 \\
\hline II & 42 & $4 \cdot 9$ & 50 & 6.2 & 50 & 7.2 & 69 & 7.2 & 80 & 7.0 & 8 \\
\hline I 2 & $5^{8}$ & 4.8 & 68 & $6 . \mathrm{I}$ & 78 & $7 \cdot 3$ & 92 & $7 \cdot 5$ & 107 & $7 \cdot 7$ & 8 \\
\hline 13 & 74 & $4 \cdot 7$ & 87 & 6. I & 100 & $7 \cdot 5$ & II6 & 7.6 & I 33 & 7.8 & 8 \\
\hline I4 & 92 & 4.6 & 107 & 6.2 & 122 & 7.6 & I4I & 8.4 & 160 & 8.6 & 8 \\
\hline I 5 & IIO & $4 \cdot 9$ & 127 & 6.6 & I 47 & 8.2 & I 68 & 9.0 & I90 & 9.8 & 9 \\
\hline I6 & I 29 & $5 \cdot \mathrm{I}$ & I 50 & 6.9 & 172 & 8.7 & I96 & 10.0 & 222 & II. 3 & 9 \\
\hline I 7 & $\ldots$. & $\ldots \ldots$ & I 74 & 6.9 & 200 & $9 \cdot 3$ & 226 & II. 2 & 255 & I $3 \cdot 5$ & 9 \\
\hline I 8 & $\ldots \ldots$ & $\ldots \ldots$ & 198 & 6.9 & 227 & 10.0 & 257 & 12.6 & $29 I$ & 15.0 & IO \\
\hline I9 & $\ldots$. & $\ldots \ldots$ & 223 & 6.9 & 257 & IO. 4 & 292 & I3. 6 & 328 & 17.0 & IO \\
\hline 20 & $\ldots$. & $\ldots \ldots$ & 250 & 7.1 & 288 & I I. 6 & 327 & I 5.2 & 368 & I9. 2 & Io \\
\hline $2 I$ & $\ldots \ldots$ & $\ldots \ldots$ & 276 & 7.9 & 318 & I 2.5 & 363 & I6.8 & 409 & $2 I .4$ & II \\
\hline 22 & $\ldots$. & $\ldots \ldots$ & 305 & $7 \cdot 9$ & 350 & 13.8 & 400 & I9.I & $45^{I}$ & 23.7 & II \\
\hline 23 & $\ldots$. & $\ldots \ldots$ & 333 & 8.5 & 385 & I 5.2 & 440 & $21 \cdot 3$ & 493 & 27.0 & II \\
\hline 24 & $\ldots$. & $\ldots \ldots$ & 363 & 9.2 & 420 & I6. 8 & 479 & $24 \cdot 3$ & 538 & 31.0 & I 2 \\
\hline 25 & $\ldots$. & $\ldots \ldots$ & 396 & 9.7 & 457 & I 8.7 & 520 & 27.2 & $5^{8} 3$ & 35.8 & I 2 \\
\hline
\end{tabular}

Note. - The volume in "topwood" (top and branches) was obtained by subtracting the aggregate cubic volume of sawlogs to a top diameter of 6 inches, inside bark, from the total used vclume of the tree, in cubic feet (to a minimum diameter of 2 inches, outside bark).

1 Taken from U. S. Forest Service Bull. 96.

2 Ten per cent deducted for circular saw kerf. 
TABLE XXIX. - CHESTNUT. ${ }^{1}$ VOLUME IN TIES, LITCHFIELD COUNTY, CONNECTICUT.

\begin{tabular}{|c|c|c|c|c|c|c|c|c|c|c|c|}
\hline \multirow{4}{*}{$\begin{array}{l}\text { Diam- } \\
\text { eter. } \\
\text { breast } \\
\text { high. }\end{array}$} & \multicolumn{11}{|c|}{ Height of tree in feet. } \\
\hline & \multicolumn{2}{|c|}{50} & \multicolumn{2}{|c|}{60} & \multicolumn{2}{|c|}{70} & \multicolumn{2}{|c|}{80} & \multicolumn{3}{|c|}{90} \\
\hline & \multicolumn{11}{|c|}{ Volume. } \\
\hline & Ties. & $\begin{array}{l}\text { Top- } \\
\text { wood. }\end{array}$ & Ties. & $\begin{array}{c}\text { Top- } \\
\text { wood. }\end{array}$ & Ties. & $\begin{array}{l}\text { Top- } \\
\text { wood. }\end{array}$ & Ties. & $\begin{array}{l}\text { Top- } \\
\text { wood. }\end{array}$ & Ties. & $\begin{array}{l}\text { Top- } \\
\text { wood. }\end{array}$ & Basis. \\
\hline Inches. & No. & Cu. ft. & No. & Cu. ft. & No. & $\mathrm{Cu} . \mathrm{ft}$. & No. & Cu. ft. & No. & Cu. ft. & Trees. \\
\hline Io & I & 9.0 & I & 10.3 & I & I I. I & I & 10. 5 & 3 & 9.5 & 4 \\
\hline I I & I & 8.2 & I & 9.6 & 2 & 10.7 & 2 & 10.4 & 4 & 9.8 & 9 \\
\hline I 2 & 2 & $7 \cdot 5^{\circ}$ & 2 & 9.0 & 3 & 10. 4 & 3 & 10.3 & 4 & 10. $x$ & 9 \\
\hline 13 & 3 & 6.9 & 3 & 8.3 & 3 & $9 \cdot 7$ & 4 & 10.0 & 5 & 10. 2 & II \\
\hline I4 & 3 & 6.2 & 3 & 7.8 & 5 & $9 \cdot 4$ & 5 & 10.0 & 8 & 10. 3 & 17 \\
\hline $\mathrm{I}_{5}$ & 5 & $6 . I$ & 5 & 7.6 & 5 & 9.3 & 6 & 10.0 & 9 & 10.7 & 6 \\
\hline 16 & 6 & 6.0 & 6 & $7 \cdot 2$ & 7 & 9.1 & 7 & 10.2 & 9 & II . 2 & 14 \\
\hline 17 & $\ldots \ldots$ & $\ldots \ldots$ & 6 & $6: 7$ & 8 & 9.0 & 8 & 10.7 & I0 & 12.7 & 6 \\
\hline 18 & $\ldots$ & $\ldots \ldots$ & 7 & $5 \cdot 9$ & 8 & 9.2 & 9 & I I. 5 & II & I 3.5 & I I \\
\hline 19 & $\ldots$. & $\ldots \ldots$ & 7 & 5.6 & 8 & 9.2 & Io & I $2 . \mathrm{I}$ & 12 & 15.3 & 6 \\
\hline 20 & $\ldots$. & $\ldots \ldots$ & 8 & $5 \cdot I$ & 10 & 9.9 & I I & I 3.5 & I3 & 17.3 & 4 \\
\hline $2 I$ & $\ldots \ldots$ & $\ldots \ldots$ & 9 & 5.1 & ro & 10.3 & II & 14.7 & I4 & 19.4 & 3 \\
\hline 22 & $\ldots \ldots$ & $\ldots \ldots$ & I I & $4 \cdot 5$ & ro & 10.9 & I 4 & I6.8 & I 7 & 21.8 & 4 \\
\hline 23 & $\ldots \ldots$ & $\ldots \ldots$ & 12 & $4 \cdot 4$ & 12 & II. 8 & 14 & 18.8 & 17 & 25.2 & 5 \\
\hline 24 & $\ldots$. & $\ldots \ldots$ & 12 & $4 \cdot 7$ & I3 & 13.2 & 15 & 21.6 & 19 & 29. I & 2 \\
\hline 25 & $\ldots$. & $\ldots \ldots$ & 16 & 4.9 & 15 & 14.8 & I 8 & $24 \cdot 4$ & $2 I$ & 34.0 & 2 \\
\hline
\end{tabular}

All first-class ties $-6^{\prime \prime} \times 8^{\prime \prime} \times 8^{\prime}$.

Nole. - The volume in "topwood" (top and branches) was obtained by subtracting the aggregate cubic volume of tie logs to a minimum top diameter of 9 inches, outside bark, from the total used volume of the tree, in cubic feet (to a minimum diameter of 2 inches, outside bark).

1 Taken from U. S. Forest Service Bull. 96. 


\section{TABLE XXX. - RED MAPLE. ${ }^{1}$ VOLUME IN STANDARD CORDS OF I28 CUBIC FEET, HARVARD FOREST, PETERSHAM, MASS., IgIO-II.}

(Revised and enlarged in 1915.$)$

\begin{tabular}{|c|c|c|c|c|c|c|c|}
\hline \multirow{3}{*}{$\begin{array}{c}\text { Diameter, } \\
\text { breast } \\
\text { high. }\end{array}$} & \multicolumn{7}{|c|}{ Total height of tree - feet. } \\
\hline & 20 & 30 & 40 & 50 & 60 & 70 & 80 \\
\hline & \multicolumn{7}{|c|}{ Merchantable volume - cords. } \\
\hline Inches. & & & & & & & \\
\hline 3 & 0.009 & 0.011 & 0.015 & 0.018 & $\ldots \ldots \ldots$ & $\ldots \ldots \ldots$ & $\ldots \ldots \ldots$ \\
\hline 4 & 0.015 & 0.019 & 0.024 & 0.029 & $\ldots \ldots \ldots$ & $\ldots \ldots \ldots$ & $\ldots \ldots \ldots$ \\
\hline 5 & $\ldots \ldots$ & 0.031 & 0.034 & 0.043 & 0.051 & $\ldots \ldots \ldots$ & $\ldots \ldots \ldots$ \\
\hline 6 & $\ldots \ldots$ & $\ldots \ldots$ & 0.048 & 0.060 & 0.072 & $0.08 \mathrm{I}$ & $\ldots \ldots \ldots$ \\
\hline 7 & $\ldots \ldots$ & $\ldots \ldots$ & 0.063 & 0.079 & 0.095 & O.II3 & $\ldots \ldots \ldots$ \\
\hline 8 & $\ldots \ldots$ & $\ldots \ldots$ & 0.078 & O.IOI & 0.122 & 0.140 & 0.153 \\
\hline 9 & $\ldots \ldots$ & $\ldots \ldots$ & 0.095 & 0.125 & 0.149 & o.I 68 & 0.184 \\
\hline 10 & $\ldots \ldots$ & $\ldots \ldots$ & $\ldots \ldots \ldots$ & $0 . I_{5}$ & o.179 & ०.I99 & 0.217 \\
\hline I I & & $\ldots \ldots$ & $\ldots \ldots$ & O.I79 & 0.212 & 0.235 & 0.252 \\
\hline 12 & $\ldots \ldots$ & $\ldots \ldots$ & $\ldots \ldots \ldots$ & 0.210 & $0.25 \mathrm{I}$ & 0.276 & 0.294 \\
\hline I3 & $\ldots \ldots$ & $\ldots \ldots$ & $\ldots \ldots$ & 0.246 & 0.292 & 0.324 & 0.343 \\
\hline I4 & & $\ldots \ldots$ & $\ldots \ldots \ldots$ & 0.286 & 0.338 & 0.374 & 0.392 \\
\hline 15 & $\ldots \ldots$ & $\ldots \ldots$ & $\ldots \ldots$ & 0.332 & 0.390 & 0.430 & $0.45^{\circ}$ \\
\hline 16. & & $\ldots \ldots$ & $\ldots \ldots \ldots$ & $0.3^{8} 3$ & 0.451 & $0.49 \mathrm{I}$ & $0.5^{6} 5$ \\
\hline I7 & & & $\ldots \ldots$ & $\ldots \ldots \ldots$ & $\ldots \ldots$ & $\ldots \ldots \ldots$ & 0.607 \\
\hline
\end{tabular}

1 Taken from "A Volume Table for Red Maple on the Harvard Forest," by E. E. Carter. Bulle tin of the Harvard Forestry Club, Vol. II, I9I3, pp. I-8. 
TABLE XXXI. - SUGAR MAPLE ${ }^{1}$ IN NEW HAMPSHIRE, 2 VOLUME IN BOARD FEET.

\begin{tabular}{|c|c|c|c|c|c|c|c|c|c|c|c|}
\hline \multirow{3}{*}{$\begin{array}{c}\text { Diam- } \\
\text { eter, } \\
\text { breast } \\
\text { high. }\end{array}$} & \multicolumn{8}{|c|}{ Number of 16 -foot logs. } & \multirow{3}{*}{$\begin{array}{l}\text { Diam- } \\
\text { eter, } \\
\text { inside } \\
\text { bark } \\
\text { of top. }\end{array}$} & \multirow{3}{*}{$\begin{array}{l}\text { Height } \\
\text { of } \\
\text { stump. }\end{array}$} & \multirow{3}{*}{ Basis. } \\
\hline & $\frac{1}{1}$ & I & $I_{1}^{\frac{1}{2}}$ & 2 & 21 & 3 & $3 \frac{1}{2}$ & 4 & & & \\
\hline & \multicolumn{8}{|c|}{ Volume - board feet in tens. } & & & \\
\hline Inches. & $\mathbf{I}$ & I & & $\ldots \ldots$ & & & & & $\begin{array}{c}\text { Inches. } \\
6\end{array}$ & $\begin{array}{r}\text { Feet. } \\
2.0\end{array}$ & $\begin{array}{c}\text { Trees. } \\
\text { I }\end{array}$ \\
\hline $\begin{array}{l}7 \\
8\end{array}$ & I & $\begin{array}{l}1 \\
2\end{array}$ & 2 & 3 & $\begin{array}{l}\cdots \\
\ldots \ldots\end{array}$ & $\cdots$ & $\begin{array}{l}\cdots \\
\cdots \\
\cdots\end{array}$ & $\cdots \cdots$ & $\begin{array}{l}0 \\
6\end{array}$ & $\begin{array}{l}2.0 \\
2.0\end{array}$ & $\begin{array}{l}\mathrm{I} \\
3\end{array}$ \\
\hline 9 & 2 & 2 & 3 & 4 & 5 & $\ldots \ldots$ & $\ldots \ldots$ & $\ldots \ldots$ & 7 & 2.0 & 3 \\
\hline 10 & 3 & 3 & 4 & 5 & 6 & 7 & $\ldots \ldots$ & $\ldots \ldots$ & 7 & 2.0 & I 3 \\
\hline I I & 4 & 4 & 5 & 7 & 8 & 9 & $\ldots \ldots$ & $\ldots \ldots$ & 8 & $2 . I$ & I 8 \\
\hline 12 & 4 & 5 & 7 & 8 & 9 & I I & I 2 & $\ldots \ldots$ & 8 & $2 . I$ & 25 \\
\hline 13 & 5 & 7 & 8 & 10 & II & I3 & I4 & $\ldots \ldots$ & 9 & $2 . I$ & 24 \\
\hline 14 & 6 & 8 & 9 & I I & I 3 & I 5 & 17 & $\ldots \ldots$ & 10 & $2 . I$ & I9 \\
\hline I 5 & . & 9 & I I & I 3 & I 6 & I 8 & 2 I & 24 & IO & 2.I & 22 \\
\hline I6 & $\ldots$ & I I & I3 & I 5 & I 8 & $2 I$ & 24 & 27 & I I & 2.2 & 32 \\
\hline I7 & $\ldots$ & I3 & I 5 & I 8 & $2 I$ & 24 & 27 & $3 I$ & I I & 2.2 & I9 \\
\hline I 8 & $\ldots$ & I 4 & 17 & 21 & 24 & 27 & $3 I$ & 35 & I 2 & 2.2 & 28 \\
\hline I9 & $\ldots$ & I 6 & 20 & 23 & 27 & 30 & 34 & 39 & I3 & $2 \cdot 3$ & 23 \\
\hline 20 & $\ldots$ & I 8 & 23 & 27 & 30 & 34 & $3^{8}$ & 43 & I3 & $2 \cdot 3$ & 22 \\
\hline $2 I$ & $\ldots$ & $\ldots$ & 26 & 30 & 34 & 38 & $4^{2}$ & 47 & I4 & 2.4 & I 6 \\
\hline 22 & . . & $\ldots$ & 30 & 34 & $3^{8}$ & 42 & 47 & $5 I$ & 14 & 2.4 & $2 \mathrm{I}$ \\
\hline 23 & $\ldots$ & $\ldots$ & 34 & $3^{8}$ & 42 & 47 & $5^{I}$ & 56 & I 5 & 2.4 & 18 \\
\hline 24 & $\ldots$ & $\ldots$ & 39 & 43 & 47 & $5^{2}$ & 57 & $6 r$ & I 6 & $2 \cdot 5$ & I5 \\
\hline 25 & $\ldots$ & $\ldots$ & 43 & 48 & 52 & 57 & 62 & 67 & I 6 & $2 \cdot 5$ & 9 \\
\hline 26 & $\ldots$ & $\ldots$ & 48 & 52 & 57 & 63 & 67 & 73 & 17 & 2.6 & 6 \\
\hline 27 & $\ldots$ & $\ldots$ & $\ldots \ldots$ & 57 & 63 & 68 & 73 & 79 & I 8 & 2.6 & 6 \\
\hline 28 & $\ldots$ & . & $\ldots \ldots$ & $6_{3}$ & 68 & 74 & 79 & 85 & I 8 & 2.7 & 6 \\
\hline 29 & $\ldots$ & 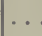 & $\ldots \ldots$ & 68 & 74 & 80 & 86 & 92 & I9 & 2.8 & 4 \\
\hline 30 & ... & $\ldots$ & $\ldots \ldots$ & 73 & 79 & 86 & 92 & 99 & 20 & 2.9 & 3 \\
\hline $3 I$ & $\ldots$ & $\ldots$ & $\ldots \ldots$ & 78 & 85 & 92 & 98 & 106 & 20 & 2.9 & 3 \\
\hline 32 & . & & $\ldots \ldots$ & 84 & $9 \mathrm{I}$ & 97 & IO4 & I I 3 & $2 I$ & 3.0 & I \\
\hline & & & & & & & & & & & 360 \\
\hline
\end{tabular}

Logs scaled as cut, 8 to 16 feet long, by the Scribner Decimal C rule. Utilization as close as form of tree allowed.

1 Taken from The Northern Hardwood Forest, etc., by E. H. Frothingham. U. S. Dept. of Agr., Bul. No. 285.

3 Grafton County. 


\section{TABLE XXXII. - SECOND-GROWTH SUGAR MAPLE.1 VOLUME IN CUBIC FEET.}

Based on measurements of 200 trees.

\begin{tabular}{|c|c|c|c|c|c|c|}
\hline \multirow{3}{*}{$\begin{array}{l}\text { Diameter, } \\
\text { breast } \\
\text { high, } \\
\text { inches. }\end{array}$} & \multicolumn{5}{|c|}{ Total height in feet. } & \multirow{3}{*}{$\begin{array}{c}\text { Limb } \\
\text { wood alone. }\end{array}$} \\
\hline & 40 & 50 & 60 & 70 & 80 & \\
\hline & \multicolumn{5}{|c|}{ Total volume, trunk and limbs, cubic feet. } & \\
\hline 2 & 0.3 & $\ldots \ldots$ & $\ldots \ldots$ & $\ldots \ldots$ & $\ldots \ldots \ldots$ & $\ldots \ldots \ldots$ \\
\hline 3 & 0.8 & I.O & $\ldots \ldots \ldots$ & $\ldots \ldots \ldots$ & $\ldots \ldots \ldots$ & $\ldots \ldots \ldots \ldots$ \\
\hline 4 & I. 4 & 2.0 & 2.0 & $\ldots \ldots \ldots$ & $\ldots \ldots \ldots$ & 0.0 \\
\hline 5 & $\ldots \ldots \ldots$ & $3 \cdot I$ & 3.6 & $\ldots \ldots \ldots$ & $\ldots \ldots \ldots$ & 0.2 \\
\hline 6 & $\ldots \ldots \ldots$ & $4 \cdot 6$ & $5 \cdot 4$ & $\ldots \ldots \ldots$ & $\ldots \ldots \ldots$ & 0.4 \\
\hline 7 & $\ldots \ldots \ldots$ & 6.5 & $7 \cdot 3$ & 9.I & 9.7 & 0.7 \\
\hline 8 & $\ldots \ldots \ldots$ & 8.8 & 9.8 & I I . 6 & I 2.3 & I.I \\
\hline 9 & $\ldots \ldots \ldots$ & II . 6 & I3.0 & $14 \cdot 4$ & I 5.0 & I. 6 \\
\hline IO & $\ldots \ldots \ldots$ & $\ldots \ldots \ldots$ & I6. I & 16.8 & I 8.6 & 2.2 \\
\hline I I & $\ldots \ldots \ldots$ & $\ldots \ldots \ldots$ & I9.9 & 20.6 & 22.6 & 2.9 \\
\hline I 2 & $\ldots \ldots \ldots$ & $\ldots \ldots \ldots$ & 24.1 & 24.8 & 27.4 & 3.6 \\
\hline I3 & $\ldots \ldots \ldots$ & $\ldots \ldots \ldots$ & 28.6 & 30.0 & $3 I . I$ & 4.4 \\
\hline 14 & $\ldots \ldots \ldots$ & $\ldots \ldots \ldots$ & $\ldots \ldots \ldots$ & 35.8 & $37 \cdot 4$ & 4.9 \\
\hline I5 & $\ldots \ldots \ldots$ & $\ldots \ldots \ldots$ & $\ldots \ldots \ldots$ & $\ldots \ldots \ldots$ & $\ldots \ldots \ldots$ & 5.2 \\
\hline
\end{tabular}

1 Taken from The Management of Second Growth Hardwoods in Vt., by A. F. Hawes and B. A. Chandler. Vt. Forest Service Publication No. 13. 


\section{TABLE XXXIII. - RED OAK. ${ }^{1}$ VOLUME IN CUBIC AND BOARD FEET, SOUTHERN NEW HAMPSHIRE.}

Based on measurements of $68_{3}$ trees.

\begin{tabular}{|c|c|c|c|c|c|c|c|c|c|c|c|}
\hline \multirow{4}{*}{$\begin{array}{c}\text { Diam- } \\
\text { eter, } \\
\text { breast } \\
\text { high. } \\
\\
\text { Inches. }\end{array}$} & \multicolumn{10}{|c|}{ Used length in feet. } & \multirow{3}{*}{$\begin{array}{l}\text { Num- } \\
\text { ber of } \\
\text { board } \\
\text { feet per } \\
\text { cubic } \\
\text { foot of } \\
\text { log. }\end{array}$} \\
\hline & \multicolumn{2}{|c|}{10} & \multicolumn{2}{|l|}{20} & \multicolumn{2}{|l|}{30} & \multicolumn{2}{|l|}{40} & \multirow{2}{*}{\multicolumn{2}{|c|}{50}} & \\
\hline & \multicolumn{8}{|c|}{ Volume. } & & & \\
\hline & Cu. ft. & Bd. $\mathrm{ft}^{2}{ }^{2}$ & Cu. ft. & Bd. ft. & Cu. ft. & Bd. ft. & Cu. ft. & Bd. ft. & Cu. ft. & Bd. ft. & \\
\hline 5 & I. 7 & 7 & $2 \cdot 3$ & $\ldots \ldots$ & $\ldots \ldots$ & $\ldots \cdots$ & $\ldots \ldots$ & $\ldots \ldots$ & $\ldots$ & $\ldots$ & 3.6 \\
\hline 6 & 2.2 & 9 & 3.2 & I 5 & $\cdots \cdots$ & $\ldots \ldots$ & $\ldots \ldots$ & $\ldots \ldots$ & $\ldots$. & $\ldots$. & 4.0 \\
\hline 7 & 2.9 & I 4 & $4 \cdot 7$ & 22 & 6.0 & 29 & $7 \cdot 5$ & 34 & $\ldots$. & $\ldots \ldots$ & $4 \cdot 4$ \\
\hline 8 & 3.6 & I 8 & 6.0 & 30 & $7 \cdot 5$ & 39 & 9.2 & 43 & $\ldots$ & $\ldots \ldots$ & 4.8 \\
\hline 9 & 4.6 & 25 & $7 \cdot 5$ & 40 & $9 \cdot 4$ & 48 & I I . 4 & $5^{8}$ & $\ldots \ldots$ & $\ldots$ & $5 \cdot I$ \\
\hline IO & $5 \cdot 7$ & $3 I$ & 9.I & 50 & I I. 3 & 60 & I3.8 & 73 & I 7.4 & 99 & $5 \cdot 4$ \\
\hline I I & 7.0 & 37 & I 1.0 & $6_{3}$ & 13.9 & 74 & I6. 4 & 90 & 20.5 & I 18 & $5 \cdot 5$ \\
\hline I 2 & 8.3 & 44 & I3. I & 78 & 16.3 & 89 & 19.5 & IIO & 23.9 & 143 & $5 \cdot 7$ \\
\hline I3 & $9 \cdot 5$ & 54 & I 5.7 & 93 & 19.2 & 107 & 22.9 & 132 & 27.4 & I74 & 5.8 \\
\hline 14 & I I. I & 65 & I 8.3 & IO9 & 22.2 & I 26 & 26.5 & 160 & 3 I. 8 & 208 & 5.9 \\
\hline I 5 & $\ldots$. & $\ldots \ldots$ & 21.2 & I 24 & 25.8 & 149 & 30.7 & I90 & 36.1 & 243 & 6.1 \\
\hline 16 & $\ldots$. & $\ldots \ldots$ & $24 \cdot 2$ & 143 & 29.2 & I 73 & 35.0 & 225 & 4 I. 2 & 288 & 6.2 \\
\hline I 7 & $\ldots$ & $\ldots \ldots$ & 27.8 & I63 & $33 \cdot 3$ & 201 & 39.9 & 262 & 46.8 & 330 & 6.4 \\
\hline I8 & $\ldots$ & $\ldots \ldots$ & 31.2 & I $8 I$ & 37.8 & 232 & 45.0 & 308 & 53.0 & 378 & 6.6 \\
\hline I9 & $\ldots$. & $\ldots \ldots$ & 34.9 & 202 & 42.0 & 265 & 50.7 & $35^{6}$ & $59 \cdot 3$ & 428 & 6.8 \\
\hline \multirow[t]{2}{*}{20} & $\ldots$ & $\ldots \ldots$ & $\ldots$. & 223 & $\ldots \ldots$ & 300 & 56.7 & 405 & \multirow{2}{*}{\multicolumn{2}{|c|}{$\begin{array}{r}\text { Average } \\
\text { Aver } 478 \\
\end{array}$}} & 7.0 \\
\hline & & & & & & & & & & & $5 \cdot 57$ \\
\hline
\end{tabular}

1 Taken from Biennial Report of the New Hampshire Forestry Commission for 1905-1906.

2 Actual mill cut in $x$-inch round-edged boards, allowing t-inch for drying and dressing. 


\section{TABLE XXXIV. - RED, BLACK AND SCARLET OAKS. ${ }^{1}$ \\ VOLUME IN CUBIC FEET, NEW LONDON COUNTY, CONNECTICUT; HYDE PARK, NEW YORK. ${ }^{2}$}

Based on measurements of $44 \mathrm{I}$ trees.

\begin{tabular}{|c|c|c|c|c|c|c|c|}
\hline \multirow{3}{*}{$\begin{array}{c}\text { Diameter, } \\
\text { breast } \\
\text { high, } \\
\text { inches. }\end{array}$} & \multicolumn{7}{|c|}{ Height of tree in feet. } \\
\hline & 20 & 30 & 40 & 50 & 60 & 70 & 80 \\
\hline & \multicolumn{7}{|c|}{ Volume in cubic feet. } \\
\hline 2 & 0.3 & 0.4 & $\ldots \ldots$ & $\ldots$ & $\ldots \ldots \ldots$ & $\ldots \ldots \ldots$ & $\ldots \ldots \ldots$ \\
\hline 3 & $\ldots \ldots$ & .9 & I.O & $\ldots \ldots$ & $\ldots \ldots \ldots$ & $\ldots \ldots \ldots$ & $\ldots \ldots \ldots$ \\
\hline 4 & $\ldots \ldots$ & I. 5 & 2.0 & 2.6 & $\ldots \ldots \ldots$ & $\ldots \ldots \ldots$ & $\ldots \ldots \ldots$ \\
\hline 5 & $\ldots \ldots$ & 2.4 & 2.8 & 3.6 & $\ldots \ldots \ldots$ & $\ldots \ldots \ldots$ & $\ldots \ldots \ldots$ \\
\hline 6 & $\ldots \ldots$ & $\ldots \ldots \ldots$ & $4 \cdot 2$ & 5.0 & 6.0 & $\ldots \ldots \ldots$ & $\ldots \ldots \ldots$ \\
\hline 7 & $\ldots \ldots$ & $\ldots \ldots \ldots$ & $5 \cdot 7$ & 6.6 & 7.6 & 8.9 & $\ldots \ldots \ldots$ \\
\hline 8 & $\ldots \ldots$ & $\ldots \ldots \ldots$ & 7.0 & 8.5 & 10. 2 & 12.0 & $\ldots \ldots \ldots$ \\
\hline 9 & $\ldots \ldots$ & $\ldots \ldots \ldots$ & 8.7 & 10.9 & 13.0 & I5.2 & I 7.3 \\
\hline IO & $\ldots \ldots$ & $\ldots \ldots \ldots$ & 10.5 & I3. I & I 5.7 & I8.4 & 21.0 \\
\hline I I & $\ldots \ldots$ & $\ldots \ldots \ldots$ & 13.0 & 16.0 & 19.0 & $22 . I$ & 25.2 \\
\hline I 2 & $\ldots \ldots$ & $\ldots \ldots \ldots$ & 16.4 & 19.7 & $22 \cdot 3$ & 26.2 & $29 \cdot 3$ \\
\hline 13 & $\ldots \ldots$ & $\ldots \ldots \ldots$ & 21.0 & $24 \cdot 3$ & $27 \cdot 7$ & 31.0 & $34 \cdot 3$ \\
\hline I4 & $\ldots \ldots$ & $\ldots \ldots$ & $25 \cdot 3$ & 29.0 & 32.6 & $36 \cdot 3$ & 40.0 \\
\hline I5 & $\ldots \ldots$ & $\ldots \ldots \ldots$ & 30.2 & 34.2 & 38.1 & 42.0 & 45.8 \\
\hline 16 & $\ldots \ldots$ & $\ldots \ldots \ldots$ & $\ldots \ldots \ldots$ & 40.0 & $44 . I$ & 48.2 & $5^{2} .4$ \\
\hline 17 & $\ldots \ldots$ & $\ldots \ldots \ldots$ & $\ldots \ldots \ldots$ & $\ldots \ldots \ldots$ & $\ldots \ldots \ldots$ & 54.6 & 59.1 \\
\hline I 8 & $\ldots \ldots$ & $\ldots \ldots \ldots$ & $\ldots \ldots \ldots$ & $\ldots \ldots \ldots$ & $\ldots \ldots \ldots$ & 61.0 & 66.0 \\
\hline I9 & $\ldots \ldots$ & $\ldots \ldots \ldots$ & $\ldots \ldots \ldots$ & $\ldots \ldots \ldots$ & $\ldots \ldots \ldots$ & 68.0 & 74.0 \\
\hline
\end{tabular}

Volumes include stem and topwood, with bark, up to a minimum diameter of 2 inches. Average stump heights vary from 5 inches for small trees to 21 inches for large ones.

1 Taken from U. S. Forest Service Bull. 96.

2 Volumes for trees under 9 inches diameter, breast high, are from measurements made in I 905 at Hyde Park, New York, by Mr. J. G. Peters. 


\section{TABLE XXXV. - RED, BLACK AND SCARLET OAKS. ${ }^{1}$ VOLUME IN BOARD FEET, NEW LONDON COUNTY, CONNECTICUT.}

By International $\log ^{2}$ Rule. Based on measurements of 175 trees.

\begin{tabular}{|c|c|c|c|c|c|c|c|c|c|}
\hline \multirow{4}{*}{$\begin{array}{l}\text { Diameter, } \\
\text { breast } \\
\text { high. }\end{array}$} & \multicolumn{8}{|c|}{ Height of tree in feet. } & \multirow{4}{*}{$\begin{array}{c}\text { Diameter } \\
\text { (inside } \\
\text { bark) of } \\
\text { top. }\end{array}$} \\
\hline & \multicolumn{2}{|c|}{50} & \multicolumn{2}{|c|}{60} & \multicolumn{2}{|c|}{70} & \multicolumn{2}{|c|}{80} & \\
\hline & \multicolumn{8}{|c|}{ Volume. } & \\
\hline & Stem. & $\begin{array}{l}\text { Top- } \\
\text { wood. }\end{array}$ & Stem. & $\begin{array}{l}\text { Top- } \\
\text { wood. }\end{array}$ & Stem. & $\begin{array}{l}\text { Top- } \\
\text { wood. }\end{array}$ & Stem. & $\begin{array}{l}\text { Top- } \\
\text { wood. }\end{array}$ & \\
\hline Inches. & Bd. ft. & Cu. ft. & Bd. ft. & Cu. ft. & Bd. ft. & Cu. ft. & Bd. ft. & Cu. ft. & Inches. \\
\hline 9 & 14 & 6.4 & 17 & 8.0 & $2 I$ & 9.6 & $\ldots \ldots$ & $\ldots \ldots$ & 7 \\
\hline IO & 24 & 6.8 & 30 & 8.2 & 38 & 9.7 & 49 & 10.5 & 7 \\
\hline I I & 35 & $7 \cdot 5$ & 45 & 8.8 & 56 & 9.8 & 68 & 10.5 & 8 \\
\hline 12 & 48 & 8.5 & 60 & $9 \cdot 4$ & 75 & 10.2 & 89 & 10.6 & 8 \\
\hline 13 & 62 & IO. I & 77 & 10.8 & 94 & 10.9 & I 13 & 10.9 & 8 \\
\hline 14 & 78 & I I. 4 & 96 & II.9 & II 7 & II.9 & 140 & II. 7 & 9 \\
\hline I5 & 95 & 12.9 & 117 & 13.3 & 141 & 13.0 & I68 & I2. I & 9 \\
\hline 16 & I I 4 & 14.9 & 140 & I5. I & 168 & 14.2 & I98 & 12.9 & 9 \\
\hline 17 & $\ldots \ldots$ & $\ldots \ldots$ & $\ldots \ldots$ & $\ldots \ldots$ & I95 & I 5.6 & 229 & 13.4 & 10 \\
\hline I8 & $\ldots \ldots$ & .... & $\ldots \ldots$ & $\ldots \ldots$ & 224 & I6.9 & 263 & 13.9 & IO \\
\hline 19 & $\ldots \ldots$ & $\ldots \ldots$ & $\ldots \ldots$ & ..... & 254 & 18.7 & 300 & I $5 \cdot 5$ & IO \\
\hline
\end{tabular}

Nole. - The volume in "topwood" (top and branches) was obtained by subtracting the aggregate cubic volume of tie logs to a minimum top diameter of 9 inches, outside bark. from the total used volume of the tree, in cubic feet (to a minimum diameter of 2 inches, outside bark).

1 Taken from U. S. Forest Service Bull. 96.

Ten per cent deducted for circular saw kerf. 


\section{TABLE XXXVI. - RED, BLACK AND SCARLET OAKS. ${ }^{1}$ VOLUME IN TIES.}

Based on measurements of I $_{59}$ trees.

\begin{tabular}{|c|c|c|c|c|c|c|c|c|c|}
\hline \multirow{4}{*}{$\begin{array}{c}\text { Diameter, } \\
\text { breast } \\
\text { high. }\end{array}$} & \multicolumn{8}{|c|}{ Height of tree in feet. } & \multirow{4}{*}{ Basis. } \\
\hline & \multicolumn{2}{|c|}{50} & \multicolumn{2}{|c|}{60} & \multicolumn{2}{|c|}{70} & \multicolumn{2}{|c|}{80} & \\
\hline & \multicolumn{8}{|c|}{ Volume. } & \\
\hline & Ties. & $\begin{array}{l}\text { Top- } \\
\text { wood. }\end{array}$ & Ties. & $\begin{array}{l}\text { Top- } \\
\text { wood. } \\
\text { S }\end{array}$ & Ties. & $\begin{array}{l}\text { Top- } \\
\text { wood. }\end{array}$ & Ties. & $\begin{array}{l}\text { Top- } \\
\text { wood. }\end{array}$ & \\
\hline $\begin{array}{c}\text { Inches. } \\
\text { I0 }\end{array}$ & $\begin{array}{c}\text { No. } \\
\text { I }\end{array}$ & $\begin{array}{c}\text { Cu. ft. } \\
8.4\end{array}$ & $\begin{array}{c}\text { No. } \\
\text { I }\end{array}$ & $\begin{array}{l}\text { Cu. } \mathrm{ft} \text {. } \\
\text { ro. } 8\end{array}$ & $\begin{array}{c}\text { No. } \\
\text { I }\end{array}$ & $\begin{array}{l}\text { Cu. ft. } \\
\text { I } 2.9\end{array}$ & $\begin{array}{c}\text { No. } \\
\text { I }\end{array}$ & $\begin{array}{l}\text { Cu. ft. } \\
\text { I5.O }\end{array}$ & $\begin{array}{c}\text { Trees. } \\
24\end{array}$ \\
\hline I I & I & 9.0 & $\mathbf{I}$ & 10.8 & 2 & I 2.6 & 2 & 14.2 & 35 \\
\hline I 2 & 2 & 9.8 & 2 & I I.I & 2 & I 2.6 & 3 & I3. I & 33 \\
\hline I3 & 2 & II.I & 2 & 12.2 & 3 & 12.7 & 4 & 12.5 & 30 \\
\hline 14 & 2 & I $2 \cdot 3$ & 4 & 13.0 & 5 & I3. I & 5 & I 2.4 & I3 \\
\hline I5 & 4 & I3. 7 & 4 & 14.0 & 5 & I $3 \cdot 5$ & 7 & I 2.2 & I 2 \\
\hline I6 & 4 & 15.7 & 4 & $15 \cdot 3$ & 6 & 14.2 & 7 & I2.I & 5 \\
\hline I 7 & $\ldots \ldots$ & $\ldots \ldots$ & $\cdots$ & $\ldots \ldots$ & 7 & 14.6 & 8 & I $2 . I$ & 4 \\
\hline I8 & & & & & 8 & 14.8 & IO & II. 5 & 2 \\
\hline I9 & & $\ldots \ldots$ & & ...... & 8 & I 5.2 & I I & I I. 8 & I \\
\hline
\end{tabular}

All first-class ties $-6^{\prime \prime} \times 8^{\prime \prime} \times 8^{\prime}$.

Note. - The volume in "topwood" (top and branches) was obtained by subtracting the aggregate cubic volume of tie logs to a minimum top diameter of 9 inches, outside bark, from the total used volume of the tree, in cubic feet (to a minimum diameter of 2 inches, outside bark).

1 Taken from U. S. Forest Service Bull. 06. 
TABLE XXXVII. - SECOND-GROWTH WHITE OAK. ${ }^{1}$ VOLUME OF CORD WOOD IN CUBIC FEET, HYDE

PARK, NEW YORK. ${ }^{2}$

Based on measurements of 349 trees.

\begin{tabular}{|c|c|c|c|c|c|}
\hline \multirow{3}{*}{$\begin{array}{l}\text { Diameter, } \\
\text { breast high, } \\
\text { in inches. }\end{array}$} & \multicolumn{5}{|c|}{ Height of tree in feet. } \\
\hline & 20 & 30 & 40 & 50 & 60 \\
\hline & \multicolumn{5}{|c|}{ Volume of cord wood in cubic feet. ${ }^{3}$} \\
\hline 2 & 0.2 & 0.5 & $\ldots \ldots \ldots \ldots$ & $\ldots \ldots \ldots \ldots$ & $\ldots \ldots \ldots$ \\
\hline 3 & .5 & .8 & I. I & $\ldots \ldots \ldots \ldots$ & $\ldots \ldots \ldots$ \\
\hline 4 & .9 & I. 4 & I. 8 & $\ldots \ldots \ldots \ldots$ & $\ldots \ldots \ldots \ldots$ \\
\hline 5 & $\ldots \ldots \ldots$ & 2.3 & 2.7 & 3.2 & $\ldots \ldots \ldots \ldots$ \\
\hline 6 & $\ldots \ldots \ldots$ & $3 \cdot 4$ & $4 \cdot 0$ & 4.8 & $5 \cdot 7$ \\
\hline 7 & $\ldots \ldots \ldots$ & 4.8 & $5 \cdot 7$ & 6.6 & 7.9 \\
\hline 8 & $\ldots \ldots \ldots$ & $\ldots \ldots \ldots \ldots$ & 7.7 & 9.0 & 10. 6 \\
\hline 9 & $\ldots \ldots \ldots$ & $\ldots \ldots \ldots \ldots$ & $\ldots \ldots \ldots \ldots$ & II. 8 & 13.6 \\
\hline IO & $\ldots \ldots \ldots$ & $\ldots \ldots \ldots \ldots$ & $\ldots \ldots \ldots \ldots$ & I 5.3 & 17.3 \\
\hline II & $\ldots \ldots \ldots$ & $\ldots \ldots \ldots \ldots$ & $\ldots \ldots \ldots \ldots$ & 19.6 & 22.6 \\
\hline 12 & $\ldots \ldots \ldots$ & $\ldots \ldots \ldots \ldots$ & $\ldots \ldots \ldots \ldots$ & 24.6 & 28.0 \\
\hline 13 & $\ldots \ldots \ldots$ & $\ldots \ldots \ldots \ldots$ & $\ldots \ldots \ldots \ldots$ & $\ldots \ldots \ldots$ & 32.2 \\
\hline
\end{tabular}

${ }^{1}$ Measurements by J. G. Peters of the U. S. Forest Service in 1905.

2 This table may be used for other second-growth hardwoods to be cut into cord wood.

These volumes include all the tree that may be utilized for cord wood down to 1 inch in diameter. A cord made up of mixed diameters of second-growth wood is considered to contain 80 cubic leet of solid wood, and this table can be reduced to cords by dividing by 80 . 
TABLE XXXVIII. - WHITE AND CHESTNUT OAKS. ${ }^{1}$ VOLUME IN CUBIC FEET, NEW LONDON COUNTY, CONNECTICUT; HYDE PARK, NEW YORK. ${ }^{2}$

Based on measurements of 293 trees.

\begin{tabular}{|c|c|c|c|c|c|c|c|}
\hline \multirow{3}{*}{$\begin{array}{l}\text { Diameter, } \\
\text { breast } \\
\text { high, } \\
\text { in inches. }\end{array}$} & \multicolumn{7}{|c|}{ Height of tree in feet. } \\
\hline & 20 & 30 & 40 & 50 & 60 & 70 & 80 \\
\hline & \multicolumn{7}{|c|}{ Volume in cubic feet. } \\
\hline 2 & 0.3 & 0.4 & $\ldots \ldots$ & $\ldots \ldots$ & $\ldots \ldots \ldots$ & $\ldots \ldots \ldots$ & $\ldots \ldots \ldots$ \\
\hline 3 & $\ldots \ldots$ & .9 & I.O & $\ldots \ldots$ & $\ldots \ldots \ldots$ & $\ldots \ldots:: 2$ & $\ldots \ldots \ldots$ \\
\hline 4 & $\ldots \ldots$ & I. 5 & 2.0 & 2.6 & $\ldots \ldots \ldots$ & $\ldots \ldots \ldots$ & $\ldots \ldots \ldots$ \\
\hline 5 & $\ldots \ldots$ & 2.4 & 2.9 & 3.6 & $\ldots \ldots \ldots$ & $\ldots \ldots \ldots$ & $\ldots \ldots \ldots$ \\
\hline 6 & $\ldots \ldots$ & $\ldots \ldots \ldots$ & 4.2 & 5.0 & 6.0 & $\ldots \ldots \ldots$ & $\ldots \ldots \ldots$ \\
\hline 7 & $\ldots \ldots$ & $\ldots \ldots \ldots$ & $5 \cdot 7$ & 6.6 & 7.6 & 8.9 & $\ldots \ldots \ldots$ \\
\hline 8 & $\ldots \ldots$ & $\ldots \ldots \ldots$ & $7 \cdot 4$ & 8.7 & 10.3 & 12.2 & $\ldots \ldots \ldots$ \\
\hline 9 & $\ldots \ldots$ & $\ldots \ldots \ldots$ & $9 \cdot 3$ & I I. I & $\mathrm{I} 3 \cdot 5$ & I6.0 & I8. 9 \\
\hline 10 & $\ldots \ldots$ & $\ldots \ldots \ldots$ & II. 2 & I3. 7 & I6. 5 & $19 \cdot 5$ & 22.6 \\
\hline I I & $\ldots \ldots$ & $\ldots \ldots$ & I $3 \cdot 3$ & I6. 5 & 19.8 & 23.2 & 26.8 \\
\hline I 2 & $\ldots$. & $\ldots \ldots \ldots$ & I 5.7 & I9. 3 & $23 . I$ & 27.2 & 3 I. 4 \\
\hline I3 & & $\ldots \ldots \ldots$ & $\ldots \ldots \ldots$ & 22.4 & 26.9 & $3 I .5$ & 36.3 \\
\hline I4 & $\ldots \ldots$ & $\ldots \ldots \ldots$ & $\ldots \ldots$ & 25.9 & 31.0 & 36.3 & 41.6 \\
\hline I 5 & $\ldots \ldots$ & $\ldots \ldots$ & $\ldots \ldots \ldots$ & $\ldots \ldots \ldots$ & $35 \cdot 5$ & $4 \mathrm{I} \cdot 7$ & 48.1 \\
\hline I6 & $\ldots \ldots$ & $\ldots \ldots$ & $\ldots \ldots \ldots$ & $\ldots \ldots \ldots$ & $40 \cdot 5$ & $47 \cdot 5$ & 55.0 \\
\hline
\end{tabular}

Volumes include stem and topwood, with bark, up to a minimum diameter of 2 inches. Average stump heights vary from 6 inches for small trees to 21 inches for large ones.

1 Taken from U. S. Forest Service Bull. 96.

2 Volumes for trees under 9 inches diameter, breast high, are from measurements made in 1905 at Hyde Park, New York, by Mr. J. G. Peters. 


\section{TABLE XXXIX. - WHITE AND CHESTNUT OAKS. ${ }^{1}$ VOLUME IN BOARD FEET, LITCHFIELD COUNTY, CONNECTICUT.}

By International ${ }^{2}$ Log Rule. Based on measurements of 26 trees.

\begin{tabular}{|c|c|c|c|c|c|c|c|}
\hline \multirow{4}{*}{$\begin{array}{c}\text { Diameter, } \\
\text { breast } \\
\text { high. }\end{array}$} & \multicolumn{6}{|c|}{ Height of tree in feet. } & \multirow{4}{*}{$\begin{array}{l}\text { Diameter } \\
\text { (inside } \\
\text { bark) of } \\
\text { top. }\end{array}$} \\
\hline & \multicolumn{2}{|c|}{50} & \multicolumn{2}{|c|}{60} & \multicolumn{2}{|c|}{70} & \\
\hline & \multicolumn{6}{|c|}{ Volume. } & \\
\hline & Stem. & Topwood. & Stem. & Topwood. & Stem. & Topwood. & \\
\hline Inches. & Bd. ft. & Cu. $\mathrm{ft}$. & Bd. ft. & Cu. ft. & Bd. ft. & Cu. ft. & Inches. \\
\hline 9 & I8 & 6.3 & 23 & $7 \cdot 7$ & 30 & 9.2 & 7 \\
\hline Io & 29 & 6.3 & 36 & 7.8 & 47 & 9.4 & 8 \\
\hline II & 41 & 6.3 & 50 & 8. I & 66 & 9.4 & 8 \\
\hline 12 & 56 & 6.3 & 66 & 8.2 & $8_{5}$ & $9 \cdot 5$ & 8 \\
\hline 13 & 72 & 6.1 & 84 & 8.5 & 107 & 9.7 & 9 \\
\hline 14 & 90 & 6.1 & 104 & 8.6 & 130 & 9.9 & 9 \\
\hline 15 & $\ldots \ldots$ & $\ldots \ldots \ldots$ & I 26 & 8.9 & 156 & 10.3 & 9 \\
\hline 16 & $\ldots \ldots$ & $\ldots \ldots \ldots$ & 149 & 9.4 & I 80 & 10.8 & 9 \\
\hline
\end{tabular}

Note. - The volume in "topwood" (top and brancbes) was obtained by subtracting the aggregate cubic volume of tie logs to a minimum top diameter of 9 inches, outside bark, from the total used volume of tree, in cubic feet (to a minimum diameter of 2 inches, outside bark).

1 Taken from U. S. Forest Service Bull. 96.

2 Ten per cent deducted for circular saw kerf.

\section{TABLE XL. - WHITE AND CHESTNUT OAKS. 1 VOLUME IN TIES, NEW LONDON COUNTY, CONNECTICUT.}

Based on measurements of 25 trees.

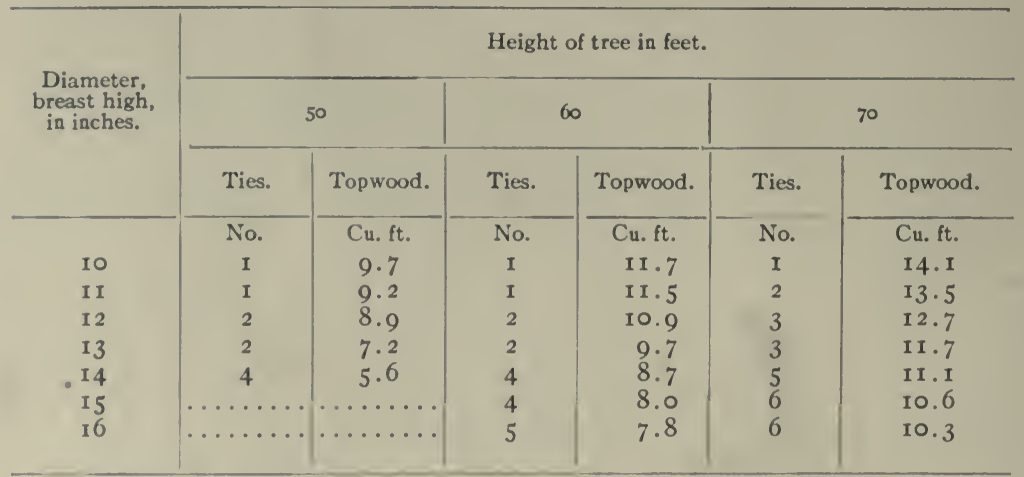

All first-class ties $-6^{\prime \prime} \times 8^{\prime \prime} \times 8^{\prime}$.

Nole. - The volume in "topwood" (top and bpanches) was obtained by subtracting the aggregate cubic volume of tie logs to a minimum top diameter of 9 inches, outside bark, from the total used volume of the tree, in cubic feet (to a minimum diameter of 2 inches, outside bark).

1 Taken from U. S. Forest Service Bull. 96. 


\section{TABLE XLI. - CORDWOOD CONVERTING FACTORS. ${ }^{1}$}

Converting factors for second-growth hardwoods, by D.B.H. classes, with corresponding diameters of the average four-foot stick in the tree or in the stack. With the aid of this table the volume in cords of single trees can be secured by dividing the volumes in cubic feet given in tables XXVII, XXXIV and XXXVIII by the "cubic feet per cord" values given in this table for a tree of the same diameter, breast high. If it is desired to convert the contents in cubic feet of an entire stand into cords, the average diameter, breast high, of all the trees in the stand should be found, and the "cubic feet per cord" value corresponding to this diameter should be used.

While these converting factors are intended especially for chestnut and oaks they can be used safely with other hardwoods.

\begin{tabular}{|c|c|c|c|c|c|c|}
\hline \multirow{2}{*}{$\begin{array}{c}\text { Diameter, } \\
\text { breast } \\
\text { high. }\end{array}$} & \multicolumn{2}{|c|}{ Chestnut. } & \multicolumn{2}{|c|}{ Black Oaks. } & \multicolumn{2}{|c|}{ White Oaks. } \\
\hline & $\begin{array}{l}\text { Diameter, } \\
\text { average stick. }\end{array}$ & $\begin{array}{l}\text { Cubic feet }{ }^{2} \\
\text { per cord. }\end{array}$ & $\begin{array}{l}\text { Diameter, } \\
\text { average stick. }\end{array}$ & $\begin{array}{l}\text { Cubic feet } \\
\text { per cord. }\end{array}$ & $\begin{array}{l}\text { Diameter, } \\
\text { average } \\
\text { stick. }\end{array}$ & $\begin{array}{l}\text { Cubic feet } \\
\text { per cord. }\end{array}$ \\
\hline $\mathbf{I}$ & 0.9 & & & & $\cdots \ldots$ & $\ldots \ldots \ldots$ \\
\hline 2 & I. 8 & 63 & I. 8 & 63 & I. 8 & 63 \\
\hline 3 & 2.6 & 70 & $2 \cdot 5$ & 69 & 2.5 & 69 \\
\hline 4 & $3 \cdot 3$ & 75 & $3 . I$ & 74 & $3 \cdot I$ & 74 \\
\hline 5 & 4.0 & 79 & 3.6 & 77 & $3 \cdot 5$ & 76 \\
\hline 6 & $4 \cdot 7$ & 83 & 4. I & 80 & 3.9 & 79 \\
\hline 7 & $5 \cdot 2$ & 85 & $4 \cdot 5$ & 82 & 4.2 & $8 \mathrm{I}$ \\
\hline 8 & 5.8 & 88 & 4.8 & 84 & $4 \cdot 5$ & 82 \\
\hline 9 & 6.2 & 89 & 5.0 & 85 & $4 \cdot 7$ & 83 \\
\hline Io & 6.7 & $9 I$ & $5 \cdot 3$ & 86 & $4 \cdot 9$ & 84 \\
\hline II & 7.0 & 92 & $5 \cdot 4$ & 86 & 5.0 & 85 \\
\hline I 2 & $7 \cdot 4$ & 93 & 5.6 & 87 & $5 \cdot I$ & 85 \\
\hline I3 & $7 \cdot 7$ & 94 & $5 \cdot 7$ & 88 & 5.2 & 85 \\
\hline I4 & $7 \cdot 9$ & 94 & $5 \cdot 7$ & 88 & $5 \cdot 2$ & 85 \\
\hline I 5 & 8.2 & 95 & 5.8 & 88 & $5 \cdot 3$ & 86 \\
\hline I6 & 8.4 & 95 & 5.9 & 88 & $5 \cdot 4$ & 86 \\
\hline 17 & 8.5 & 95 & 5.9 & 88 & & \\
\hline I8 & $\begin{array}{r}.7 \\
. \quad 8\end{array}$ & 95 & 6.0 & 89 & & \\
\hline I9 & 8.9 & 96 & 6.0 & 89 & & \\
\hline 20 & 9.0 & 96 & & & & \\
\hline $2 I$ & 9.2 & 96 & & & & \\
\hline 22 & $9 \cdot 3$ & 96 & & & & \\
\hline 23 & $9 \cdot 5$ & 97 & & & & \\
\hline 24 & 9.6 & 97 & & & & \\
\hline 25 & $9 \cdot 7$ & 97 & & & & \\
\hline 26 & 9.8 & 97 & & & & \\
\hline 27 & 10.0 & 97 & & & & \\
\hline 28 & IO. I & 97 & & & & \\
\hline 29 & 10.2 & 97 & & & & \\
\hline 30 & 10.3 & 97 & & & & \\
\hline $3^{I}$ & 10.4 & 97 & & & & \\
\hline 32 & 10.6 & 98 & & at & & \\
\hline
\end{tabular}

1 Taken from U. S. Forest Service Bull. 96.

: Solid cubic feet. 


\section{TABLE XLII. - BALSAM FIR ${ }^{1}$ IN MAINE AND NEW YORK. VOLUME (TOTAL) IN CORDS.}

Based on 2I7I trees.

\begin{tabular}{|c|c|c|c|c|c|c|c|}
\hline \multirow{3}{*}{ Diameter, breast high (inches). } & \multicolumn{7}{|c|}{ Height of tree (feet). } \\
\hline & 20 & 30 & 40 & 50 & 60 & 70 & 80 \\
\hline & \multicolumn{7}{|c|}{ Cords per tree. } \\
\hline 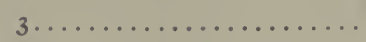 & 0.005 & 0.008 & $\ldots \ldots$ & $\ldots \ldots$ & $\ldots \ldots$ & $\ldots \ldots$ & $\ldots$ \\
\hline $4 \ldots \ldots \ldots \ldots \ldots \ldots \ldots$ & 0.009 & 0.016 & 0.022 & $\ldots \ldots$ & $\ldots$ & $\ldots \ldots$ & $\ldots \ldots$ \\
\hline $5 \ldots \ldots \ldots \ldots \ldots \ldots \ldots \ldots \ldots \ldots \ldots$ & 0.016 & 0.024 & 0.033 & 0.042 & $\ldots \ldots$ & $\ldots \ldots$ & $\ldots \ldots$ \\
\hline $6 \ldots \ldots \ldots \ldots \ldots \ldots \ldots$ & $\ldots \ldots$ & 0.034 & 0.045 & 0.057 & 0.068 & $\ldots \ldots$ & $\ldots \ldots$ \\
\hline $7 \ldots \ldots \ldots \ldots \ldots \ldots$ & $\ldots \ldots$ & 0.045 & 0.060 & 0.075 & $\circ .089$ & 0.105 & $\ldots \ldots$ \\
\hline 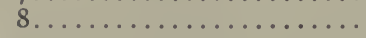 & $\ldots \ldots$ & $\ldots \ldots$ & 0.078 & 0.096 & 0.114 & 0.137 & 0.168 \\
\hline $9 \ldots \ldots \ldots \ldots \ldots \ldots \ldots \ldots \ldots \ldots$ & $\ldots \ldots$ & $\ldots \ldots$ & 0.099 & ०.IIg & 0.142 & $0.17 \mathrm{I}$ & 0.203 \\
\hline 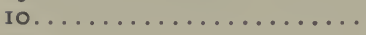 & & $\ldots \ldots$ & 0.121 & 0.146 & 0.173 & 0.204 & 0.240 \\
\hline I $\ldots \ldots \ldots \ldots \ldots \ldots \ldots$ & $\ldots \ldots$ & $\ldots \ldots$ & 0.146 & 0.178 & 0.206 & $0.24 \mathrm{I}$ & 0.278 \\
\hline 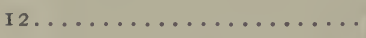 & & & $\ldots \ldots$ & $0.2 \mathrm{I}_{3}$ & 0.244 & $0.28 \mathrm{I}$ & 0.320 \\
\hline $13 \ldots \ldots \ldots \ldots \ldots \ldots \ldots \ldots$ & $\ldots \ldots$ & $\ldots \ldots$ & $\ldots \ldots$ & $\ldots \ldots$ & 0.284 & 0.324 & 0.368 \\
\hline I $4 \ldots \ldots \ldots \ldots \ldots \ldots \ldots$ & $\ldots \ldots$ & $\ldots \ldots$ & $\ldots \ldots$ & $\ldots \ldots$ & $\ldots \ldots$ & 0.366 & 0.419 \\
\hline
\end{tabular}

TABLE XLIII. - BALSAM FIR ${ }^{1}$ IN GRAFTON COUNTY, N. H., MERCHANTABLE VOLUME IN CORDS.

Top diameter, 6 inches.

\begin{tabular}{|c|c|c|c|}
\hline \multirow{3}{*}{ Diameter, breast high (inches). } & \multicolumn{3}{|c|}{ Height of tree (feet). } \\
\hline & 40 & 50 & 60 \\
\hline & \multicolumn{3}{|c|}{ Cords per tree. } \\
\hline 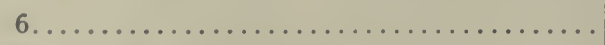 & 0.019 & 0.022 & $\ldots \ldots$ \\
\hline 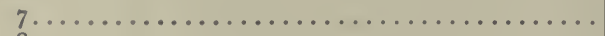 & 0.040 & 0.045 & 0.052 \\
\hline 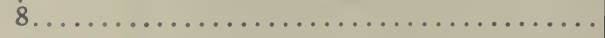 & 0.062 & 0.071 & $0.08 \mathrm{I}$ \\
\hline 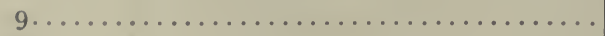 & 0.086 & 0.099 & 0.113 \\
\hline 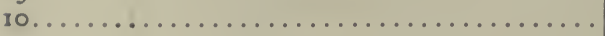 & 0.112 & 0.128 & 0.148 \\
\hline 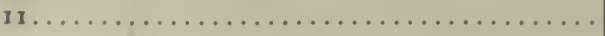 & 0.140 & O.I 59 & 0.184 \\
\hline 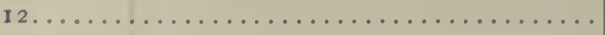 & $\ldots \ldots \ldots$ & 0.192 & 0.221 \\
\hline 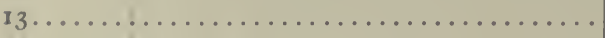 & $\ldots \ldots \ldots$ & 0.247 & 0.260 \\
\hline 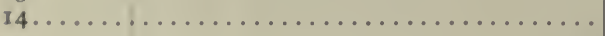 & $\ldots \ldots \ldots$ & $\ldots \ldots \ldots$ & 0.300 \\
\hline 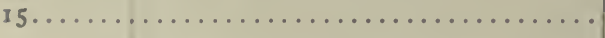 & $\ldots \ldots \ldots$ & $\ldots \ldots \ldots$ & 0.342 \\
\hline
\end{tabular}

1 Taken from the Balsam Fir, by Raphael Zon. U. S. Dept. Agr., Bul. 55. 
TABLES

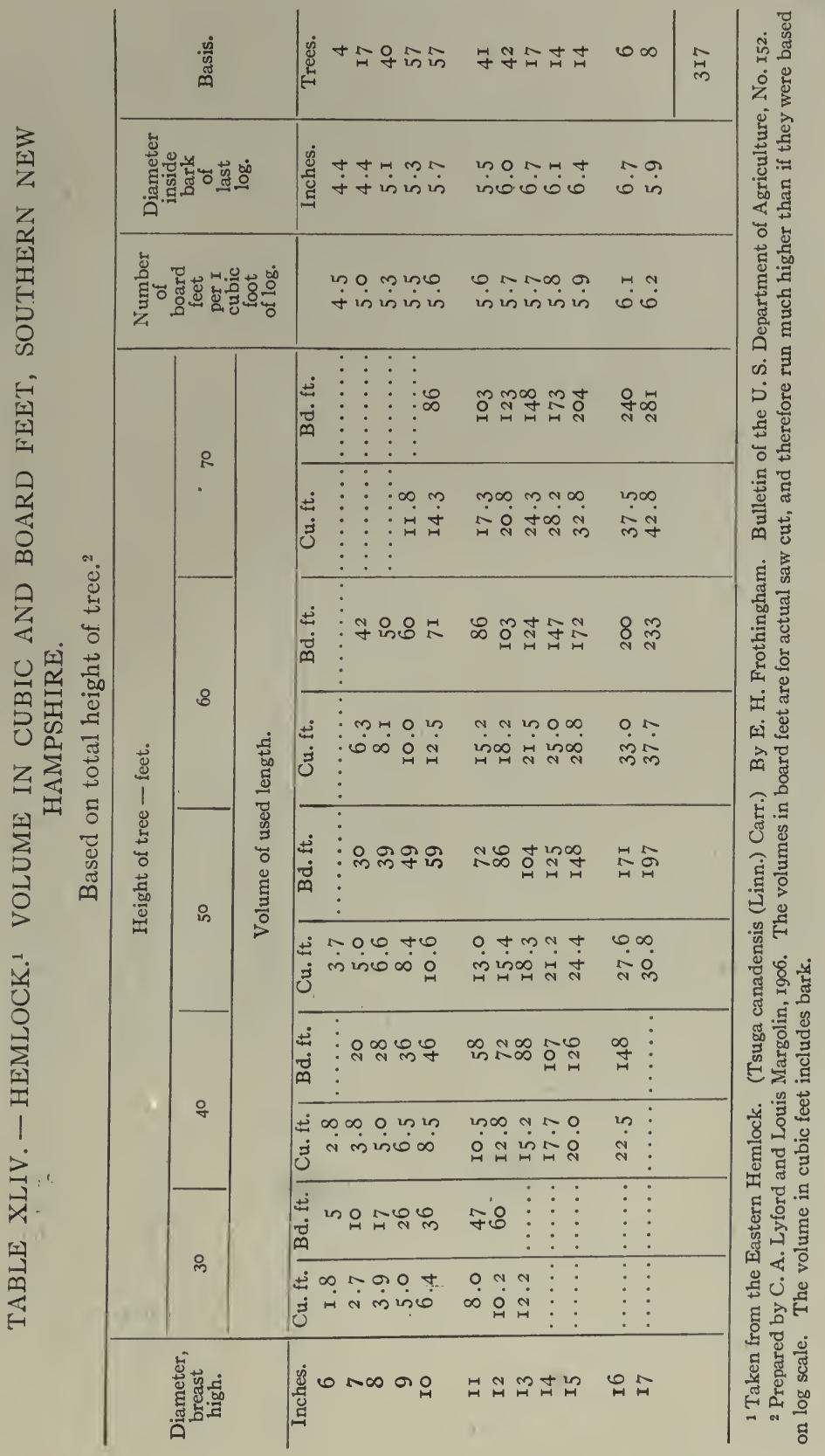


TABLE XLV. - HEMLOCK. VOLUME IN BOARD FEET, VERMONT RULE.

Based on 400 trees.

\begin{tabular}{|c|c|c|c|c|c|c|c|}
\hline \multirow{2}{*}{$\begin{array}{c}\text { Diameter, } \\
\text { breast } \\
\text { high, } \\
\text { in inches. }\end{array}$} & \multicolumn{6}{|c|}{ Total height of tree in feet. } & \multirow[b]{2}{*}{100} \\
\hline & 40 & 50 & 60 & 70 & 80 & 90 & \\
\hline S & $\underline{35}^{-1}$ & $\ldots \ldots \ldots$ & $\cdots \cdots \cdots$ & $\ldots \ldots$ & $\ldots \ldots \ldots$ & $\cdots \cdots \cdots$ & $\ldots \ldots$ \\
\hline 9 & $\underline{42}$ & $5^{I}$ & 60 & $\ldots \ldots \ldots$ & $\ldots \ldots \ldots$ & $\cdots \cdots \cdots$ & $\cdots \cdots \cdots$ \\
\hline 10 & 53 & $\underline{66}$ & 76 & & $\ldots \ldots \ldots$ & $\cdots \ldots \ldots$ & $\ldots \ldots \ldots$ \\
\hline I I & 66 & $8 \mathrm{r}$ & 94 & 109 & I 20 & $\therefore \ldots \ldots$ & $\ldots \ldots \ldots$ \\
\hline I 2 & 74 & 93 & 113 & 132 & 153 & $\ldots \ldots$ & $\ldots \ldots \ldots$ \\
\hline I3 & $\cdots \cdots$ & I 8 & 132 & 156 & 180 & $\cdots \cdots \cdots$ & $\ldots \ldots \ldots$ \\
\hline 14 & $\cdots \cdots$ & 140 & 160 & 182 & 214 & $24 I$ & $\ldots \ldots \ldots$ \\
\hline I5 & $\cdots \cdots$ & 160 & I 85 & 217 & 248 & 284 & $\cdots \cdots \cdots$ \\
\hline I6 & $\cdots \cdots$ & $\ldots \ldots \ldots$ & 214 & 248 & 282 & 320 & $\ldots \ldots \ldots$ \\
\hline I 7 & $\cdots \cdots$ & $\ldots \ldots \ldots$ & 250 & 283 & $\underline{3 I 7}$ & 360 & $\ldots \ldots \ldots$ \\
\hline I 8 & $\cdots \cdots$ & $\ldots \ldots \ldots$ & 293 & 330 & 364 & 405 & 454 \\
\hline 19 & $\cdots \cdots$ & $\ldots \ldots \ldots$ & 335 & 372 & $\underline{408}$ & $45^{\circ}$ & 500 \\
\hline 20 & $\cdots \cdots$ & $\ldots \ldots \ldots$ & 380 & 4 I 5 & 454 & 498 & 545 \\
\hline $2 \mathrm{I}$ & $\cdots \cdots$ & $\ldots \ldots \ldots$ & $\ldots \ldots \ldots$ & 455 & $\underline{497}$ & 545 & 590 \\
\hline 22 & $\cdots \cdots$ & $\ldots \ldots$ & $\ldots \ldots \ldots$ & $49 I$ & $\underline{540}$ & 594 & 650 \\
\hline 23 & $\cdots \cdots$ & $\ldots \ldots \ldots$ & $\ldots \ldots \ldots$ & 520 & 582 & 650 & 710 \\
\hline 24 & $\cdots \cdots$ & $\ldots \ldots$ & $\ldots \ldots \ldots$ & $\ldots \ldots \ldots$ & 626 & $\underline{712}$ & 780 \\
\hline 25 & $\cdots \cdots$ & $\ldots \ldots$ & $\ldots \ldots \ldots$ & $\cdots \ldots \ldots$ & 675 & 777 & $8_{36}$ \\
\hline 26 & . & $\ldots \ldots \ldots$ & $\ldots \ldots \ldots$ & $\ldots \ldots \ldots$ & $74^{2}$ & 840 & 906 \\
\hline 27 & $\cdots \cdots$ & $\ldots \ldots$ & $\ldots \ldots \ldots$ & $\ldots \ldots \ldots$ & 790 & $\overline{897}$ & 968 \\
\hline 28 & $\ldots \ldots$ & $\ldots \ldots$ & $\ldots \ldots \ldots$ & $\ldots \ldots \ldots$ & $\ldots \ldots \ldots$ & 978 & $104^{\circ}$ \\
\hline 29 & $\cdots \cdots$ & $\ldots \ldots$ & $\ldots \ldots \ldots$ & $\ldots \ldots \ldots$ & $\ldots \ldots \ldots$ & 1040 & 1100 \\
\hline 30 & $\cdots \cdots$ & $\ldots \ldots \ldots$ & $\ldots \ldots \ldots$ & $\ldots \ldots \ldots$ & $\ldots \ldots \ldots$ & 1100 & I 160 \\
\hline
\end{tabular}

1 The figures underscored indicate the average height of the trees in each diameter class. 


\section{TABLE XLVI. - HEMLOCK ${ }^{1}$ BARK. VOLUME IN STACKED CORDS, VERMONT.}

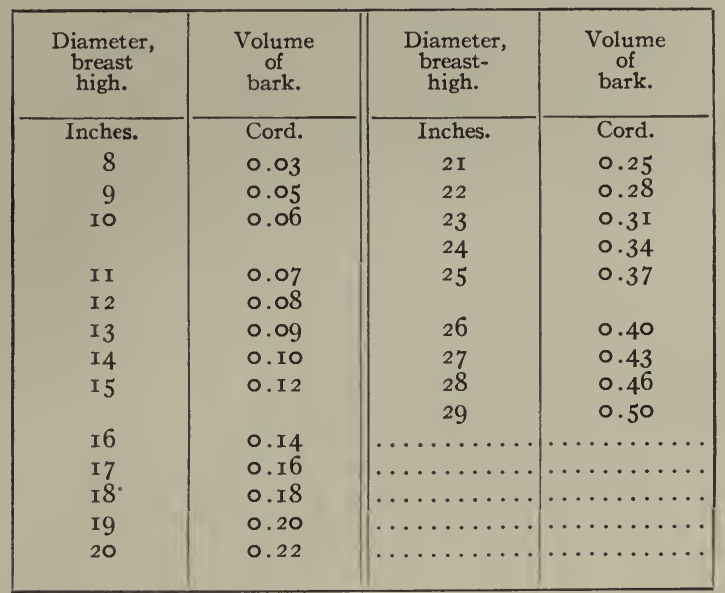

1 Taken from "Hemlock in Vermont," by A. F. Hawes, State forester; Vt. Agr. Exp. Sta., Bulletin I6I (January, I912), p. 8. The table was constructed by "subtracting the volumes of the trees inside the bark from their volumes outside the bark, and multiplying by 0.4 , on the assumption that 40 per cent of an average stacked cord of bark is solid bark." The accuracy of this factor (taken from Schenck's "Forest Mensuration," I905, p. 14) was borne out by investigations of a few piles of bark. 
TABLE XLVII. - NORWAY PINE. ${ }^{1}$ VOLUME IN BOARD FEET.

\begin{tabular}{|c|c|c|c|c|c|c|c|c|c|c|c|}
\hline \multirow{3}{*}{$\begin{array}{l}\text { Diam- } \\
\text { eter, } \\
\text { breast } \\
\text { high. }\end{array}$} & \multirow{2}{*}{$\begin{array}{c}\text { A ver- } \\
\text { age } \\
\text { for all } \\
\text { heights. }\end{array}$} & \multicolumn{10}{|c|}{ Height of tree (feet). } \\
\hline & & 30 & 40 & 50 & 60 & 70 & 80 & 90 & 100 & 110 & 120 \\
\hline & \multicolumn{11}{|c|}{ Volume (board feet). } \\
\hline Inches. & & & & & & & & & & & \\
\hline 8 & 24 & 10 & I3 & I 7 & 26 & 34 & 46 & 53 & 65 & $\cdots \cdots$ & $\ldots \ldots$ \\
\hline 9 & 43 & I 4 & 20 & 28 & 39 & $5 \mathrm{I}$ & 64 & 77 & 92 & $\ldots \ldots$ & $\ldots \ldots$ \\
\hline IO & 66 & 20 & 28 & 40 & 53 & 68 & 86 & 100 & I 20 & $\ldots \ldots$ & $\ldots \ldots$ \\
\hline I I & 90 & $\ldots$ & 38 & 53 & 69 & 87 & I 10 & 130 & 150 & $\ldots \ldots$ & $\ldots \ldots$ \\
\hline I 2 & I 20 & $\ldots$ & 48 & 67 & 86 & I IO & I30 & I 50 & 180 & 210 & $\ldots$ \\
\hline I3 & I 50 & . & 60 & $8 \mathrm{I}$ & 100 & I 30 & 160 & I 80 & 210 & 240 & $\ldots \ldots$ \\
\hline I4 & I 90 & $\ldots$ & 70 & 96 & I 20 & 160 & I90 & 210 & 250 & 280 & $\ldots \ldots$ \\
\hline I5 & 230 & $\ldots$ & $\ldots$ & I 10 & I50 & I 80 & 220 & 250 & 290 & 320 & $\ldots \ldots$ \\
\hline 16 & 270 & $\ldots$ & $\ldots$ & 130 & 170 & 210 & 250 & 290 & 330 & 360 & 390 \\
\hline I 7 & 320 & $\cdots$ & $\ldots$ & 140 & I 90 & 240 & 290 & 3.30 & 370 & 410 & 440 \\
\hline I 8 & 370 & $\ldots$ & $\ldots$ & I 60 & 220 & 280 & 330 & 380 & 420 & 460 & 500 \\
\hline I9 & 430 & $\ldots$ & .. & $\ldots \ldots$ & 260 & 320 & 380 & 430 & 480 & 520 & 560 \\
\hline 20 & 490 & $\ldots$ & $\ldots$ & $\ldots \ldots$ & 290 & 360 & 430 & 490 & 540 & 590 & 630 \\
\hline $2 I$ & 560 & $\ldots$ & $\ldots$ & $\ldots \ldots$ & $\ldots \ldots$ & 400 & 480 & 550 & 610 & 670 & 710 \\
\hline 22 & 640 & $\cdots$ & $\cdots$ & $\ldots \ldots$ & $\ldots \ldots$ & 450 & 540 & 620 & 690 & 750 & 800 \\
\hline 23 & 720 & $\ldots$ & $\ldots$ & $\ldots \ldots$ & $\ldots \ldots$ & 500 & 600 & 680 & 760 & 830 & 890 \\
\hline 24 & 810 & $\ldots$ & .. & $\ldots \ldots$ & $\ldots \ldots$ & 550 & 660 & 760 & 850 & 920 & 990 \\
\hline 25 & 910 & $\ldots$ & $\ldots$ & $\ldots \ldots$ & $\ldots \ldots$ & 600 & 720 & 840 & 940 & 1020 & 1090 \\
\hline 26 & roro & $\ldots$ & ... & $\ldots \ldots$ & $\ldots \ldots$ & 660 & 790 & 920 & 1030 & I I 20 & 1200 \\
\hline 27 & I I 20 & $\ldots$ & . & $\ldots \ldots$ & $\ldots \ldots$ & $\ldots \ldots$ & 860 & $1000^{\circ}$ & I 120 & I 220 & I3IO \\
\hline 28 & I 240 & $\ldots$ & $\ldots$ & $\ldots \ldots$ & $\ldots \ldots$ & $\ldots \ldots$ & 940 & Iogo & I 220 & I 330 & 1430 \\
\hline 29 & I 360 & $\ldots$ & $\ldots$ & $\ldots \ldots$ & $\ldots \ldots$ & $\ldots \ldots$ & 1020 & I I 70 & I 320 & I 440 & I 560 \\
\hline 30 & 1480 & $\ldots$ & $\ldots$ & $\ldots \ldots$ & $\ldots \ldots$ & $\ldots \ldots$ & 1090 & I 260 & 1420 & I 560 & I 700 \\
\hline $3 I$ & I6Io & $\ldots$ & $\ldots$ & $\ldots \ldots$ & $\ldots \ldots$ & $\ldots \ldots$ & $\ldots \ldots$ & I 360 & I 530 & I 690 & I 850 \\
\hline 32 & I 760 & $\ldots$ & $\ldots$ & $\ldots \ldots$ & $\ldots \ldots$ & $\ldots \ldots$ & $\ldots \ldots$ & I 460 & 1640 & 1820 & 2000 \\
\hline 33 & I9IO & $\ldots$ & .. & $\ldots \ldots$ & $\ldots \ldots$ & & & I $55^{\circ}$ & $175^{\circ}$ & I960 & 2160 \\
\hline 34 & 2070 & 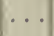 & $\cdots$ & $\ldots \ldots$ & $\ldots . .$. & $\ldots \ldots$ & $\ldots \ldots$ & I650 & I 870 & 2100 & 2320 \\
\hline
\end{tabular}

1 Taken from Norway Pine in the Lake States, by T. S. Woolsey, Jr., and H. H. Chapman, U.S. Dept. of Agr., Bul. 139. 
TABLES

TABLE XLVIII. - WHITE PINE. ${ }^{1}$ VOLUME IN BOARD FEET, SOUTHERN NEW HAMPSHIRE.

\begin{tabular}{|c|c|c|c|c|c|c|c|c|c|c|c|}
\hline \multirow{3}{*}{$\begin{array}{c}\text { Diam- } \\
\text { eter, } \\
\text { breast } \\
\text { high, in } \\
\text { inches. }\end{array}$} & \multicolumn{10}{|c|}{ Height of tree in feet. } & \multirow{3}{*}{ Basis. } \\
\hline & 30 & 40 & 50 & 60 & 70 & 80 & 90 & $1 \infty$ & IIO & 120 & \\
\hline & \multicolumn{10}{|c|}{ Volume in board feet. ${ }^{2}$} & \\
\hline & & & & & & & & & & & Trees. \\
\hline 5 & 8 & I 2 & I5 & $\ldots \ldots$ & $\cdots \cdots$ & $\ldots \ldots$ & $\ldots \ldots$ & $\ldots \ldots$ & $\ldots \ldots$ & $\ldots \ldots$ & 7 \\
\hline 6 & I3 & 20 & 23 & 27 & 29 & $\ldots \ldots$ & $\ldots \ldots$ & $\ldots \ldots$ & $\ldots \ldots$ & $\ldots \ldots$ & 41 \\
\hline 7 & I8 & 28 & 34 & 39 & 44 & $\ldots \ldots$ & $\ldots \ldots$ & $\therefore \ldots$ & $\ldots \ldots$ & $\ldots \ldots$ & 75 \\
\hline 8 & 24 & 36 & 45 & 53 & 62 & $\ldots \ldots$ & $\ldots \ldots$ & $\ldots \ldots$ & $\ldots \ldots$ & $\ldots \ldots$ & I 28 \\
\hline 9 & 32 & 44 & 56 & 69 & $8 I$ & 93 & $\ldots \ldots$ & $\ldots \ldots$ & $\ldots \ldots$ & $\ldots \ldots$ & I 56 \\
\hline IO & $4 \mathrm{I}$ & 53 & 70 & 85 & 102 & II9 & I38 & $\ldots \ldots$ & $\ldots \ldots$ & $\ldots \ldots$ & 177 \\
\hline II & $\ldots$ & 63 & 84 & IO3 & I 26 & 147 & I 68 & $\ldots \ldots$ & $\ldots \ldots$ & $\ldots \ldots$ & 164 \\
\hline I 2 & $\ldots$ & 73 & 100 & 125 & I 5 I & I 77 & 200 & 228 & 245 & $\ldots \ldots$ & 146 \\
\hline I3 & $\ldots$ & 84 & I I 7 & 148 & 180 & 210 & 238 & 270 & 293 & $\ldots .$. & 137 \\
\hline 14 & $\ldots$ & 95 & I 37 & 173 & 210 & 243 & 277 & 312 & 348 & $\ldots \ldots$ & $9 I$ \\
\hline I 5 & $\ldots$ & I05 & $15^{8}$ & 200 & $24 I$ & 282 & $32 \mathrm{I}$ & 362 & 406 & $\ldots \ldots$ & $6 I$ \\
\hline I6 & $\ldots$ & $\ldots$ & I $8 \mathrm{I}$ & 230 & 277 & 323 & 370 & $4 I 5$ & 470 & $\ldots \ldots$ & 88 \\
\hline I 7 & $\ldots$ & $\ldots$ & 209 & $26 \mathrm{I}$ & 313 & 368 & $42 I$ & $47 \mathrm{I}$ & 540 & & 70 \\
\hline I8 & $\ldots$ & $\ldots$ & 238 & 297 & $35^{2}$ & $4 \mathrm{II}$ & 475 & $53 \mathrm{I}$ & 610 & 688 & 68 \\
\hline I9 & $\ldots$ & $\ldots$ & 270 & 336 & 393 & 460 & 530 & 598 & 682 & 763 & 44 \\
\hline 20 & $\ldots$ & $\ldots$ & 302 & 379 & 436 & 506 & $5^{8} 3$ & 660 & $75^{\circ}$ & 840 & 35 \\
\hline $2 I$ & $\ldots$ & $\ldots$ & $\ldots \ldots$ & 425 & 480 & 553 & 634 & 720 & 820 & 918 & 23 \\
\hline 22 & $\ldots$ & $\ldots$ & $\ldots \ldots$ & $\ldots$. & 522 & 597 & $68 I$ & 779 & 887 & 990 & I6 \\
\hline 23 & $\ldots$ & $\ldots$ & $\ldots \ldots$ & $\ldots \ldots$ & 566 & 639 & 727 & 834 & $95^{8}$ & 1065 & I9 \\
\hline 24 & $\ldots$ & $\ldots$ & $\ldots \ldots$ & $\ldots \ldots$ & $\ldots \ldots$ & 674 & 769 & 899 & IO30 & I I35 & 9 \\
\hline 25 & $\ldots$ & $\ldots$ & $\ldots \ldots$ & $\ldots \ldots$ & $\therefore \ldots$ & 706 & 809 & 942 & 1105 & $\ldots .$. & 12 \\
\hline 26 & $\ldots$ & $\ldots$ & $\ldots \ldots$ & $\ldots \ldots$ & $\ldots \ldots$ & 737 & 846 & 994 & I I 80 & $\ldots \ldots$ & II \\
\hline \multirow[t]{2}{*}{27} & $\cdots$ & $\ldots$ & $\ldots \ldots$ & $\ldots \ldots$ & $\ldots \ldots$ & $\ldots \ldots$ & $\ldots \ldots$ & 1046 & $\ldots \ldots$ & $\ldots \ldots$ & $\ldots \ldots$ \\
\hline & & & & & & & & & & & I 578 \\
\hline
\end{tabular}

1 Measurements by L. Margolin, U. S. Forest Service in coöperation with the state of New Hampshire, New Hampshire Forestry Report, rgo5-1906. Stumps averaged about I foot in height.

2 The volume given is actual saw cut. Sixty per cent was round-edged and forty per cent squared, 70 per cent $\mathrm{I}$-inch boards and 30 per cent $2 \frac{1}{8}$-inch plank. 


\section{TABLE XLIX. - SECOND-GROWTH WHITE PINE ${ }^{1}$ IN MASSACHUSETTS. VOLUME IN BOARD FEET.}

\begin{tabular}{|c|c|c|c|c|c|c|c|c|}
\hline \multirow{3}{*}{$\begin{array}{c}\text { Diameter, } \\
\text { breast } \\
\text { high. }\end{array}$} & \multicolumn{8}{|c|}{ Height of tree (feet). } \\
\hline & 30 & 40 & 50 & 60 & 70 & 80 & 90 & 100 \\
\hline & \multicolumn{8}{|c|}{ Volume (board feet). ${ }^{2}$} \\
\hline Inches. & & & & & & & & \\
\hline 5 & IO & $\cdots \cdots$ & $\cdots \cdots$ & $\ldots \ldots$ & $\cdots \cdots$ & $\ldots \ldots \ldots$ & $\ldots \ldots$ & $\ldots \ldots \ldots$ \\
\hline 6 & 15 & 20 & 30 & $\ldots \ldots$ & $\ldots \ldots$ & $\cdots \cdots \cdots$ & $\ldots \ldots$ & $\ldots \ldots \ldots$ \\
\hline 7 & 20 & 30 & 40 & 50 & $6_{5}$ & $\ldots \ldots \ldots$ & $\ldots \ldots \ldots$ & $\ldots \ldots \ldots$ \\
\hline 8 & 25 & 35 & 50 & 65 & 85 & $\ldots \ldots \ldots$ & $\ldots \ldots \ldots$ & $\ldots \ldots \ldots$ \\
\hline 9 & 30 & 45 & 60 & 80 & 105 & II5 & $\ldots \ldots \ldots$ & $\ldots \ldots \ldots$ \\
\hline IO & 40 & 55 & 75 & 95 & I 25 & 145 & $\ldots \ldots \ldots$ & $\ldots \ldots \ldots$ \\
\hline I I & $\ldots \ldots$ & 65 & 90 & I I 5 & $\mathrm{r} 45$ & 170 & 200 & 230 \\
\hline 12 & $\ldots \ldots$ & 75 & 105 & 135 & 165 & 200 & 230 & 260 \\
\hline I3 & $\ldots \ldots$ & 85 & 120 & I 55 & 190 & 235 & 260 & 295 \\
\hline 14 & $\cdots$ : & 100 & 140 & 175 & 215 & 265 & 310 & 335 \\
\hline I 5 & $\ldots \ldots$ & I I 5 & 160 & 200 & 245 & 300 & 340 & 375 \\
\hline 16 & $\ldots$ & $\ldots$. & I 80 & 230 & 275 & 335 & 380 & 420 \\
\hline 17 & $\ldots$ & $\ldots \ldots$ & $\ldots \ldots$ & 260 & 310 & 370 & 425 & 470 \\
\hline 18 & $\ldots \ldots$ & $\ldots \ldots$ & $\ldots$ & 295 & $35^{\circ}$ & 410 & 475 & 530 \\
\hline I9 & $\ldots$ & $\ldots \ldots$ & $\cdots$ & 335 & 390 & 455 & 530 & 600 \\
\hline 20 & $\ldots$ & $\ldots \ldots$ & $\ldots \ldots$ & 380 & 435 & 505 & 580 & 660 \\
\hline $2 \mathrm{I}$ & $\ldots$ & $\ldots$. & $\ldots \ldots$ & $\ldots \ldots$ & 480 & $55^{\circ}$ & 635 & 720 \\
\hline 22 & $\ldots$ & $\ldots \ldots$ & $\ldots \ldots$ & $\ldots \ldots$ & 520 & 595 & 680 & 780 \\
\hline 23 & $\ldots$ & $\ldots$ & $\ldots$ & $\ldots \ldots$ & 565 & 640 & 730 & 835 \\
\hline 24 & $\ldots$ & $\ldots \ldots$ & $\ldots$ & $\ldots \ldots$ & 600 & 690 & 780 & 890 \\
\hline 25 & $\ldots$ & $\ldots \ldots$ & $\ldots \ldots$ & $\ldots \ldots$ & 645 & 740 & 830 & 940 \\
\hline 26 & $\ldots \ldots$ & $\ldots \ldots$ & $\ldots \ldots$ & $\ldots \ldots$ & $\ldots \ldots$ & $\ldots \ldots \ldots$ & 885 & 995 \\
\hline 27 & $\ldots$ & $\ldots \ldots$ & $\ldots \ldots$ & 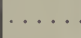 & 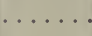 & $\ldots \ldots \ldots$ & 940 & $\ldots \ldots \ldots$ \\
\hline
\end{tabular}

1 Taken from White Pine under Forest Management, by E. H. Frothingham. U. S. Department of Agriculture, Bul. No. I3.

2 The volumes are for actual saw cut - circular saw - with 3 -inch kerf. The logs were scaled to a minimum top diameter of 4 inches. The stump height was 6 inches. 


\section{TABLES}

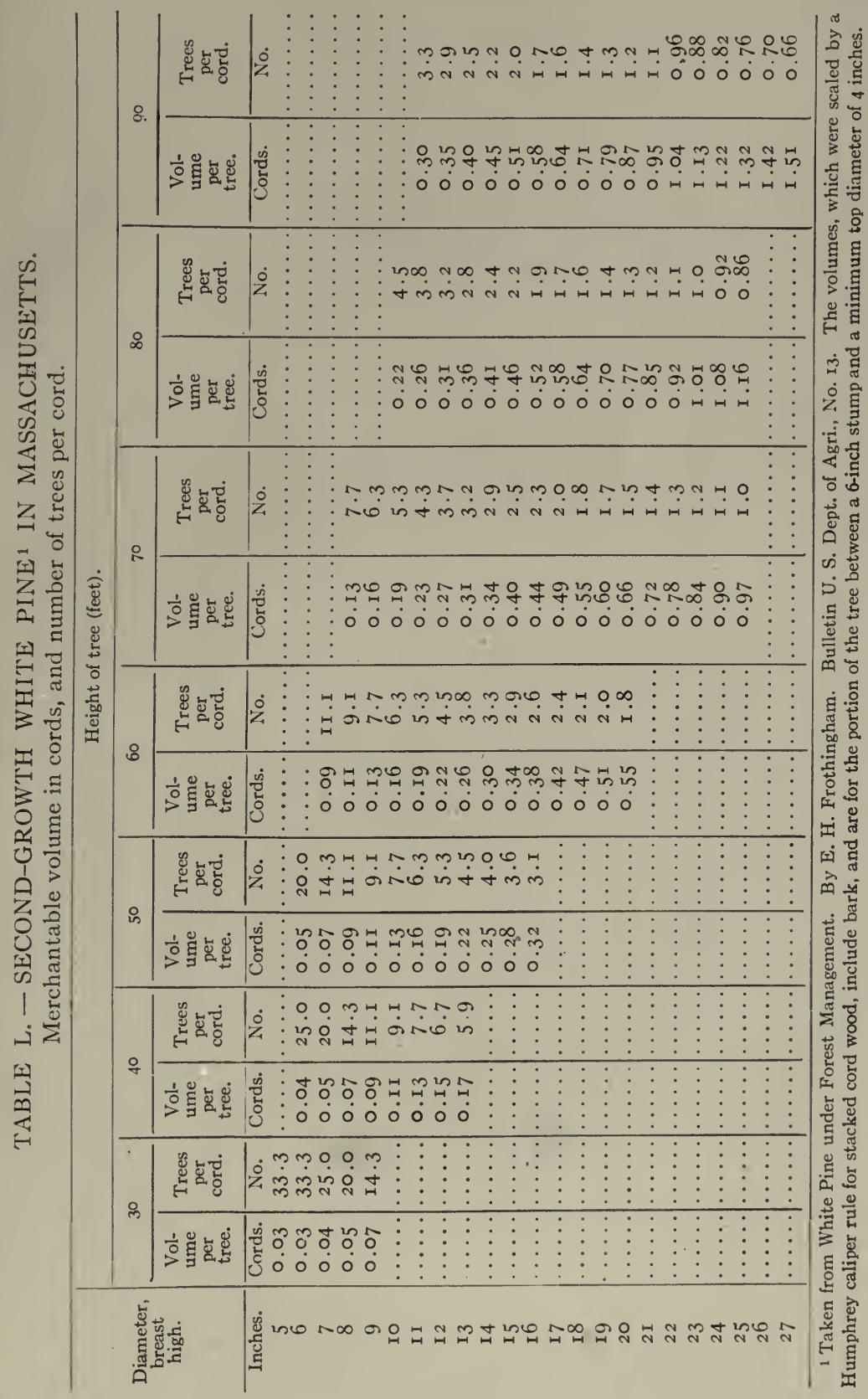


TABLE LI. - White PINE. ${ }^{1}$ VOLUME IN CUBIC FEeT, MASSACHUSETTS.

Volume outside bark, up to a 4 -inch top. Stumps taken at $\frac{1}{2}$ foot.

\begin{tabular}{|c|c|c|c|c|c|c|c|}
\hline \multirow{3}{*}{$\begin{array}{c}\text { Diameter, } \\
\text { breast } \\
\text { high, } \\
\text { in inches. }\end{array}$} & \multicolumn{7}{|c|}{ Total height in feet. } \\
\hline & 30 & 40 & 50 & 60 & 70 & 80 & 90 \\
\hline & \multicolumn{7}{|c|}{ Cubic feet. } \\
\hline 5 & I. 8 & & & & & & \\
\hline 6 & 2.6 & $3 \cdot 3$ & $4 \cdot 3$ & & & & \\
\hline 7 & $3 \cdot 4$ & $4 \cdot 4$ & 6.1 & $7 \cdot 7$ & & & \\
\hline 8 & $4 \cdot 5$ & 6.0 & 7.8 & 9.8 & I 2.0 & & \\
\hline 9 & $5 \cdot 9$ & $7 \cdot 7$ & 10.0. & 12.0 & I 5.0 & & \\
\hline Io & $\ldots \ldots$ & 9.6 & I 2.0 & I5.0 & 17.9 & 20.9 & \\
\hline II & $\ldots \ldots$ & II. 6 & I4. 6 & 17.9 & $2 \mathrm{I} .4$ & $24 \cdot 9$ & 28.7 \\
\hline I 2 & $\ldots \ldots$ & 13.9 & 17.6 & $2 \mathrm{I} . \mathrm{I}$ & $25 \cdot 3$ & 29.8 & $33 \cdot 7$ \\
\hline 13 & $\ldots \ldots$ & I6. 2 & 20.4 & 24.8 & 29.2 & 34.7 & 38.7 \\
\hline 14 & $\ldots \ldots$ & $\ldots \ldots \ldots$ & 23.7 & 28.7 & $32 \cdot 5$ & 39.6 & 43.6 \\
\hline I5 & $\ldots \ldots$ & $\ldots . .$. & 26.8 & 32.6 & 37.9 & $44 \cdot 5$ & $49 \cdot 5$ \\
\hline 16 & $\ldots \ldots$ & $\ldots \ldots \ldots$ & 30.5 & 36.5 & $42 \cdot 3$ & 49.8 & 55.9 \\
\hline I7 & $\ldots \ldots$ & $\ldots \ldots \ldots$ & $\ldots \ldots \ldots$ & 40.3 & 47.2 & 56.7 & 62.3 \\
\hline I 8 & $\ldots \ldots$ & $\ldots \ldots \ldots$ & $\ldots \ldots \ldots$ & 44.6 & $5^{2} .6$ & $6 \mathrm{I} .5$ & 69.1 \\
\hline I9 & $\ldots .$. & $\ldots \ldots \ldots$ & $\ldots \ldots \ldots$ & 49.0 & 57.9 & 67.8 & 76.9 \\
\hline 20 & $\ldots \ldots$ & $\ldots \ldots \ldots$ & $\ldots \ldots \ldots$ & 52.9 & 63.2 & 74.7 & 84.8 \\
\hline $2 I$ & $\ldots \ldots$ & $\ldots \ldots \ldots$ & $\ldots \ldots \ldots$ & $\ldots \ldots \ldots$ & $69 . x$ & 82.0 & 92.6 \\
\hline 22 & $\ldots \ldots$ & $\ldots \ldots \ldots$ & $\ldots \ldots \ldots$ & $\ldots \ldots \ldots$ & 74.9 & $89 \cdot 3$ & IOI. 4 \\
\hline 23 & & $\ldots \ldots \ldots$ & $\ldots \ldots \ldots$ & $\ldots \ldots \ldots$ & $8 \mathrm{I} \cdot 3$ & $98 . \mathrm{I}$ & I 10.8 \\
\hline 24 & $\ldots \ldots$ & $\ldots \ldots \ldots$ & $\ldots \ldots \ldots$ & $\ldots \ldots \ldots$ & 87.1 & 104.9 & I I9.0 \\
\hline 25 & $\ldots \ldots$ & $\ldots \ldots$ & $\ldots \ldots \ldots$ & $\ldots \ldots \ldots$ & 94.0 & I 12.6 & I 28.8 \\
\hline
\end{tabular}

1 Taken from "Forest Mensuration of the White Pine in Massachusetts." 
TABLE LII. - RED SPRUCE, ${ }^{1}$ VOLUME IN BOARD FEET BY THE NEW HAMPSHIRE RULE, ${ }^{2}$ GRAFTON CO., N. H.

\begin{tabular}{|c|c|c|c|c|c|c|c|}
\hline \multirow{3}{*}{$\begin{array}{c}\text { Diameter, } \\
\text { breast } \\
\text { high, } \\
\text { inches. }\end{array}$} & \multicolumn{6}{|c|}{ Total height of tree - feet. } & Basis. \\
\hline & 30 & 40 & 50 & 60 & 70 & 80 & \multirow{2}{*}{ Trees. } \\
\hline & \multicolumn{6}{|c|}{ Volume - board feet. } & \\
\hline 8 & 26 & 30 & 36 & 44 & $5 I$ & $\ldots \ldots \ldots$ & 76 \\
\hline 9 & 35 & 43 & 50 & 60 & 71 & $\ldots \ldots$ & 75 \\
\hline IO & 45 & $5^{6}$ & 66 & 78 & 9I & 100 & 87 \\
\hline I I & 58 & 70 & 83 & 97 & I IO & 120 & 76 \\
\hline 12 & 72 & $8_{5}$ & 100 & 120 & I 30 & I5O & 87 \\
\hline I3 & $\ldots \ldots$ & 100 & I 20 & 140 & 150 & I 80 & 54 \\
\hline I4 & $\ldots \ldots$ & I 20 & 140 & 160 & I 80 & 210 & 68 \\
\hline$I_{5}$ & $\ldots$ & 140 & 160 & 180 & 210 & 240 & 33 \\
\hline I6 & $\ldots$ & 160 & 180 & 210 & 240 & 270 & 36 \\
\hline 17 & & 180 & 200 & 240 & 270 & 310 & 24 \\
\hline I 8 & $\ldots \ldots$ & 200 & 230 & 270 & 300 & $35^{\circ}$ & $2 I$ \\
\hline I9 & $\ldots \ldots$ & $\ldots \ldots$ & 260 & 300 & 340 & 390 & I3 \\
\hline 20 & $\ldots$ & $\ldots \ldots$ & 290 & 330 & 380 & 430 & 9 \\
\hline $2 I$ & $\ldots$ & $\ldots \ldots$ & 320 & 360 & 420 & 470 & 3 \\
\hline 22 & $\ldots \ldots$ & $\ldots \ldots$ & $35^{\circ}$ & 400 & 460 & 510 & 3 \\
\hline 23 & $\ldots \ldots$ & $\ldots \ldots$ & $\ldots \ldots$ & 440 & 500 & 560 & ...... \\
\hline 24 & $\ldots$ & $\ldots \ldots$ & $\ldots \ldots$ & 470 & 540 & 610 & $\ldots \ldots$ \\
\hline 25 & $\ldots \ldots$ & $\ldots \ldots$ & $\ldots \ldots$ & 510 & 580 & 660 & ..... \\
\hline 26 & $\ldots \ldots$ & $\ldots \ldots$ & $\ldots \ldots$ & 540 & 620 & 710 & 3 \\
\hline & & & & & & & 668 \\
\hline
\end{tabular}

1 Taken from The Red Spruce, by L. Murphy, Bull. 544, U. S. Dept. of Agriculture.

2 Based on taper curves; scaled mostly at 16.3 -foot logs, with a few shorter logs where necessary. Stump height one foot. Diameter inside bark of top 6 inches. 


\section{TABLE LIII. - RED SPRUCE. ${ }^{1}$ VOLUME IN BOARD FEET. ${ }^{2}$}

\begin{tabular}{|c|c|c|c|c|c|c|c|c|c|c|}
\hline \multirow{2}{*}{$\begin{array}{l}\text { Diam- } \\
\text { eter. } \\
\text { breast } \\
\text { high. } \\
\text { in inches. }\end{array}$} & \multicolumn{10}{|c|}{ Total height of tree in feet. } \\
\hline & 40 & 45 & 50 & 55 & 60 & 65 & 70 & 75 & 80 & 90 \\
\hline 7 & 20 & 20 & 20 & 25 & 25 & & & & & \\
\hline 8 & 20 & 25 & 30 & 35 & 40 & 45 & & & & \\
\hline 9 & 30 & 35 & 40 & 45 & 50 & 55 & & & & \\
\hline 10 & 40 & 45 & $5^{\circ}$ & 60 & 65 & 70 & 8o & & & \\
\hline II & $\ldots \ldots$ & 55 & 65 & 70 & 80 & 90 & 105 & I I 5 & & \\
\hline I 2 & $\ldots \ldots$ & 65 & 75 & 85 & 100 & I10 & 120 & I35 & 150 & \\
\hline 13 & $\ldots \ldots$ & 75 & 90 & 100 & II 5 & 125 & 140 & I55 & 170 & \\
\hline I 4 & $\ldots \ldots$ & $\ldots \ldots$ & 105 & I 20 & 135 & 150 & 165 & 180 & 195 & \\
\hline I5 & $\ldots \ldots$ & $\ldots \ldots$ & I 20 & 135 & 155 & I 70 & 190 & 205 & 220 & \\
\hline I6 & $\ldots \ldots$ & $\ldots \ldots$ & $\ldots \ldots$ & I 55 & 170 & 185 & 205 & 225 & 250 & 3 I5 \\
\hline 17 & $\ldots \ldots$ & $\ldots \ldots$ & $\ldots \ldots$ & 170 & 190 & 210 & 230 & 250 & 275 & 350 \\
\hline I8 & $\ldots \ldots$ & $\ldots \ldots$ & $\ldots \ldots$ & 185 & 210 & 235 & 255 & 280 & 310 & 390 \\
\hline I9 & ..... & $\ldots \ldots$ & $\ldots \ldots$ & 205 & 235 & 260 & 290 & 320 & 350 & 430 \\
\hline 20 & $\ldots .$. & $\ldots \ldots$ & $\ldots \ldots$ & 235 & 265 & 295 & 325 & 355 & 385 & 470 \\
\hline $2 I$ & $\ldots \ldots$ & $\ldots \ldots$ & $\ldots \ldots$ & $\ldots \ldots$ & 300 & 330 & 360 & 390 & 425 & 510 \\
\hline 22 & $\ldots \ldots$ & $\ldots \ldots$ & $\ldots \ldots$ & $\ldots \ldots$ & 330 & 360 & 395 & 430 & 465 & $55^{\circ}$ \\
\hline 23 & $\ldots \ldots$ & $\ldots \ldots$ & $\ldots \ldots$ & $\ldots \ldots$ & 360 & 400 & 435 & 470 & 510 & 600 \\
\hline 24 & $\ldots \ldots$ & $\ldots \ldots$ & $\ldots \ldots$ & $\ldots \ldots$ & 400 & 440 & 480 & $5^{15}$ & 555 & 650 \\
\hline
\end{tabular}

"Taken from "A Manual for Northern Woodsmen." Mr. Austin Cary, the author, considers tables XL, XLI and XLII applicable to other coniferous species with certain modifications. For balsam fir he advises a deduction of 8 per cent.

2 Based on 2500 trees scaled in 16-foot log lengths up to 6 inches in diameter by the Maine log rule and discounted from 5 to 10 per cent. 


\section{TABLE LIV. - RED SPRUCE. ${ }^{1}$ VOLUME IN CUBIC FEET OF ENTIRE STEM INCLUDING BARK. ${ }^{2}$}

\begin{tabular}{|c|c|c|c|c|c|c|c|c|c|c|}
\hline \multirow{2}{*}{$\begin{array}{l}\text { Diam- } \\
\text { eter, } \\
\text { breast } \\
\text { high, } \\
\text { in inches. }\end{array}$} & \multicolumn{10}{|c|}{ Total height of tree in feet. } \\
\hline & 40 & 45 & 50 & 55 & 60 & 65 & 70 & 75 & 80 & 90 \\
\hline 6 & $4 \cdot 9$ & $5 \cdot 3$ & 5.8 & 6.5 & & & & & & \\
\hline 7 & 6.3 & 6.9 & 7.6 & 8.5 & 9.6 & & & & & \\
\hline 8 & 7.8 & 8.6 & $9 \cdot 5$ & 10.6 & 12.0 & I4 & & & & \\
\hline 9 & 9.8 & 10. 8 & I 2.0 & I 3.4 & I5.0 & 17 & & & & \\
\hline 10 & I 2.0 & 13.5 & I 5.0 & 16.5 & I 8.2 & 20 & $2 I$ & & & \\
\hline II & $\ldots \ldots$ & I6.0 & I 8.0 & 19.7 & 22 & 23 & 25 & 27 & & \\
\hline I 2 & $\ldots \ldots$ & I8. 5 & $2 I$ & 23 & 25 & 27 & 29 & 32 & 34 & \\
\hline I3 & $\ldots \ldots$ & 22 & 24 & 27 & 29 & 3 I & 34 & 36 & 39 & \\
\hline I4 & $\ldots \ldots$ & $\ldots \ldots$ & 28 & 30 & 33 & $3^{6}$ & $3^{8}$ & $4 I$ & 44 & \\
\hline I5 & $\ldots \ldots$ & $\ldots \ldots$ & $3 I$ & 34 & 37 & 40 & 43 & 46 & 49 & \\
\hline I6 & $\ldots \ldots$ & $\ldots \ldots$ & $\ldots \ldots$ & $3^{8}$ & $4 \mathrm{I}$ & 44 & 47 & 5 I & 55 & 63 \\
\hline I 7 & $\ldots \ldots$ & $\ldots \ldots$ & $\ldots \ldots$ & 43 & 46 & 49 & 52 & $5^{6}$ & $6 I$ & 70 \\
\hline I8 & $\ldots \ldots$ & $\ldots \ldots$ & $\ldots \ldots$ & 47 & $5^{\circ}$ & 54 & $5^{8}$ & 62 & 67 & 77 \\
\hline I9 & $\ldots \ldots$ & $\ldots \ldots$ & $\ldots \ldots$ & $5^{2}$ & 55 & 59 & 64 & 69 & 74 & 85 \\
\hline 20 & $\ldots \ldots$ & & $\ldots \ldots$ & $5^{6}$ & 60 & 65 & 70 & $7^{6}$ & $8 \mathrm{I}$ & 93 \\
\hline $2 \mathrm{I}$ & $\ldots \ldots$ & $\ldots \ldots$ & $\ldots \ldots$ & $\ldots .$. & $\ldots .$. & 72 & 77 & 82 & 87 & 98 \\
\hline 22 & $\ldots \ldots$ & $\ldots \ldots$ & $\ldots \ldots$ & $\ldots .$. & $\ldots \ldots$ & 79 & 84 & 88 & 93 & 105 \\
\hline 23 & $\ldots \ldots$ & $\ldots \ldots$ & $\ldots \ldots$ & $\ldots \ldots$ & $\ldots \ldots$ & 87 & 92 & 95 & 100 & I I 4 \\
\hline 24 & $\ldots \ldots$ & $\ldots \ldots$ & $\ldots \ldots$ & ...... & $\ldots \ldots$ & ${ }^{\circ} 96$ & 100 & 104 & 108 & 123 \\
\hline
\end{tabular}

1 Taken from "A Manual for Northern Woodsmen."

2 Based on 2500 trees. Bark is estimated to form about $12 \frac{1}{2}$ per cent of the total volume.

\section{TABLE LV. - RED SPRUCE. ${ }^{1}$ VOLUME IN CORDS. ${ }^{2}$}

\begin{tabular}{|c|c|c|c|c|c|c|c|c|c|}
\hline \multirow{2}{*}{$\begin{array}{c}\text { Diameter, } \\
\text { breast } \\
\text { high, } \\
\text { in inches. }\end{array}$} & \multicolumn{9}{|c|}{ Total height of tree in feet. } \\
\hline & 40 & 45 & 50 & 55 & 60 & 65 & 70 & 75 & 80 \\
\hline 6 & .04 & .05 & .05 & .06 & & & & & \\
\hline 7 & .06 & .06 & .07 & .08 & .09 & & & & \\
\hline 8 & .07 & .08 & .09 & .10 & .12 & .13 & & & \\
\hline 9 & .09 & . 10 & .12 & .13 & .14 & .16 & & & \\
\hline ro & II & .12 & .14 & .16 & .17 & .19 & .20 & .22 & \\
\hline II & $\ldots \ldots \ldots$ & .15 & .17 & . I9 & .20 & .22 & .24 & .26 & .28 \\
\hline I 2 & $\ldots \ldots \ldots$ & .18 & .20 & .22 & .24 & .26 & .28 & $\cdot 30$ & $\cdot 32$ \\
\hline I3 & $\ldots \ldots \ldots$ & $.2 \mathrm{I}$ & .23 & .25 & .27 & $\cdot 30$ & .32 & $\cdot 34$ & .37 \\
\hline I 4 & $\ldots \ldots \ldots$ & $\ldots \ldots$ & .26 & .29 & $\cdot 3 \mathrm{I}$ & $\cdot 34$ & $\cdot 36$ & $\cdot 39$ & .42 \\
\hline I5 & $\ldots \ldots \ldots$ & $\ldots \ldots$ & $\ldots \ldots$ & $\cdot 32$ & .35 & $\cdot 38$ & .40 & .43 & .47 \\
\hline 16 & $\ldots \ldots \ldots$ & $\ldots \ldots$ & $\ldots \ldots$ & .36 & .39 & .42 & .45 & .48 & $.5^{2}$ \\
\hline I 7 & $\ldots \ldots \ldots$ & $\ldots \ldots$ & $\ldots \ldots$ & .40 & .43 & .46 & .50 & $\cdot 54$ & .59 \\
\hline I8 & $\ldots \ldots \ldots$ & $\ldots \ldots$ & $\ldots \ldots$ & .45 & .48 & .50 & $\cdot 55$ & .59 & .64 \\
\hline I9 & $\ldots \ldots \ldots$ & $\ldots \ldots$ & $\ldots \ldots$ & .49 & $\cdot 5^{2}$ & $\cdot 5^{6}$ & .60 & .65 & .70 \\
\hline 20 & $\ldots \ldots \ldots$ & $\ldots \ldots$ & $\ldots \ldots$ & $\cdot 5^{2}$ & $\cdot 57$ & .62 & .66 & .72 & .77 \\
\hline
\end{tabular}

1 Taken from "A Manual for Northern Woodsmen."

${ }^{2}$ Derived from Table XLI by deducting a fair allowance for waste in stump, also volume of top above 4 inches diameter, and dividing by 96 , the usual number of cubic feet, solid wood, in a piled cord. 
TABLE LVI. - RED SPRUCE. ${ }^{1}$ VOLUME OF UNPEELED PULP WOOD IN CUBIC FEET, SOUTHERN NEW HAMPSHIRE. ${ }^{2}$

\begin{tabular}{|c|c|c|c|c|c|c|c|}
\hline \multirow{3}{*}{$\begin{array}{c}\text { Diameter. } \\
\text { breast } \\
\text { high, } \\
\text { in inches. }\end{array}$} & \multicolumn{6}{|c|}{ Height of tree in feet. } & \multirow{3}{*}{ Basis. } \\
\hline & 40 & 50 & 60 & 70 & 80 & 90 & \\
\hline & \multicolumn{6}{|c|}{ Volume in cubic feet. } & \\
\hline & & & & & & & Trees. \\
\hline 5 & 1.9 & $2 \cdot 5$ & 3.0 & $\cdots \cdots$ & $\ldots \ldots$ & $\ldots \ldots$ & 29 \\
\hline 6 & $3 \cdot 5$ & 4.2 & 5.2 & 6.4 & $\ldots \ldots \ldots$ & $\ldots \ldots \ldots$ & 98 \\
\hline 7 & 5.0 & 6.2 & $7 \cdot 5$ & 9.0 & $\ldots \ldots \ldots$ & $\ldots \ldots \ldots$ & 128 \\
\hline 8 & 6.6 & 8.4 & 10.0 & 11.7 & $\ldots \ldots \ldots$ & $\ldots \ldots \ldots$ & 165 \\
\hline 9 & 8.5 & 10.8 & 12.7 & 14.8 & $\ldots \ldots \ldots$ & $\ldots \ldots \ldots$ & $16 I$ \\
\hline 10 & $\ldots \ldots$ & $13 \cdot 5$ & 15.6 & 18.0 & $\ldots \ldots \ldots$ & $\ldots \ldots \ldots$ & $\mathrm{I}_{3}$ \\
\hline II & $\ldots .$. & 16.5 & I8.8 & $21 \cdot 5$ & $\ldots \ldots \ldots$ & $\ldots \ldots \ldots$ & 78 \\
\hline 12 & $\ldots \ldots$ & 19.5 & 22.3 & $25 \cdot 4$ & $\ldots \ldots \ldots$ & $\ldots \ldots \ldots$ & 63 \\
\hline 13 & $\ldots \ldots$ & $\ldots \ldots \ldots$ & 26.0 & $29 \cdot 5$ & $34 \cdot 5$ & $\ldots \ldots \ldots$ & 42 \\
\hline 14 & $\ldots \ldots$ & $\ldots \ldots \ldots$ & 30.0 & 34.0 & $39 \cdot 5$ & $\ldots \ldots \ldots$ & 55 \\
\hline 15 & $\ldots \ldots$ & $\ldots \ldots \ldots$ & $34 \cdot 5$ & 38.5 & 44.0 & $\ldots \ldots \ldots$ & 56 \\
\hline 16 & $\ldots \ldots$ & $\ldots \ldots \ldots$ & 39.0 & $43 \cdot 5$ & 49.0 & $\ldots \ldots \ldots$ & 49 \\
\hline 17 & $\ldots \ldots$ & $\ldots \ldots \ldots$ & $43 \cdot 5$ & 49.0 & 55.0 & 63.5 & 38 \\
\hline 18 & $\ldots \ldots$ & $\ldots \ldots \ldots$ & 48.0 & $54 \cdot 5$ & 61.0 & 70.0 & 44 \\
\hline 19 & $\ldots \ldots$ & $\ldots \ldots \ldots$ & 53.0 & 60.5 & 67.5 & 77.0 & 30 \\
\hline 20 & $\ldots \ldots$ & $\ldots \ldots \ldots$ & $5^{8} .0$ & 67.0 & $74 \cdot 5$ & $83 \cdot 5$ & 21 \\
\hline $2 I$ & $\ldots \ldots$ & $\ldots \ldots \ldots$ & $\ldots \ldots \ldots$ & 74.0 & 82.0 & $90 \cdot 5$ & 18 \\
\hline 22 & $\ldots \ldots$ & $\ldots \ldots \ldots$ & $\ldots \ldots \ldots$ & $8 \mathrm{I} \cdot 5$ & 89.0 & 98.0 & 16 \\
\hline 23 & $\ldots \ldots$ & $\ldots \ldots \ldots$ & $\ldots \ldots \ldots$ & 88.5 & 96.5 & 106.0 & 10 \\
\hline 24 & $\ldots \ldots$ & ........ & $\ldots \ldots \ldots$ & $95 \cdot 5$ & $104 \cdot 5$ & 114.0 & 5 \\
\hline 25 & $\cdots \cdots$ & $\ldots \ldots \ldots$ & $\ldots \ldots \ldots$ & 102.0 & 112.0 & 123.0 & 2 \\
\hline 26 & $\ldots \ldots$ & $\ldots \ldots \ldots$ & $\ldots \ldots \ldots$ & 109.0 & I 20.0 & $131 \cdot 5$ & 2 \\
\hline \multirow{3}{*}{$\begin{array}{l}27 \\
28\end{array}$} & $\ldots \ldots$ & $\ldots \ldots \ldots$ & $\ldots \ldots \ldots$ & $\ldots \ldots \ldots$ & 128.0 & 140.0 & 2 \\
\hline & \multirow{2}{*}{$\ldots \ldots$} & \multirow{2}{*}{$\ldots \ldots$} & \multirow{2}{*}{$\ldots \ldots$} & \multirow[t]{2}{*}{$\cdots \cdots \cdots$} & \multirow[t]{2}{*}{$135 \cdot 5$} & \multirow[t]{2}{*}{148.5} & I \\
\hline & & & & & & & I 226 \\
\hline
\end{tabular}

1 Taken from "The Woodsman's Handbook."

2 Stumps varying from $\frac{1}{3}$ to $x \frac{1}{3}$ feet and tops above 4 -inch diameter point are excluded. To reduce to cords divide by 100 or point off two places. Some use 95 or 96 cubic feet per cord. Bark equals II per cent of total volume. 


\section{TABLE LVII. - NUMBER OF TREES ${ }^{1}$ OF EACH SIZE RE- QUIRED TO YIELD.}

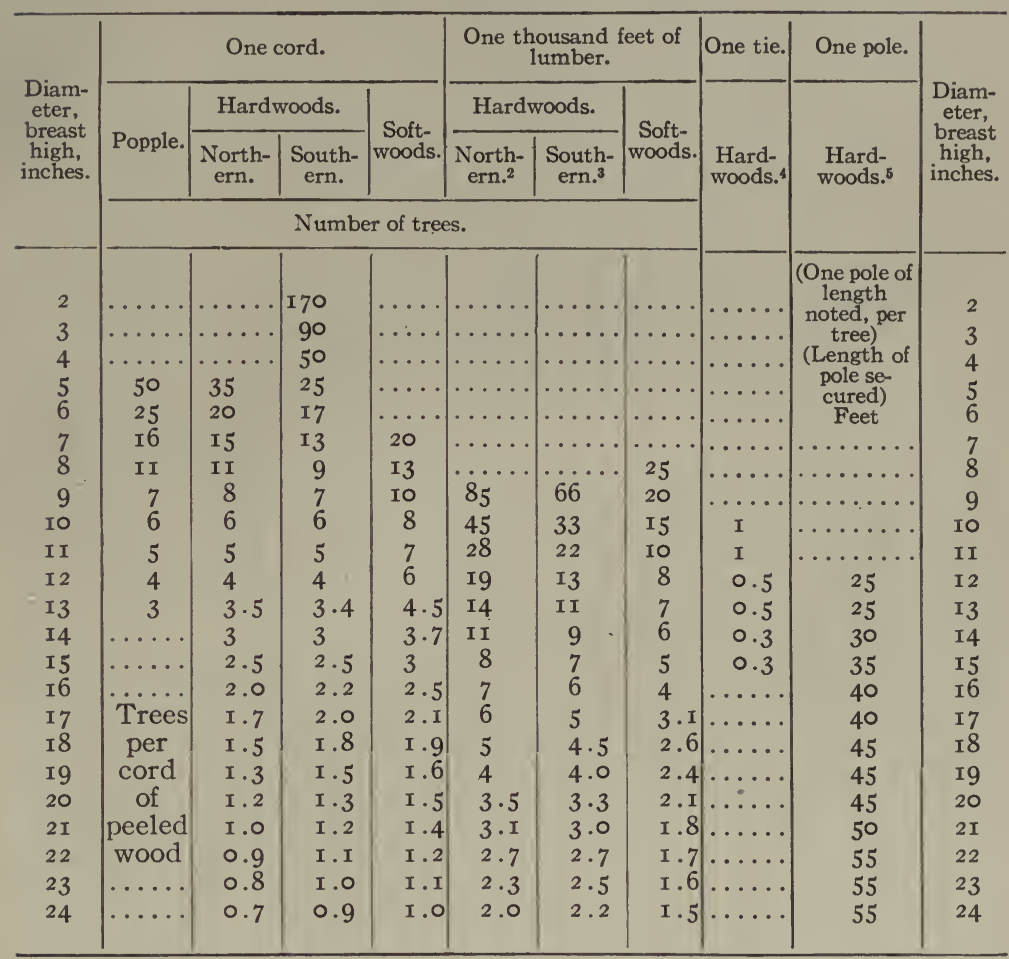

Note. - Softwoods, to 4 " top diameter. Northern hardwoods: beech, birch and maple to $4^{\prime \prime}$ top diameter. Southern hardwoods: chestnut, oak, hickory, basswood, ash, etc., to $3^{\prime \prime}$ top diameter.

1 Taken from Woodlot Forestry by R. Rosenbluth, N. Y. Conservation Commission Bull. 9.

2 For every thousand feet of lumber about two-thirds of a cord of wood can also be cut.

${ }^{8}$ For every thousand feet of lumber about three-quarters of a cord of wood can also be cut.

- For every ten ties about one cord of wood can also be cut.

${ }^{5}$ For every ten poles about one cord of wood can also be cut. 
TABLE LVIII. - APPROXIMATE AMOUNTS OF VARIOUS FOREST PRODUCTS CONTAINED IN A STANDARD CAR OF 60,000 POUNDS CAPACITY.

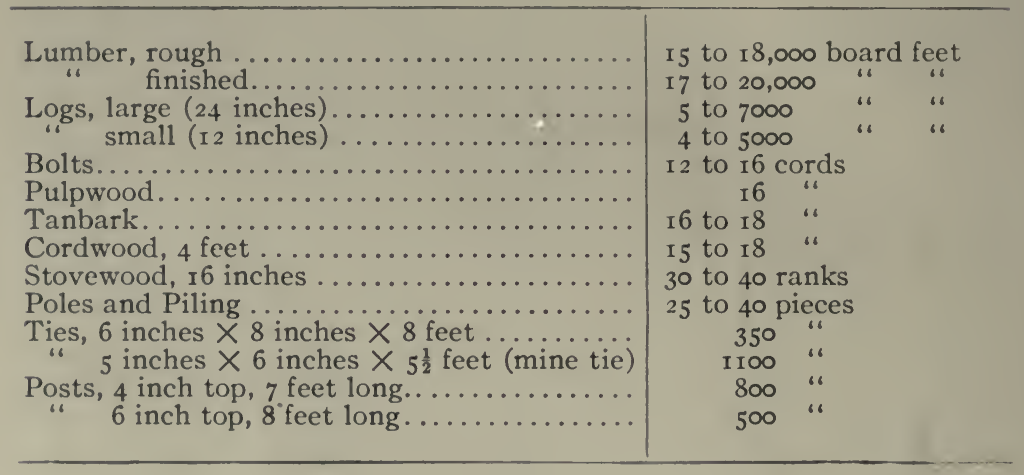


TABLES

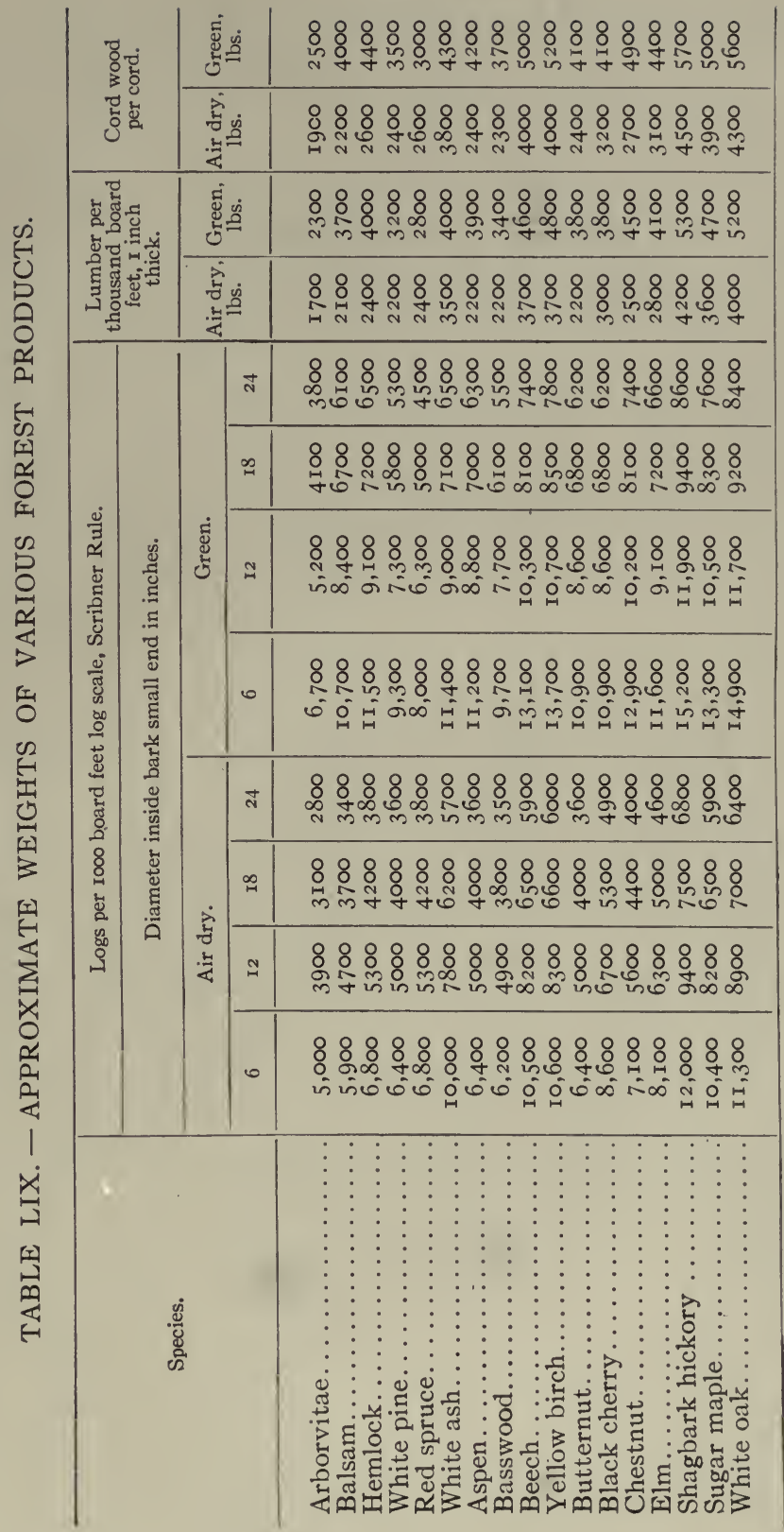




\section{GROWTH OF INDIVIDUAL TREES.}

TABLE LX. - WHITE ASH. ${ }^{1}$ DIAMETER AND HEIGHT GROWTH ON UPLANDS IN CENTRAL NEW YORK.

\begin{tabular}{|c|c|c|c|c|c|c|c|c|}
\hline \multirow{3}{*}{ Age. } & \multicolumn{4}{|c|}{ A. On moist clay soil. ${ }^{2}$} & \multicolumn{4}{|c|}{$B$. On fresh to moist sandy loam. ${ }^{3}$} \\
\hline & \multicolumn{2}{|c|}{ Fast growth. } & \multicolumn{2}{|c|}{ Average growth. } & \multicolumn{2}{|c|}{ Fast growth. } & \multicolumn{2}{|c|}{ Average growth. } \\
\hline & $\begin{array}{c}\text { Diameter, } \\
\text { breast } \\
\text { high. }\end{array}$ & Height. & $\begin{array}{c}\text { Diameter, } \\
\text { breast } \\
\text { high. }\end{array}$ & Height. & $\begin{array}{c}\text { Diameter, } \\
\text { breast } \\
\text { high. }\end{array}$ & Height. & $\begin{array}{c}\text { Diameter, } \\
\text { breast } \\
\text { high. }\end{array}$ & Height. \\
\hline $\begin{array}{l}\text { Years. } \\
\text { Io }\end{array}$ & $\begin{array}{c}\text { Inches. } \\
2.1\end{array}$ & $\begin{array}{c}\text { Feet. } \\
25\end{array}$ & $\begin{array}{c}\text { Inches. } \\
\text { I. } 3\end{array}$ & $\begin{array}{c}\text { Feet. } \\
\text { I } 7\end{array}$ & $\begin{array}{c}\text { Inches. } \\
2.5\end{array}$ & $\begin{array}{c}\text { Feet. } \\
29\end{array}$ & $\begin{array}{c}\text { Inches. } \\
\text { I. } 3\end{array}$ & $\begin{array}{c}\text { Feet. } \\
\text { I } 7\end{array}$ \\
\hline I5 & $3 \cdot 7$ & 38 & 2.4 & 27 & $5 \cdot 5$ & 42 & 3.0 & 27 \\
\hline 20 & $5 \cdot 3$ & 50 & $3 \cdot 5$ & 36 & 8.2 & 52 & $4 \cdot 5$ & 34 \\
\hline 25 & 6.7 & 59 & $4 \cdot 5$ & 43 & 10.4 & 60 & $5 \cdot 9$ & $4 I$ \\
\hline 30 & 8.0 & 67 & $5 \cdot 4$ & 49 & 12.2 & 67 & $7 \cdot 1$ & 47 \\
\hline 35 & 9.2 & 73 & 6.2 & 55 & I 3.9 & 71 & $8 \cdot 3$ & 53 \\
\hline 40 & 10. 2 & 77 & 6.9 & 59 & I 5.3 & 75 & $9 \cdot 4$ & 57 \\
\hline 45 & I I . 2 & SI & 7.6 & 63 & I 6.6 & 78 & 10.3 & $6 I$ \\
\hline 50 & I 2.0 & $8_{3}$ & 8.3 & 66 & 17.7 & 79 & II. 2 & 65 \\
\hline 55 & I 2.9 & 85 & 8.9 & 69 & I8.7 & SI & I 2.2 & 68 \\
\hline 60 & I 3.7 & 87 & $9 \cdot 5$ & 71 & r9. 6 & $8 \mathrm{I}$ & I3.I & $7 \mathrm{I}$ \\
\hline 65 & 14.5 & 88 & IO.I & 73 & 20.4 & 82 & I 3.9 & 74 \\
\hline 70 & I 5.2 & 89 & 10. 6 & 75 & 2 I. 2 & $8_{3}$ & 14.8 & 76 \\
\hline 75 & 16.0 & 90 & I I . 2 & 77 & 22.0 & 82 & I5.6 & 78 \\
\hline 80 & I 6.7 & 92 & II . 7 & 79 & 22.8 & $8_{3}$ & 16.5 & $8 \mathrm{I}$ \\
\hline 85 & I 7.3 & 93 & 12.2 & $8 \mathrm{I}$ & $\ldots \ldots$ & $\ldots \ldots$ & $\ldots \ldots$ & $\ldots \ldots$ \\
\hline 90 & I7.9 & 94 & 12.6 & 82 & $\ldots \ldots$ & $\ldots \ldots$ & $\ldots \ldots$ & $\ldots \ldots$ \\
\hline 95 & 18.5 & 95 & I3.I & 83 & $\ldots \ldots$ & $\ldots \ldots$ & $\ldots \ldots$ & $\ldots \ldots$ \\
\hline 100 & I9.I & 97 & I3.6 & 85 & $\ldots \ldots$ & $\ldots \ldots$ & $\ldots \ldots$ & $\ldots \ldots$ \\
\hline
\end{tabular}

1 Taken from The Ashes: their Characteristics and Management. By W. D. Sterrett. U. S. Dept. of Agri. Bull. No. 299.

2 Based on complete analyses of 47 trees, mostly 80 to 100 years old.

Based on complete analyses of 138 trees, mostly 30 to 70 years old. 
TABLES

TABLE LXI. - ASPEN. ${ }^{1}$ DIAMETER AND HEIGHT GROWTH.

Based on measurements of 409 trees.

\begin{tabular}{|c|c|c|c|c|c|c|c|c|c|}
\hline \multirow[b]{2}{*}{ Age. } & \multicolumn{3}{|c|}{ Quality I. } & \multicolumn{3}{|c|}{ Quality II. } & \multicolumn{3}{|c|}{ Quality III. } \\
\hline & $\begin{array}{c}\text { Diam- } \\
\text { eter, } \\
\text { breast } \\
\text { high, } \\
\text { outside } \\
\text { bark. }\end{array}$ & Hëight. & $\begin{array}{l}\text { Total } \\
\text { vol- } \\
\text { ume, } \\
\text { exclud- } \\
\text { ing } \\
\text { bark. }\end{array}$ & $\begin{array}{c}\text { Diam- } \\
\text { eter, } \\
\text { breast } \\
\text { high, } \\
\text { outside } \\
\text { bark. }\end{array}$ & Height. & $\begin{array}{c}\text { Total } \\
\text { vol- } \\
\text { ume, } \\
\text { exclud- } \\
\text { ing } \\
\text { bark. }\end{array}$ & $\begin{array}{c}\text { Diam- } \\
\text { eter, } \\
\text { breast } \\
\text { high, } \\
\text { outside } \\
\text { bark. }\end{array}$ & Height. & $\begin{array}{l}\text { Total } \\
\text { vol- } \\
\text { ume, } \\
\text { exclud- } \\
\text { ing } \\
\text { bark. }\end{array}$ \\
\hline $\begin{array}{c}\text { Years. } \\
5\end{array}$ & $\begin{array}{r}\text { Inches. } \\
\text { I. } 3\end{array}$ & $\begin{array}{l}\text { Ft. } \\
\text { I I }\end{array}$ & $\begin{array}{l}\mathrm{Cu} . \mathrm{ft} . \\
\ldots \ldots \ldots\end{array}$ & $\begin{array}{r}\text { Inches. } \\
0.6\end{array}$ & $\begin{array}{r}\text { Ft. } \\
7\end{array}$ & $\begin{array}{l}\mathrm{Cu} . \mathrm{ft} . \\
\ldots \ldots\end{array}$ & $\begin{array}{r}\text { Inches. } \\
0.2\end{array}$ & $\begin{array}{r}\text { Ft. } \\
4\end{array}$ & $\begin{array}{l}\text { Cu. ft. } \\
\ldots \ldots \ldots\end{array}$ \\
\hline I0 & 2.7 & $2 I$ & $\ldots \ldots$ & I. 6 & I5 & $\ldots \ldots$ & I.O & 8 & $\ldots \ldots$ \\
\hline 20 & $5 \cdot 3$ & 40 & I.O & 3.8 & 32 & $\ldots \ldots$ & 2.4 & I 7 & $\ldots \ldots$ \\
\hline 30 & 8.0 & 55 & $7 \cdot 5$ & 5.8 & 45 & 2.0 & 3.6 & 28 & $\ldots \ldots$ \\
\hline 40 & IO. 4 & 66 & I6.5 & 7.8 & 56 & 7.0 & $4 \cdot 7$ & 39 & 0.5 \\
\hline 50 & 12.7 & 75 & $27 \cdot 5$ & $9 \cdot 4$ & 65 & 13.0 & 5.8 & 50 & 2.5 \\
\hline 60 & 14.8 & $8 \mathrm{I}$ & $42 \cdot 5$ & I0. 9 & $7 I$ & 19.0 & 7.0 & 57 & $5 \cdot 5$ \\
\hline 70 & 17.0 & 85 & 62.0 & I 2.3 & 74 & 25.0 & 8.2 & $6 I$ & 8.5 \\
\hline 80 & 19.2 & 87 & $82 \cdot 5$ & I 3.4 & 75 & $31 \cdot 5$ & $9 \cdot 3$ & 64 & I 2.5 \\
\hline 90 & $2 \mathrm{I} \cdot 3$ & 88 & 104.0 & $14 \cdot 3$ & 77 & 37.0 & 10.5 & 66 & I 6.5 \\
\hline 100 & $23 \cdot 3$ & 89 & I 26.0 & I5.I & 78 & $42 \cdot 5$ & II.7 & 66 & 20.5 \\
\hline
\end{tabular}

1 Taken from U. S. Forest Service Bull. 93.

TABLE LXII. - PAPER BIRCH. ${ }^{1}$ HEIGHT, DIAMETER AND VOLUME GROWTH.

\begin{tabular}{|c|c|c|c|c|c|c|c|c|}
\hline \multirow{2}{*}{ Age. } & \multicolumn{2}{|c|}{ Height. } & \multicolumn{2}{|c|}{$\begin{array}{c}\text { Diameter, breast } \\
\text { high. }\end{array}$} & \multicolumn{2}{|c|}{ Total stem volume. } & \multicolumn{2}{|c|}{ Volume, N. H. rule. } \\
\hline & Seedlings. ${ }^{2}$ & Sprouts. ${ }^{3}$ & Seedlings. & Sprouts. & Seedlings. ${ }^{2}$ & Sprouts. ${ }^{3}$ & Seedlings. & Sprouts. \\
\hline $\begin{array}{c}\text { Yrs. } \\
5\end{array}$ & $\begin{array}{c}\text { Feet. } \\
5\end{array}$ & $\begin{array}{c}\text { Feet. } \\
\text { Io }\end{array}$ & $\begin{array}{c}\text { Inches. } \\
0.2\end{array}$ & $\begin{array}{c}\text { Inches. } \\
0.7\end{array}$ & $\begin{array}{l}\text { Cu.ft. } \\
\ldots \ldots \ldots\end{array}$ & $\begin{array}{c}\text { Cu. ft. } \\
\text { I. } 8\end{array}$ & $\begin{array}{c}\text { Bd. ft. } \\
\ldots \ldots\end{array}$ & $\begin{array}{l}\text { Bd. ft. } \\
\ldots \ldots\end{array}$ \\
\hline I0 & I3 & I9 & I. I & I. 8 & $2 \cdot 3$ & $3 \cdot 2$ & $\ldots \ldots$ & I3 \\
\hline I5 & 22 & 28 & 2.2 & 2.9 & 3.6 & $4 \cdot 6$ & I6 & I9 \\
\hline 20 & 30 & 36 & $3 \cdot 4$ & 4.0 & 5.2 & 6.1 & 22 & 26 \\
\hline 25 & 37 & 43 & $4 \cdot 4$ & $4 \cdot 9$ & 6.9 & $7 \cdot 7$ & 29 & 34 \\
\hline 30 & 44 & 49 & $5 \cdot 3$ & 5.6 & 8.6 & $9 \cdot 5$ & 37 & 43 \\
\hline 35 & 49 & 55 & $6 . I$ & 6.3 & 10.5 & II . 4 & 46 & $5^{2}$ \\
\hline 40 & 54 & 60 & 6.8 & 6.9 & 12.3 & $13 \cdot 5$ & 55 & $6 r$ \\
\hline 45 & $5^{8}$ & 65 & $7 \cdot 5$ & $7 \cdot 5$ & $\mathrm{I} 4 . \mathrm{I}$ & I $5 \cdot 5$ & 64 & $7 \mathrm{I}$ \\
\hline 50 & 62 & 70 & 8.0 & 7.9 & I6.0 & $\ldots \ldots$ & 73 & $\ldots \ldots$ \\
\hline 55 & 65 & 74 & 8.5 & 8.4 & 17.7 & $\ldots \ldots$ & 82 & $\ldots \ldots$ \\
\hline 60 & 68 & 78 & 8.9 & 8.8 & $19 \cdot 3$ & $\ldots \ldots$ & 90 & $\ldots \ldots$ \\
\hline 65 & $7 \mathrm{I}$ & 82 & $9 \cdot 3$ & $\ldots \ldots$ & $20: 7$ & $\ldots \ldots$ & 97 & $\ldots \ldots$ \\
\hline 70 & 74 & $\ldots \ldots$ & $9 \cdot 7$ & $\ldots \ldots$ & $\ldots \ldots$ & $\ldots \ldots$ & $\ldots \ldots$ & $\ldots \ldots$ \\
\hline 75 & 76 & $\ldots \ldots$ & 10.0 & $\ldots \ldots$ & $\ldots \ldots$ & $\ldots \ldots$ & $\ldots \ldots$ & $\ldots \ldots$ \\
\hline 80 & 78 & $\ldots \ldots$ & I0. 2 & $\ldots \ldots$ & $\ldots \ldots \ldots$ & $\ldots \ldots$ & $\ldots \ldots$ & $\ldots \ldots$ \\
\hline 85 & 80 & $\ldots \ldots$ & $\ldots \ldots$ & $\ldots \ldots$ & $\ldots \ldots$ & $\ldots \ldots$ & $\ldots \ldots$ & $\ldots \ldots$ \\
\hline 90 & $8 I$ & $\ldots \ldots$ & $\ldots \ldots \ldots$ & $\ldots \ldots$ & $\ldots \ldots$ & $\ldots \ldots$ & $\ldots \ldots$ & $\ldots \ldots$ \\
\hline
\end{tabular}

1 Taken from U. S. Forest Service Circular I63. $\quad{ }^{2}$ Based on measurements of 50 trees. Based on measurements of 30 trees. 


\section{TABLE LXIII. - BALSAM FIR ${ }^{1}$ AND RED SPRUCE. COMPARATIVE GROWTH, IN HEIGHT AND DIAMETER, IN MAINE.}

Growth in height.

\begin{tabular}{|c|c|c|c|c|c|}
\hline \multirow[b]{2}{*}{$\begin{array}{l}\text { Diameter, } \\
\text { breast high } \\
\text { (inches). }\end{array}$} & \multicolumn{2}{|c|}{ Height (feet). } & \multirow{2}{*}{$\begin{array}{l}\text { Diameter, } \\
\text { breast high } \\
\text { (inches). }\end{array}$} & \multicolumn{2}{|c|}{ Height (feet). } \\
\hline & $\begin{array}{l}\text { Red spruce. } \\
\text { (Based on } \\
485 \text { trees.) }\end{array}$ & $\begin{array}{l}\text { Balsam fir. } \\
\text { (Based on } \\
456 \text { trees.) }\end{array}$ & & $\begin{array}{l}\text { Red spruce. } \\
\text { (Based on } \\
485 \text { trees.) }\end{array}$ & $\begin{array}{l}\text { Balsam fir. } \\
\text { (Based on } \\
456 \text { trees.) }\end{array}$ \\
\hline I & 7 & I 2 & IO & $5^{2}$ & 68 \\
\hline 2 & 14 & 20 & I I & 55 & 72 \\
\hline 3 & $2 \mathrm{I}$ & 27 & I 2 & $5^{8}$ & 75 \\
\hline 4 & 28 & 35 & I3 & 60 & 78 \\
\hline 5 & 3.3 & 42 & I4 & 63 & $8 \mathrm{I}$ \\
\hline 6 & 37 & 48 & I 5 & 65 & 84 \\
\hline 7 & $4 I$ & 54 & I 6 & 67 & 86 \\
\hline-8 & 44 & 60 & 17 & 68 & $\ldots \ldots$ \\
\hline 9 & 48 & 64 & I 8 & 70 & $\ldots \ldots \ldots$ \\
\hline
\end{tabular}

Growth in diameter.

\begin{tabular}{|c|c|c|c|c|c|}
\hline \multirow[b]{2}{*}{ Age (years). } & \multicolumn{2}{|c|}{ Diameter, breast high (inches). } & \multirow[b]{2}{*}{ Age (years). } & \multicolumn{2}{|c|}{ Diameter, breast high (inches) } \\
\hline & $\begin{array}{l}\text { Red spruce. } \\
\text { (Based on } \\
274 \text { trees.) }\end{array}$ & $\begin{array}{l}\text { Balsam fir. } \\
\text { (Based on } \\
456 \text { trees.) }\end{array}$ & & $\begin{array}{l}\text { Red spruce. } \\
\text { (Based on } \\
274 \text { trees.) }\end{array}$ & $\begin{array}{l}\text { Balsam fir. } \\
\text { (Based on } \\
456 \text { trees.) }\end{array}$ \\
\hline 20 & 0.1 & I. 2 & 90 & 2.7 & $9 \cdot 9$ \\
\hline 30 & 0.6 & 2.7 & 100 & 3.2 & 10.7 \\
\hline 40 & 0.8 & $4 \cdot I$ & IIO & $3 \cdot 7$ & I I 3 \\
\hline 50 & I. I & $5 \cdot 5$ & I 20 & $4 \cdot 3$ & I I. 9 \\
\hline 60 & I. 5 & 6.7 & I30 & $4 \cdot 9$ & 12.3 \\
\hline 70 & I. 8 & $<7.9$ & 140 & $5 \cdot 5$ & 12.6 \\
\hline 80 & 2.2 & 8.9 & I 50 & 6.2 & I 2.9 \\
\hline
\end{tabular}

1 Taken from Balsam Fir by Raphael Zon, U. S. Dept. of Agr, Bull. 55. 
TABLE LXIV. - BALSAM FIR ${ }^{1}$ IN NEW YORK. VOLUME GROWTH, IN CUBIC FEET.

\begin{tabular}{|c|c|c|c|c|c|c|c|c|c|}
\hline \multirow[b]{2}{*}{$\begin{array}{l}\text { Age, } \\
\text { years. }\end{array}$} & \multicolumn{3}{|c|}{ Hardwood slope. } & \multicolumn{3}{|c|}{ Flat. } & \multicolumn{3}{|c|}{ Swamp. } \\
\hline & $\begin{array}{l}\text { Vol- } \\
\text { ume. }\end{array}$ & $\begin{array}{c}\text { Growth } \\
\text { in vol- } \\
\text { ume } \\
\text { every } \\
5 \text { years. }\end{array}$ & $\begin{array}{l}\text { Annual } \\
\text { growth } \\
\text { in vol- } \\
\text { ume } \\
\text { within } \\
\text { 5-year } \\
\text { period. }\end{array}$ & $\begin{array}{l}\text { Vol- } \\
\text { ume. }\end{array}$ & $\begin{array}{l}\text { Growth } \\
\text { in vol- } \\
\text { ume } \\
\text { every } \\
5 \text { years. }\end{array}$ & $\begin{array}{l}\text { Annual } \\
\text { growth } \\
\text { in vol- } \\
\text { ume } \\
\text { within } \\
\text { 5-year } \\
\text { period. }\end{array}$ & $\begin{array}{l}\text { Vol- } \\
\text { ume. }\end{array}$ & $\begin{array}{c}\text { Growth } \\
\text { in vol- } \\
\text { ume } \\
\text { every } \\
5 \text { years. }\end{array}$ & $\begin{array}{l}\text { Annual } \\
\text { growth } \\
\text { in vol- } \\
\text { ume } \\
\text { within } \\
\text { 5-year } \\
\text { period. }\end{array}$ \\
\hline 40 & I . 73 & I .O9 & 0.218 & I.Og & & $\cdots \cdots$ & & $\ldots \ldots$ & $\ldots \ldots$ \\
\hline 45 & 2.82 & I.09 & 0.218 & I.92 & 0.83 & ०.166 & 0.98 & $\ldots \ldots$ & \\
\hline 50 & $3 \cdot 9 \mathrm{I}$ & I.O9 & 0.218 & 2.80 & 0.88 & o.1 76 & I .47 & 0.49 & 0.098 \\
\hline 55 & 5.00 & I.O9 & 0.218 & 3.67 & 0.87 & 0.174 & 2.01 & 0.54 & 0.108 \\
\hline 60 & 6.10 & I. IO & 0.220 & $4 \cdot 57$ & 0.90 & 0.180 & 2.60 & 0.59 & O.II 8 \\
\hline 65 & $7 \cdot 20$ & I. IO & 0.220 & $5 \cdot 47$ & 0.90 & 0.180 & 3.21 & $0.6 \mathrm{I}$ & 0.122 \\
\hline 70 & 8.30 & I. IO & 0.220 & 6.36 & $0.89>$ & 0.178 & 3.88 & 0.67 & 0.134 \\
\hline 75 & $9 \cdot 40$ & I. IO & 0.220 & $7 \cdot 23$ & 0.87 & o.174 & $4 \cdot 56$ & $\left.0.68^{\circ}\right)$ & 0.136 \\
\hline 80 & 10.50 & I. IO & 0.220 & 8.09 & 0.86 & 0.172 & $5 \cdot 24$ & $0.68 /$ & o. 136 \\
\hline 85 & II. 63 & $1.13 \gamma$ & 0.226 & $8.9 I$ & 0.82 & o.164 & $5 \cdot 92$ & 0.68 & 0.136 \\
\hline 90 & I 2.74 & I. I I & 0.222 & $9 \cdot 74$ & $0.8_{3}$ & o. 166 & 6.59 & 0.67 & o. I34 \\
\hline 95 & I 3.85 & I. I I & 0.222 & 10. $5^{6}$ & 0.82 & o. I64 & $7 \cdot 26$ & 0.67 & 0.134 \\
\hline 100 & I 4.93 & I .08 & 0.216 & II . 40 & 0.84 & o. 168 & $7 \cdot 94$ & 0.68 & 0.136 \\
\hline 105 & 16.00 & I .07 & 0.214 & 12.23 & 0.83 & o. 166 & 8.62 & 0.68 & o. 136 \\
\hline I IO & 17.05 & I. 05 & 0.210 & I3.09 & 0.86 & 0.172 & $9 \cdot 30$ & 0.68 & 0.136 \\
\hline I I 5 & I8. Io & I. 05 & 0.210 & I3.94 & 0.85 & 0.170 & 9.98 & 0.68 & 0.136 \\
\hline I 20 & I9.I5 & 1.05 & 0.210 & 14.80 & 0.86 & o.172 & 10. 66 & 0.68 & 0.136 \\
\hline I 25 & 20.19 & I . 04 & 0.208 & I5. 64 & 0.84 & o.168 & I I . 34 & 0.68 & 0.136 \\
\hline 130 & $2 I .23$ & I. 04 & 0.208 & I6. 50 & 0.86 & 0.172 & I 2.02 & 0.68 & c. I36 \\
\hline I 35 & 22.29 & I. .06 & 0.212 & I 7.34 & 0.84 & ०. I 68 & I 2.70 & 0.68 & 0.136 \\
\hline I 40 & $23 \cdot 34$ & I. 05 & 0.210 & 18.20 & 0.86 & o. I7 2 & I $3 \cdot 38$ & 0.68 & 0.136 \\
\hline I 45 & $24 \cdot 37$ & I. 03 & 0.206 & I9. 04 & 0.84 & o.168 & 14.09 & $0.7 \mathrm{I}$ & 0.142 \\
\hline I 50 & 25.43 & I. .06 & $0.2 \mathrm{I} 2$ & I9.90 & 0.86 & 0.172 & 14.80 & $0.7 \mathrm{I}$ & 0.142 \\
\hline
\end{tabular}

1 Taken from Balsam Fir, by Raphael Zon, U. S. Dept. of Agr. Bull. 55. 
TABLE LXV. - BALSAM FIR ${ }^{1}$ IN MAINE. VOLUME GROWTH IN CUBIC FEET.

\begin{tabular}{|c|c|c|c|}
\hline Age (years). & Volume. & $\begin{array}{l}\text { Growth in } \\
\text { volume } \\
\text { every } \\
5 \text { years. }\end{array}$ & $\begin{array}{l}\text { Annual growth } \\
\text { in volume } \\
\text { within 5-year } \\
\text { period. }\end{array}$ \\
\hline 65 & $8.8 \mathrm{I}$ & $\ldots \ldots$ & $\cdots \cdots$ \\
\hline 70 & 10. 64 & I. 83 & 0.366 \\
\hline 75 & I 2.55 & I. 9 I & 0.382 \\
\hline 80 & 14.50 & I. 95 & 0.390 \\
\hline 85 & 16.51 & 2.01 & 0.402 \\
\hline 90 & I8.6o & 2.09 & 0.418 \\
\hline 95 & 20.73 & 2.13 & 0.426 \\
\hline 100 & 22.90 & 2.17 & 0.434 \\
\hline
\end{tabular}

1 Taken from Balsam Fir, by Raphael Zon. U. S. Dept. of Agr. Bull. No. 55.

\section{TABLE LXVI. - HEMLOCK ${ }^{1}$ IN VERMONT. DIAMETER AND VOLUME GROWTH.}

\begin{tabular}{|c|c|c|}
\hline Age. & $\begin{array}{l}\text { Diameter, } \\
\text { breast high. }\end{array}$ & Volume. \\
\hline Years. & Inches. & Bd. ft. \\
\hline I30 & 7.0 & $\ldots \ldots \ldots$ \\
\hline 140 & 8.0 & 34 \\
\hline 150 & 9.0 & 48 \\
\hline 160 & 10.2 & 69 \\
\hline 170 & I I . 4 & 100 \\
\hline 180 & I 2.6 & 140 \\
\hline I90 & $13 \cdot 9$ & 180 \\
\hline 200 & 15.2 & 230 \\
\hline
\end{tabular}

'Taken from " Hemlock in Vermont," by A. F. Hawes. Vermont Experiment Station Bull. 161. Volumes scaled by Vermont rule. 
YIELD TABLES.

TABLE LXVII. - WHITE ASH. ${ }^{1}$ YIELD OF PURE, EVENAGED, WELL-STOCKED STANDS. ${ }^{2}$

Quality I.

\begin{tabular}{|c|c|c|c|c|c|}
\hline \multirow{3}{*}{ Age. } & \multirow{3}{*}{$\begin{array}{l}\text { Number of } \\
\text { trees per } \\
\text { acre } 3^{\prime \prime} \text { and } \\
\text { over. }\end{array}$} & \multirow{3}{*}{$\begin{array}{l}\text { Average diam- } \\
\text { eter, breast } \\
\text { high, } 3^{\prime \prime} \text { and } \\
\text { over. }\end{array}$} & \multicolumn{3}{|c|}{ Yield per acre. } \\
\hline & & & $\begin{array}{l}\text { Scribner deci- } \\
\text { mal C. }\end{array}$ & \multirow{2}{*}{$3^{\prime \prime}$ and over. } & \multirow{2}{*}{ Cords. } \\
\hline & & & $7^{\prime \prime}$ and over. & & \\
\hline $\begin{array}{c}\text { Years. } \\
20\end{array}$ & $\begin{array}{c}\text { Number. } \\
427\end{array}$ & $\begin{array}{c}\text { Inches. } \\
5.4\end{array}$ & $\begin{array}{c}\text { Board feet. } \\
2, \infty 00\end{array}$ & $\begin{array}{c}\text { Cubic feet. } \\
2,200\end{array}$ & 24.4 \\
\hline 25 & $39 I$ & 6.5 & 4,200 & 3,100 & 34.4 \\
\hline 30 & 375 & $7 \cdot 5$ & 6,500 & 3,900 & $43 \cdot 3$ \\
\hline 35 & 361 & 8.3 & 9,000 & 4,600 & $5 \mathrm{I} . \mathrm{I}$ \\
\hline 40 & $34 \mathrm{I}$ & 9.1 & 11,700 & 5,250 & 58.3 \\
\hline 45 & 322 & 9.9 & 14,700 & 5,830 & 64.8 \\
\hline 50 & 288 & 10.5 & I 8,000 & 6,350 & 70.6 \\
\hline 55 & $25^{I}$ & II. 2 & 21,700 & 6,800 & 75.6 \\
\hline 60 & 224 & II .8 & 25,700 & 7,220 & 80.2 \\
\hline 65 & 203 & I 2.4 & 29,500 & 7,600 & 84.4 \\
\hline 70 & 188 & 13.0 & 32,800 & 7,950 & 88.3 \\
\hline 75 & I 76 & $13 \cdot 5$ & 35,600 & 8,280 & 92.0 \\
\hline 80 & r66 & 14.0 & $38, \infty 00$ & 8,600 & 95.6 \\
\hline
\end{tabular}

Quality II.

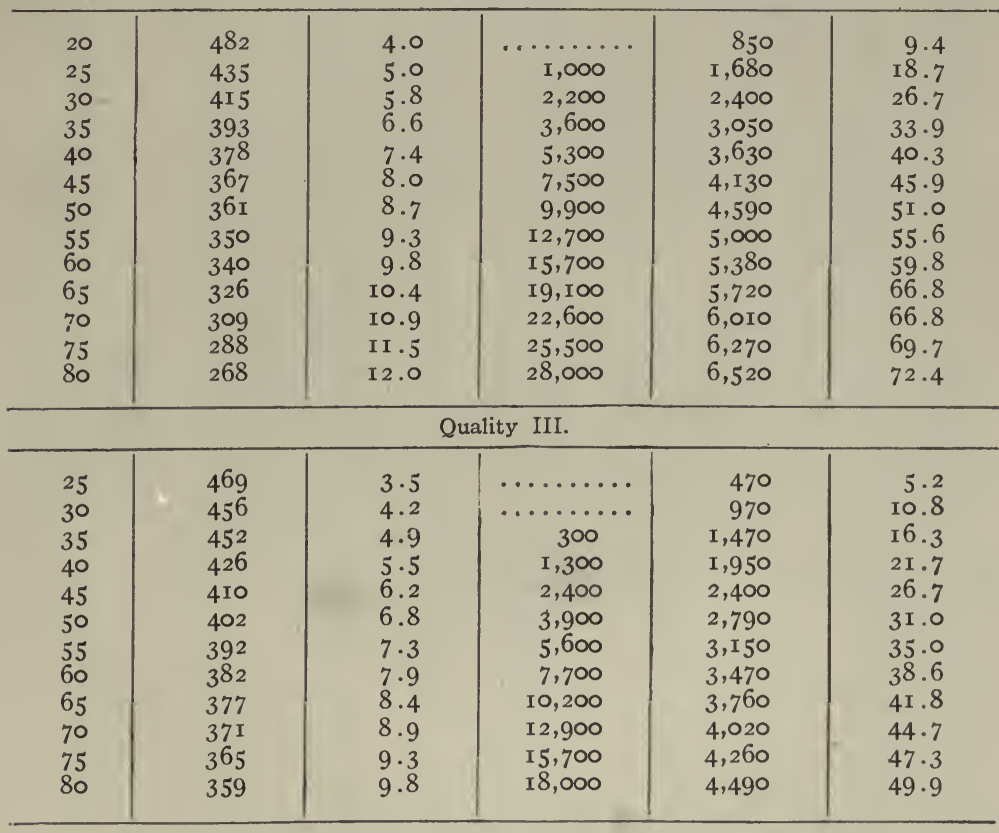

1 Taken from The Ashes: Their Characteristics and Management. By W. D. Sterrett. U. S. Dept. of Agr. Bull. No. 299.

2 Based on 18 plots; Quality I, 30 plots, Quality II, I4 plots, Quality III, with a total area of $\mathbf{I 6 . 9}$ acres. 


\section{TABLE LXVIII. - PAPER BIRCH. YIELD PER ACRE. PURE (100 PER CENT) BIRCH STANDS.}

Penobscot, Piscataquis, Somerset and Franklin counties, Maine.

(Data gathered by R. L. Marston for Paper Birch Study, 1903-1907.)

\begin{tabular}{|c|c|c|c|c|c|c|c|c|}
\hline \multirow[b]{2}{*}{ Age. } & \multicolumn{4}{|c|}{ Quality I. } & \multicolumn{4}{|c|}{ Quality II. } \\
\hline & $\begin{array}{l}\text { Average } \\
\text { diam- } \\
\text { eter, } \\
\text { breast } \\
\text { high. }\end{array}$ & $\begin{array}{l}\text { Average } \\
\text { height. }\end{array}$ & $\begin{array}{l}\text { Total. } \\
\text { yield. }\end{array}$ & $\begin{array}{l}\text { Yield of trees } \\
6 \text { inches and } \\
\text { over in per- } \\
\text { centage of total } \\
\text { yield. }\end{array}$ & $\begin{array}{l}\text { A verage } \\
\text { diam- } \\
\text { eter, } \\
\text { breast } \\
\text { high. }\end{array}$ & $\begin{array}{l}\text { Average } \\
\text { height. }\end{array}$ & $\begin{array}{l}\text { Total } \\
\text { yield. }\end{array}$ & $\begin{array}{l}\text { Yield of trees } \\
6 \text { inches and } \\
\text { over in per- } \\
\text { centage of total } \\
\text { yield. }\end{array}$ \\
\hline Years. & Inches. & $\mathrm{Ft}$ & Cu. ft. & Per cent. & Inches. & $\mathrm{Ft}$. & Cu. ft. & Per cent. \\
\hline $\begin{array}{l}15 \\
20\end{array}$ & $\begin{array}{l}2.3 \\
3.4\end{array}$ & $\begin{array}{l}24 \\
33\end{array}$ & $\begin{array}{r}710 \\
1020\end{array}$ & $\begin{array}{l}0 \\
4\end{array}$ & $\begin{array}{r}1.8 \\
2.6\end{array}$ & $\begin{array}{l}2 \mathrm{I} \\
28\end{array}$ & $\begin{array}{l}410 \\
580\end{array}$ & $\begin{array}{l}0 \\
0\end{array}$ \\
\hline 25 & $4 \cdot 5$ & $4 I$ & I340 & 27 & 3.4 & 34 & 770 & I 8 \\
\hline 30 & 5.6 & 48 & I 700 & 46 & $4 \cdot 3$ & 40 & IOIO & 35 \\
\hline 35 & 6.4 & 54 & 2090 & $6_{3}$ & 5.0 & 45 & I 290 & 50 \\
\hline 40 & 7.2 & $5^{8}$ & 2520 & 75 & $5 \cdot 7$ & 49 & I 580 & 63 \\
\hline 45 & 7.8 & 62 & 2950 & 85 & 6.3 & 53 & I 890 & 73 \\
\hline 50 & 8.4 & 65 & 3340 & $9 I$ & 6.8 & $5^{6}$ & 2220 & 82 \\
\hline 55 & 8.8 & 68 & 3660 & 96 & 7.2 & 59 & 2530 & 89 \\
\hline 60 & 9.2 & 70 & 3940 & 98 & 7.6 & $6 I$ & 2810 & 94 \\
\hline 65 & 9.6 & 72 & 4190 & 100 & 7.9 & 64 & 3060 & 97 \\
\hline 70 & 10.0 & 74 & $445^{\circ}$ & 100 & 8.2 & 66 & 3300 & 100 \\
\hline
\end{tabular}

Note. - These sample plots were taken in unmanaged stands. All plots with a density less than 50 per cent were discarded. All plots containing less than 40 per cent birch were discarded and the remainder reduced to 100 per cent birch by dividing the actual birch yield by the percentages of the total basal area formed by the birch. Hence the table applies only to pure birch stands of average density (quality I, 83 per cent and quality II, 75 per cent). For the yield of a mixed stand, containing, for example, 60 per cent of birch, a corresponding reduction would be made in the yield. The number of trees per acre was exceedingly irregular and was, therefore, excluded from the table.

The volume given is total stem volume, though the lowest measurement taken in the sample trees was at 4.5 feet, and this disregard for butt swelling makes the yield conservative.

Based on 20 quality I and 26 quality II, sample plots. 
TABLE LXIX. - CHESTNUT TYPE. ${ }^{1}$ GROWTH IN HEIGHT, DIAMETER AND NUMBER OF TREES FOR THREE QUALITIES OF SOIL, ${ }^{2}$ CONNECTICUT.

\begin{tabular}{|c|c|c|c|c|c|c|c|c|c|}
\hline \multirow[b]{2}{*}{ Age. } & \multicolumn{3}{|c|}{ Quality I. } & \multicolumn{3}{|c|}{ Quality II. } & \multicolumn{3}{|c|}{ Quality III. } \\
\hline & $\begin{array}{l}\text { Height of } \\
\text { dominant } \\
\text { trees. }\end{array}$ & $\begin{array}{l}\text { D.B.H. } \\
\text { of av- } \\
\text { erage } \\
\text { tree. }\end{array}$ & $\begin{array}{l}\text { Num- } \\
\text { ber of } \\
\text { trees } \\
\text { per } \\
\text { acre. }\end{array}$ & $\begin{array}{l}\text { Height of } \\
\text { dominant } \\
\text { trees. }\end{array}$ & $\begin{array}{l}\text { D.B.H. } \\
\text { of av- } \\
\text { erage } \\
\text { tree. }\end{array}$ & $\begin{array}{l}\text { Num- } \\
\text { ber of } \\
\text { trees } \\
\text { per } \\
\text { acre. }\end{array}$ & $\begin{array}{c}\text { Height of } \\
\text { dominant } \\
\text { trees. }\end{array}$ & $\begin{array}{c}\text { D.B.H. } \\
\text { of av- } \\
\text { erage } \\
\text { tree. }\end{array}$ & $\begin{array}{l}\text { Num- } \\
\text { ber of } \\
\text { trees } \\
\text { per } \\
\text { acre. }\end{array}$ \\
\hline $\begin{array}{c}\text { Years. } \\
\text { I }_{5}\end{array}$ & $\begin{array}{c}\text { Feet. } \\
38\end{array}$ & $\begin{array}{c}\text { Inches. } \\
3.2\end{array}$ & $\begin{array}{l}\text { Trees. } \\
\text { rooo }\end{array}$ & $\begin{array}{c}\text { Feet. } \\
30\end{array}$ & $\begin{array}{c}\text { Inches. } \\
2.6\end{array}$ & $\begin{array}{l}\text { Trees. } \\
\text { I } 160\end{array}$ & $\begin{array}{c}\text { Feet. } \\
2 \text { I }\end{array}$ & $\begin{array}{c}\text { Inches. } \\
2.0\end{array}$ & $\begin{array}{l}\text { Trees. } \\
1360\end{array}$ \\
\hline 20 & 50 & $4 \cdot 4$ & 830 & 40 & 3.6 & 930 & 30 & 2.7 & I I 80 \\
\hline 25 & $5^{8}$ & $5 \cdot 4$ & 680 & 48 & $4 \cdot 5$ & 800 & 37 & $3 \cdot 5$ & 990 \\
\hline 30 & 64 & 6.4 & 550 & 54 & $5 \cdot 3$ & 675 & 44 & $4 \cdot 3$ & 790 \\
\hline 35 & 70 & $7 \cdot 3$ & 460 & 60 & 6.1 & 560 & 50 & 5.0 & 670 \\
\hline 40 & 74 & $8 . \mathrm{I}$ & 400 & 64 & 6.8 & 490 & 55 & 5.6 & 580 \\
\hline 45 & 77 & 8.9 & $35^{\circ}$ & 68 & $7 \cdot 5$ & 425 & 59 & 6.2 & 500 \\
\hline 50 & So & 9.6 & 310 & $7 \mathrm{I}$ & 8.2 & 370 & 62 & 6.8 & $45^{\circ}$ \\
\hline 55 & 83 & 10. 3 & 280 & 74 & 8.8 & 335 & 64 & $7 \cdot 3$ & 400 \\
\hline 60 & 85 & 10.9 & 260 & 76 & 9.4 & 300 & 67 & 7.8 & 360 \\
\hline 65 & 87 & II. 6 & 235 & 77 & 9.9 & 280 & 68 & 8.3 & 330 \\
\hline 70 & 88 & I 2.2 & 220 & 79 & 10.5 & 255 & 70 & 8.7 & 3 Io \\
\hline 75 & 90 & I 2.8 & 200 & 80 & II.O & 240 & 71 & 9.2 & 290 \\
\hline
\end{tabular}

1 Taken from U. S. Forest Service Bull. 96.

2 For trees over 2 inches in diameter, breast high; based on normally stocked plots, $\frac{x}{8}$ to $\frac{x}{2}$ acre in size. Quality classes based on height of dominant trees. 
TABLE LXX. - OAK-CHESTNUT TYPE. ${ }^{1}$ GROWTH IN HEIGHT, DIAMETER AND NUMBER OF TREES FOR THREE QUALITIES OF SOIL, ${ }^{2}$ CONNECTICUT.

\begin{tabular}{|c|c|c|c|c|c|c|c|c|c|}
\hline \multirow[b]{2}{*}{ Age. } & \multicolumn{3}{|c|}{ Quality I. } & \multicolumn{3}{|c|}{ Quality II. } & \multicolumn{3}{|c|}{ Quality III. } \\
\hline & $\begin{array}{l}\text { Height of } \\
\text { dominant } \\
\text { trees. }\end{array}$ & $\begin{array}{c}\text { D.B.H. } \\
\text { of av- } \\
\text { erage } \\
\text { tree. }\end{array}$ & $\begin{array}{l}\text { Num- } \\
\text { ber of } \\
\text { trees } \\
\text { per } \\
\text { acre. }\end{array}$ & $\begin{array}{l}\text { Height of } \\
\text { dominant } \\
\text { trees. }\end{array}$ & $\begin{array}{c}\text { D.B.H. } \\
\text { of av- } \\
\text { erage } \\
\text { tree. }\end{array}$ & $\begin{array}{l}\text { Num- } \\
\text { ber of } \\
\text { trees } \\
\text { per } \\
\text { acre. }\end{array}$ & $\begin{array}{l}\text { Height of } \\
\text { dominant } \\
\text { trees. }\end{array}$ & $\begin{array}{c}\text { D.B.H. } \\
\text { of av- } \\
\text { erage } \\
\text { tree. }\end{array}$ & $\begin{array}{l}\text { Num- } \\
\text { ber of } \\
\text { trees } \\
\text { per } \\
\text { acre. }\end{array}$ \\
\hline $\begin{array}{l}\text { Years. } \\
\text { I5 }\end{array}$ & $\begin{array}{c}\text { Feet. } \\
35\end{array}$ & $\begin{array}{c}\text { Inches. } \\
2.9\end{array}$ & $\begin{array}{l}\text { Trees. } \\
\text { I I } 30\end{array}$ & $\begin{array}{c}\text { Feet. } \\
28\end{array}$ & $\begin{array}{c}\text { Inches. } \\
2.5\end{array}$ & $\begin{array}{l}\text { Trees. } \\
\text { I I } 80\end{array}$ & $\begin{array}{c}\text { Feet. } \\
23\end{array}$ & $\begin{array}{c}\text { Inches. } \\
2.0\end{array}$ & $\begin{array}{l}\text { Trees. } \\
\text { I500 }\end{array}$ \\
\hline 20 & 46 & 4.0 & 9ro & 38 & $3 \cdot 3$ & 950 & $3 I$ & 2.8 & I070 \\
\hline 25 & 55 & $4 \cdot 9$ & 750 & 46 & $4 . I$ & 770 & 38 & $3 \cdot 3$ & 1000 \\
\hline 30 & 62 & 5.8 & 610 & $5^{2}$ & 4.8 & 675 & 43 & 3.9 & 855 \\
\hline 35 & 68 & 6.6 & 525 & 57 & $5 \cdot 5$ & 610 & 48 & $4 \cdot 4$ & 755 \\
\hline 40 & 73 & $7 \cdot 4$ & 455 & $6 x$ & 6.1 & 530 & 52 & 4.8 & 700 \\
\hline 45 & 77 & 8.2 & 400 & 65 & 6.7 & 470 & 55 & $5 \cdot 3$ & 620 \\
\hline 50 & 80 & 8.9 & 360 & 68 & $7 \cdot 3$ & 425 & $5^{8}$ & $5 \cdot 7$ & 570 \\
\hline 55 & 83 & 9.6 & 320 & 71 & 7.8 & 390 & 60 & 6.1 & $5^{25}$ \\
\hline 60 & 85 & 10.3 & 290 & 73 & 8.4 & 355 & 62 & 6.5 & 475 \\
\hline 65 & 87 & 10.9 & 270 & 75 & 8.9 & 325 & 64 & 6.9 & 445 \\
\hline 70 & 89 & I I . 5 & 250 & 77 & 9.4 & 305 & 66 & 7.2 & 420 \\
\hline 75 & 90 & I2.I & 235 & 78 & 9.8 & 285 & 67 & 7.6 & 390 \\
\hline
\end{tabular}

Taken from U. S. Forest Service Bull. 96 .

2 For trees over 2 inches in diameter, breast high; based on normally stocked plots, $\frac{1}{\delta}$ to $\frac{1}{2}$ acre in size. Quality classes based on height of dominant trees. 


\section{TABLE LXXI. - OAK TYPE. ${ }^{1}$ GROWTH IN HEIGHT, DIAMETER AND NUMBER OF TREES FOR THREE QUALITIES OF SOIL,² CONNECTICUT.}

\begin{tabular}{|c|c|c|c|c|c|c|c|c|c|}
\hline \multirow[b]{2}{*}{ Age. } & \multicolumn{3}{|c|}{ Quality I. } & \multicolumn{3}{|c|}{ Quality II. } & \multicolumn{3}{|c|}{ Quality III. } \\
\hline & $\begin{array}{l}\text { Height of } \\
\text { dominant } \\
\text { trees. }\end{array}$ & $\begin{array}{c}\text { D.B.H. } \\
\text { of av- } \\
\text { erage } \\
\text { tree. }\end{array}$ & $\begin{array}{l}\text { Num- } \\
\text { ber of } \\
\text { trees } \\
\text { per } \\
\text { acre. }\end{array}$ & $\begin{array}{c}\text { Height of } \\
\text { dominant } \\
\text { trees. }\end{array}$ & $\begin{array}{c}\text { D.B.H. } \\
\text { of av- } \\
\text { erage } \\
\text { tree. }\end{array}$ & $\begin{array}{l}\text { Num- } \\
\text { ber of } \\
\text { trees } \\
\text { per } \\
\text { acre. }\end{array}$ & $\begin{array}{l}\text { Height of } \\
\text { dominant } \\
\text { trees. }\end{array}$ & $\begin{array}{c}\text { D.B.H. } \\
\text { of av- } \\
\text { erage } \\
\text { tree. }\end{array}$ & $\begin{array}{l}\text { Num- } \\
\text { ber of } \\
\text { trees } \\
\text { per } \\
\text { acre. }\end{array}$ \\
\hline Years. & Feet. & Inches. & Trees. & Feet. & Inches. & Trees. & Feet. & Inches. & Trees. \\
\hline I5 & 25 & 2.5 & I 320 & 22 & 2.2 & I 400 & I8 & I. 9 & I $55^{\circ}$ \\
\hline 20 & 38 & $3 \cdot 5$ & 960 & $3 I$ & 3.0 & 1060 & 25 & 2.5 & I 290 \\
\hline 25 & 49 & $4 \cdot 5$ & 740 & 40 & $3 \cdot 9$ & 795 & $3^{2}$ & 3.2 & 1000 \\
\hline 30 & 57 & $5 \cdot 5$ & 575 & 47 & 4.6 & 675 & 37 & $3 \cdot 7$ & 880 \\
\hline 35 & 63 & 6.4 & 475 & 53 & $5 \cdot 3$ & 575 & 42 & 4.2 & 770 \\
\hline 40 & 68 & 7.2 & 405 & 57 & 6.0 & 485 & 46 & $4 \cdot 7$ & 650 \\
\hline 45 & 72 & 8.0 & $35^{\circ}$ & $6 I$ & 6.6 & $43^{\circ}$ & 49 & $5 \cdot 1$ & 560 \\
\hline 50 & 75 & 8.7 & 3 Io & 64 & $7 . I$ & 390 & $5^{2}$ & 5.5 & 5 I 5 \\
\hline 55 & 78 & 9.4 & 280 & 67 & 7.6 & 355 & 54 & 5.8 & 480 \\
\hline 60 & 80 & I0.0 & 260 & 68 & 8.1 & $3^{25}$ & 56 & 6.2 & $45^{\circ}$ \\
\hline 65 & 82 & 10. 6 & 240 & 70 & 8.5 & 300 & 58 & 6.5 & 400 \\
\hline 70 & 84 & II. I & 220 & 72 & 8.9 & 280 & 60 & 6.6 & 375 \\
\hline 75 & 86 & II. 6 & 210 & 73 & $9 \cdot 4$ & 255 & $6 \mathrm{I}$ & $7 \cdot I$ & 345 \\
\hline
\end{tabular}

1 Taken from U. S. Forest Service Bull. 96.

2 For trees over 2 inches in diameter, breast high; based on normally stocked plots, $\frac{1}{3}$ to $\frac{1}{2}$ acre in size. Quality classes based on height of dominant trees. 


\section{TABLE LXXII. - YIELD IN CORDS ${ }^{1}$ FOR THREE TYPES AND QUALITIES OF SOIL, ${ }^{2}$ CONNECTICUT.}

\begin{tabular}{|c|c|c|c|c|c|c|c|c|c|}
\hline \multirow{2}{*}{ Age. } & \multicolumn{3}{|c|}{$\begin{array}{c}\text { Chestnut type.3 } \\
\text { Quality. }\end{array}$} & \multicolumn{3}{|c|}{$\begin{array}{c}\text { Oak-chestnut type. }{ }^{3} \\
\text { Quality. }\end{array}$} & \multicolumn{3}{|c|}{$\begin{array}{l}\text { Oak type. }{ }^{3} \\
\text { Quality. }\end{array}$} \\
\hline & I. & II. & III. & I. & II. & III. & I. & II. & III. \\
\hline Years. & \multicolumn{9}{|c|}{ Cords. } \\
\hline I 5 & I6 & I 2 & 9 & I 2 & IO & 8 & 9 & 8 & 6 \\
\hline 20 & 23 & I 8 & 13 & I9 & I6 & I 2 & I 5 & I 2 & IO \\
\hline 25 & 30 & 24 & 18 & 28 & 22 & I 7 & 23 & I 8 & I4 \\
\hline 30 & - 37 & 30 & 23 & 36 & 28 & 20 & 30 & 24 & 17 \\
\hline 35 & 43 & 35 & 27 & $4 I$ & 33 & 24 & 36 & 28 & $2 I$ \\
\hline 40 & 48 & 40 & $3 I$ & 46 & 36 & 27 & 40 & 32 & 24 \\
\hline 45 & 53 & 43 & 34 & 49 & 40 & 30 & 44 & 35 & 26 \\
\hline 50 & 57 & 46 & 37 & 53 & 42 & 32 & 48 & 38 & 29 \\
\hline 55 & $6 I$ & 49 & 39 & 56 & 45 & 33 & $5 I$ & 40 & 30 \\
\hline 60 & 63 & $5^{I}$ & $4 I$ & 59 & 47 & 35 & 53 & 43 & 32 \\
\hline $6_{5}$ & 66 & 53 & 42 & 62 & 49 & 37 & 55 & 45 & 34 \\
\hline 70 & 68 & 55 & 44 & 64 & $5^{I}$ & 38 & $5^{8}$ & 47 & 35 \\
\hline 75 & 70 & 57 & 45 & 66 & 53 & 39 & 60 & 48 & 36 \\
\hline
\end{tabular}

1 Taken from U. S. Forest Service Bull. 96.

${ }^{2}$ For trees over 2 inches in diameter, breast high. Based on selected, normally stocked plots 1 to acre in size. Plots varying in basal area by not more than 10 per cent of the average were considered normally stocked. Quality classes based on average height of dominant trees. Yields computed in cubic feet by volume tables, to minimum diameters of 2 inches, outside bark, and reduced to cords by table of converting factors. Chestnut converting factors used for chestnut type, black oak factors for oak-chestnut type, and white oak factors for oak type.

3 A sub-type included in the mixed hardwoods type of the sprout hardwoods region. 
TABLE LXXIII. - CHESTNUT TYPE. ${ }^{1}$ YIELD IN LUMBER AND ADDITIONAL CORDWOOD, ${ }^{2}$ CONNECTICUT.

By International Log Rule. ${ }^{3}$

\begin{tabular}{|c|c|c|c|c|c|c|}
\hline \multirow{3}{*}{ Age. } & \multicolumn{6}{|c|}{ Quality. } \\
\hline & \multicolumn{2}{|c|}{ I. } & \multicolumn{2}{|c|}{ II. } & \multicolumn{2}{|c|}{ III. } \\
\hline & Lumber. & $\begin{array}{l}\text { Additional } \\
\text { cordwood. }\end{array}$ & Lumber. & $\begin{array}{l}\text { Additional } \\
\text { cordwood. }\end{array}$ & Lumber. & $\begin{array}{l}\text { Additional } \\
\text { cordwood. }\end{array}$ \\
\hline Years. & Board feet. & Cords. & Board feet. & Cords. & Board feet. & Cords. \\
\hline 20 & 300 & $2 \mathrm{I}$ & & & & \\
\hline 25 & I , 400 & 27 & & & & \\
\hline 30 & 2,850 & 30 & 900 & 27 & & \\
\hline 35 & 5,100 & 29 & 2,100 & 29 & 900 & 24 \\
\hline 40 & 8,200 & 28 & 3,700 & $3 I$ & 1,800 & 26 \\
\hline 45 & I I , , O & 28 & 5,400 & $3 I$ & 2,900 & 26 \\
\hline 50 & I 3,800 & 28 & 7,700 & 29 & 4,100 & 26 \\
\hline 55 & I6,500 & 27 & 9,900 & 28 & 5,500 & 25 \\
\hline 60 & I9, IOO & 25 & I 2,000 & 26 & 7,000 & 24 \\
\hline 65 & 21,600 & 24 & 14,000 & 25 & 8,400 & 22 \\
\hline 70. & 23,900 & 22 & I6, I 00 & 23 & 9,800 & $2 I$ \\
\hline 75 & 25,700 & $2 I$ & I 7,800 & $2 I$ & II, I OO & I9 \\
\hline
\end{tabular}

1 Taken from U. S. Forest Service Bull. 96.

2 Based on 123 normally stocked plots, from $\frac{x}{8}$ to $\frac{1}{2}$ acre in size. Cordwood converting factor used $=80$ cubic feet per cord. $\quad 3$ Ten per cent deducted for circular saw kerf.

\section{TABLE LXXIV. - CHESTNUT TYPE. ${ }^{1}$ YIELD IN TIES ${ }^{2}$} AND ADDITIONAL CORDWOOD. ${ }^{3}$

\begin{tabular}{|c|c|c|c|c|c|c|}
\hline \multirow{3}{*}{ Age. } & \multicolumn{6}{|c|}{ Quality. } \\
\hline & \multicolumn{2}{|c|}{ I. } & \multicolumn{2}{|c|}{ II. } & \multicolumn{2}{|c|}{ III. } \\
\hline & Ties. & $\begin{array}{l}\text { Additional } \\
\text { cordwood. }\end{array}$ & Ties. & $\begin{array}{l}\text { Additional } \\
\text { cordwood. }\end{array}$ & Ties. & $\begin{array}{l}\text { Additional } \\
\text { cordwood. }\end{array}$ \\
\hline Years. & Number. & Cords. & Number. & Cords. & Number. & Cords. \\
\hline 25 & 25 & 29 & & & & \\
\hline 30 & 76 & 34 & 20 & 29 & & \\
\hline 35 & 140 & 37 & 55 & 33 & 20 & 25 \\
\hline 40 & 225 & 38 & 100 & 36 & 45 & 28 \\
\hline 45 & 320 & 37 & I 50 & 36 & 75 & 30 \\
\hline 50 & 435 & 35 & 215 & 35 & IIO & $3 I$ \\
\hline 55 & 565 & 32 & 290 & 33 & I 45 & $3 I$ \\
\hline 60 & 710 & 29 & 365 & 30 & I90 & 30 \\
\hline 65 & 855 & 26 & 440 & 28 & 235 & 29 \\
\hline 70 & 975 & 25 & 510 & 26 & 280 & 28 \\
\hline 75 & 1075 & 24 & 575 & 25 & 330 & 26 \\
\hline
\end{tabular}

1 Taken from U. S. Forest Service Bull. 96. All $6^{\circ} \times 8^{\circ} \times 8^{\prime}$

3 Based on 123 normally stocked sample plots, from $\frac{1}{8}$ to $\frac{1}{3}$ acre in size. Cordwood converting factor used $=80$ cubic feet per cord. 


\section{TABLE LXXV. - MIXED SECOND-GROWTH HARDWOOD, 1 VERMONT. YIELD PER ACRE FOR STANDS OF AVERAGE DENSITY. \\ Based on 100 plots. \\ Soil Quality I.}

\begin{tabular}{|c|c|c|c|c|c|c|}
\hline \multirow{2}{*}{$\begin{array}{l}\text { Age, } \\
\text { years. }\end{array}$} & \multirow{2}{*}{$\begin{array}{l}\text { Average } \\
\text { diameter. } \\
\text { breast high, } \\
\text { in inches. }\end{array}$} & \multirow{2}{*}{$\begin{array}{c}\text { Average } \\
\text { height, } \\
\text { feet. }\end{array}$} & \multirow{2}{*}{$\begin{array}{l}\text { Total num- } \\
\text { ber of trees. }\end{array}$} & \multirow{2}{*}{$\begin{array}{l}\text { Volume per } \\
\text { acre expressed } \\
\text { in cords alone. }\end{array}$} & \multicolumn{2}{|c|}{ Volume per acre expressed in } \\
\hline & & & & & $\begin{array}{l}\text { lumber, }{ }^{2} \\
\text { board feet. }\end{array}$ & $\begin{array}{l}\text { and in } \\
\text { additional } \\
\text { cords. }\end{array}$ \\
\hline 20 & 2.9 & 34 & 1480 & I 7.4 & $\ldots \ldots \ldots$ & $\ldots \ldots$ \\
\hline 25 & $3 \cdot 3$ & 39 & I 340 & 21.6 & $\ldots \ldots \ldots$ & $\ldots \ldots$ \\
\hline 30 & 3.6 & 43 & I 200 & 25.6 & $\ldots \ldots \ldots$ & $\ldots \ldots$ \\
\hline 35 & $4 \cdot I$ & 48 & I060 & 29.6 & $\ldots \ldots \ldots$ & $\ldots \ldots$ \\
\hline 40 & $4 \cdot 6$ & $5^{2}$ & 880 & $33 \cdot 3$ & 3,500 & $24 \cdot I$ \\
\hline 50 & 5.8 & 60 & $5^{80}$ & $39 \cdot 9$ & 9,900 & 22.9 \\
\hline 60 & 7.0 & 65 & 410 & $45 \cdot 3$ & 13,800 & 20.6 \\
\hline 70 & $7 \cdot 9$ & 69 & 320 & $49 \cdot 5$ & I 5,100 & I 8.8 \\
\hline 75 & 8.2 & 70 & 300 & $5 \mathrm{I} \cdot 2$ & $\ldots \ldots \ldots$ & $\ldots \ldots$ \\
\hline 30 & $\ldots \ldots \ldots$ & $\ldots \ldots$ & $\ldots \ldots \ldots$ & $5^{2} \cdot 9$ & I 5,800 & I 8.2 \\
\hline 85 & $\ldots \ldots \ldots$ & $\ldots \ldots$ & $\ldots \ldots \ldots$ & $54 . I$ & $\ldots \ldots \ldots$ & $\ldots \ldots \ldots$ \\
\hline
\end{tabular}

Soil Quality II.

\begin{tabular}{|c|c|c|c|c|c|c|}
\hline 20 & 2.5 & 33 & 1650 & I 4.4 & $\ldots \ldots \ldots$ & $\ldots \ldots$ \\
\hline 25 & 2.9 & 37 & I 520 & I 7.6 & $\ldots \ldots \ldots \ldots$ & $\ldots \ldots$ \\
\hline 30 & $3 \cdot 3$ & $4 I$ & 1380 & 20.8 & $\ldots \ldots \ldots \ldots$ & $\ldots \ldots$ \\
\hline 35 & $3 \cdot 7$ & 45 & I 230 & 24.0 & $\ldots \ldots \ldots$ & $\ldots \ldots$ \\
\hline 40 & $4 \cdot I$ & 48 & 1070 & 26.7 & $2, \infty 00$ & 2 I. 2 \\
\hline 45 & 4.6 & $5^{I}$ & 910 & $29 \cdot 5$ & $\ldots \ldots \ldots \ldots$ & $\ldots \ldots$ \\
\hline 50 & 5.0 & 54 & $75^{\circ}$ & 32.8 & 4,500 & 22.9 \\
\hline 55 & $5 \cdot 5$ & 56 & 630 & 34.4 & $\ldots \ldots \ldots \ldots$ & $\ldots \ldots$ \\
\hline 60 & $5 \cdot 9$ & $5^{8}$ & 540 & 36.5 & 8,200 & 22.6 \\
\hline 65 & 6.3 & 59 & 470 & $3^{8.2}$ & $\ldots \ldots \ldots \ldots$ & $\ldots \ldots$ \\
\hline 70 & 6.6 & 60 & 420 & 40.0 & 10,900 & 20.6 \\
\hline 75 & 6.9 & $6 r$ & 390 & 41.4 & $\ldots \ldots \ldots \ldots$ & $\ldots \ldots$ \\
\hline 80 & $\ldots \ldots \ldots$ & $\ldots \ldots$ & $\ldots \ldots \ldots \ldots$ & $42 \cdot 9$ & I 2,800 & I9. 4 \\
\hline $8_{5}$ & $\ldots \ldots \ldots \ldots$ & & $\ldots \ldots \ldots \ldots$ & $44 \cdot 2$ & $\ldots \ldots \ldots$ & $\ldots \ldots$ \\
\hline
\end{tabular}

\begin{tabular}{|c|c|c|c|c|c|c|}
\hline \multicolumn{7}{|c|}{ Soil Quality III. } \\
\hline 20 & 2.4 & $3 I$ & I 740 & IO. 9 & $\ldots \ldots \ldots$ & $\ldots \ldots$ \\
\hline 25 & 2.7 & 34 & 1600 & 13.4 & $\ldots \ldots \ldots$ & $\ldots \ldots$ \\
\hline 30 & 3.0 & 38 & 1460 & I5. 6 & $\ldots \ldots \ldots \ldots$ & $\ldots \ldots$ \\
\hline 35 & $3 \cdot 3$ & $4 I$ & 1320 & I 7.9 & $\ldots \ldots \ldots$ & $\ldots \ldots$ \\
\hline 40 & 3.6 & 44 & 1 I 80 & 20.2 & $1, \infty 00$ & I $7 . I$ \\
\hline 45 & $3 \cdot 9$ & 46 & 1025 & 22.4 & $\ldots \ldots \ldots$ & $\ldots \ldots$ \\
\hline 50 & $4 \cdot 3$ & 48 & 880 & $24 \cdot 4$ & 3,000 & $2 I .2$ \\
\hline 55 & $4 \cdot 7$ & 50 & 770 & 26.4 & $\ldots \ldots \ldots$ & $\ldots \ldots$ \\
\hline 60 & 5.1 & 51 & 680 & 28.1 & 6,600 & I 7.6 \\
\hline 65 & $5 \cdot 5$ & $5^{2}$ & 600 & 29.6 & $\ldots \ldots \ldots$ & $\ldots \ldots$ \\
\hline 70 & 5.8 & 54 & 540 & $3 I .2$ & 9,100 & 16.2 \\
\hline 75 & 6.1 & 55 & 480 & 32.4 & $\ldots \ldots \ldots$ & $\ldots \ldots$ \\
\hline 80 & $\ldots \ldots \ldots$ & $\ldots \ldots$ & $\ldots \ldots \ldots$ & $33 \cdot 5$ & 10,600 & I $5 \cdot 9$ \\
\hline 85 & $\ldots \ldots \ldots$ & $\ldots \ldots$ & $\ldots \ldots \ldots$ & $34 \cdot 7$ & $\ldots \ldots \ldots \ldots$ & $\ldots \ldots$ \\
\hline
\end{tabular}

${ }_{1}$ Taken from The Management of Second-Growth Hardwoods in Vt., by A. F. Hawes and B. A. Chandler. Vt. Forest Service Publication No. 13.

2 All logs six inches or over at the top were scaled, whether merchantable or not. 
TABLES

TABLE LXXVI. - WHITE PINE. 1 YIELD PER ACRE FOR PURE, EVEN-AGED SECOND-GROWTH STANDS.

Quality I.

\begin{tabular}{|c|c|c|c|c|c|c|c|c|c|c|c|}
\hline 总 & 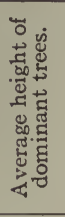 & 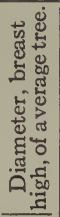 & 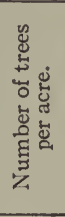 & 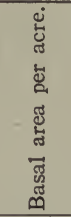 & $\begin{array}{l}\frac{0}{0} \\
\frac{\pi}{\pi} \\
\stackrel{\pi}{0} \\
\stackrel{0}{0}\end{array}$ & 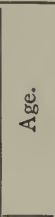 & 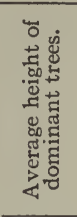 & 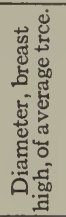 & 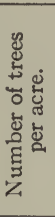 & 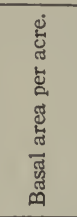 & 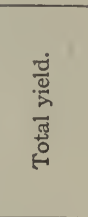 \\
\hline $\begin{array}{c}\text { Yrs. } \\
\text { Io }\end{array}$ & $\begin{array}{r}\text { Feet. } \\
7.2\end{array}$ & $\begin{array}{c}\text { Ins. } \\
\text { I . } 7\end{array}$ & I 728 & $\begin{array}{r}\text { Sq. ft. } \\
29\end{array}$ & $\begin{array}{l}\text { Cu. ft. } \\
8000\end{array}$ & $\begin{array}{l}\text { Yrs. } \\
60\end{array}$ & $\begin{array}{l}\text { Feet. } \\
85 \cdot 5\end{array}$ & $\begin{array}{l}\text { Ins. } \\
\text { I } 2.8\end{array}$ & 3II & $\begin{array}{r}\text { Sq. ft. } \\
278\end{array}$ & $\begin{array}{l}\mathrm{Cu} . \mathrm{ft} . \\
\mathrm{I0}, 500\end{array}$ \\
\hline 15 & 14.5 & 2.9 & 1520 & 68 & 1400 & 65 & 90.5 & I3. 7 & 279 & 286 & I I , 300 \\
\hline 20 & $24 \cdot 5$ & 4.0 & 1322 & II 5 & 2100 & 70 & $94 \cdot 5$ & 14.7 & 249 & 293 & II, 900 \\
\hline 25 & $34 \cdot 5$ & $5 \cdot 2$ & III 5 & I62 & 3000 & 75 & 98.0 & 15.6 & 226 & 300 & 12,500 \\
\hline 30 & 44.0 & 6.4 & 879 & I 96 & 4000 & 80 & IOI. 5 & 16.5 & 207 & 307 & I 3,000 \\
\hline 35 & 53.0 & $7 \cdot 5$ & 710 & 218 & 5200 & 85 & 105.0 & 17.4 & I9O & $3 \mathrm{I} 3$ & I 3,500 \\
\hline 40 & 6 го.о & 8.6 & $5^{8} 3$ & 235 & 6500 & 90 & I08.0 & 18.2 & 177 & 3I9 & 14,000 \\
\hline 45 & 68.0 & $9 \cdot 7$ & 485 & 249 & 7700 & 95 & I IO . 5 & 19.0 & 165 & 324 & 14,400 \\
\hline 50 & $74 \cdot 5$ & 10.8 & 408 & 260 & 8800 & 100 & II 3.0 & 19.8 & I 54 & $\cdot 330$ & 14,700 \\
\hline 55 & 80.5 & II 8 & 354 & 269 & 9700 & & & & & & \\
\hline
\end{tabular}

Quality II.

\begin{tabular}{|c|c|c|c|c|c|c|c|c|c|c|c|}
\hline I0 & 6.0 & I. 4 & 2015 & 20 & 650 & 60 & 74.5 & 10.7 & 397 & 248 & 8,500 \\
\hline I5 & 12.0 & 2.2 & I 834 & 50 & II 50 & 65 & 79.0 & II. 6 & 348 & 255 & 9,200 \\
\hline 20 & 19.5 & 3.2 & 1626 & 90 & $175^{\circ}$ & 70 & 83.0 & I 2.4 & 3I I & 261 & 9,840 \\
\hline 25 & 28.0 & 4. I & 1420 & I3I & 2420 & 75 & 86.5 & I $3 \cdot 3$ & 277 & 267 & 10,400 \\
\hline 30 & $3^{6.5}$ & $5 \cdot I$ & I 192 & I69 & $325^{\circ}$ & 80 & 90.0 & I4. I & $25^{I}$ & 272 & 10,930 \\
\hline 35 & 44.5 & 6.1 & $95^{\circ}$ & I93 & 4180 & 85 & 93.0 & I4.9 & 229 & 277 & II, 400 \\
\hline 40 & 5 I. 5 & 7.1 & 760 & 209 & 5130 & 90 & $95 \cdot 5$ & I 5.7 & 210 & 282 & II, $85^{\circ}$ \\
\hline 45 & 58.0 & 8.0 & 633 & $22 \mathrm{I}$ & 6100 & 95 & 98.0 & 16.4 & 195 & 286 & I 2,250 \\
\hline 50 & 64.0 & 8.9 & 537 & 232 & 7000 & 100 & 100.0 & I 7.I & 182 & 290 & I 2,630 \\
\hline 55 & $69 \cdot 5$ & 9.8 & 460 & $24 \mathrm{I}$ & 7800 & & & & & & 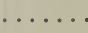 \\
\hline
\end{tabular}

Quality III.

\begin{tabular}{|c|c|c|c|c|c|c|c|c|c|c|c|}
\hline IO & 4.0 & I.O & 2408 & I 4 & 530 & $6 o$ & 64.0 & 8.6 & 543 & 219 & 6,530 \\
\hline I 5 & 9.0 & I. 6 & 2234 & 33 & 900 & 65 & 68.0 & $9 \cdot 4$ & 465 & 224 & 7,160 \\
\hline 20 & $\mathrm{I} 4 \cdot 5$ & $2 \cdot 3$ & 2060 & 60 & $135^{\circ}$ & 70 & $71 \cdot 5$ & $10 . I$ & 412 & 229 & 7,760 \\
\hline 25 & 21.0 & $3 . \mathrm{I}$ & I 886 & 98 & 1850 & 75 & 75.0 & 10.9 & $36 I$ & 234 & 8,320 \\
\hline 30 & 28.5 & $3 \cdot 9$ & I676 & I39 & $245^{\circ}$ & 80 & 78.0 & II .7 & 318 & 238 & 8,820 \\
\hline 35 & 36.0 & $4 \cdot 7$ & 1400 & I 67 & 3100 & 85 & 8 I. & I 2.4 & 288 & 242 & 9,300 \\
\hline 40 & $42 \cdot 5$ & $5 \cdot 5$ & I I I 8 & I 83 & 3780 & 90 & 83.0 & I 3.2 & $25^{8}$ & 245 & 9,750 \\
\hline 45 & 48.5 & 6.3 & 900 & I94 & 4500 & 95 & $85 \cdot 5$ & I 3.8 & 239 & 248 & $10, I 50$ \\
\hline 50 & 54.0 & 7.0 & 764 & 204 & 5200 & 100 & 87.0 & 14.5 & 219 & $25^{I}$ & 10,530 \\
\hline 55 & $5^{8} .0$ & 7.8 & 639 & 212 & 5870 & & & & $\cdots$ & & $\ldots \ldots$ \\
\hline
\end{tabular}

1 Taken from White Pine Under Forest Management, by E. H. Frothingham, Bull. U. S. Dept. of Agr. No. 13 . 
TABLE LXXVII. - WHITE PINE. ${ }^{1}$ YIELD PER ACRE IN LUMBER OF PURE EVEN-AGED SECOND-GROWTH STANDS.

\begin{tabular}{|c|c|c|c|c|c|c|c|}
\hline \multirow{2}{*}{ Age. } & \multicolumn{3}{|c|}{ Lumber yield per acre. } & \multirow{2}{*}{ Age. } & \multicolumn{3}{|c|}{ Lumber yield per acre. } \\
\hline & Quality I. & Quality II. & Quality III. & & Quality I. & Quality II. & Quality III. \\
\hline $\begin{array}{c}\text { Years. } \\
20\end{array}$ & $\begin{array}{c}\text { Board feet. } \\
4,500\end{array}$ & $\begin{array}{c}\text { Board feet. } \\
\ldots \ldots\end{array}$ & $\begin{array}{c}\text { Board feet. } \\
\ldots \ldots\end{array}$ & $\begin{array}{c}\text { Years. } \\
65\end{array}$ & $\begin{array}{c}\text { Board feet. } \\
65,100\end{array}$ & $\begin{array}{c}\text { Board feet. } \\
51,600\end{array}$ & $\begin{array}{c}\text { Board feet. } \\
3^{8,100}\end{array}$ \\
\hline 25 & 8,400 & 5,400 & $\ldots \ldots$ & 70 & 69,900 & 56,100 & 42,300 \\
\hline 30 & 13,900 & 9,600 & 5,300 & 75 & 74,100 & 60,200 & 46,300 \\
\hline 35 & 22,500 & I 5,900 & 9,300 & 80 & 77,850 & $64, \infty 00$ & 50,100 \\
\hline 40 & 32,800 & 23,500 & 14,200 & 85 & 81,400 & 67,500 & 53,700 \\
\hline 45 & 41,800 & 30,600 & $\mathrm{I} 9,200$ & 90 & 84,800 & 70,900 & 57,000 \\
\hline 50 & 49,100 & 36,600 & 24,100 & 95 & 88,000 & 74,000 & $60, \infty 00$ \\
\hline 55 & $55, \infty 00$ & $42, \infty 00$ & 29,000 & 100 & 91,200 & 77,000 & 62,000 \\
\hline 60 & 60,200 & 46,900 & 33,600 & $\ldots \ldots$ & $\ldots \ldots$ & $\ldots \ldots$ & $\ldots \ldots$ \\
\hline
\end{tabular}

1 Taken from White Pine Under Forest Management, by E. H. Frothingham, Bull. U. S. Dept. of Agr. No. 13 .

TABLE LXXVIII. - WHITE PINE. ${ }^{1}$ YIELD PER ACRE IN BOARD FEET, CORDS, AND CUBIC FEET.

\begin{tabular}{|c|c|c|c|c|c|c|c|c|c|}
\hline \multirow{2}{*}{$\begin{array}{c}\text { Age, } \\
\text { years. }\end{array}$} & \multicolumn{3}{|c|}{ Quality I. } & \multicolumn{3}{|c|}{ Quality II. } & \multicolumn{3}{|c|}{ Quality III. } \\
\hline & $\begin{array}{l}\text { I-inch } \\
\text { boards. }\end{array}$ & Cords. & $\begin{array}{l}\text { Cubic } \\
\text { feet. }\end{array}$ & $\begin{array}{c}\text { I-inch } \\
\text { boards. }\end{array}$ & Cords. & $\begin{array}{l}\text { Cubic } \\
\text { feet. }\end{array}$ & $\begin{array}{c}\text { I-inch } \\
\text { boards. }\end{array}$ & Cords. & $\begin{array}{c}\text { Cubic } \\
\text { feet. }\end{array}$ \\
\hline 25 & 10,825 & $25 . I$ & 2080 & $6,75^{\circ}$ & I 6.4 & I 300 & 3,975 & 10. 8 & $75^{\circ}$ \\
\hline 30 & 19,900 & 44.0 & $375^{\circ}$ & 12,500 & $3 \mathrm{I} .2$ & 2740 & 7,500 & I 8.2 & 1400 \\
\hline 35 & 31,150 & 60.4 & 5420 & 24,400 & 49.0 & 4375 & I 6,950 & 35.8 & 3035 \\
\hline 40 & 40,650 & 70.6 & 6590 & 32,800 & $5^{8} .0$ & 5300 & 25,200 & 46.2 & 4080 \\
\hline 45 & $49,35^{\circ}$ & 78.0 & 7420 & 40,600 & 64.8 & 6075 & 32,100 & 51.8 & 4785 \\
\hline 50 & 55,150 & 84.2 & 8035 & 46,500 & 700 & 6725 & 37,550 & 56.6 & 5475 \\
\hline 55 & 59,650 & 89.2 & 8575 & 50,550 & 74.8 & 7200 & 42,100 & 60.8 & 6015 \\
\hline 60 & 63,600 & 93.4 & 9075 & 53,200 & 79.2 & 7655 & 44,550 & 64.6 & 6340 \\
\hline 65 & 67,050 & 97.2 & $955^{\circ}$ & 56,600 & 83.0 & 8050 & 46,150 & 68.4 & 6550 \\
\hline
\end{tabular}

1 Taken from "Forest Mensuration of the White Pine in Massachusetts." 
TABLE LXXIX. - WHITE PINE. ${ }^{1}$ AVERAGE ANNUAL GROWTH PER ACRE, BY QUALITY CLASSES.

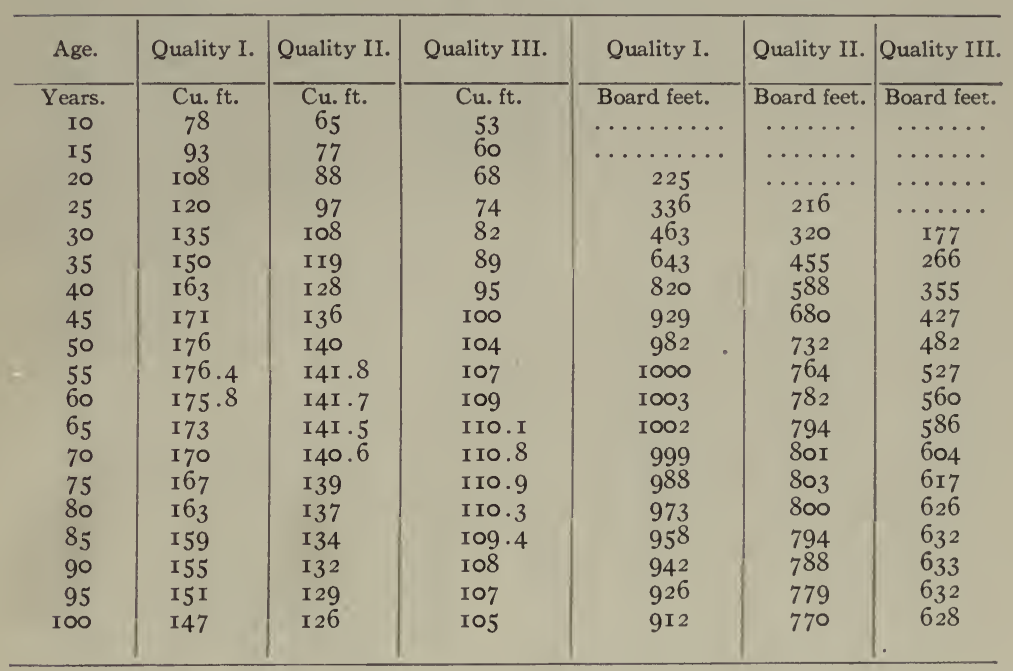

1 Taken from White Pine Under Forest Management, by E. H. Frothingham, Bull. 13, U. S. Dept. of Agr. 


\section{TABLE LXXX. - RED SPRUCE. ${ }^{1}$ YIELD PER ACRE FOR PURE EVEN-AGED STANDS.}

Quality I.

\begin{tabular}{|c|c|c|c|c|c|c|c|}
\hline Age. & $\begin{array}{l}\text { Trees per } \\
\text { acre. }\end{array}$ & Basal area. & $\begin{array}{l}\text { Average } \\
\text { diameter, } \\
\text { breast high }\end{array}$ & Height. & \multicolumn{3}{|c|}{ Yield per acre. } \\
\hline $\begin{array}{c}\text { Years. } \\
20\end{array}$ & $\begin{array}{l}\text { Number. } \\
\text { I } 294\end{array}$ & $\begin{array}{c}\text { Sq. ft. } \\
\text { IO2 }\end{array}$ & $\begin{array}{c}\text { Inches. } \\
3.8\end{array}$ & $\begin{array}{c}\text { Feet. } \\
24\end{array}$ & $\begin{array}{c}\text { Bd. } \mathrm{ft}^{2}{ }^{2} \\
\ldots \ldots \ldots\end{array}$ & $\begin{array}{l}\mathrm{Cu} \cdot \mathrm{ft}^{3}{ }^{2} \\
\ldots \ldots \ldots\end{array}$ & $\begin{array}{c}\text { Cords." } \\
\ldots \ldots\end{array}$ \\
\hline 25 & 1076 & 140 & $4 \cdot 9$ & $3 I$ & $\ldots \ldots$ & & $\cdots \cdots$ \\
\hline 30 & 887 & I 69 & 5.9 & 36 & $\ldots \ldots$ & $\cdots \cdots$ & $\cdots \cdots$ \\
\hline 35 & 756 & I90 & 6.8 & 42 & $\ldots \ldots$ & & $\cdots \cdots$ \\
\hline 40 & 668 & 205 & $7 \cdot 5$ & 46 & I 5,200 & 3660 & $\cdots \cdots$ \\
\hline 45 & 603 & 216 & 8. I & $5 I$ & I 9,700 & & $3 I$ \\
\hline 50 & $55^{8}$ & 225 & 8.6 & 55 & 23,300 & $\begin{array}{l}4500 \\
5140\end{array}$ & 40 \\
\hline 55 & 527 & 232 & 9.0 & 58 & 26,200 & 5140 & 48 \\
\hline 60 & 506 & 238 & 9.3 & $6 I$ & 28,500 & 5600 & 55 \\
\hline 65 & 490 & 242 & 05 & 64 & & 5950 & 60 \\
\hline 70 & 478 & & 9.5 & & 30,500 & 6240 & 64 \\
\hline 75 & 467 & 247 & 9.7 & 66 & $32, \mathrm{ICO}$ & 6490 & 68 \\
\hline 80 & & $25^{\circ}$ & $9 \cdot 9$ & 68 & 33,500 & 6700 & 70 \\
\hline 85 & & 253 & IO.I & 70 & 34,800 & 6890 & 72 \\
\hline & 447 & 256 & 10.2 & 72 & 35,900 & 7050 & 74 \\
\hline 90 & 437 & 259 & IO. 4 & 73 & 37,000 & 7180 & 76 \\
\hline $\begin{array}{r}95 \\
00\end{array}$ & 427 & 262 & 10.6 & 74 & 38,100 & 7300 & 77 \\
\hline 100 & 417 & 264 & 10.8 & 76 & 39,100 & 7390 & 78 \\
\hline
\end{tabular}

Quality II.

\begin{tabular}{|c|c|c|c|c|c|c|c|}
\hline 20 & 1603 & 84 & $3 \cdot I$ & 19 & $\ldots \ldots$ & $\ldots \ldots$ & $\ldots \ldots$ \\
\hline 25 & I 3 I 6 & II 5 & 4.0 & 25 & $\ldots \ldots$ & $\ldots \ldots$ & $\ldots \ldots$ \\
\hline 30 & 1062 & I 39 & $4 \cdot 9$ & $3 I$ & $\ldots \ldots$ & $\ldots \ldots$ & $\ldots \ldots$ \\
\hline 35 & 890 & I 57 & $5 \cdot 7$ & 36 & $\ldots \ldots$ & $\ldots \ldots$ & $\ldots \ldots$ \\
\hline 40 & 774 & I 71 & 6.3 & 40 & 10,700 & 3000 & 23 \\
\hline 45 & 697 & I 81 & 6.9 & 44 & I 4,100 & 3770 & $3 I$ \\
\hline 50 & 643 & 189 & $7 \cdot 4$ & 47 & 17,100 & 4320 & 38 \\
\hline 55 & 605 & rg6 & $7 \cdot 7$ & 50 & I 9,600 & 4720 & 44 \\
\hline 60 & 575 & 201 & 8.0 & 53 & 21,700 & 5050 & 48 \\
\hline 65 & $55^{1}$ & 206 & 8.2 & 55 & 23,500 & 5310 & $5^{2}$ \\
\hline 70 & 532 & 210 & 8.5 & 57 & 25,000 & 5550 & 54 \\
\hline 75 & 516 & 213 & 8.7 & 59 & 26,200 & 5750 & 57 \\
\hline 80 & 503 & 216 & 8.9 & $6 I$ & 27,300 & 5910 & 59 \\
\hline 85 & 492 & 220 & 9.0 & 63 & 28,300 & 6050 & $6 \mathrm{I}$ \\
\hline 90 & 482 & 223 & 9.2 & 64 & 29,300 & 6170 & 62 \\
\hline 95 & 472 & 226 & 9.4 & 65 & 30,200 & 6280 & 63 \\
\hline 100 & $4^{6} 3$ & 228 & $9 \cdot 5$ & 66 & 31,100 & 6370 & 64 \\
\hline
\end{tabular}

Based on 59 plots, in even-aged old pasture stands; area 131 acres, taken in Oxford and Penobscot counties, Maine; Coos, Grafton and Sullivan counties, New Hampshire; Caledonia and Windsor counties, Vermont.

No suppressed trees were measured in making this table.

2 Taken from The Red Spruce, by L. Murphy, Bull. 544, U. S. Dept. of Agr.

3 Trees 7 inches and over in diameter breast high; top diameter inside bark 6 inches. New Hampshire rule.

- Trees 4 inches and over in diameter breast high; top diameter outside bark 4 inches.

- Trees 6 inches and over in diameter breast high; top diameter outside bark 5 inches. 
TABLE LXXX. - RED SPRUCE. ${ }^{1}$ YIELD PER ACRE FOR PURE EVEN-AGED STANDS (Continued). Quality III.

\begin{tabular}{|c|c|c|c|c|c|c|c|}
\hline \multirow{3}{*}{$\begin{array}{l}\text { Age. } \\
\begin{array}{c}\text { Years. } \\
20\end{array}\end{array}$} & \multirow{3}{*}{$\begin{array}{c}\text { Trees } \\
\text { per acre. } \\
\text { Number. } \\
2 \text { I } 34\end{array}$} & \multirow{3}{*}{$\begin{array}{c}\text { Basal area. } \\
\begin{array}{c}\text { Sq. ft. } \\
67\end{array}\end{array}$} & \multirow{3}{*}{$\begin{array}{c}\begin{array}{c}\text { Average } \\
\text { diameter, } \\
\text { breast high. }\end{array} \\
\text { Inches. } \\
2.4\end{array}$} & \multirow{3}{*}{$\begin{array}{c}\text { Height. } \\
\begin{array}{c}\text { Feet. } \\
\text { I4 }\end{array}\end{array}$} & \multicolumn{3}{|c|}{ Yield per acre. } \\
\hline & & & & & Bd. ft. ${ }^{2}$ & Cu. $\mathrm{ft}^{8}{ }^{\mathrm{r}}$ & Cords. 4 \\
\hline & & & & & $\ldots \ldots$ & $\ldots \ldots$ & ..... \\
\hline 25 & I 620 & 90 & 3.2 & 20 & ...... & $\ldots \ldots$ & $\ldots \ldots$ \\
\hline 30 & I304 & 109 & $3 \cdot 9$ & 25 & $\ldots \ldots$ & $\ldots \ldots$ & $\ldots \ldots$ \\
\hline 35 & 1074 & I 24 & 4.6 & 30 & $\ldots \ldots$ & $\ldots \ldots$ & $\ldots \ldots$ \\
\hline 40 & 924 & I 36 & 52 & 34 & 6,200 & 2330 & I5 \\
\hline 45 & 827 & 145 & $5 \cdot 7$ & 37 & 8,600 & 3000 & 22 \\
\hline 50 & 755 & I 53 & 6.1 & 40 & Io,900 & 3500 & 28 \\
\hline 55 & 703 & I 59 & 6.4 & 42 & 13,000 & 3860 & 32 \\
\hline 60 & 664 & 164 & 6.7 & 45 & I 4,900 & 4150 & 36 \\
\hline 65 & 634 & 168 & 7.0 & 47 & I 6,500 & 4390 & 39 \\
\hline 70 & 609 & 172 & 7.2 & 49 & I 7,800 & 4590 & $4 I$ \\
\hline 75 & 588 & I 76 & $7 \cdot 4$ & 50 & I 8,900 & 4760 & 43 \\
\hline 80 & 569 & 180 & 7.6 & 52 & I 9,800 & 4920 & 45 \\
\hline 85 & $55 \mathrm{I}$ & 183 & 7.8 & 53 & 20,600 & 5050 & 47 \\
\hline 90 & 533 & I 86 & 8.0 & 55 & 21,300 & 5170 & 48 \\
\hline 95 & 516 & 189 & 8.2 & 56 & 21,900 & 5260 & 49 \\
\hline 100 & 499 & 192 & 8.4 & 57 & 22,500 & 5340 & 50 \\
\hline
\end{tabular}





\section{INDEX}

Accretion, 188

Age of stands, 196

Age of trees, 189

Applewood, uses, I79, I80, 185

Approximate' amounts various forest products contained in standard car, 256

Approximate weight various forest products, 257

Arborvitæ, silvicultural characteristics, 35

uses, $181,185,187$

Ash, 6

Ash, white, diameter and height growth on uplands in Central New York, 258 per cent of ash in dry leaves, 6 second growth, volume in cubic feet, 218

silvicultural characteristics, $4 \mathrm{I}$

uses, $179,180,182,185,186$

volume in board feet, 217

yield in pure, even-aged, well-stocked stands, 263

Aspen, see Poplar

diameter and height growth, 259

merchantable volume in cubic feet, 219

merchantable volume in cords and number of trees per cord, 220

Assimilation, 4

Back firing, 157

Balsam, silvicultural characteristics, 30 uses, $179,180,183,186$

Balsam fir and red spruce, comparative growth in height and diameter, 260 in Maine and New York, volume in cords, 242
Balsam fir and red spruce, in Grafton County, N. H., volume in cords, 242 in Maine, volume growth in cubic feet, 262

in New York, volume growth in cubic feet, $26 \mathrm{I}$

Bangor log rule, 207

Basswood, in Lake States, volume table, 22 I

silvicultural characteristics, 42

uses, $178, \mathrm{I} 79, \mathrm{I} 80, \mathrm{I} 8 \mathrm{I}, \mathrm{I} 82, \mathrm{I} 85, \mathrm{I} 86$

Beech in New Hampshire, volume table, 222

nitrogen consumption, 7

second growth, volume table, 223

silvicultural characteristics, 40

uses, $178,179,180,181,182,185,186$

Birch, nitrogen consumption, 7

Birch, gray, silvicultural characteristics, 39

Birch, paper, height, diameter and volume growth, 259

silvicultural characteristics, 38

solid contents per stacked cord, volume table, 226

uses, $179, \mathrm{I} 85$

volume table, 224,225

yield per acre, 264

Birch, yellow, in New Hampshire, volume tables, 226

second growth volume table, 227

silvicultural characteristics, 38

uses, $178, \mathbf{1 7 9}, \mathbf{I} 80, \mathbf{1} 81,182, \mathbf{1} 85, \mathbf{1} 86$

Birds, 100

Blister rust, of white pine, $20,22,74,129$

Bobbins, 179

Bolts, 180

Boxes, I79 
Broadcast sowing, 69

Broadleaved trees, 6

Brown-tail moth, II5

Brush disposal, I 46

Bucket pump. 153

Butternut, uses, I82, I86

Carbo-hydrates, 4

Carbon, 4,6

Cedar, northern white, see arborvitæ

Cedar, red, silvicultural characteristics, 35

Chairs, 179

Chemical constituents of soil, 5, 6

Chemical fire extinguishers, 152

Cherry, uses, 179,185

Chestnut bark disease, I 24

Chestnut, I3, I 24

$\log$ rule, $2 \mathrm{I} 3$

silvicultural characteristics, 44

type, growth in height, diameter, etc., Conn., 265

type, yield in lumber and additional cordwood, 269

type, yield in ties and additional cordwood, 269

uses, $181,185,187$

volume table, board feet, 229

volume table, cubic feet, 227,228

volume table in ties, 230

Chlorophyll, 4

Circular plots for estimating, $\mathbf{I} 66$

Clapboards, 178

Clark's International Log Rule, 2 I I

Cleanings, 7

Clear cutting, $5^{I}$

in patches, 56

in strips, 55

the whole stand, 54

with artificial reproduction, 53, 68

with natural reproduction, 54

\section{Climate, I}

Climatic factors, I, 2

Codominant, 84

Conifers, 6, 13, 74, 140, 175

Contents, solid of logs in cubic feet, 215

Composite, 14
Cooperage stock, I80, I8r

Coppice, 13, 14, 62, 63

Cordwood converting factors, 24 I

Cordwood, see firewood

Cottonwood, uses, I8r

Crates, 179

Crown classes, 83

Cutting cycle, 50

Cutting schedule, 62

Deciduous, I3, I40, I 75

Deer, 100

Diameter growth, I9 I, 196

Diameter limit, 97

Distillation, wood for, $\mathrm{I} 82$

Dominant, 84

Doyle $\log$ rule, 206

Elm, uses, I 78, I80, I81, I85, I86

Elm-leaf beetle, i 8

European pine-shoot moth, I08

Even-aged, 14, 50, 52, 198

Evergreen, see conifers

Excelsior, I80, I82, I86

Final cutting, 60,82

Fir, balsam, see balsam

Fir, nitrogen consumption, 7

Fire lines, 147

Fires, causes, I4I

damage, 135,157

fighting, 151,156

insurance against, I4I

incendiary, I 43

kind, 136

lightning, I 43

prevention, I 43

railroad patrol, I44

Firewood, 184, 187

Forest fire wagons, 155

Forest products, utilization, $\mathbf{I} 75$

Forestry, I, 8

Forest tent caterpillar, I 20

French method, see thinnings

Frosts, early, 2

late, 2

Furniture, 179

Fungi, 124 
Gipsy moth, Ir2

Grazing, 102

Growth, 188

Handles, 179,180

Hardwoods, 7, I 2, 66, 74, I75, I86

Heeling in trees, $7 \mathrm{I}$

Height growth, I88, 192, I96

Hemlock bark, volume in stacked cords, Vermont, 245

Hemlock, silvicultural characteristics, 3 I

uses, I 79, I81, I83, I $85, \mathrm{I} 86$

Vermont, diameter and volume growth, 262

volume table in board feet, 244

volume table in cubic and board feet, southern N. H., 243

Hickory, uses, I 79, I80, I85

High forest, $\mathrm{I} 3, \mathrm{I} 4$

Hogs, I03

Holland log rule, 207

Humphrey decimal cord measure, 2I 4

Hypsometer, 162, 192

Increment, I 88

Insects, 104

Intermediate, 84

Intermediate cuttings, 77

schedule of, 95

Intolerant, 5

June bug, I 2 I

Juniper, see cedar, red

Larch, European, silvicultural characteristics, 34

Larch sawfly, i 6

Liberation cuttings, 77,79

Light, 2, 5

Lime, 7,8

Log grades, 176

Log prices, 186

Log rules, 205

Lookout stations, 144

Lumber grades, I 75

Lumbering, $\mathbf{I} 7 \mathrm{I}$

costs, $\mathrm{I} 74$
Maine, Holland, or Bangor log rule, 207

Maple, red, silvicultural characteristics, 37

Maple, red, volume table in standard cords, $23 \mathrm{I}$

Maple, soft, see Maple, red

Maple, sugar, second-growth, volume table, 233

silvicultural characteristics, 36

uses, I76, I 78, I79, I80, I81, I82, I85, I 86

volume table in board feet, 232

Maple sugar, 186

Maple syrup, 186

Marketing timber, I 7 I

Mean annual growth, 197

Mensuration, I6I

Mice, Ioo

Mixed forest, 73

Mixed second-growth hardwood, Vermont, yield per acre, 270

New Hampshire Log rule, 208, 209

Nitrogen, 6, 7, I40

Normal yield tables, 198

Number of trees of each size required to yield, 255

Number trees per acre, 9

Oak, black, volume table, 235, 236, 237

Oak, chestnut type, growth in height, diameter, etc., 266

volume table, 239, 240

Oak, red, silvicultural characteristics, 46 uses, I 78, I 79, I80, I8 I, I85, I 86, I 87 volume tables, 234, 235, 236, 237

Oak, scarlet, volume tables, 235, 236, 237

Oak, white, 13

second-growth, volume table, 238

silvicultural characteristics, 46

type, growth in height, diameter, etc., 267

uses, I 78, I 79, I80, I8I, I85, I86, I87

volume table, 239,240

Overtopped, 84 
Partial seeding, 70

Physical qualities of soil, 5

Piling, 182

Pine-bark aphid, 106

Pine, maritime, nitrogen accumulation,

$$
7
$$

Pine, Norway, silvicultural characteristics, $2 \mathrm{I}$

volume in board feet, 246

Pine, pitch, silvicultural characteristics, 23

Pine, red, see Norway

Pine sawfly, i 8

Pine, Scotch, silvicultural characteristics, 25

Pine shoot moth, European, 108

Pine, white, average annual growth per acre by quality classes, 273

blight, I 34

blister rust, 20, 22, 74, 129

$\log$ rule for, 212

per cent of ash in dry leaves, 6

second growth, log rule for, 212

second-growth, volume in board feet, 248

second-growth, volume in cords, 249

silvicultural characteristics, 17

uses, $177, \mathrm{I} 79, \mathrm{I} 8 \mathrm{I}, \mathrm{I} 83 \mathrm{3}, \mathrm{I} 86$

volume in board feet, southern N. H., 247

volume in cubic feet, 250

yield per acre for pure, even-aged second-growth stands, 27 I

yield per acre in lumber of pure evenaged second-growth stands, 272

yield per acre in board feet, cords, and cubic feet, 272

Planing mill products, $\mathbf{I} 78$

Planting, 68

costs, 76

definition, 69

Poles, I8r

Polewood coppice, 62, 64

Polyporus schweinitzii, 128

Poplar disease, 13 I

Poplar, silvicultural characteristics, 42 uses, $179,182,183,185,186$
Posts, $18 \mathrm{r}$

Precipitation, 2, 4

Preparatory cuttings, 60

Pruning, 98

Puddling trees, 72

Pulpwood, I80, I83, I 86

Pump for fire fighting, I 53

Pure forests, II, 73

Quality, soil, II

Rabbits, 100

Rainfall, 2

Railroad ties, $\mathbf{1} 8 \mathbf{I}$

Red rot, 126

Removal cuttings, 60

Reproduction, artificial, 52, 53

see also planting and seeding

by sprouts, 62

cutting, 77,95

estimating value, $\mathbf{I} 59$

methods of natural, 49,52

Root hairs, 3

Root systems, 5

Rotation, 5I, 58, 63, 64

Salvage cuttings, 77,94

Scribner log rule, 205

Second-growth hardwoods, $\log$ rule for, 213

Seed cutting, 6o, 66

Seeding, 68

costs, 76

definition, 69

Seed spot, 70

Seed tree method, 56

Selection forest, 15

Selection method, 49

Shelterwood method, 58

Shuttles, 179

Silvics, I

Silviculture, I

Silvicultural characteristics, I7

Softwood, I 2, 175

Soil moisture, 2

Soil, quality, II

Sounding boards, 178 
Spacing in plantations, 74

Spools, 179

Spruce, budworm, II I

Spruce-destroying beetle, Io9

Spruce, nitrogen consumption, 7

Spruce, Norway, silvicultural characteristics, 29

Spruce, red, silvicultural characteristics, 27

and balsam fir, comparative growth in height and diameter, 260

uses, I 78, I79, I80, I81, I83, I86

volume in board feet by New Hampshire rule, $25 \mathrm{I}$

volume in board feet, 252

volume in cords, 253

volume in cubic feet on entire stem, including bark, 253

volume of unpeeled pulpwood in cubic feet, 254

yield per acre for pure even-aged stands, 274,275

Squirrels, 100

Stacked cubic feet in logs of given dimensions, 216

\section{Stand, 8}

age, 196

growth, 195, 196

mixed, II

pure, II

Sycamore, uses, $18 \mathrm{r}$

Tallying trees, 162

Tamarack, silvicultural characteristics, 33 uses, 181,183

Tanning bark, 185,187

Temperature, average, $\mathbf{x}$

Thinnings, 77,82

French method, 87

grades, 85

increased growth after, 5,89
Ties, $18 \mathrm{r}, \mathrm{I} 87$

Timber estimating, $\mathbf{r} 6 \mathbf{I}$

Tolerant, 5, 9

Tools for fire fighting, $\mathbf{I}_{5} 2$

Top lopping, $\mathbf{1} 46$

Transpiration, 3, 4

Tulip tree, see whitewood

Two-storied, 16

Types, forest, 8

permanent, io

temporary, 1o

Underplanting, I3

Uneven-aged, $15,49,198$

Utilization of forest products, 175

Valuation survey, 167

Value of standing timber, I 70

Vehicles, I8o

Veneer, 177

Vermont $\log$ rule, 2 ro

Virgin forest, I3, I5, 49

Volume growth, I93, 197

Volume tables, 163, 217

Water table, 4

Weeks' bill, 145

White-heart rot, I3 I

White pine blight, I34

White pine blister rust, see under white pine

White pine weevil, I04

Whitewood, silvicultural characteristics, 47

uses, 180

Windfall, 52, $5^{8}$

Wind shake, 32

Yellow poplar, see whitewood

Yield in cords for 3 types and qualities of soil, Conn., 268

Yield tables, 197 


025000017 


.



NOV 231992 


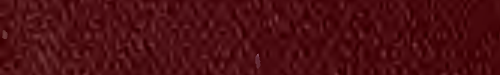

